Advanced Manufacturing Office

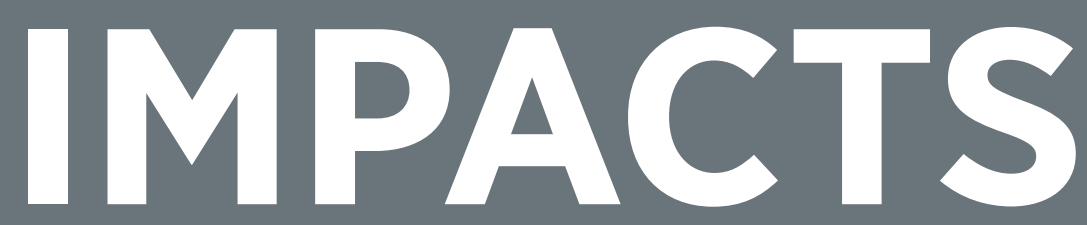

Results Summary for CY 2010

\title{
March 2013
}




\section{Table of Contents}

\section{Table of Contents}

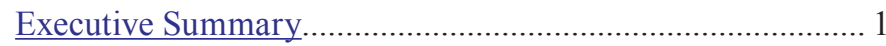

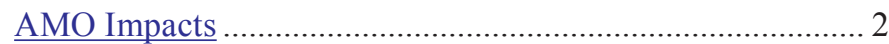

Industrial Energy Use

Advanced Manufacturing Office

Technology Tracking Process

Results

Appendix A:

AMO -Sponsored Technologies Commercially Available.. A-1

\section{Appendix B:}

AMO Emerging Technologies

B-1

Appendix C:

Historical AMO Technology Successes ............................... C-1

Appendix D:

Method of Calculating Results for the IAC Program.......... D-1

\section{Appendix E:}

Method of Calculating Results for Technology Deployment

Program

E-1

\section{Appendix F:}

Method of Calculating Results from DOE's Combined Heat and Power Activities.

\section{Appendix G:}

Methodology for Technology Tracking

and Assessment of Benefits 


\section{Executive Summary}

IMPACTS

Manufacturing converts a wide range of raw materials, components, and parts into finished goods that meet market expectations. The U.S. Department of Energy's (DOE's) Advanced Manufacturing Office (AMO) partners with industry, small business, universities, and other stakeholders to identify and invest in emerging technologies with the potential to create high-quality domestic manufacturing jobs and enhance the global competitiveness of the United States. This document offers a 2010 summary of selected impacts of AMO's initiatives that are designed to increase energy productivity and expand U.S. leadership in clean energy markets.

Industry is the largest and most diverse energy-consuming sector in the U.S. economy. In recent years, the industrial sector used one-third of the energy consumed in the nation, produced about 1,500 MMT of $\mathrm{CO}_{2}$ per year, contributed $12 \%$ to the overall U.S. gross domestic product, and provided nearly 12 million manufacturing jobs. When combined with concerns surrounding energy security, job creation, and global competitiveness, these statistics emphasize the strategic role that improved industrial energy efficiency can have in addressing some of the nation's most pressing energy, economic, and environmental challenges.

Over the past 30 years, AMO has supported more than 600 separate RD\&D projects that have produced over 250 commercialized technologies. In 2010 alone, 98 AMO supported commercialized technologies have saved 43.1 trillion Btus. While these energy savings are impressive, industry has reaped even greater benefits from improved productivity, reduced resource consumption, decreased emissions, and enhanced product quality associated with these technological advances. For the period 1992 - 2010, AMO-sponsored projects have resulted in 50 R\&D 100 awards and 265 issued patents. Also, many AMO-supported projects have significantly expanded knowledge about complex industrial processes and have laid the foundation for future energy-efficient technologies.

Investing in high-risk, high-value RD\&D that will reduce industry's energy requirements while stimulating economic productivity and growth is a primary role for AMO initiatives. Energy is a major input for many key manufacturing industries.

In addition to tracking current and cumulative energy savings, AMO monitors other benefits associated with the successfully commercialized technologies resulting from its research partnerships. These benefits include cumulative reductions of various air pollutants including particulates, volatile organic compounds, nitrogen oxides, sulfur oxides, and carbon. In 2010, AMO programs were instrumental in saving industry
713 trillion Btu or $\$ 5.12$ billion. Cumulatively these net benefits correspond to about 10.7 quadrillion Btu or $\$ 56.5$ billion (in 2010 dollars).

This report has seven appendices. Appendix A describes the 98 AMO-supported commercial technologies currently available, their applications, and benefits. Appendix $B$ lists the 168 AMO-supported emerging technologies likely to be commercialized within two or three years. Appendix $C$ describes 132 AMO- supported technologies used in past commercial applications. Appendices $D$ and $E$ summarize the benefits of AMO technology deployment activities: the Industrial Assessment Centers and other technology deployment programs. Appendix $F$ summarizes the benefits of DOE supported CHP systems. Finally, Appendix $G$ describes the methodology used to assess and track AMOsupported technologies. 


\section{Industrial Energy Use}

Industry is the largest and most diverse energy-consuming sector of the U.S. economy. In recent years, the industrial sector has used one-third of the energy consumed in the nation, produced about 1,500 MMT of $\mathrm{CO}_{2}$ per year, contributed $12 \%$ to the overall U.S. gross domestic product (GDP), and provided nearly 12 million manufacturing jobs. When combined with concerns surrounding energy security, job creation, and global competitiveness, these statistics emphasize the strategic role that improved industrial energy efficiency can play in responding to some of the nation's most pressing energy, economic, and environmental challenges.

In 2010, the industrial sector used 30.14 quads of all types of energy including losses associated with electricity transmission of 6.88 quads (see Figure 1). Petroleum (8.01 quads), natural gas (8.11 quads), and electricity (3.28 quads delivered) are the three fuels most used by industry, with coal and renewable energy (predominantly biomass) providing another 3.86 quads combined. The industrial sector consumed a total of 23.26 quads, of which 19.66 quads were consumed by manufacturing industries. Of those 19.66 quads, energy-intensive industries consumed 15.82 quads.
The non-energy-intensive industries (3.84 quads) and non-manufacturing industries (agriculture, mining, and construction -3.60 quads combined) accounted for the remaining energy consumption. Industry used 5.53 quads of the fossil fuels for feedstocks - raw materials for plastics and chemicals - rather than as fuels. Energy expenditures associated with manufacturing account for approximately $\$ 230$ billion annually.

Energy-intensive industries such as forest products, chemicals, petroleum refining, nonmetallic minerals (glass and cement, especially), and primary metals account for about $80 \%$ of all manufacturing energy use. Many of these industries are limited in their choice of fuels because the process technologies these industries use require a specific fuel. For example, aluminum production requires large amounts of electricity to reduce the alumina to metal. Paper pulping leaves a large amount of residual wood lignin that can be reprocessed for its chemical content and consequently supplies the industry with half of its primary energy. This means that the selection of a number of fuels (and feedstocks)

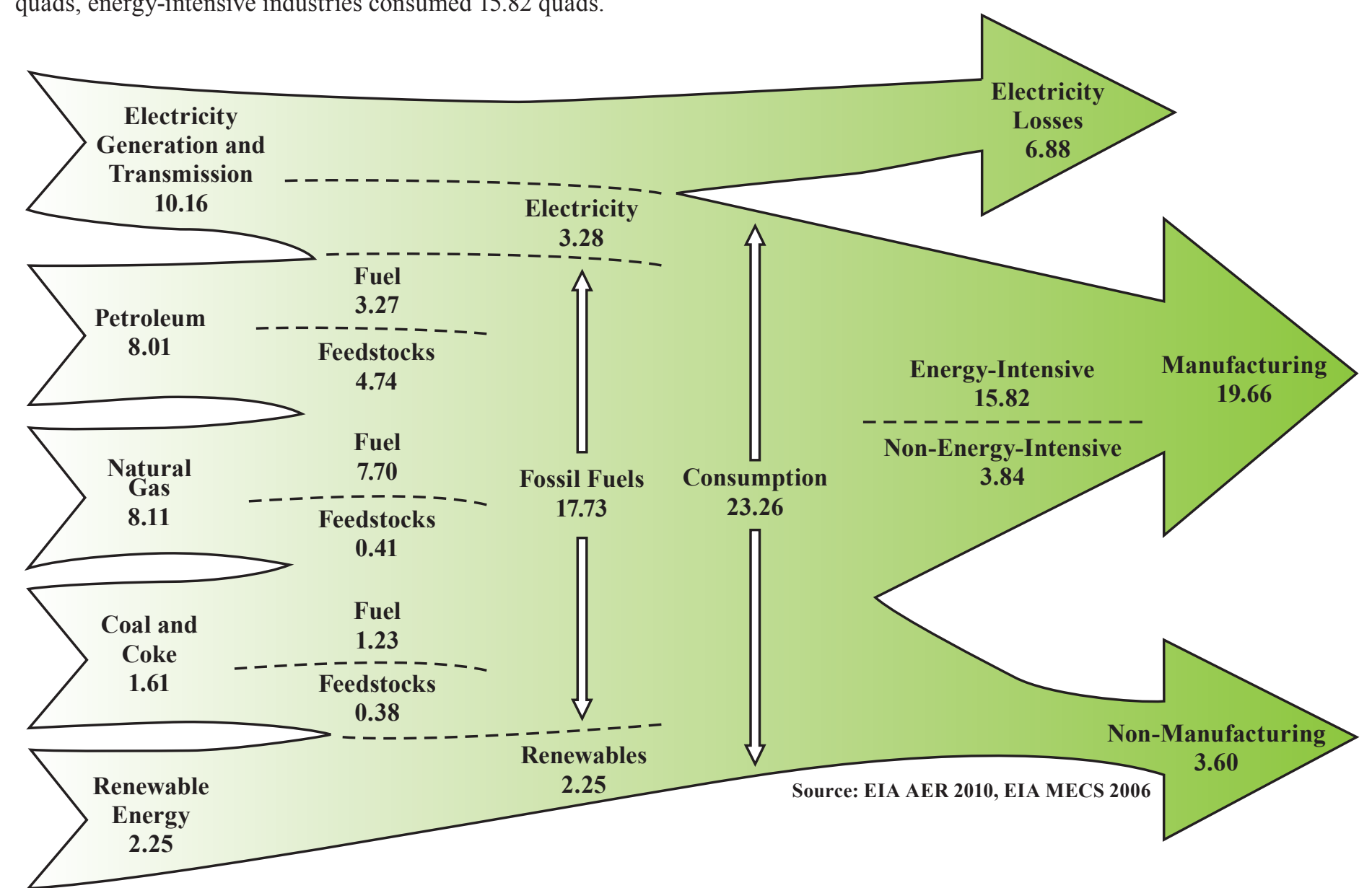

Figure 1. Industrial Energy Flows (Quads), 2010 
AMO Impacts

IMPACTS

used in the industrial sector is a reflection of the specific requirements of the process(es) used to make particular goods or commodities. Because of these energy requirements, the industrial sector offers a wide variety of opportunities for energy-efficiency improvements that are specific to particular industries. In addition, certain technologies (e.g., boilers and motors) crosscut many industries.
The energy intensity of the industrial sector has been declining over the past decade, in part because of investments in the development of energy-efficient technologies by AMO. Since its peak in 1992, industrial sector energy intensity has declined more than $40 \%$, from $15,500 \mathrm{Btu} /$ dollar of real industrial GDP to $8,900 \mathrm{Btu} /$ dollar of real industrial GDP in 2010 (see Figure 2).

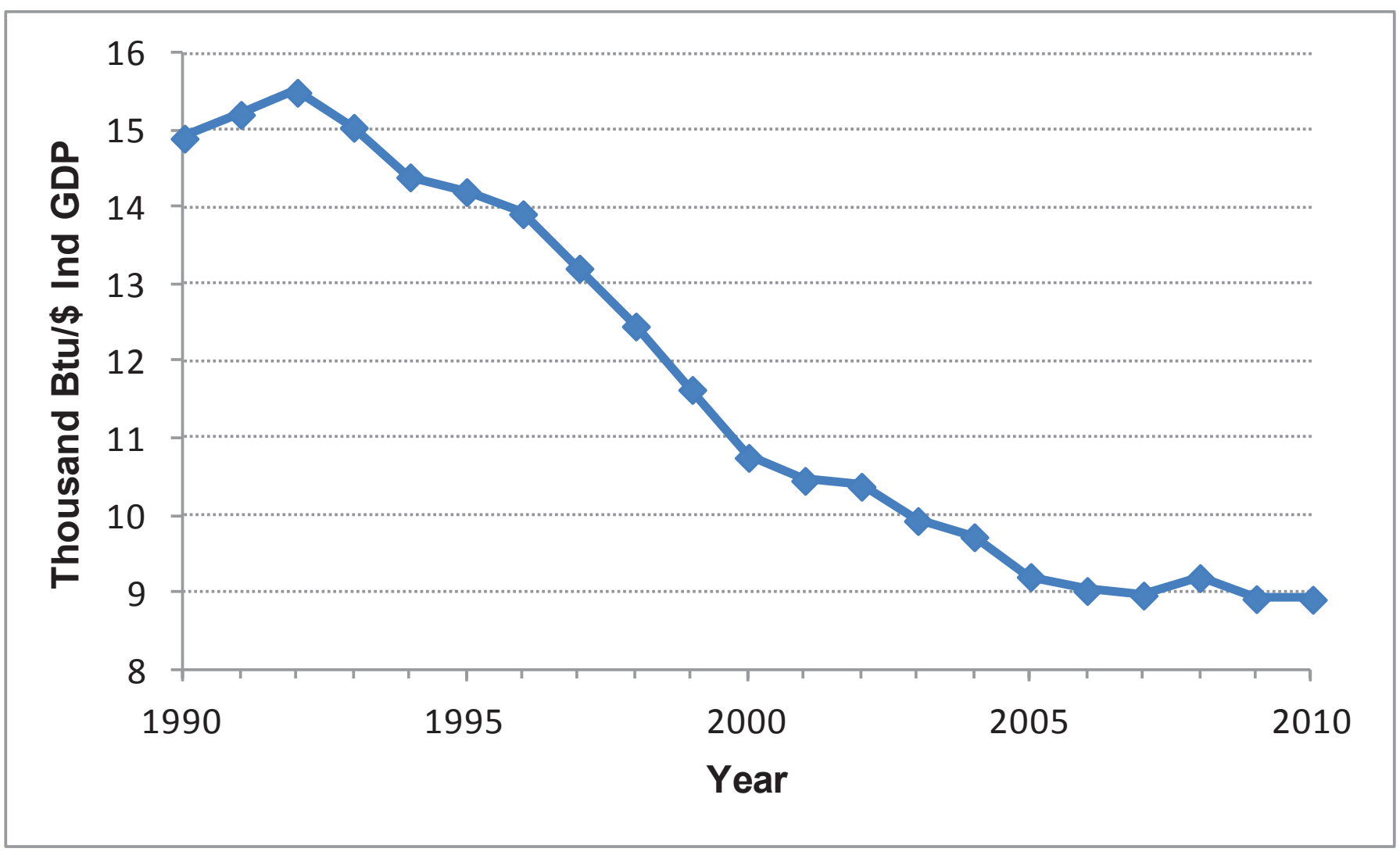

Sources: EIA Annual Energy Review, 2010, Table 2.1d and BEA, Value Added for Industry, 1990-1997 and 1998-2010, (Constant \$2010)

Figure 2. Historical Industrial Energy Intensity 


\section{The Advanced Manufacturing Office}

$\mathrm{AMO}$ is the lead government program working to develop and deploy new, energy-efficient technologies for the U.S. manufacturing sector. Programs within AMO are tailored to address specific barriers faced by technology developers and manufacturers to ensure that cost-effective technologies are effectively transitioned from fundamental to applied research, developed into commercially available products, and effectively deployed where they are needed throughout U.S. supply chains.

Manufacturing converts a wide range of raw materials, components, and parts into finished goods that meet market expectations. AMO partners with industry, small business, universities, and other stakeholders to identify and invest in emerging technologies with the potential to create highquality domestic manufacturing jobs and enhance the global competitiveness of the United States.

\section{Research \& Development Activities}

Technology innovation drives economic growth. AMO R\&D projects explore novel processes and materials to expand U.S. leadership in advanced manufacturing and the global clean energy economy. Projects are competitively selected and cost-shared with industry to maximize energy savings and economic benefits. In addition, shared infrastructure and facilities are available to support innovation in key areas such as:

- Innovative Manufacturing Initiative: Investments in transformational manufacturing processes and materials promise to reduce energy use, revitalize existing industries, and enable products with new functionality.

- Manufacturing Demonstration Facilities (MDF): MDFs provide access to advanced physical and virtual tools for rapidly demonstrating new manufacturing technologies and optimizing critical processes.

- Critical Materials Hub: Multidisciplinary teams at the Hub will explore ways to address challenges in critical materials, including mineral processing, manufacture, substitution, efficient use, and end-of-life recycling.

Small Business Innovative Research (SBIR): SBIR awards support small businesses to advance scientific discoveries and develop and commercialize manufacturing solutions.

- Combined Heat and Power (CHP): Development, testing, and validation of advanced CHP and distributed energy systems paves the way for accelerated deployment in manufacturing and other applications.
- Next Generation Materials: Innovative materials can open new design spaces for high-performance and renewable energy technology manufacturing. Projects focus on three areas with clear energy, carbon, and economic benefits.

AMO R\&D investments move emerging technology along the innovation pipeline through what is referred to as a technology's "Valley of Death," a span of time from applied R\&D to full manufacturing-scale demonstration.

\section{Technology Deployment Activities}

As technologies proceed along the development pipeline, most face major hurdles as they attempt to enter commercial markets. AMO's technology deployment programs help lower a range of institutional barriers and prepare energyefficient technologies and energy management systems for full commercial deployment. These activities include the following:

Better Buildings, Better Plants Program: Promotes corporate partners who demonstrate their commitment to energy savings and share experiences in order to foster replication.

- Superior Energy Performance: Provides a platform for measuring, certifying, and recognizing energy savings achieved by facilities that conform to the ISO 50001 Energy Management Standard.

Software tools: Available at no cost, these tools help companies identify and analyze opportunities to save energy in manufacturing.

Industrial Assessment Centers (IACs): A network of IACs allows teams of trained engineering students to perform energy audits for small- and mid-sized manufacturers.

- Clean Energy Application Centers (CEACs): Provide outreach to manufacturers considering adoption of combined heat and power (CHP) technology — to save energy and money.

Energy Experts and Qualified Specialists: Are available to help manufacturers apply DOE software tools and resources. 


\section{Technology Tracking Process}

For the last 20 years, AMO has worked with Pacific Northwest National Laboratory (PNNL) to track the progress of the technologies developed as part of their research development and deployment initiatives. An AMO technology is classified as commercial and is placed on the active tracking list when the full-scale unit is operational in a commercial setting. When a commercially successful technology unit has been in operation for 10 years, that particular unit is then considered a mature technology, reclassified as historical, and is no longer actively tracked. The active tracking process collects technical and market data on each commercially successful technology including:

- Number of units sold, installed, and operating in the United States and abroad (including size and location)

Units decommissioned since the previous year

$\checkmark$ Energy saved

$\checkmark$ Environmental benefits

- Improvements in quality and productivity achieved

Other impacts, such as employment and effects on health and safety

Marketing issues and barriers.

Information on these commercial technologies is gathered through direct contact with either the technology's vendors or end users. This data includes the number of operational units (equal to the number of units installed minus the number of units that have been decommissioned or classified as mature in a given year) and is used to calculate both unit energy savings and overall energy savings for each technology.

Once cumulative energy savings have been determined, longterm impacts on the environment are calculated by estimating the associated reduction of air pollutants. This calculation is based on the type of fuel saved and the pollutants typically associated with combustion of that fuel and uses assumed average emission factors.

The annual energy savings for each fuel type is multiplied by the fuel's price, with prices adjusted to reflect the fuel's current costs. The sum of all energy saved times the respective fuel prices yields an estimate of the cost savings in that particular year. To arrive at the net economic benefits, the energy-related cost savings are reduced by the appropriation allocated by the government for AMO initiatives and by the cost industry sustains to adopt the new technologies. More details on this methodology are provided in Appendix G.

Benefits documented by PNNL are conservative estimates based on technology users' and developers' testimonies. Because these estimates do not include secondary technical innovation that is a direct result of AMO's original investments, the actual benefits are likely to be much higher than the numbers reported here. The process of tracking these benefits is shown in Figure 3.

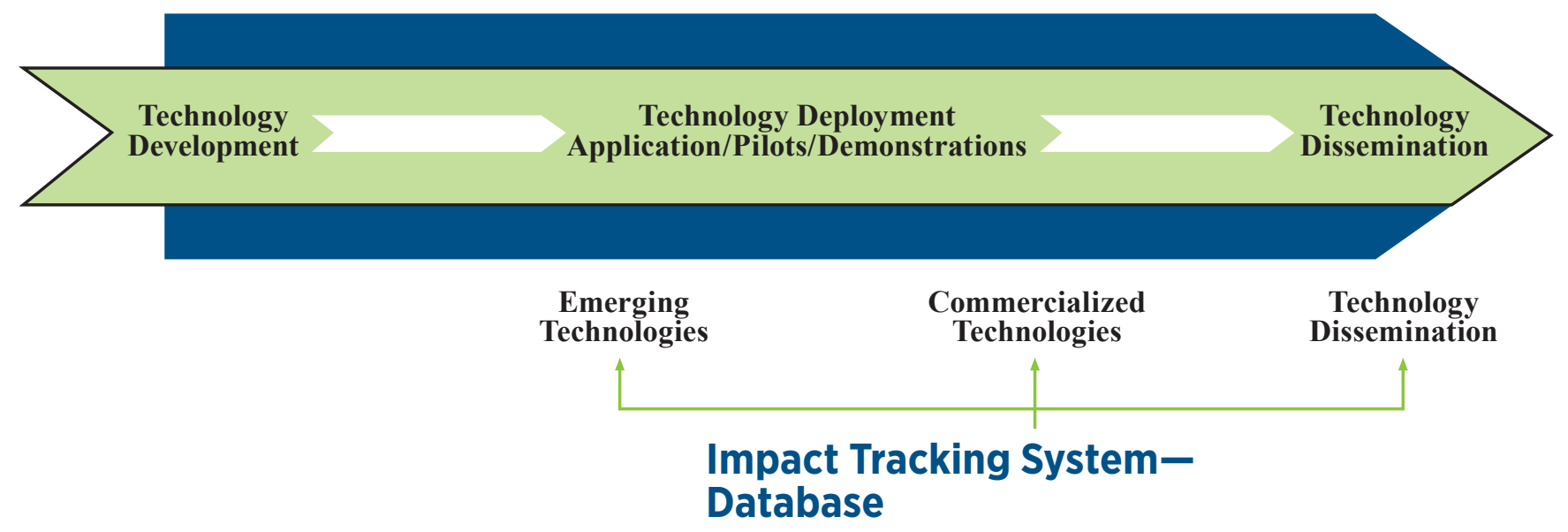

\section{Key impact categories tracked:}

- Cumulative energy savings, current energy savings, type of fuel saved, units operating

- Cumulative and annual pollution reductions (particulates, nitrogen oxides, volatile organic compounds, sulfur dioxide, carbon dioxide) 


\section{Results}

Over the past 30 years, AMO has supported more than 600 separate $R \& D$ projects that have produced over 250 technologies in commercial use. In 2010, there were 98 technologies that were in commercial use and yielding benefits. Table 1 contains basic information on the currently tracked commercial technologies. This table shows energy savings in 2010, as well as cumulative energy savings and pollution reductions. The 98 commercial technologies in use during 2010 saved 43.1 trillion Btu. Cumulatively, these technologies have saved 0.20 quads. Appendix $A$ includes fact sheets on these 98 technologies. The fact sheets include both technical and commercial applications data that could help industry identify opportunities for adapting AMO technologies to their own operational needs.

Appendix $B$ describes 168 emerging technologies that show promise of being commercialized within the next two to three years.

After an AMO-supported commercial technology has contributed to energy and cost savings for ten years, it is reclassified as historical and is no longer actively tracked. There are 132 historical technologies that have cumulatively saved 3.53 quads. The cumulative energy savings for all commercial and historical technologies are shown in Table 1 and in Figure 4. Appendix $C$ describes the 132 historical technologies that have been used in commercial applications in the past.
The estimated benefits attributable to Industrial Assessment Center (IAC) activities are discussed in Appendix D. As Table 1 shows, the centers saved an estimated 241 trillion Btu in 2010 and have cumulatively saved 2.44 quads since the activity's inception in 1977.

The estimated benefits for technology deployment programs (TDP) are described in Appendix E. As shown in Table 1, TDP saved 214 trillion Btu in 2010 and has cumulatively saved an estimated 1.58 quads since its inception in 1998.

Benefits attributable to DOE's combined heat and power (CHP) activities are described in Appendix F. As shown in Table 1, CHP activities saved 215 trillion Btu in 2010 and have cumulatively saved 2.96 quads since 1990 .

Figure 4 shows the cumulative energy savings attributable to AMO programs since the Office's inception in 1976. As of 2010, AMO programs have saved about 10.7 quads. In 2010, AMO programs were instrumental in saving industry 713 trillion Btu or $\$ 5.12$ billion. As shown in Figure 5, over AMO's entire history these cumulative net benefits are about $\$ 56.5$ billion (in 2010 dollars). In addition, the AMO programs have cumulatively reduced emissions of carbon by 236 million tons, of nitrogen oxides by 2 million tons, and of sulfur dioxides by 4 million tons, as Table 1 shows. The net economic benefits calculated from the energy saved by AMO initiatives are discussed in Appendix G. Using the energy savings from the technologies as well as the IACs, TDP, and CHP activities, the cost savings are determined annually for the fuels saved.

Table 1. AMO Program Impacts

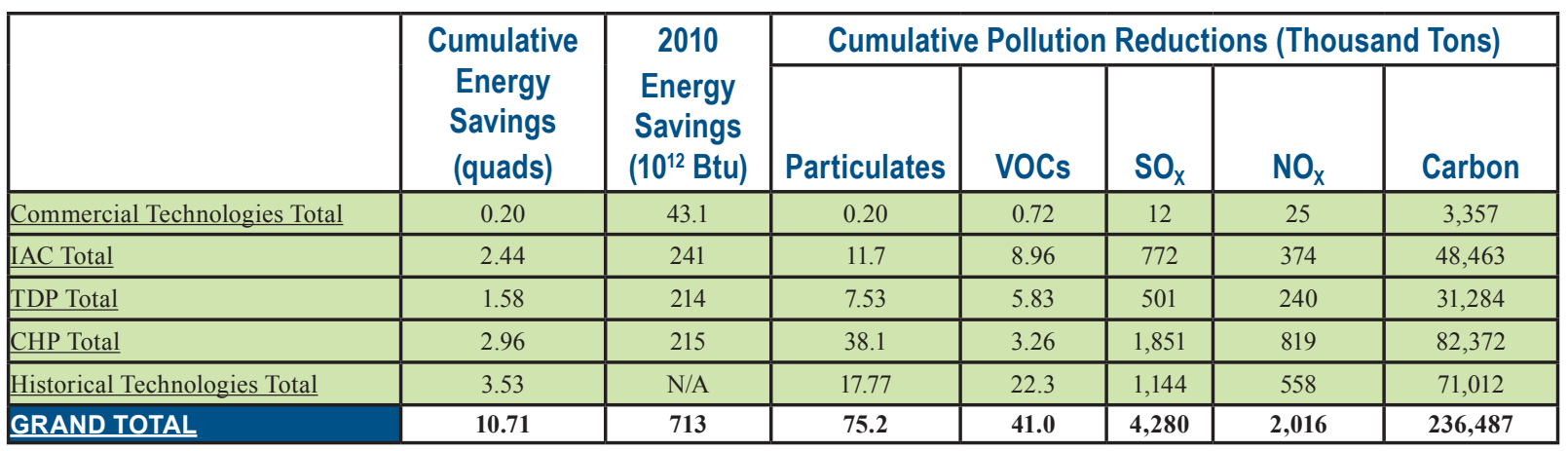




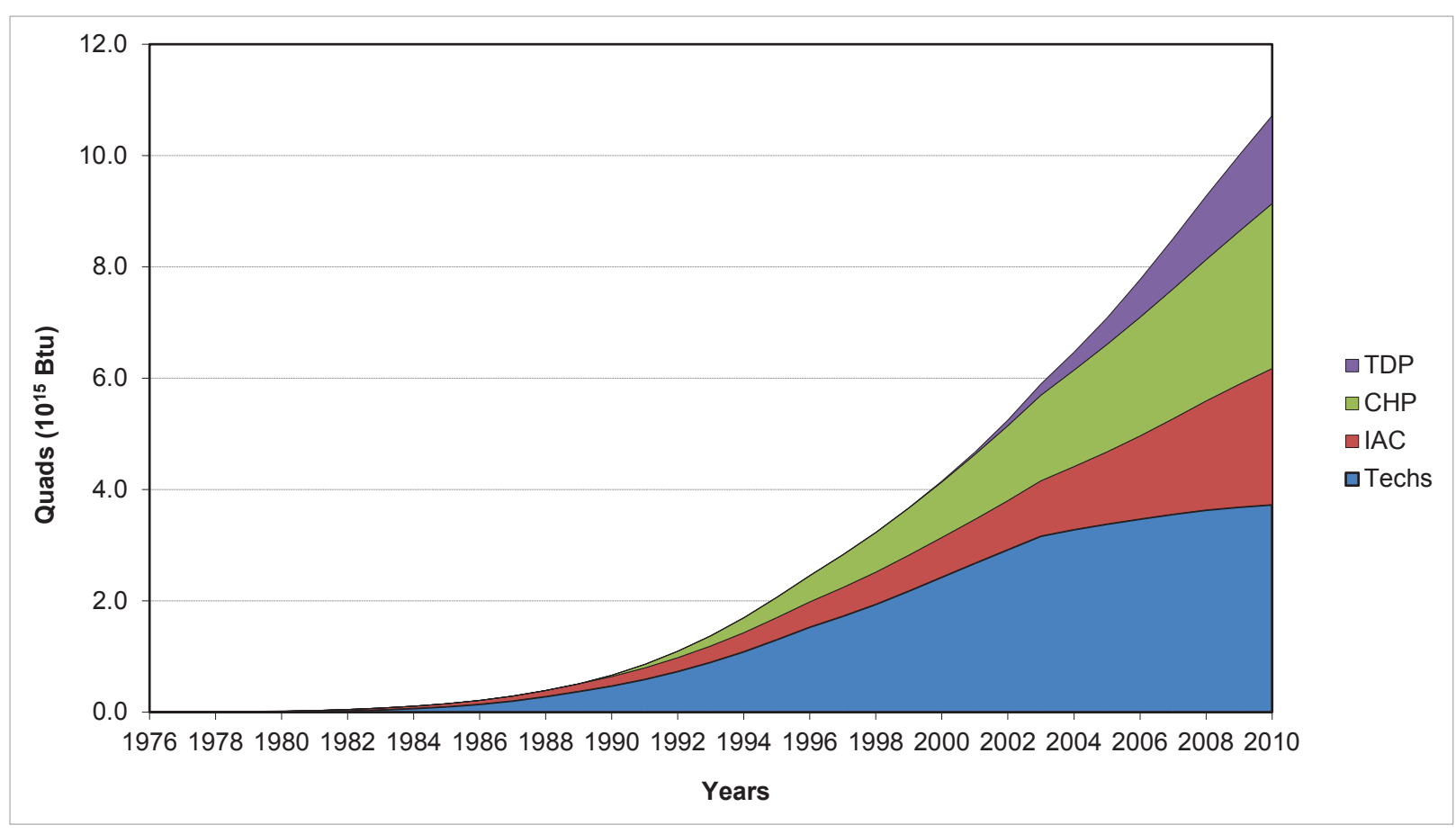

Figure 4. AMO Cumulative Energy Savings

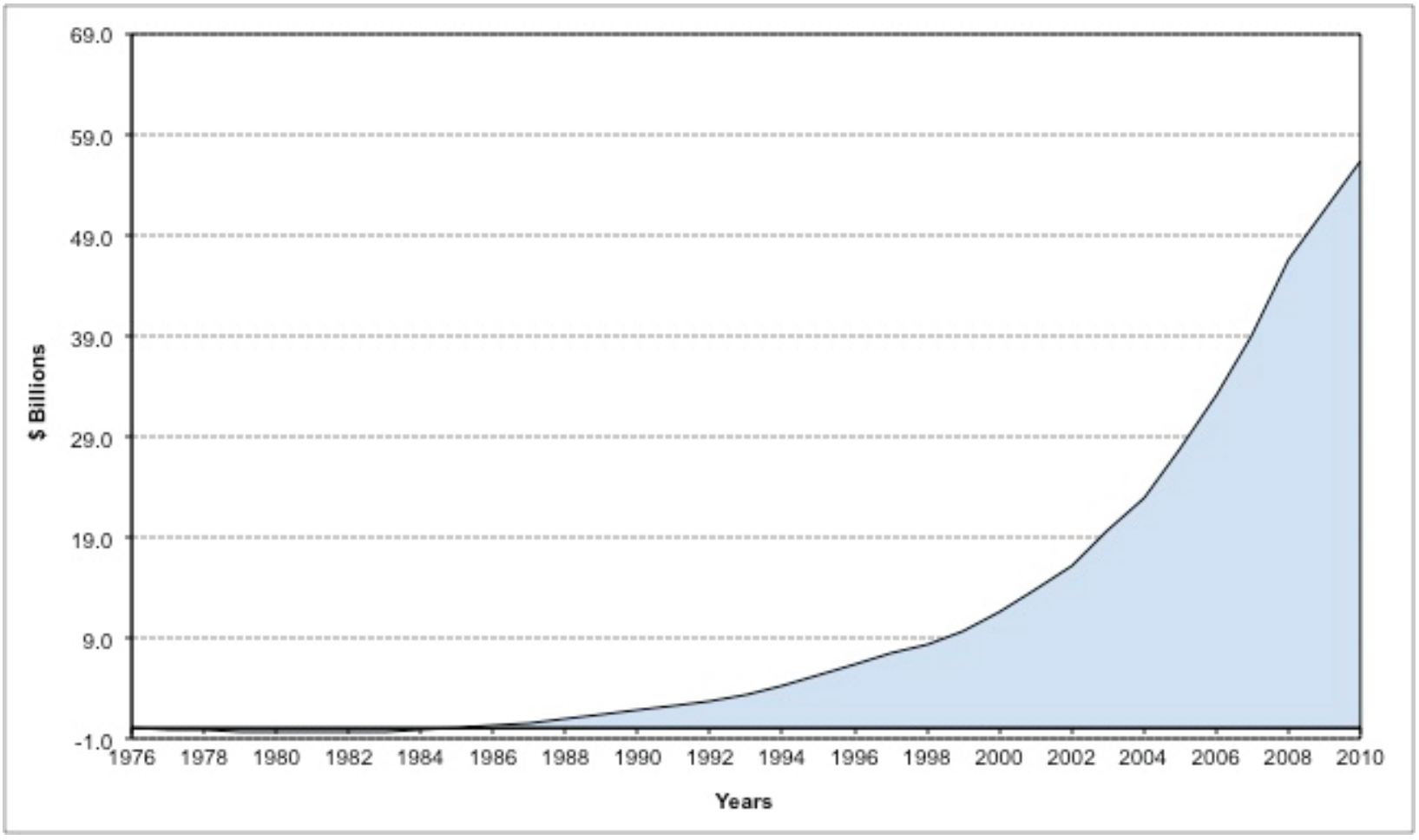

Figure 5. AMO Cumulative Cost Savings 



\section{Appendix A: AMO-Sponsored Technologies Commercially Available}

Aluminum A-5

Aluminum Reclaimer for Foundry Applications.

A-6

$\checkmark$ Isothermal Melting.

Chemicals

Cavity-Enhanced Gas Analyzer for Process Control.

Hollow-Fiber Membrane Compressed Air Drying System

A-11

$\checkmark$ Improved Methods for the Production of Polyurethane Foam

A-12

Low-Cost, Robust Ceramic Membranes for Gas Separation

A-13

- Low-Frequency Sonic Mixing Technology

A-14

Membranes for Reverse-Organic Air Separations

A-15

Mixed Solvent Electrolyte Model

A-16

Nylon Carpet Recycling .

A-17

Pressure Swing Adsorption for Product Recovery

A-18

Process Heater for Stoichiometric Combustion Control

A-19

$\checkmark$ Titania-Activated Silica System for Emission Control.

A-20

Total Cost Assessment Tool.

A-21

TruePeak Process Laser Analyzer.

A-22

Forest Products

A-23

$\checkmark$ Advanced Quality Control (AQC) Solution for Thermo-Mechanical Pulping ...

A-24

Biological Air Emissions Control

A-25

Borate Autocausticizing

A-26

$\checkmark$ Continuous Digester Control Technology .

Detection and Control of Deposition on Pendant Tubes in Kraft Chemical Recovery Boilers.

MultiWave ${ }^{\mathrm{TM}}$ Automated Sorting System for Efficient Recycling

- Screenable Pressure-Sensitive Adhesives.

Thermodyne ${ }^{\mathrm{TM}}$ Evaporator - A Molded Pulp Products Dryer. A-31

\section{Glass}

High Luminosity, Low-NO Burner. A-34

High Throughput Vacuum Processing for Producing Innovative Glass/Photovoltaic Solar Cells.

Process for Converting Waste Glass Fiber into Value-Added Products A-36

\section{Metal Casting.}

CFD Modeling for Lost Foam White Side

Die Casting Copper Motor Rotors.

Improved Magnesium Molding Process (Thixomolding)

Improvement of the Lost Foam Casting Process.

Low Permeability Components for Aluminum Melting and Casting

A- 42

$\checkmark$ Titanium Matrix Composite Tooling Material for Aluminum Die Castings

\section{Mining}

Belt Vision Inspection System

Digital Through-The-Earth Communication System

Horizon Sensor ${ }^{\mathrm{TM}}$

Lower-pH Copper Flotation Reagent System. 


\section{AMO-Sponsored Technologies Commercially Available}

\section{Steel}

Aluminum Bronze Alloys to Improve Furnace Component Life.

$\checkmark$ Automated Steel Cleanliness Analysis Tool (ASCAT)

Electrochemical Dezincing of Steel Scrap

H-Series Cast Austenitic Stainless Steels

$\checkmark$ HotEye $^{\circledR}$ Steel Surface Inspection System

ITmk3: High-Quality Iron Nuggets Using a Rotary Hearth Furnace

Laser Contouring System for Refractory Lining Measurements

Life Improvement of Pot Hardware in Continuous Hot Dipping Processes

Low-Temperature Colossal Supersaturation of Stainless Steels.

Microstructure Engineering for Hot Strip Mills

Vanadium Carbide Coating Process

\section{Crosscutting}

Adjustable-Speed Drives for 500 to 4000 Horsepower Industrial Applications

Advanced Aerodynamic Technologies for Improving Fuel Economy in Ground Vehicles

Advanced Diagnostics and Control for Furnaces, Fired Heaters, and Boilers

Advanced Reciprocating Engine Systems (ARES)

Aerogel-Based Insulation for Industrial Steam Distribution Systems

Autotherm ${ }^{\circledR}$ Energy Recovery System

Barracuda ${ }^{\circledR}$ Computational Particle Fluid Dynamics $\left(\right.$ CPFD $\left.^{\circledR}\right)$ Software ..

$\checkmark$ Callidus Ultra-Blue (CUBL) Burner.

Catalytic Combustion

- Composite-Reinforced Aluminum Conductor

Cromer Cycle Air Conditioner.

Electrochromic Windows - Advanced Processing Technology...

Energy-Conserving Tool for Combustion-Dependent Industries ....

Fiber-Optic Sensor for Industrial Process Measurement and Control

Fiber Sizing Sensor and Controller.

A-79

Force Modulation System for Vehicle Manufacturing

A- 80

Freight Wing ${ }^{\mathrm{TM}}$ Aerodynamic Fairings..

Functionally Graded Materials for Manufacturing Tools and Dies.

$\checkmark$ Ice Bear ${ }^{\circledR}$ Storage Module

In-Situ, Real Time Measurement of Elemental Constituents ..

Materials and Process Design for High-Temperature Carburizing...

Mobile Zone Optimized Control System for Energy-Efficient Surface-Coating

Nanocoatings for High-Efficiency Industrial Hydraulic and Tooling Systems.....

- Novel Refractory Materials for High-Temperature, High-Alkaline Environments.

Portable Parallel Beam X-Ray Diffraction System

$\checkmark$ Predicting Corrosion of Advanced Materials and Fabricated Components..

Process Particle Counter.

Pulsed Laser Imager for Detecting Hydrocarbon and VOC Emissions.

Self-Healing Polymeric Coatings

$\checkmark$ Sensor Network for Motor Energy Management

- Simple Control for Single-Phase AC Induction Motors.

$\checkmark$ Solid-State Sensors for Monitoring Hydrogen

SpyroCor ${ }^{\mathrm{TM}}$ Radiant Tube Heater Inserts

Three-Phase Rotary Separator Turbine.

Ultra-Low $\mathrm{NO}_{\mathrm{X}}$ Premixed Industrial Burner.

Ultrananocrystalline Diamond (UNCD) Seal Faces.

Vibration Power Harvesting.

$\checkmark$ Wireless Sensors for Process Stream Sampling and Analysis.. 


\section{AMO-Sponsored Technologies Commercially Available}

IMPACTS

\section{Other Industries}

A-105

Advanced Membrane Devices for Natural Gas Cleaning.

A-106

Data Center Transformer from "Always On" to "Always Available"

A-107

Deep Discharge Zinc-Bromine Battery Module

Energy-Efficient Cooling Control Systems for Data Centers

High-Efficiency, Wide-Band Three-Phase Rectifiers and Adaptive Rectifier Management

A-110

High-Intensity Silicon Vertical Multi-Junction Solar Cells

A-111

Long Wavelength Catalytic Infrared Drying System

A-112

Low-Volume Server for Reduced Energy Use and Facility Space Requirements..

A-113

Management Technology for Energy Efficiency in Data Centers and Telecommunications Facilities

A-114

$\checkmark$ Plant Phenotype Characterization System

Plastics or Fibers from Bio-Based Polymers

A-115

A-116 


\section{Affordable Metallic Recovery System Saves Energy and Reduces Landfill Waste Streams}

Aluminum foundries and melters typically generate rich metallic skimmings and drosses during industrial processes. While equipment is commercially available to recover a portion of the contained metallics from skimmings and drosses, the capital investment for the previous equipment has precluded its application with smaller melting units such as crucible or reverb melters. With assistance from AMO, Q.C. Designs, Inc., developed an improved reclaiming process specifically to recover the metallics from small quantities of dross and skim. Recent advances in the technology permit an increase in the quantity of drosses being processed and allow the recovered metal to be returned to the generating furnace in molten form, in some cases. The process has recovered as much as $80 \%$ of the contained metal at the point of generation.

In operation, the process may be run either manually, with power-assisted stirring, or with a fully automatic programmed cycle. All operations are environmentally friendly, reducing the amount of smoke and fumes normally associated with dross processing and furnace cleaning. Foundries reduce their melting losses by the in-plant recovery of drosses and their contained metals, which can then be reused directly without realloying.

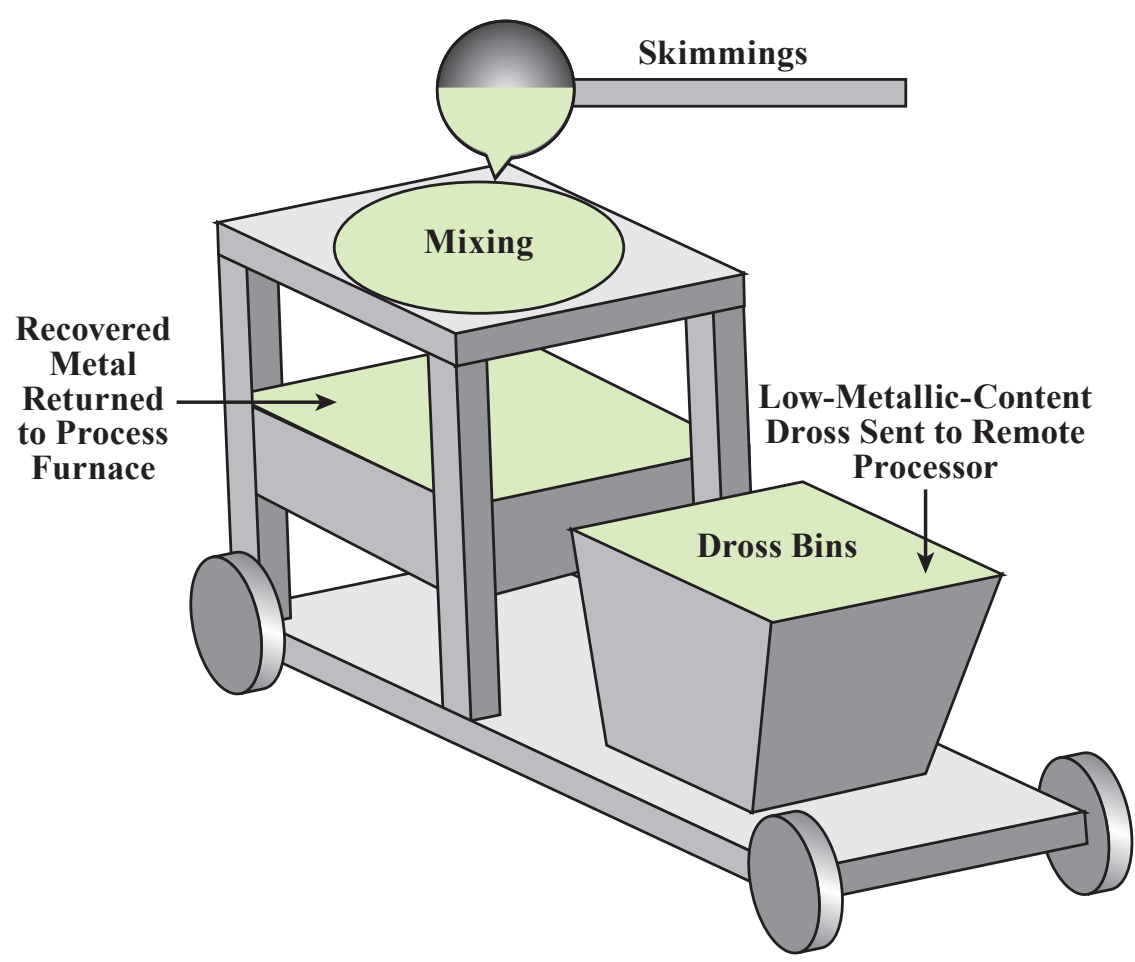

Portable Aluminum Reclaimer

\section{Overview}

Available from Q.C. Designs, Inc. (www.qcdesignsinc.com)

Commercialized in 2001

25 units installed in the United States

\section{U.S. Energy Savings}

(Trillion Btu)

\begin{tabular}{|c|c|}
\hline Cumulative through 2010 & $\mathbf{2 0 1 0}$ \\
\hline 0.005 & 0.001 \\
\hline
\end{tabular}

\section{U.S. Emissions Reductions}

(Thousand Tons, 2010)

\begin{tabular}{|c|c|c|c|}
\hline Particulates & SO $_{\mathrm{x}}$ & NO $_{\mathrm{x}}$ & Carbon \\
\hline 0.0 & 0.0 & 0.0 & 0.013 \\
\hline
\end{tabular}

\section{Applications}

In-plant aluminum foundry dross and skimming recovery

\section{Capabilities}

Processes hot dross in quantities from 10 to $500 \mathrm{lb}$

Allows automatic processing or manual operation.

Features sizes for applications in different foundry installations.

\section{Benefits}

\section{Productivity}

Contributes directly to profits by decreasing melting losses. Typical compensation for dross materials from outside processors is $10 \%$ to $20 \%$ of true value because the generating foundry has to bear the costs of transportation, remelt and processing, landfill of the waste, and return of the recovered material. In-plant processing eliminates a large portion of these costs.

\section{Waste Reduction}

Minimizes the volume of material requiring landfilling and recovers a higher percentage (up to $80 \%$ ) of metallics than current methods. 


\section{Isothermal Melting}

IMPACTS

\section{New Energy-Efficient Melting Process Saves Energy and Reduces Production Losses}

Aluminum melting is an energy intensive process that exhibits a $2 \%$ to $3 \%$ loss rate due to the generally open heating method for melting. A new immersion heating process, Isothermal Melting (ITM), has been developed by Apogee Technology, Inc., with support from AMO. The system uses immersion heaters in a closed loop multiple bay arrangement. Each bay contributes to an efficiency improvement. The pumping bay provides circulation that provides better mixing for purifying and alloying and more uniform temperature profiles throughout the molten pool. The heating bay is the major source of efficiency gain, where electricity is converted into heat through the immersion heaters and conducted directly to the molten metal. The heating bay raises the molten metal temperature (typically less than $90^{\circ} \mathrm{F}$ ) just high enough to melt the solid metal being charged into the pool. Compact charging and treatment bays provide control and introduce solid charge or alloying and purifying elements in a more energy efficient manner compared with opening hearth doors and exposing the entire surface of the pool and refractory to the plant environment.

The challenge to developing the ITM system was the creation of immersion heaters that could provide the high heat flux and the chemical, thermal, and mechanical robustness required in an industrial molten aluminum environment. Apogee Technology's research program developed new materials, fabrication techniques, and quality control systems to build immersion heaters with high heat flux (approximately 70,000 Btu/hr-ft²), approximately 5 to 10 times more than commercially available heaters. These new heater designs are based on highly thermally conductive, impact resistant ceramic coating on a metallic sheath and a highly conductive dielectric integral coupling medium between the sheath and the heat producing element. This allows heat transfer by conduction to be the dominant mode, rather than particle to particle radiation heat transfer that prevails in conventional processes. The composite refractory coating is resistant to corrosive attack by the molten aluminum, yet sufficiently thin enough to provide a high heat flux.

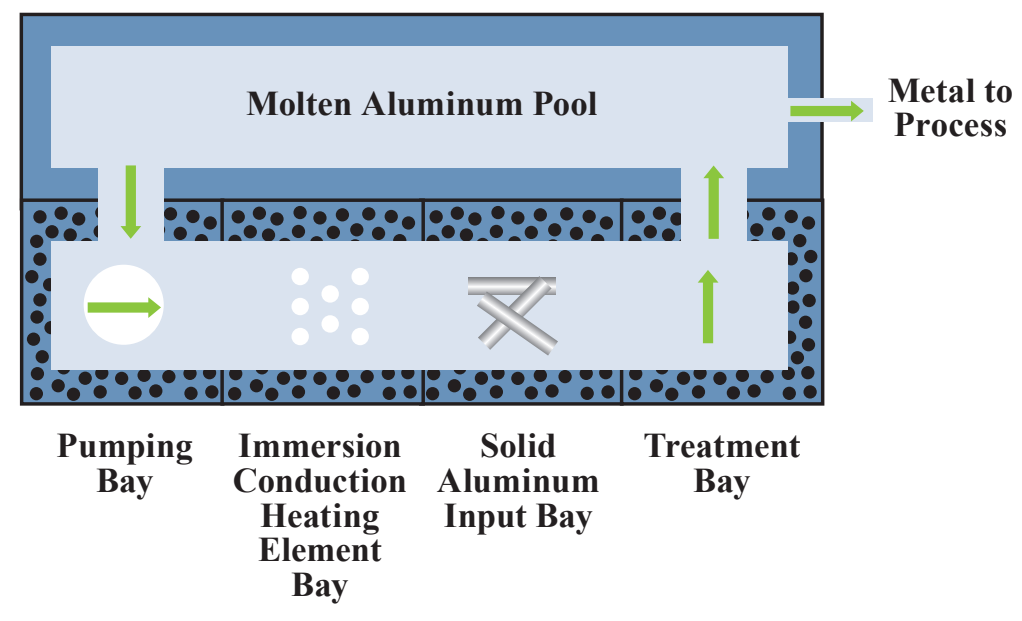

The Isothermal Melting System

\section{Overview}

$\checkmark$ Developed by Apogee Technology, Inc. (www.apogeetechinc.com)

Installed at three facilities

\section{U.S. Energy Savings} (Trillion Btu)

\begin{tabular}{|c|c|}
\hline Cumulative through 2010 & $\mathbf{2 0 1 0}$ \\
\hline 0.013 & 0.002 \\
\hline
\end{tabular}

\section{U.S. Emissions Reductions}

(Thousand Tons, 2010)

\begin{tabular}{|c|c|c|c|}
\hline Particulates & SO $_{\mathrm{x}}$ & NO $_{\mathrm{x}}$ & Carbon \\
\hline 0.0 & 0.002 & 0.001 & 0.106 \\
\hline
\end{tabular}

\section{Applications}

Can be used in aluminum melting processes and other metal melting processes

\section{Capabilities}

Can be retrofitted to existing furnaces.

Applies to multiple types of molten metal heating operations.

\section{Benefits}

\section{Cost Savings}

Reduces metal lost to oxidation to $<1 \%$.

\section{Environmental Emissions Reductions}

Produces zero in-plant emissions compared with natural gas process heating. 
IMPACTS

Cavity-Enhanced Gas Analyzer for Process Control.

A-10

Hollow-Fiber Membrane Compressed Air Drying System ......................................................................................................11

Improved Methods for the Production of Polyurethane Foam ................................................................................................. A-12

Low-Cost, Robust Ceramic Membranes for Gas Separation..................................................................................................... A-13

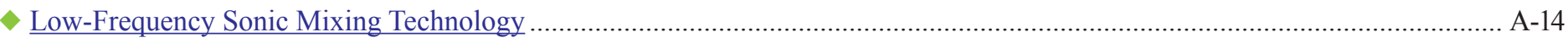

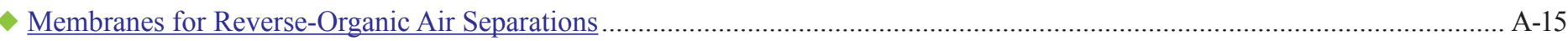

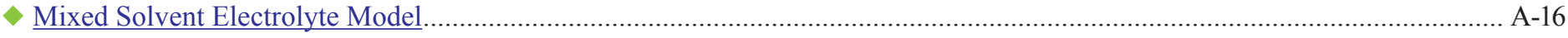

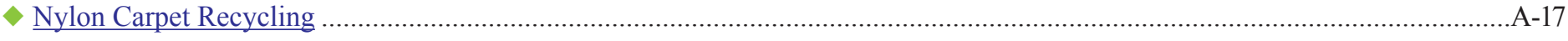

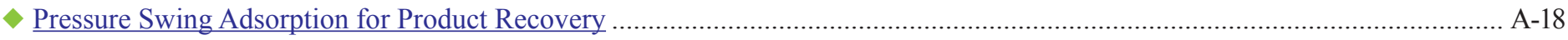

Process Heater for Stoichiometric Combustion Control ............................................................................................... A-19

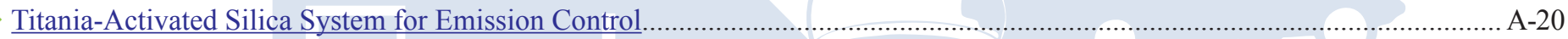

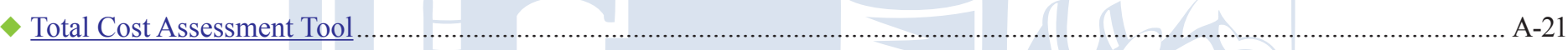

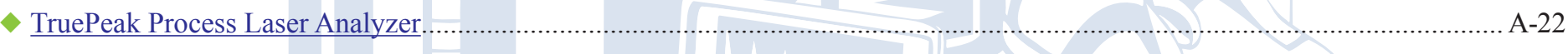

$\begin{array}{lll}\text { DOE Advanced Manufacturing Office } & \text { A-9 }\end{array}$ 


\section{Cavity-Enhanced Gas Analyzer for Process Control}

\section{Ultrasensitive Analyzer Provides Real-Time Quantification of Acetylene and Reduces Operating Costs}

Ethylene is the largest volume, largest revenue-generating organic chemical produced. Ethylene finds widespread use, serving as the building block for $50 \%$ of all organic chemicals and polymers. However, manufacturers who produce polymer-grade ethylene must constantly monitor, and if necessary, hydrogenate any acetylene that may be present in ethylene flows. Such measures are imperative because too high an increase in acetylene concentration has the potential to contaminate both the catalytic bed and the stored finished product, and if left unchecked, acetylene contamination can cost a chemical manufacturer more than $\$ 200,000$ in losses per event. As a result, the ability to quickly and accurately monitor trace levels of acetylene is a critical need for ethylene manufacturers.

Los Gatos Research, in partnership with Dow Chemical and Analytical Specialties, Inc., has developed an industrial gas process control monitor that can replace gas chromatography. Through support funding provided by DOE's SBIR program, the new gas analyzer uses a patented technology having a variation of absorption spectroscopy. The new technology increases the path-length up to several kilometers of effective path using two highly reflective mirrors in the sample cavity and a diode laser that is not sensitive to alignment. The compact robust technology, Off-Axis ICOS (Integrated Cavity Output Spectroscopy), retains the sensitivity of older detection methods, while providing an absolute, accurate measurement of acetylene contamination that is fifty times faster and one-third less expensive than traditional gas chromatography.

The Off-Axis ICOS technology can be completely integrated into gas handling and computing subsystems. The analyzer is field serviceable to permit long-term deployment in the gas processing environment. Additionally, the highly reflective mirrors can be periodically replaced without any need for realignment or adjustment, which further increases the instrument's lifetime.

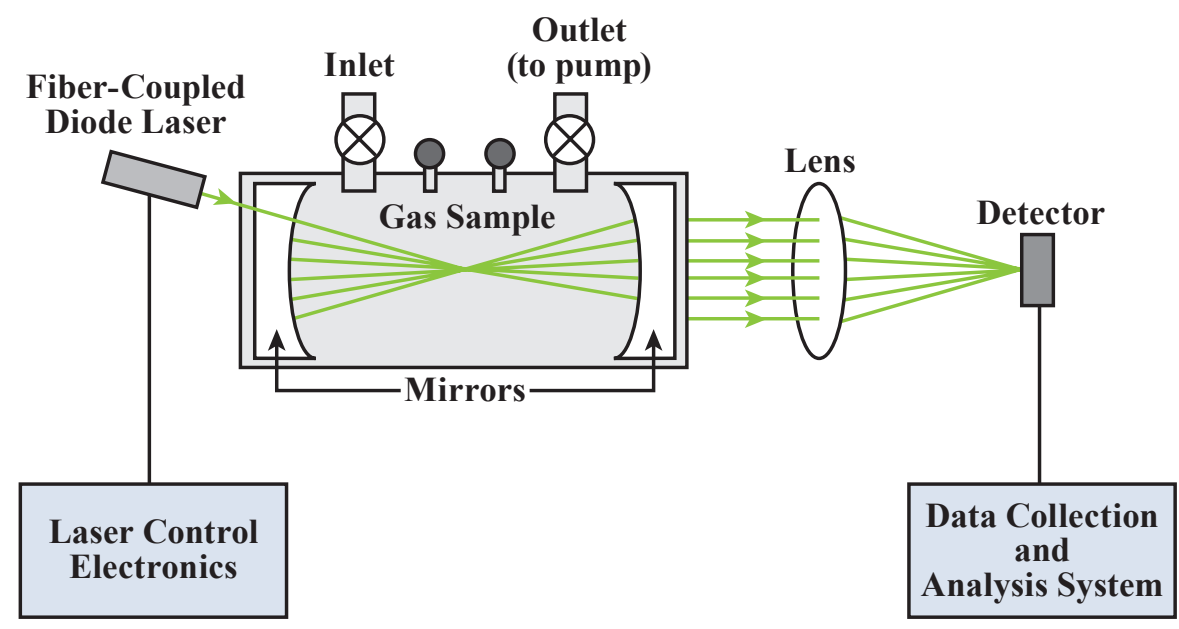

\section{Overview}

Developed by Los Gatos Research in partnership with Dow Chemical Co., and Analytical Specialties, Inc. (www.lgrinc.com)

$\checkmark$ Commercialized in 2006 with more than 25 units in operation

\section{Applications}

Can be used to measure trace acetylene concentrations in ethylene gas flows, providing a real-time measurement of potential contamination.

\section{Capabilities}

Provides measurements 50 times faster than conventional gas chromatography.

Reduces the capital cost for analytical support technologies.

Allows for the optimization of the hydrogenation reactor and minimizes product contamination.

\section{Benefits}

\section{Applicability}

Integrates into complete gas handling, sampling, and computing systems with a compact, robust design.

\section{Product Quality}

Minimizes off-specification ethylene product quality through improved process control.

\section{Profitability}

Improves raw material conversion to finished product and minimizes reprocessing and potential system contamination due to excess acetylene in the gas.

Cavity-Enhanced Gas Analyzer System 


\section{Hollow-Fiber Membrane Compressed Air Drying System}

IMPACTS

\section{New Membrane Allows Drying of Compressed Air at Lower Energy and Higher Productivity}

With the support of a $\mathrm{NICE}^{3}$ grant, a new hollow-fiber membrane for dehydrating gases has been developed by Air Products and Chemicals, Inc. The membrane has 5 times higher water vapor permeation coefficient and 25 times higher water vapor/air selectivity compared with first-generation membrane dryers. The membrane produces higher flow capacity and lower purge loss in compressed air drying, which enables high productivity and low energy consumption in drying compressed air. The membrane module contains a bundle of hollow-fiber membranes in a plastic shell with aluminum end caps. The feed air flows through the fiber bores; selective permeation of water vapor produces dry nonpermeate gas, a fraction of which is metered via a flow restrictor such as an orifice to provide a low-pressure purge gas that carries away the permeated moisture.

Compressed air is widely used as a utility in many industries and most often must be dried to avoid condensation or freezing in lines and to meet the needs of many processes. Whereas refrigerant dryers are used at pressure dew points of $35^{\circ} \mathrm{F}$ and desiccant dryers are used at dew points of $-40^{\circ} \mathrm{F}$, membranes can be used to cover the range between $35^{\circ} \mathrm{F}$ and $-40^{\circ} \mathrm{F}$. The membrane can achieve the necessary degree of drying while requiring less purge air and therefore achieves lower energy consumption than a heatless desiccant dryer. Modular membrane dryer systems with large flow capacity can be used to produce pressure dew points between $35^{\circ} \mathrm{F}$ and $-40^{\circ} \mathrm{F}$, consuming less energy than that of desiccants. Unlike desiccant systems, membrane operation is continuous, requiring only one control valve versus at least 5 valves for flow diversion/de-pressurization in the desiccant system.

\section{Benefits}

\section{Cost Savings}

Provides purge control for additional power and cost savings.

\section{Environmental}

Reduces solid waste production.

\section{Operation and Maintenance}

Operates without valves or moving parts and is maintenance-free. Requires no electrical wiring or external power and operates silently.

\section{Overview}

Developed by Air Products and Chemicals, Inc. (www.airproducts.com)

$\checkmark$ Commercialized in 2004

12,884 units operating in the United States in 2010

\section{U.S. Energy Savings}

(Trillion Btu)

\begin{tabular}{|c|c|}
\hline Cumulative through 2010 & $\mathbf{2 0 1 0}$ \\
\hline 0.033 & 0.012 \\
\hline
\end{tabular}

\section{U.S. Emissions Reductions}

(Thousand Tons, 2010)

\begin{tabular}{|c|c|c|c|}
\hline Particulates & SO $_{x}$ & NO $_{x}$ & Carbon \\
\hline 0.0 & 0.003 & 0.002 & 0.242 \\
\hline
\end{tabular}

\section{Applications}

Can be used by manufacturing industries that use compressed air

\section{Capabilities}

Is compact and lighter in weight than heatless desiccants, allowing flexibility in packaging the unit into a compressed air system.

Is rated for operation up to $150^{\circ} \mathrm{F}$ and 200 psig.

Provides excellent turndown capability, all the way down to zero feed.

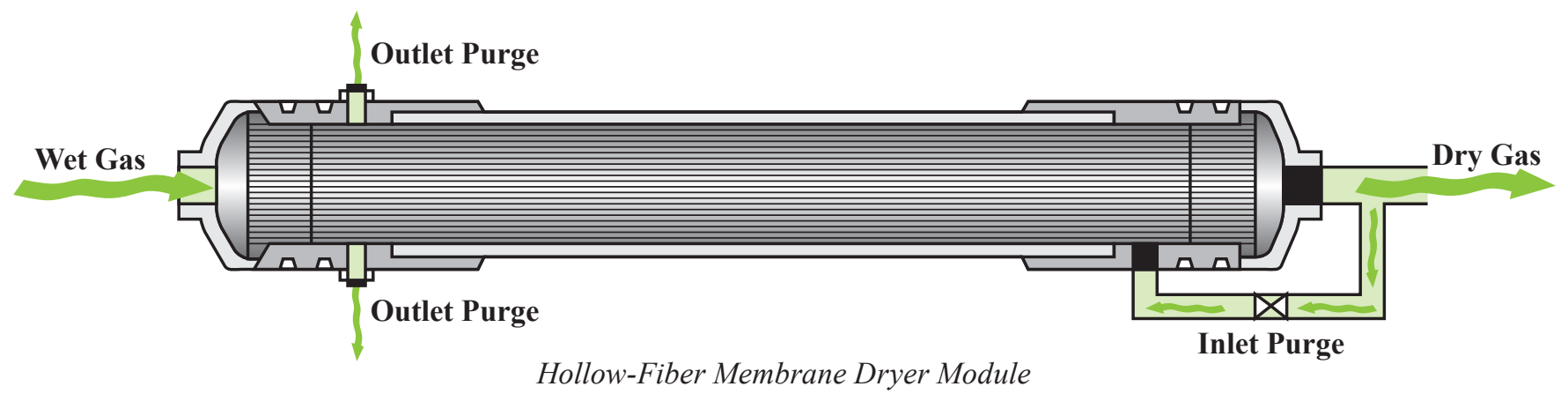




\section{New Surfactants Result in a More Environmentally Benign Production Process}

Methylene chloride, a toxic chemical that contributes to air pollution, was recently eliminated from use in the U.S. polyurethane industry. This mandated elimination did not permit production of as large a range of foam grades as was possible using methylene chloride, thus placing U.S. industry at a competitive disadvantage. Air Products and Chemicals, Inc., with financial assistance from AMO, developed new silicone surfactants enabling the efficient production of the full range of foam grades using a more environmentally benign $\mathrm{CO}_{2}$ blowing agent. In addition to lowering toxicity, the new process uses less energy and reduces the net release of $\mathrm{CO}_{2}$, which is implicated in global warming.

The challenges in using liquid $\mathrm{CO}_{2}$ as a blowing agent include rapid vaporization, rapid bubble nucleation, and difficulty in maintaining fine cell structure in the foam. The new surfactants address these challenges by emulsifying the blowing agent, thereby maintaining fine cells during foaming. The silicone surfactants have achieved superior performance, resulting in finer cell structure (better yield), higher bun heights (better yield), better top to bottom physical property gradient (product consistency), and better compatibility with flame retardants.

\section{Benefits}

\section{Productivity}

Increases yield through finer foam cell structure, higher bun heights, and improved top to bottom physical property gradients.

\section{Safety}

Improves compatibility with flame retardants.

\section{Waste Reduction}

Reduces the toxicity of the process and uses the $\mathrm{CO}_{2}$ blowing agent more effectively for reduced $\mathrm{CO}_{2}$ release to the atmosphere.

\section{Overview}

Developed by Air Products and Chemicals, Inc., and being used in eleven plants in the United States (www.airproducts.com)

$\checkmark$ Commercialized in 2006

\section{U.S. Energy Savings}

(Trillion Btu)

\begin{tabular}{|c|c|}
\hline Cumulative through 2010 & $\mathbf{2 0 1 0}$ \\
\hline 0.413 & 0.171 \\
\hline
\end{tabular}

\section{U.S. Emissions Reductions}

(Thousand Tons, 2010)

\begin{tabular}{|c|c|c|c|}
\hline Particulates & SO $_{\mathrm{x}}$ & NO $_{\mathrm{x}}$ & Carbon \\
\hline 0.0 & 0.012 & 0.016 & 2.08 \\
\hline
\end{tabular}

\section{Applications}

Can be used in polyurethane foam production

\section{Capabilities}

- Eliminates use of toxic methylene chloride.

Increases foam yield through finer foam structure.

- Improves compatibility with flame retardants.

\section{Conventional Method}

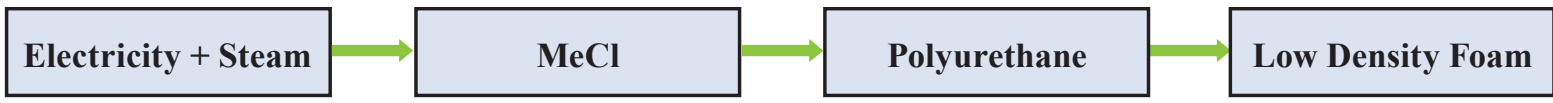

New Method

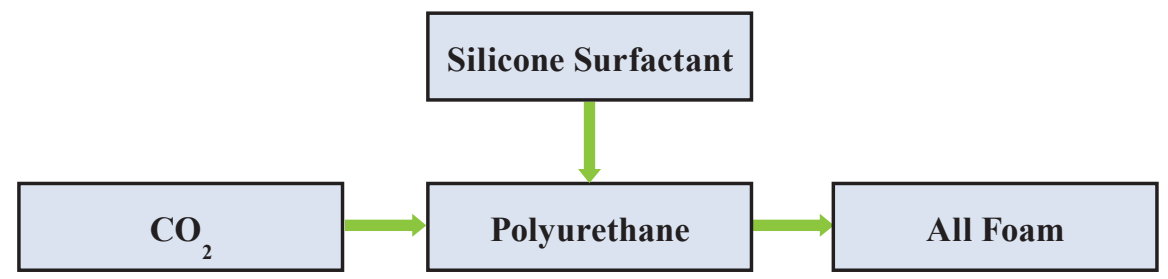

Polyurethane Foam Production 


\section{Low-Cost, Robust Ceramic Membranes for Gas Separation}

IMPACTS

\section{Innovative Ceramic Membrane Reduces Energy and Cost of Industrial Gas Separation}

Ceramic membranes offer great potential for industrial gas separation. Without a ceramic membrane, gases must be cooled before separation. Unfortunately, even though ceramic membranes can improve the productivity for many reactions and separations in the chemicals and refining industries, they are costly.

Media and Process Technology, Inc., with AMO support and industrial partners Gas Control Engineering Corporation, Southern California Gas, and the University of Southern California, developed a new technology that has overcome the cost barrier by using a low-cost, robust ceramic membrane. This membrane separates gases and vapors at temperatures up to $600^{\circ} \mathrm{C}$. Significant energy savings are possible because cooling prior to gas separation can be eliminated and valuable components removed from the gas stream can be recycled.

Applications are targeted toward hydrogen production, water and energy recovery from flue gas, and $\mathrm{CO}_{2}$ removal in natural gas processing. In addition, this low-cost membrane is currently under consideration as substrate for a wide range of thin films capable of industrial gas separations and is being used commercially without the gas separating layer for a wide range of liquid phase separations.

\section{Benefits}

\section{Energy Savings}

Allows gas separation at higher temperatures, eliminating the need to cool gases beforehand and therefore saving cooling energy.

\section{Profitability and Productivity}

Offers a low-cost material that reduces time and money spent for gas separation and allows valuable chemicals to be recycled rather than being disposed of.

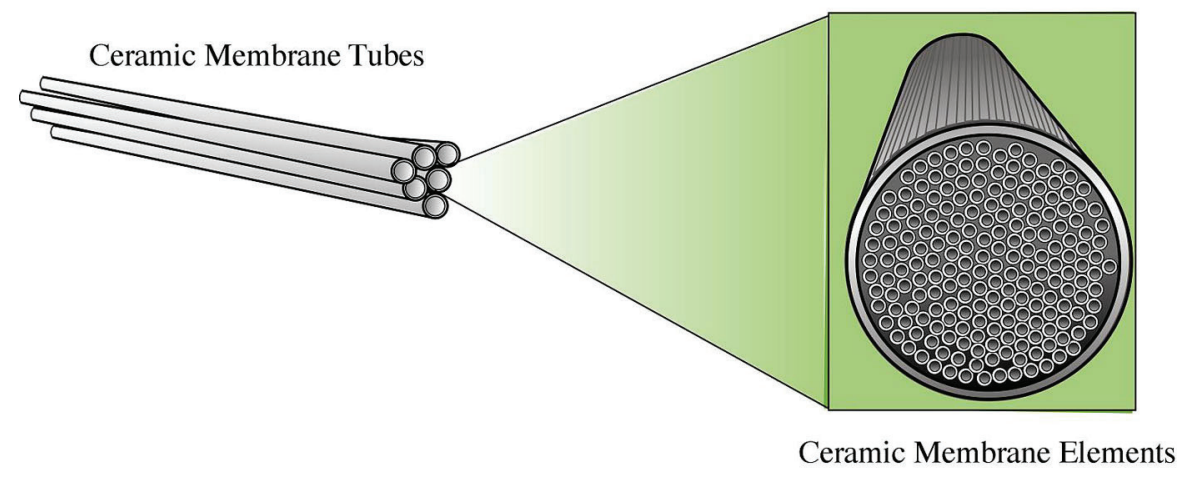

Media and Process Technology's Ceramic Membrane Tubes and Elements

\section{Overview}

Developed in joint venture among Media and Process Technology, Inc., Gas Control Engineering Corporation (GCE), Southern California Gas, and the University of Southern California (www.mediaandprocess.com)

Commercialized in 2005 and being marketed by the Gas Technology Institute

Installed in five U.S. locations for recovery of water vapor and energy, with multiple units planned for future installations.

\section{U.S. Energy Savings}

(Trillion Btu)

Cumulative through 2010

0.063

2010

0.020

\section{U.S. Emissions Reductions}

(Thousand Tons, 2010)

\begin{tabular}{|c|c|c|c|}
\hline Particulates & SO $_{\mathrm{x}}$ & NO $_{\mathrm{x}}$ & Carbon \\
\hline 0.0 & 0.0 & 0.002 & 0.317 \\
\hline
\end{tabular}

\section{Applications}

Can be used in natural gas processing, landfill gas recovery, hydrogen production, and water and energy recovery. Liquid phase separations are also possible. Can be used as low cost substrates for deposition of various membrane layers.

\section{Capabilities}

Separates gases and vapors at temperatures up to $600^{\circ} \mathrm{C}$.

Simplifies chemical production processes.

Enhances conversion of chemical reactions. 


\section{Low-Frequency Sonic Mixing Technology}

\section{New Acoustic Mixing Technology Improves Productivity Using Low-Frequency, High- Intensity Sound Energy}

Typical mixing technology uses a drive mechanism - usually an electric, hydraulic, or pneumatic motor - to rotate a shaft with one or more impellers. While many other mixer designs are available, including static mixers that do not use motors, the motor-driven mixer is the most prevalent mixing method.

Resodyn Corporation's ResonantAcoustics ${ }^{\circledR}$ mixing (RAM) technology, developed with the aid of a grant from DOE's Inventions and Innovation Program, is an improved approach to solving mixing and dispersion problems associated with conventional impeller agitation and ultrasonic mixing. Rather than mix by inducing bulk fluid flow, such as impeller agitation, RAM agitation mixes by inducing microscale turbulence through propagating acoustic waves throughout the medium. The RAM system has a lower frequency of acoustic energy and larger scale of mixing than ultrasonic agitation. Another distinct difference from ultrasonic technology is that the RAM devices are simple, mechanically driven agitators that can be made large enough to perform industrial-scale tasks at reasonable cost.

RAM introduces acoustic vibrations into liquids and slurries via the resonant vibration of a mechanical system. The impedance of the vibrating system is matched to that of the load, i.e., the process fluid. The entire system vibrates in resonance, which allows efficient energy transport to the fluid, creating smallscale eddies. Although the eddies are microscale, the entire reactor is well mixed in an extremely short time because the acoustic streaming, generated by the acoustic field, causes the microscale vortices to be distributed uniformly throughout the fluid. Multiple mixing regimes are possible by using the RAM system and the controls developed exclusively for it.

Since the commercialization of the technology, Resodyn has sold tens of laboratory-scale mixers to both U.S. and international customers and has extended the product line by adding 5-gallon and 55-gallon capacity mixers for production applications. Industries that use mixers in their production process are extremely receptive to new mixing technologies that could help improve efficiency and lower their manufacturing costs.

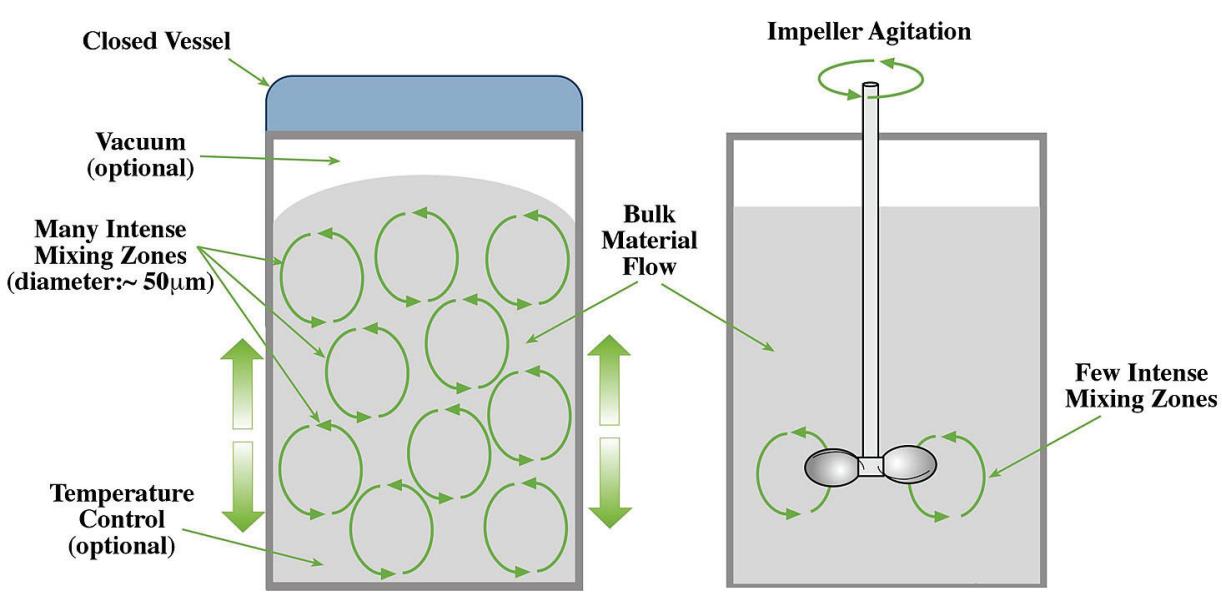

\section{Overview}

$\diamond$ Developed by Montec Research, Inc.

Commercialized in 2007

Marketed by Resodyn Acoustic Mixers, Inc.

(www.resodynmixers.com)

\section{Applications}

Can be used in a number of industries, including ceramics, biotechnology, agriculture, chemical manufacturing and processing, food, mining, municipal waste treatment, petroleum, pharmaceutical, pulp and paper, aerospace, microelectronics, and water treatment.

\section{Capabilities}

- Uses acoustic energy rather than impellers to mix gases, liquids, and slurries.

Mixes a wide viscosity range (1cP to $100+$ million $\mathrm{cP})$.

Can mix in a shipping container using a LabRAM $500 \mathrm{ml}$ mixer.

\section{Benefits}

\section{Productivity}

Enhances mass transport and improves reaction rates on both macro- and micromixing levels. Can easily tune to different frequencies, making them suitable for multiple applications, such as heat- or masstransfer limited systems, those that expend inordinate mixing energy, or those that require mixing uniformity.

\section{Profitability}

Reduces mixing time up to $62 \%$ and competes with current mixer prices in many applications. 


\section{New Membranes Use Reverse Separation to Reduce Pollutant Emissions}

Many industrial applications need a process to separate pollutants known as volatile organic compounds (VOCs) from air in order to protect the environment and save energy. One such application is the venting of vapor from underground storage tanks (UST) used in gasoline storage and dispensing. These vapors, which can build up and create high pressure within the UST, contribute to ground-level ozone and smog upon release.

Traditional separation of VOCs uses rubber-based polymer membranes; however, these membranes are inadequate for applications requiring pressure relief by venting or low-pressure condensation of VOCs because they permeate VOCs more rapidly than air. To address this shortcoming, Compact Membrane Systems, Inc., in conjunction with project partners and support from DOE's SBIR program, has developed a novel reverse separation membrane that can be used to discharge clean air at low to slightly negative pressure, while leaving the VOCs fully contained in the fuel storage tank.

In addition to recovering the fugitive emissions from storage tanks, the system enables the UST and associated piping to operate under negative pressure while providing continuous diagnostics of the refueling system, such as storage tank structural integrity. Maintaining a slight vacuum on the UST ensures that any potential leaks within the system are contained within the tank and are not accidentally released to the environment. Continuing research and development are focused on applications where robust membranes are deployed in gas separation from both vapor and liquid streams.

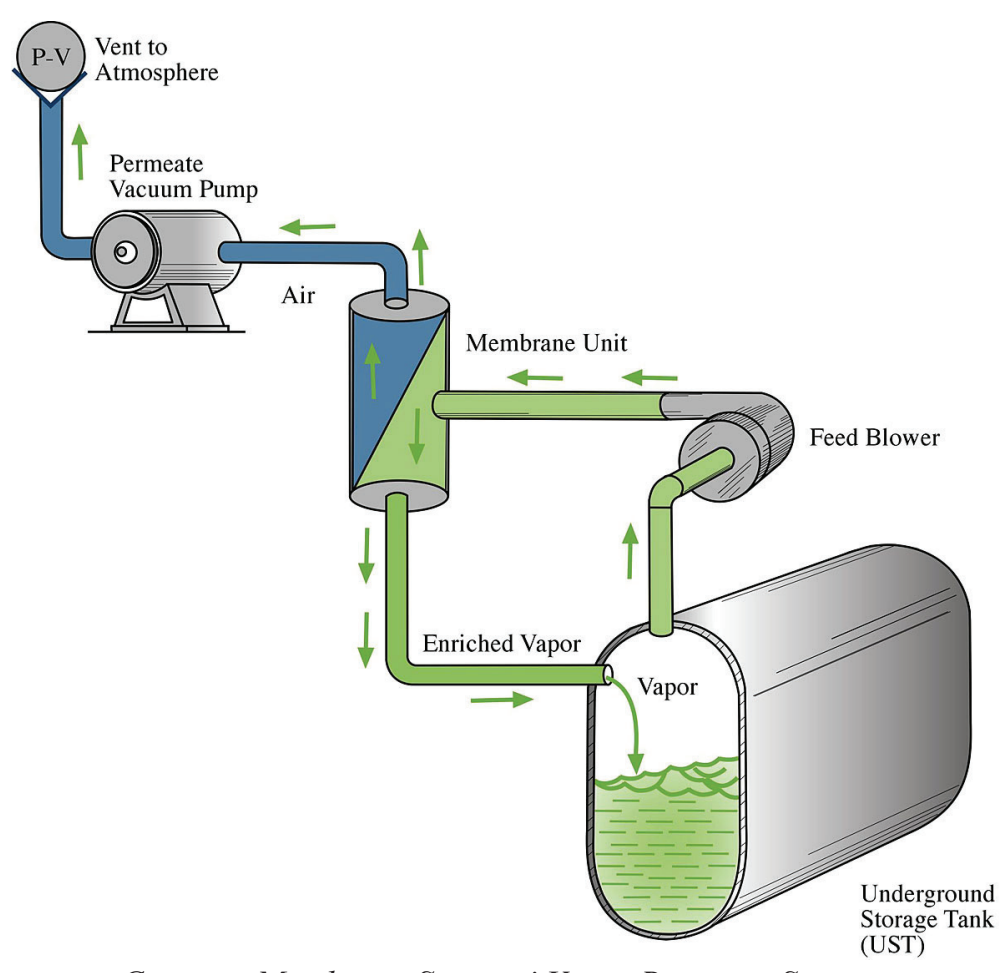

Compact Membrane Systems' Vapor Recovery System

\section{Overview}

Invented by Compact Membrane Systems, Inc. (www.compactmembrane.com)

Commercialized in 2007

\section{U.S. Energy Savings}

(Trillion Btu)

\begin{tabular}{|c|c|}
\hline Cumulative through 2010 & $\mathbf{2 0 1 0}$ \\
\hline 0.424 & 0.150 \\
\hline
\end{tabular}

\section{U.S. Emissions Reductions}

(Thousand Tons, 2010)

\begin{tabular}{|c|c|c|c|}
\hline Particulates & SO $_{x}$ & NO $_{x}$ & Carbon \\
\hline 0.001 & 0.087 & 0.023 & 3.27 \\
\hline
\end{tabular}

\section{Applications}

Can be used by gasoline storage and dispensing facilities, pharmaceutical processes, and fuel oil tank farms engaged in preventing the unintended release of VOCs from storage tanks.

\section{Capabilities}

Reduces VOC emissions below the California Air Resources Board limit of $0.38 \mathrm{lb} / \mathrm{month} / 1000$ gallon capacity.

Enables continuous monitoring of storage tank internal conditions, structural integrity, and leak-checking.

\section{Benefits}

\section{Energy Savings}

Prevents fuel vapor escape from a gasoline storage tank, thereby potentially saving 180 million gallons of gasoline per year domestically.

\section{Environmental}

Decreases VOC emissions to the atmosphere by limiting gasoline tank leakage. 


\section{Software Tool to Predict Solubility of Solids and Other Thermophysical Properties}

With assistance from AMO, OLI Systems, Inc., developed the mixed-solvent electrolyte model, a comprehensive physical property package that can predict the properties of electrolyte systems ranging from dilute solutions to fused salts in water, nonaqueous, or mixed solvents. The model accurately predicts the solubility of solids in complex multicomponent systems, thus providing a tool for designing crystallization processes. In addition, the model predicts other properties such as vapor-liquid and liquid-liquid equilibria, densities, heat effects, viscosity, electrical conductivity, and diffusivity.

The model incorporates chemical equilibria to account for chemical speciation in multiphase, multicomponent systems. For this purpose, the model combines standard-state thermochemical properties of solution species with an expression for the excess Gibbs energy. The model can accurately reproduce various types of experimental data for systems of aqueous electrolyte solutions. Separate formulations have been developed for predicting transport properties in the same range of temperature and compositions.

The model has been implemented in OLI Systems' commercial software, including the Electrolyte Simulation Program (a flowsheet simulator), StreamAnalyzer (a desktop chemical laboratory), CorrosionAnalyzer (a tool for predicting the tendency of metals to corrode), and selected interfaces to thirdparty process simulation programs. In its various implementations, the mixedsolvent electrolyte model is already used by more than 50 chemical process companies that lease OLI's software.

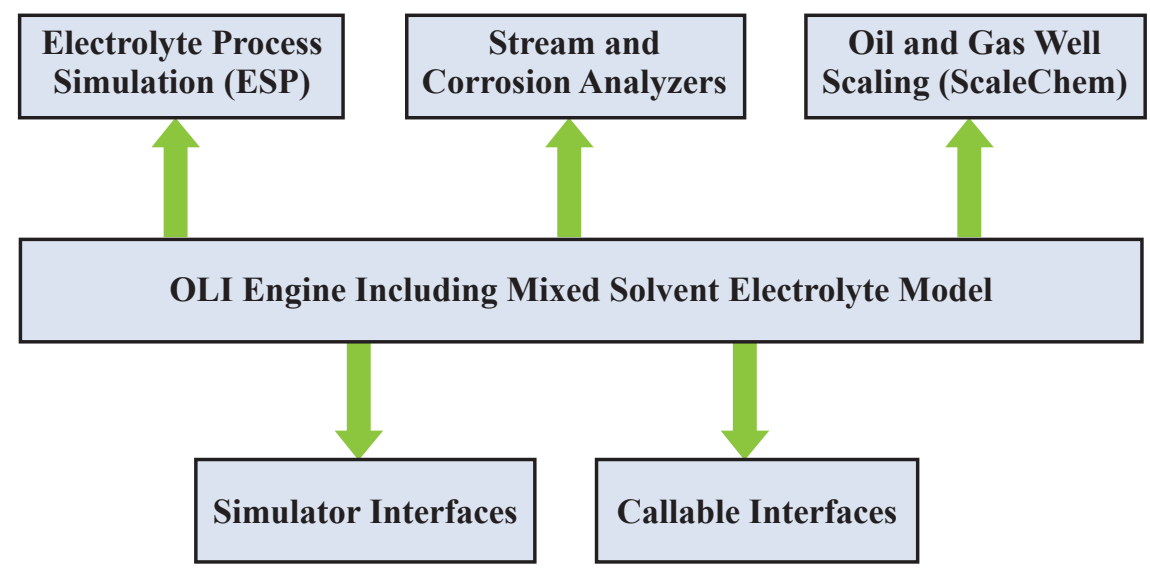

Integration of the Mixed Solvent Electrolyte Model with OLI Software

\section{Overview}

Developed and marketed by OLI Systems, Inc. (www.olisystems.com)

Commercialized in 2005

Sold 160 U.S. licenses and 128 non-U.S. licenses

\section{Applications}

Can be used to optimize crystallization and other separation processes throughout the chemical and pharmaceutical industry

\section{Capabilities}

Predicts crystallization and other separation processes.

Predicts solubility of solids and other thermophysical properties.

\section{Benefits}

\section{Efficiency}

Improves process control, filterability, and mixing efficiency.

\section{Energy Savings}

Substitutes crystallization for more energy-intensive process units.

\section{Product Quality}

Improves process control and product quality and minimizes lab and plant testing costs and risks (by using simulations). 


\section{New Process Recovers and Reuses Nylon from Waste Carpeting Saving Energy and Costs}

With a desire to keep materials out of the landfill, Shaw Industries, Inc., has incorporated a novel process developed by Honeywell International, Inc., and DSM Chemicals North America, Inc., into the largest Nylon-6 carpet recycling facility in the United States. The recovery process not only reduces the amount of carpet-based material destined for landfill, but produces virgin quality caprolactam, the monomer building block of Nylon-6 resin used to make carpet fiber.

With proof-of-principal financial assistance provided by AMO, the closed-loop depolymerization and purification process allows Nylon-6 recyclers to recover and reuse a significant percentage of the raw materials used to make carpeting while consuming less total energy compared with the conventional production of caprolactam. In addition to caprolactam recovery, the process can reclaim calcium carbonate used for carpet backing and other polymers used in carpet manufacturing for future use.

Shaw Industries' Evergreen Nylon Recycling (ENR) facility is the largest commercial-scale Nylon-6 recycling plant in the world. With the plant currently in operation, ENR is drawing from over 40 carpet collection facilities across the nation and has collectively kept over 200 million pounds of carpet out of landfills. The Cradle to Cradle ${ }^{\mathrm{TM}}$ process recovers approximately 24 million pounds of caprolactam and 35 million pounds of calcium carbonate filler each year, resulting in an annual energy savings of approximately 400 billion Btu.

\section{Benefits}

\section{Energy}

Reduces energy consumption in the production of Nylon-6 resin and carpet fiber.

\section{Environmental}

Reduces landfilling of nylon waste carpets and other Nylon-6-based materials and reduces raw material demand for the production of Nylon-6.

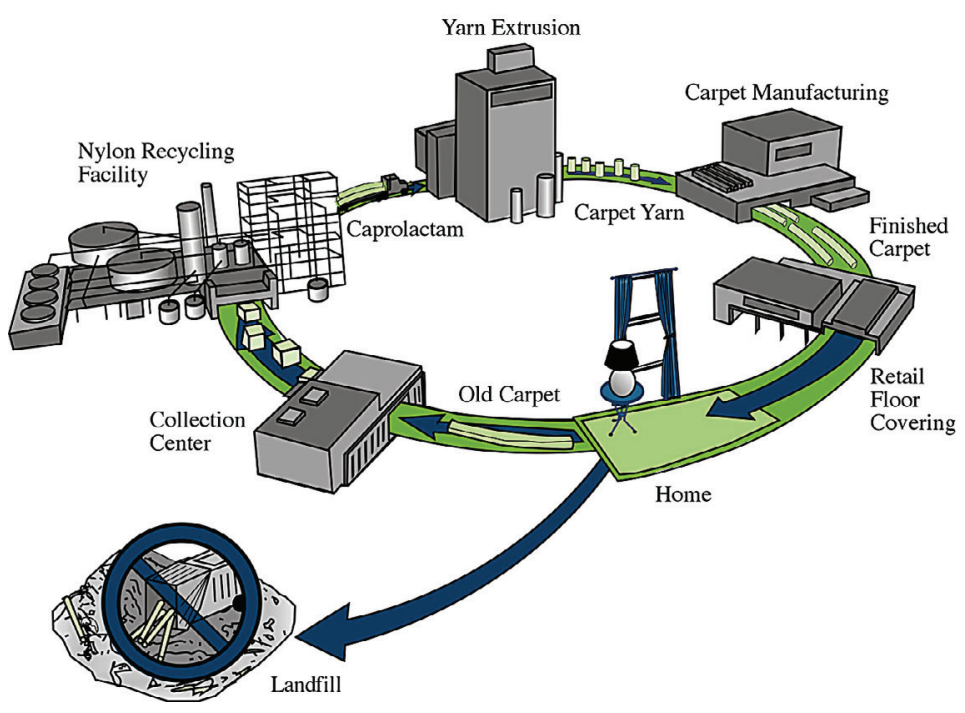

Shaw Industries' Nylon Carpet Recycling Loop

\section{Overview}

$\diamond$ Developed by Honeywell International, Inc., and DSM Chemicals North America, Inc.

Evergreen Nylon Recycling facility in Augusta, GA, is owned and operated by Shaw Industries, Inc.

(www.shawfloors.com)

Recycled over 200 million pounds of post-consumer carpeting since reopening of the facility in 2007

Produced in excess of 22 million pounds of virgin quality caprolactam in 2010

\section{U.S. Energy Savings} (Trillion Btu)

\begin{tabular}{|c|c|}
\hline Cumulative through $\mathbf{2 0 1 0}$ & $\mathbf{2 0 1 0}$ \\
\hline 1.72 & 0.398 \\
\hline
\end{tabular}

\section{U.S. Emissions Reductions}

(Thousand Tons, 2010)

\begin{tabular}{|c|c|c|c|}
\hline Particulates & SO $_{x}$ & NO $_{x}$ & Carbon \\
\hline 0.0 & 0.0 & 0.047 & 6.32 \\
\hline
\end{tabular}

\section{Applications}

Can be used to recover and reuse the primary constituents of reclaimed carpeting and carpet fibers including caprolactam, calcium carbonate, and other polymers

\section{Capabilities}

Produces virgin quality pure caprolactam using the closed-loop depolymerization and purification system.

Enables processing of whole Nylon-6 carpets and eliminates mechanical separation.

Enables reuse of recovered raw materials in Nylon-6 as carpeting, fibers, and resins. 


\section{Highly Selective Pressure Swing Adsorption Technology Recovers Valuable Components from Waste Streams}

Many polyolefin plant designs use a polymer degassing step to remove unreacted monomer, solvents, and additives from the product polymer fluff before it is processed in downstream pelletizing operations. When nitrogen is used as the stripping gas, the operation produces a low-pressure gas stream that typically contains nitrogen and valued hydrocarbons that can be recovered and recycled to the plant. If the gas is not processed for recovery, it is typically flared. The flaring step results in volatile organic compounds, $\mathrm{NO}_{\mathrm{X}}$, and $\mathrm{CO}_{2}$ emissions. Flaring can also be costly, roughly equal to the value of the purchased nitrogen.

With assistance from AMO, Air Products and Chemicals has developed a single unit operation to recover these gases. Pressure swing adsorption (PSA) is combined with partial condensation to essentially recover $100 \%$ of the hydrocarbons from the vent gas. In addition, PSA produces a high purity $\mathrm{N}_{2}$ stream, with nearly $100 \%$ recovery of nitrogen. The recovered nitrogen can be recycled to the stripping operation or used elsewhere in the facility.

Air Products' high recovery system eliminates waste streams and therefore emissions.

In this new process, the vapor stream from the partial condensation section flows into a PSA unit. Within the PSA, specially selected adsorbent materials extract hydrocarbons, thereby refining the nitrogen to a high purity with minimal pressure drop. Over time the adsorbent material in the bed becomes saturated and must be regenerated. Lowering the pressure in the saturated bed desorbs the hydrocarbon components from the adsorbent material in the PSA. The hydrocarbons are released and recovered in a low-pressure tail gas, which is recycled back to the compressor suction so the hydrocarbons are not lost. This technology provides a significant opportunity for energy and cost savings and reduced waste.

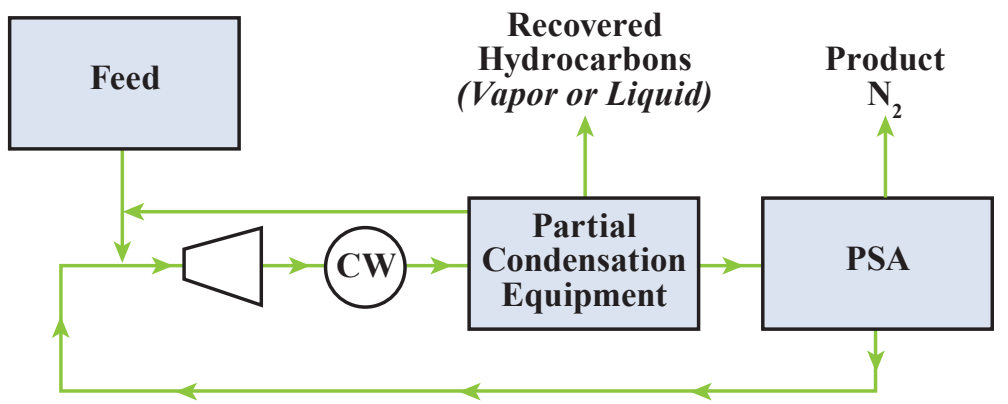

Pressure Swing Adsorption Recovery

\section{Overview}

Developed by Air Products and Chemicals (www.airproducts.com)

Commercialized in 2003

Installed in three locations in Texas

\section{U.S. Energy Savings}

(Trillion Btu)

\begin{tabular}{|c|c|}
\hline Cumulative through $\mathbf{2 0 1 0}$ & $\mathbf{2 0 1 0}$ \\
\hline 0.737 & 0.111 \\
\hline
\end{tabular}

\section{U.S. Emissions Reductions}

(Thousand Tons, 2010)

\begin{tabular}{|c|c|c|c|}
\hline Particulates & SO $_{x}$ & NO $_{x}$ & Carbon \\
\hline 0.0 & 0.0 & 0.013 & 1.76 \\
\hline
\end{tabular}

Applications

Can be used by chemical and refining industries, including polyethylene and polypropylene production processes that use $\mathrm{N}_{2}$ for degassing the polymer fluff and for treating refinery off-gas streams. Could be adapted to recover valuable products from other waste streams throughout the industry.

\section{Capabilities}

Recovers hydrogen, nitrogen, and hydrocarbons for reuse.

Is flexible enough to operate using an external refrigeration source.

\section{Benefits}

\section{Pollution Reduction}

Can collect and separate for reuse exit streams from certain processes, eliminating the emissions and need for disposal. Can save energy and costs by eliminating flaring of waste streams, which is typically part of disposal.

\section{Profitability and Productivity}

Reduces operating and emission costs by eliminating flaring and increases productivity by reusing products in the feed streams. 


\section{Process Heater for Stoichiometric Combustion Control}

IMPACTS

\section{An Enhanced, CO-Based, Low Excess Air Control System Saves Energy While Reducing Emissions}

To heat liquids and induce chemical reactions during production processing, the refining and chemicals industries rely on process heaters and boilers that consume large amounts of fuel. Bambeck Systems and Valero Energy received a grant from AMO to demonstrate how fuel can be saved by fully automating the available air to the three types of heaters typical to a refinery. Using a Bambeck fast $\mathrm{CO}$ analyzer to monitor the heater flue gas, a control scheme is installed to reduce the oxygen until a small amount of $\mathrm{CO}$ is produced. Using this parameter in the control scheme optimizes the air needed for combustion, thereby not wasting fuel to heat unneeded air.

The three requirements to successfully implement this technology are the fast $\mathrm{CO}$ analyzer, a new control strategy, and operator education. The analyzer provides $\mathrm{CO}$ data to the existing heater control system. The current control strategy is then modified to reduce the air to the heater via the controllable entrances, including stack dampers, fans, and burner registers. When a small amount of $\mathrm{CO}$ is generated, the control system automatically maintains that point, changing the controllable entrances as more or less air is required as indicated by the $\mathrm{CO}$ analyzer. Since fuel Btu content can change rapidly, the fast $\mathrm{CO}$ analyzer responds to the change in demand for $\mathrm{O}_{2}$ and, through the control system, sends commands to the dampers, fans, and registers to open or close. Because operators historically used an $\mathrm{O}_{2}$ monitor to ensure that the combustion process has excess air, the operators need to be educated to feel comfortable seeing very low $\mathrm{O}_{2}$ readings. The heater is safer because $\mathrm{CO}$ is a precursor to a combustible condition and $\mathrm{O}_{2}$ is not. In addition, reducing the excess $\mathrm{O}_{2}$ also reduces both $\mathrm{NO}_{\mathrm{X}}$ and $\mathrm{CO}_{2}$ (greenhouse gas).

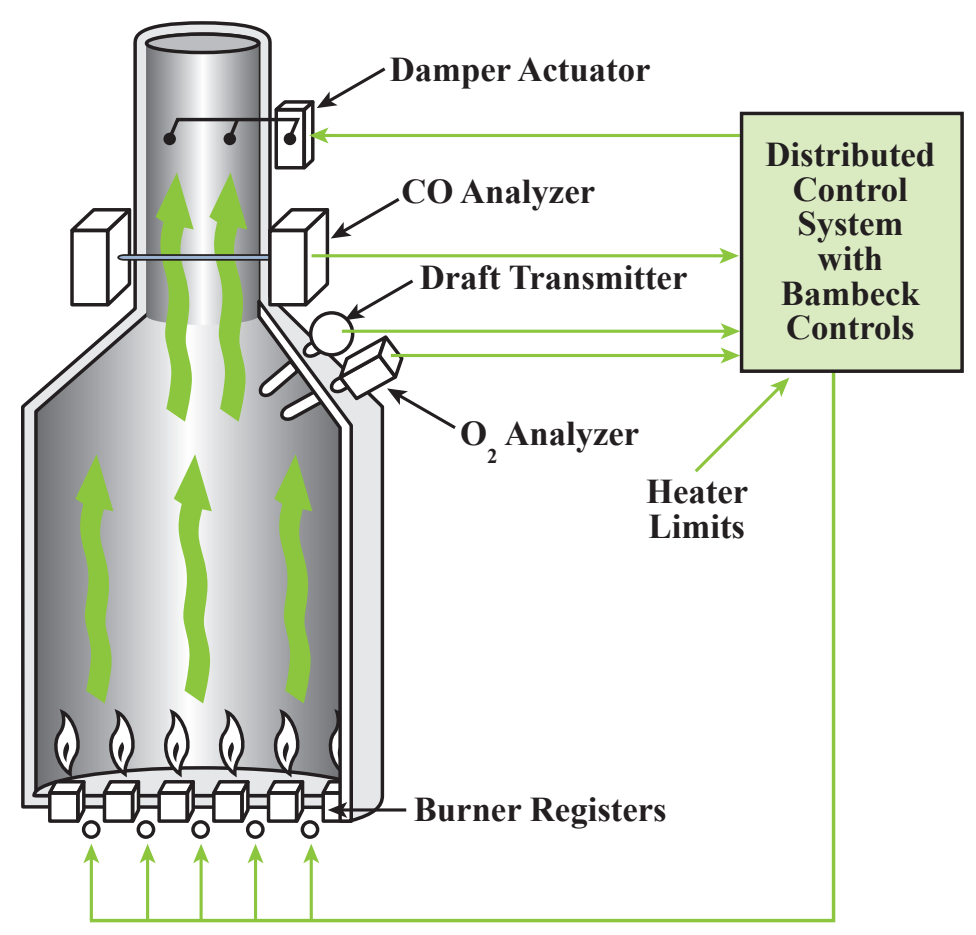

Bambeck Ultra-Low Excess Air Control System

\section{Overview}

Developed and being marketed by Bambeck Systems, Inc. (www.bambecksystems.com)

- Commercialized in 2002 with over 700 of the original technology installed

Seven enhanced ultra-low versions installed

\section{U.S. Energy Savings}

(Trillion Btu)

\begin{tabular}{|c|c|}
\hline Cumulative through 2010 & $\mathbf{2 0 1 0}$ \\
\hline 2.86 & 0.411 \\
\hline
\end{tabular}

\section{U.S. Emissions Reductions}

(Thousand Tons, 2010)

\begin{tabular}{|c|c|c|c|}
\hline Particulates & SO $_{\mathrm{x}}$ & NO $_{\mathrm{x}}$ & Carbon \\
\hline 0.0 & 0.024 & 0.051 & 6.82 \\
\hline
\end{tabular}

\section{Applications}

Can be used by the chemicals, petrochemicals, and refining industries

\section{Capabilities}

Monitors the unburned fuel gases and controls the amount of air available for the combustion process, providing the minimum amount needed.

\section{Benefits}

\section{Reduced Emissions}

Reduces $\mathrm{NO}_{\mathrm{x}}$ emissions from $30 \%$ to $45 \%$ and $\mathrm{CO}_{2}$ in proportion to the size of the heater.

\section{Safety}

Eliminates the possibility of any dangerous combustible conditions developing in the heater. 


\section{Titania-Activated Silica System for Emission Control}

IMPACTS

\section{Silica-Titania Composite (STC) Technology Safely and Cost-Effectively Removes Mercury from End- Box Exhaust in Chlor-Alkali Facilities}

The chlor-alkali industry produces valuable chemicals such as chlorine, hydrogen, and caustic soda. In 2001, between 150 and 200 chlor-alkali facilities throughout the world used the mercury-cell process. Although this process uses the mercury in a closed-loop system, mercury is released to the environment through entrainment in byproduct streams, end-box ventilation systems, and fugitive emissions. An average of about 3 tons of mercury per year must be added to the production process at each mercury-cell facility in the United States to account for losses. The National Emissions Standard for Hazardous Air Pollutants (NESHAP) for mercury-cell chlor-alkali plants requires these facilities to drastically reduce mercury emissions from their gasphase exhaust streams.

With assistance from AMO, Sol-gel Solutions, LLC, has developed silicatitania composite (STC) technology for removing mercury from end-box exhaust in chlor-alkali facilities. The technology focuses on the synergistic combination of adsorption and simultaneous photocatalytic oxidation to remove pollutants. STC technology can be regenerated in place, avoiding the cost and risk of continuously replacing and disposing of typical adsorbent materials such as activated carbon. Sol-gel Solutions has installed two full-scale reactors at a U.S. chlor-alkali facility. The reactors were installed in parallel so that one could operate while the other was regenerated. After a period of successful operation, an economic analysis showed the STC technology to have a lower cost per pound of mercury removed than activated carbon. In addition to applications in the chlor-alkali industry, Sol-gel Solutions is continuing efforts to commercialize the technology for indoor air purification and the coal-fired power industry.

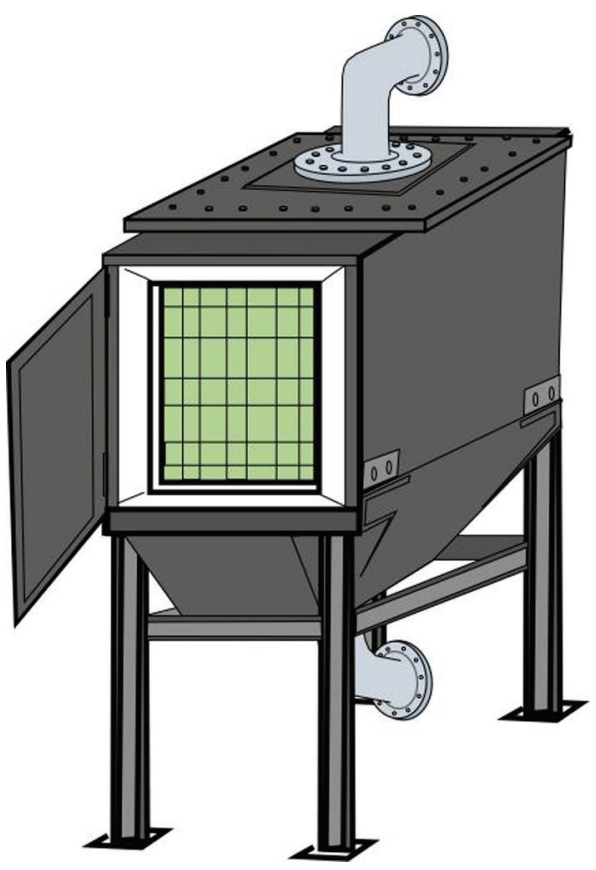

Sol-gel Solutions’ Silica-Titania Composite System

\section{Overview}

$\checkmark$ Developed at the University of Florida

$\checkmark$ Commercialized by Sol-gel Solutions, LLC

(www.sol-gel-solutions.com)

- Two units operating at a U.S. chlor-alkali facility since 2006

\section{Applications}

Can be used in the chlor-alkali industry for removing mercury from caustic exhaust streams and in coal-fired power plants for mercury removal from flue gas

\section{Capabilities}

Uses ultraviolet light to oxidize elemental mercury to more stable mercuric oxide.

\section{Benefits}

\section{Cost Savings}

Reduces the cost per pound of mercury removed compared with activated carbon.

\section{Safety}

Eliminates the risk of disposing of mercuryladen activated carbon. 


\section{Total Cost Assessment Tool}

IMPACTS

\section{New Decision-Making Software Integrates Costs into Environmental Decisions and Life Cycle Assessments}

The Total Cost Assessment (TCA) methodology enables industry to include all environmental, health, and safety costs in decision-making. In particular, TCA includes contingent liabilities such as fines and cleanup costs and intangible costs such as damage to corporate or brand image and reduced employee morale. External costs, such as costs to society, can also be included in the TCA methodology. In traditional industry decision-making, environmental health and safety (EHS) assessments have been conducted separately from life cycle cost analyses. This customary separation has limited the influence and relevance of life cycle assessment for decision-making and has left uncharacterized the important relationships and tradeoffs between the economic and environmental performance of alternative decisions.

The TCA methodology was developed by an industry collaboration of ten companies led by the American Institute of Chemical Engineers (AIChE) Center for Waste Reduction Technologies (CWRT) with support from AMO and the National Business Roundtable Industrial Pollution Prevention Council.

The Total Cost Assessment Tool (TCAce), developed and sold by Sylvatica, manages the TCA process by enabling the company to use sliding ranges and probabilities to reflect the true nature of contingencies. TCAce integrates scenario case studies and sensitivity/uncertainty/risk analysis into a company's existing economic evaluation framework to enable sound decisions. It identifies all conventional, hidden, human health, and environmental impact costs, both internal and external. TCAce requires an operating system of Windows 98 or better and recommends at least a 24MB hard drive.

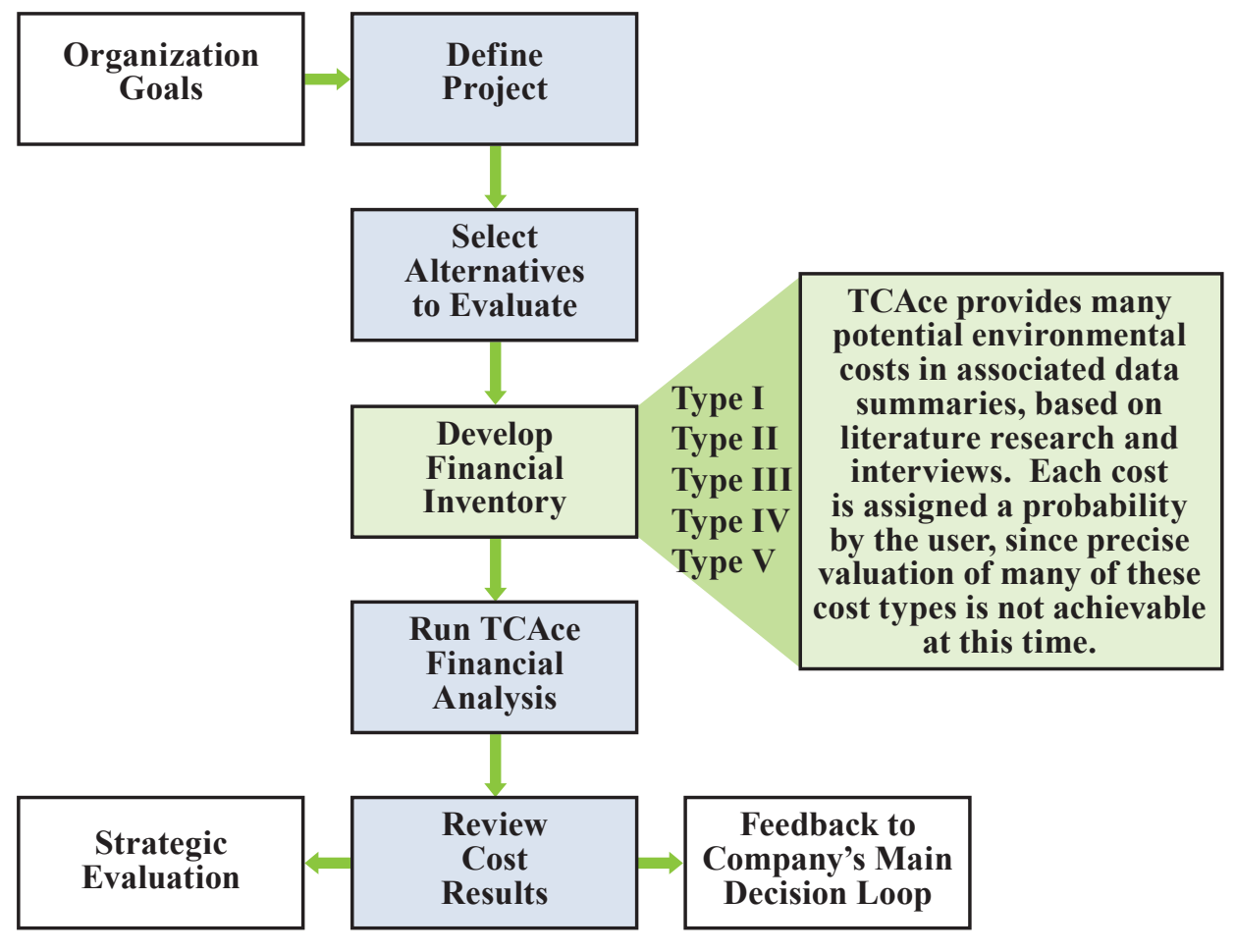

The Total Cost Assessment Process

\section{Overview}

- Software developed by Sylvatica of North Berwick, Maine (www.earthshift.com)

- Has sold 14 units to date: 4 in the United States and 10 internationally

Commercialized in 2005

\section{Applications}

Can be used throughout industry in considering all the environmental and health costs associated with a business decision, such as process, project, or corporate-level investment alternatives. The software performs and addresses the following activities: estimating baseline costs, benchmarking, process development, product mix, waste management decisions, pollution prevention alternatives, remediation alternatives, environmental management, research budget allocations, materials/supplier selection, facility location/layout, outbound logistics, marketbased environmental options, and public relations/lobbying.

\section{Capabilities}

$\checkmark$ Identifies best environmental and economic options in business decisionmaking.

Aligns environmental goals with good business strategies.

Integrates internal costs and externalities into a single assessment process.

\section{Benefits}

\section{Environmental Benefits}

Selects waste management investment decisions that are environmentally sound and reduces long-term liabilities.

\section{Profitability}

Reduces manufacturing costs by integrating life cycle assessment with life cycle cost analysis and facilitating collaborative scenario planning. 


\section{In-Situ Sensors Provide Real-Time Measurements Enabling Better Control and Process Optimization}

Current chemical process controls use few in-situ sensors, relying instead on analytic techniques that require sample conditioning and transport, and significant turnaround time. With few exceptions, these techniques lack speed of measurement, accuracy of measurement, sensitivity of measurement, and economical measurement. In-situ sensors can provide real-time measurements, enabling better understanding and control of the process and improving process optimization, product quality, and plant economics. Supported with a grant from AMO, Analytical Specialties, Inc., since acquired by Yokogawa Electric Corporation, has developed a system of in-situ sensing for more efficient process operation.

The system, called TruePeak, is a tunable diode laser analyzer that directly measures the concentration of $\mathrm{O}_{2}, \mathrm{H}_{2} \mathrm{O}$, and potentially several other gasses. TruePeak measures across an infrared absorbance region, which makes it useable in high dust and corrosive environments and provides a true interference-free analysis. The system is characterized by rapid measurement (as fast as 1 second), high process pressure capability (up to 20 bar), high temperature (up to $1500^{\circ} \mathrm{C}$ ), and no contact with the process. The system operates at the required process conditions (pressure, temperature, etc.), provides real-time or near real-time data, and significantly reduces installation and operational costs compared with currently available products.

Appropriate applications for TruePeak include combustion oxygen analysis of process heaters, furnaces, and incineration operations. The technology is also applicable to processes where reducing errors in oxygen concentration measurements can reduce plant process shutdown. The need for this technology and its measurements are driven by advances in process control systems and the need to "close the loop" in modern control systems. This rugged unit can be used in a variety of chemical process applications and can provide real-time, accurate measurements in harsh environments, which can improve process efficiency, reliability, and productivity.

\section{Overview}

Developed by Analytical Specialties, Inc.

$\checkmark$ Commercialized in 2004 and being sold by Yokogawa Electric Corporation (www.yokogawa.com)

\section{Applications}

Can be used for gas sensing in chemical processes

\section{Capabilities}

Provides in-situ analysis, eliminating errors and costs associated with extractive analyzers.

Can be used in harsh environments.

\section{Benefits}

\section{Applicability}

Operates with processes up to $1500^{\circ} \mathrm{C}$ and 20 bar and virtually interference-free.

\section{Productivity}

Reduces downtime for maintenance and provides near real-time measurements with improved accuracy for better control.

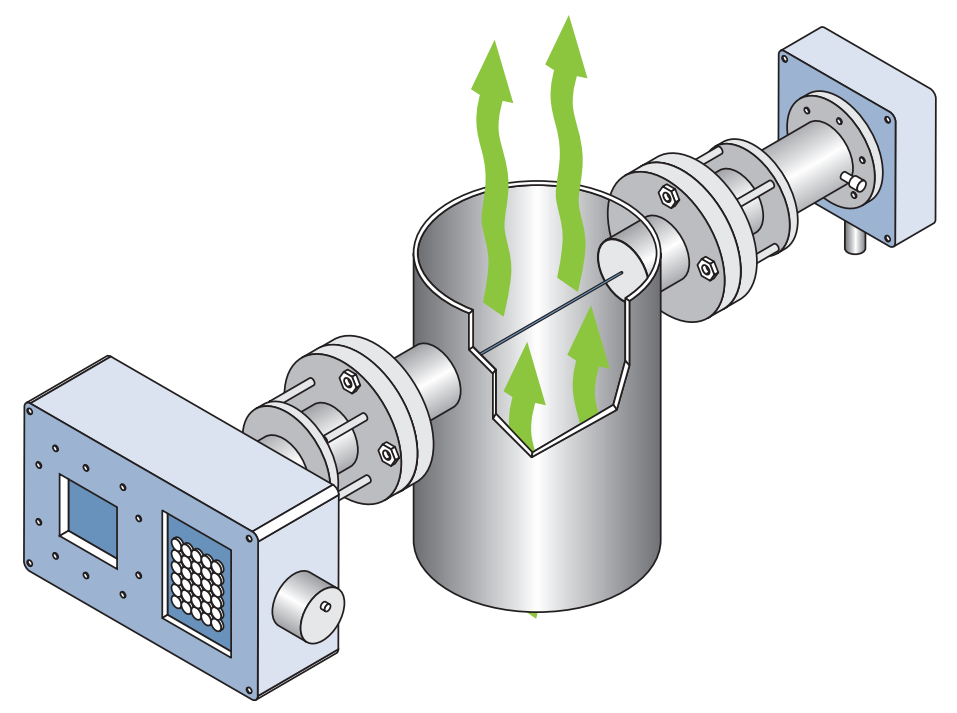

TruePeak Process Laser Analyzer 


\section{Forest Products}

IMPACTS

Advanced Quality Control (AQC) Solution for Thermo-Mechanical Pulping ...

A-24

Biological Air Emissions Control.

A-25

Borate Autocausticizing

A-26

Continuous Digester Control Technology

A-27

Detection and Control of Deposition on Pendant Tubes in Kraft Chemical Recovery Boilers

A-28

MultiWave ${ }^{\mathrm{TM}}$ Automated Sorting System for Efficient Recycling

A-29

Screenable Pressure-Sensitive Adhesives

A-30

Thermodyne ${ }^{\mathrm{TM}}$ Evaporator - A Molded Pulp Products Dryer...

A-31

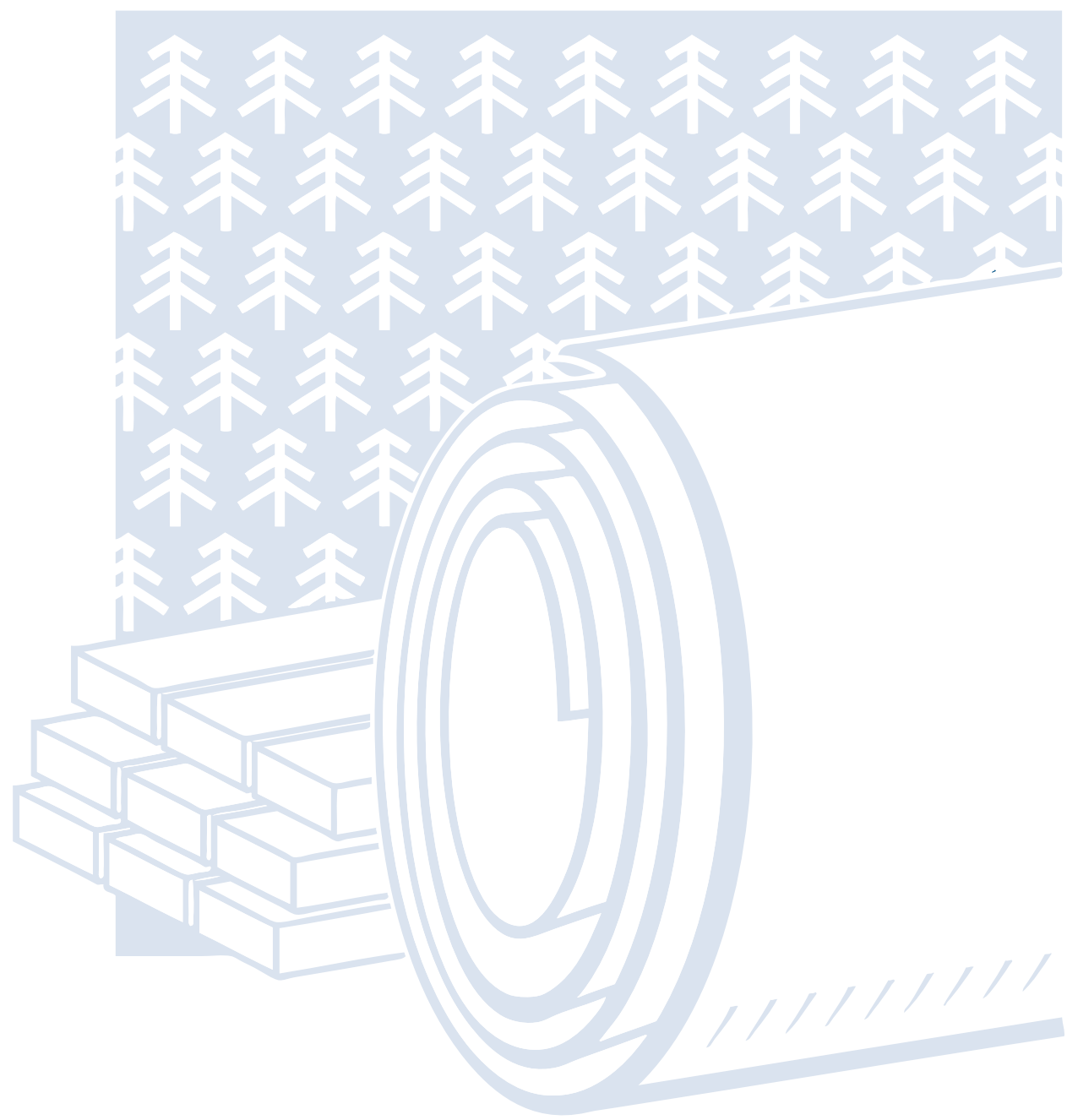




\section{Optimal Pulping Using an Advanced Control System and Sensors}

Thermo-mechanical pulping (TMP) has become the pulping method of choice for many pulp and paper mills. Electrical energy accounts for $23 \%$ of the total production cost, with over $70 \%$ of that dedicated to the TMP process. In 2001, with financial and technical support provided by AMO, Pacific Simulation assessed and implemented their AQC model-predictive controls in a TMP plant. In this demonstration, the plant realized gains in three key areas: reduced peak and specific energy consumption, reduced production line transition times, and improved freeness targets.

Commercial implementation of AQC involves coordinating advanced quality control in multiple areas of the paper mill: mainline refiners, reject refiners, screen room, and pulp quality. Sensors are used to measure controlled variable outputs for freeness, consistency, shive content, fiber length, motor load, screw speed, refiner temperature and pressure, and reject rate. The heart of the AQC system is the multivariable predictive controller (MPC) and associated software that compares "current" data against "historical" data to determine the predictive model. The MPC, coupling pulp line output with plant productivity and power consumption, can make real-time optimization changes to manipulated variables to efficiently manage pulp and finished paper quality and production capabilities while reducing specific energy consumption. The AQC Solution has been implemented on over 73 refiners in the United States, Canada, Sweden, Norway, New Zealand, and Chile.

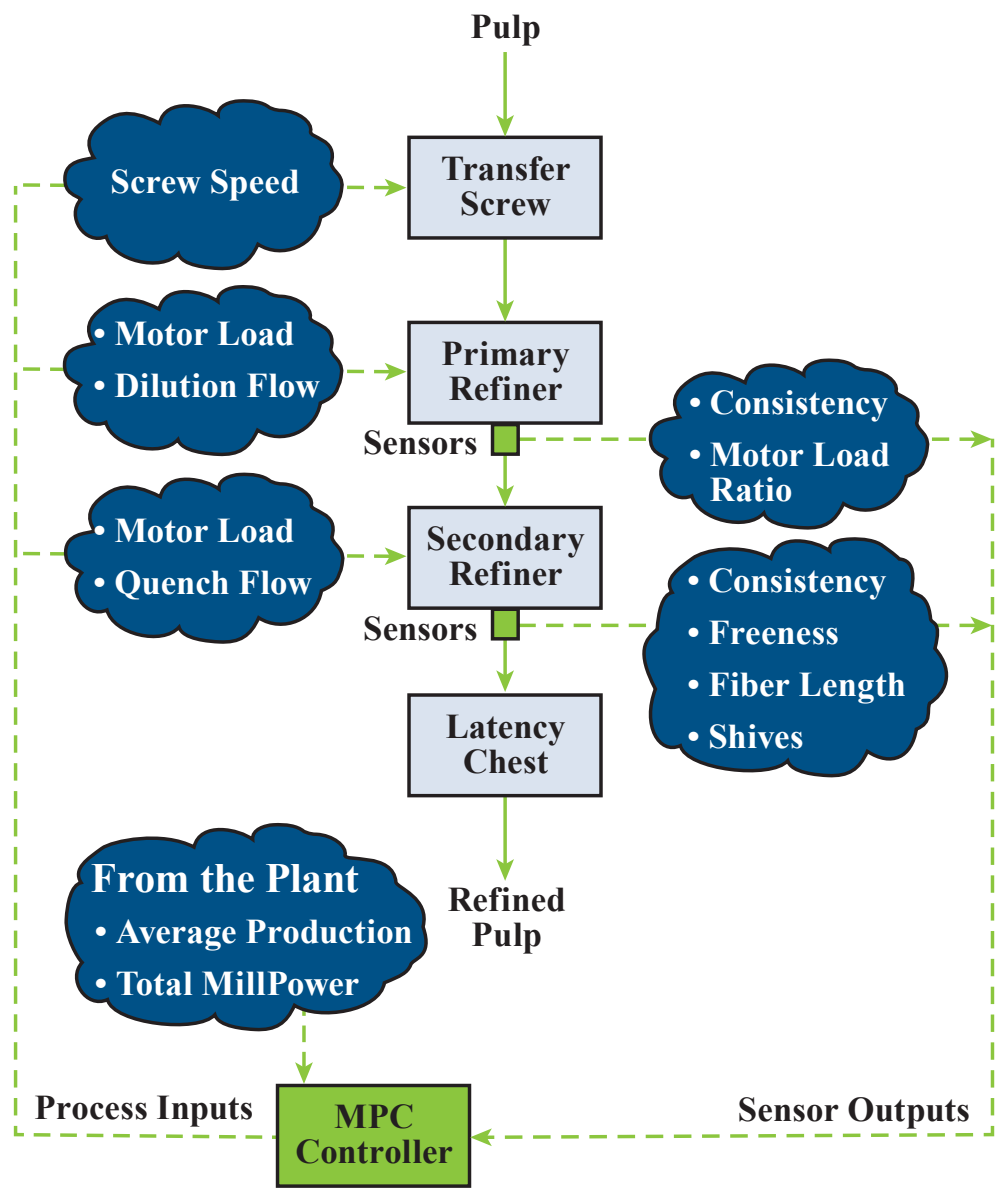

\section{Overview}

$\checkmark$ Developed and commercialized by Metso Automation's Pacific Simulation in 1995

Expanded under DOE grant in 2001

Purchased and marketed by Metso Automation in 2004

(www.metso.com)

\section{U.S. Energy Savings}

(Trillion Btu)

\begin{tabular}{|c|c|}
\hline Cumulative through $\mathbf{2 0 1 0}$ & $\mathbf{2 0 1 0}$ \\
\hline 1.50 & 0.231 \\
\hline
\end{tabular}

\section{U.S. Emissions Reductions}

(Thousand Tons, 2010)

\begin{tabular}{|c|c|c|c|}
\hline Particulates & SO $_{x}$ & NO $_{x}$ & Carbon \\
\hline 0.001 & 0.050 & 0.037 & 4.53 \\
\hline
\end{tabular}

\section{Applications}

Can be used to link final product quality with the thermo-mechanical pulping process optimizing production, quality, and cost.

\section{Capabilities}

Reduces peak and specific energy demand by matching real-time pricing from local electrical utilities.

Reduces raw material costs by limiting the required amount of purchased Kraft pulp.

Improves final pulp quality by optimizing refiner operation and output.

\section{Benefits}

\section{Energy Savings}

Reduces specific peak energy from 8 MW to 6.5 MW; uses an average of 125 horsepower days/ton in the plant down from 145 horsepower days/ton.

\section{Production}

Uses stock blending quality control to optimize the blend of feedstock quality and final paper grade to allow mills to match pulp quality production to the exact requirements of the paper machine on a grade basis. 


\section{Biological Air Emissions Control}

IMPACTS

\section{Innovative Technology Enables Low-Cost, Energy- Efficient Treatment of Industrial Exhaust Streams}

Air quality standards are becoming more stringent for the U.S. wood products industry. Emissions of volatile organic compounds (VOCs) and hazardous air pollutants (HAPs) (including methanol, formaldehyde, acetylaldehyde, and acrolein) during production of wood products must be tightly controlled. Conventional VOCs and HAPs emission control techniques such as regenerative thermal oxidation and regenerative catalytic oxidation require significant amounts of energy and generate secondary pollutants such as nitrogen oxides and excess carbon dioxide.

With assistance from AMO, BioReaction Industries, LLC, developed a novel biological treatment system that integrates two types of bio-oxidation to achieve energy-efficient emissions reduction. The technology uses microorganisms to degrade air toxins without the extensive consumption of natural gas required by thermal oxidation. The process employs a threestage treatment process for the VOC, HAP, and particulate emissions in an exhaust airstream: (1) water soluble compound and particulate removal in the bioscrubber/biotrickling filter, (2) biodegradation in the biofilm of the biotrickling filter and the sump waters, and (3) hydrophobic compound adsorption and biodegradation in the multi-layer biofilter. As of 2010, eleven units have been installed across the U.S. forest products industry, with an average air flow of approximately 100,000 CFM. Met-Pro Corporation, who purchased BioReaction Industries in 2010, is also pursuing applications of the technology for the automobile industry, particularly with paint emission streams using water soluble solvents.

\section{Benefits}

\section{Adaptability}

Modular and expandable design allows for easy adjustment to meet new process flow rate requirements. New designs are in place for odor control of municipal and other industrial and commercial applications.

\section{Cost Savings}

Reduces the labor and materials required for maintenance compared with traditional thermal oxidation systems.

\section{Overview}

- Developed by BioReaction Industries, LLC, with technical and scientific assistance from Texas A\&M University

Being marketed by Met-Pro Corporation (www.met-pro.com)

Eleven units operating in the U.S. forest products industry as of 2010

\section{U.S. Energy Savings} (Trillion Btu)

\begin{tabular}{|c|c|}
\hline Cumulative through 2010 & $\mathbf{2 0 1 0}$ \\
\hline 2.41 & 0.825 \\
\hline
\end{tabular}

\section{U.S. Emissions Reductions}

(Thousand Tons, 2010)

\begin{tabular}{|c|c|c|c|}
\hline Particulates & SO $_{\mathrm{x}}$ & NO $_{\mathrm{x}}$ & Carbon \\
\hline 0.0 & 0.003 & 0.097 & 13.1 \\
\hline
\end{tabular}

\section{Applications}

Can be used as an energy-efficient alternative to thermal oxidation of industrial process exhaust streams

\section{Capabilities}

Enables reliable operation through control panel adjustment of temperature, humidity, fan, and pump parameters.

- Uses patented BioAIRSpheres ${ }^{\mathrm{TM}}$ media for digestion and final breakdown of contaminants.

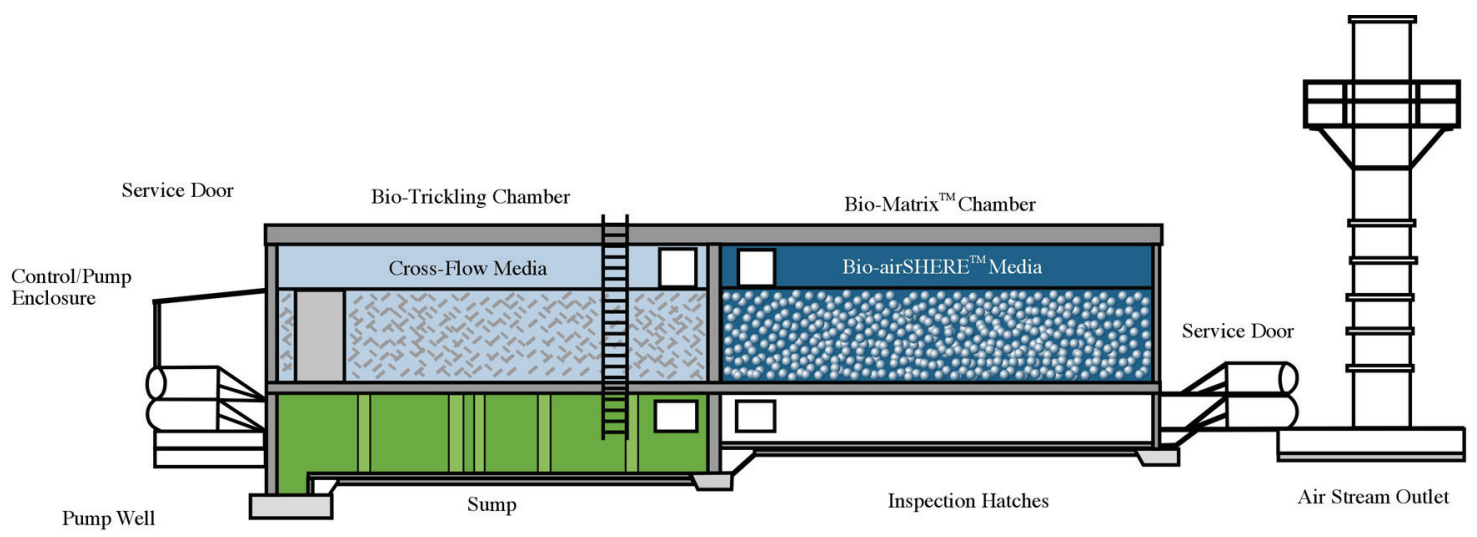

Met-Pro Corporation's Advanced Bio-Oxidation Process 


\section{Borate Autocausticizing}

IMPACTS

\section{New Technology Increases Energy Efficiency of Kraft Chemical Recovery Process and Causticizing}

Boron-based autocausticizing is a new, cost-effective technology to recover kraft pulping chemicals. Conceptually, the technology can be used to supply part or all of the sodium hydroxide requirements of the kraft process, supplementing or replacing the lime cycle. Because the de-carbonating reactions take place directly in the recovery boiler, instead of the lime kiln, this process reduces energy consumption and increases causticizing and calcining capacities.

The technology uses sodium metaborate to react with sodium carbonate in the kraft furnace. Once the reacted salts are dissolved in the green-liquor dissolving tank, sodium hydroxide is formed, and the sodium metaborate is regenerated. The technology provides more energy-efficient hydroxide production, increases the causticizing equilibrium, and, when used in conjunction with the conventional lime cycle, increases the causticizing/ calcining capacity.

Rio Tinto Minerals, with AMO support, has developed partial borate autocausticizing, which is being implemented in pulp mills worldwide to supplement conventional lime causticizing with almost no capital investment. The one U.S. application is in the P.H. Gladfelter Co. mill in Spring Grove, Pennsylvania, where it increased production by roughly $5 \%$ in 2007 .

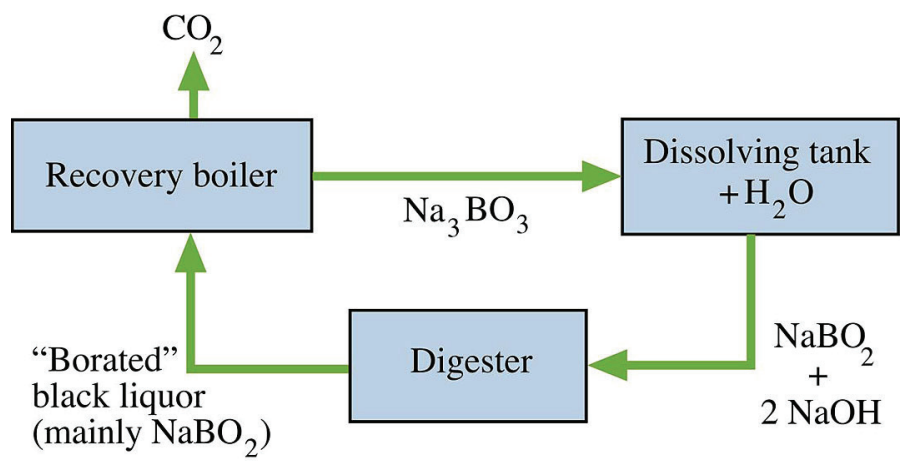

Borate Autocausticizing Process

\section{Overview}

Developed by U.S. Borax/Rio Tinto Minerals (www.borax.com)

Commercialized in 2004

Installed in one U.S. plant and in several international plants.

\section{U.S. Energy Savings}

(Trillion Btu)

\begin{tabular}{|c|c|}
\hline Cumulative through 2010 & $\mathbf{2 0 1 0}$ \\
\hline 0.035 & 0.000 \\
\hline
\end{tabular}

\section{U.S. Emissions Reductions}

(Thousand Tons, 2010)

\begin{tabular}{|c|c|c|c|}
\hline Particulates & SO $_{\mathrm{x}}$ & NO $_{\mathrm{x}}$ & Carbon \\
\hline 0.0 & 0.0 & 0.0 & 0.0 \\
\hline
\end{tabular}

\section{Applications}

Can be used to replace all or part of the kraft causticizing-calcining process, therefore providing supplemental lime kiln and causticizing capacities

\section{Capabilities}

Reduces the load on lime causticizing plants, improving the performance of clarifiers or filters and reducing the extra alkali circulated in the weak wash (weak white liquor) stream.

Reduces fresh lime usage and lime mud disposal associated with lime kiln production constraints.

\section{Benefits}

\section{Cost Savings}

Decreases the load on causticizing and lime reburning to reduce either lime purchases or kiln energy and maintenance costs.

\section{Productivity}

Increases the causticizing capacity of the mill to increase pulp production without investment in lime kilns or recausticizing equipment. 


\section{Pulp Process Model Identifies Improvements that Save Energy and Improve Productivity}

The pulp digester is known as the bottleneck unit in the pulp mill flow sheet because it can require $5 \%$ to $50 \%$ of typical on-line operation time, making this component of the pulping process very capital intensive. Improving digester performance can significantly reduce production losses, operating costs, and negative environmental effects while increasing paper quantity and quality. Using a computer-based model and control system for continuous digesters could regulate the pulping process, thereby minimizing mill downtime caused by digester problems and fostering continuous operation and pulp production.

Previous work conducted at the University of Delaware (UD) indicated that fundamental computer models could manage the internal conditions within the digester. The UD resolved the major challenge to designing such a model by developing a fundamental digester model that manages production rate changes and grade swings between hardwood and softwood feedstocks.

The digester's fundamental process model integrates physical and chemical properties as system "states" (i.e., points in the digester process) to track grade transitions. This model allows appropriate material, energy balance, and diffusion simulations to be calculated as various-origin chips pass through the digester. The observation and tracking of these data help identify process improvements. The model's first commercial application in a Texas mill allowed the temperature to be reduced in part of the pulping process, thereby saving $1 \%$ of the process energy.

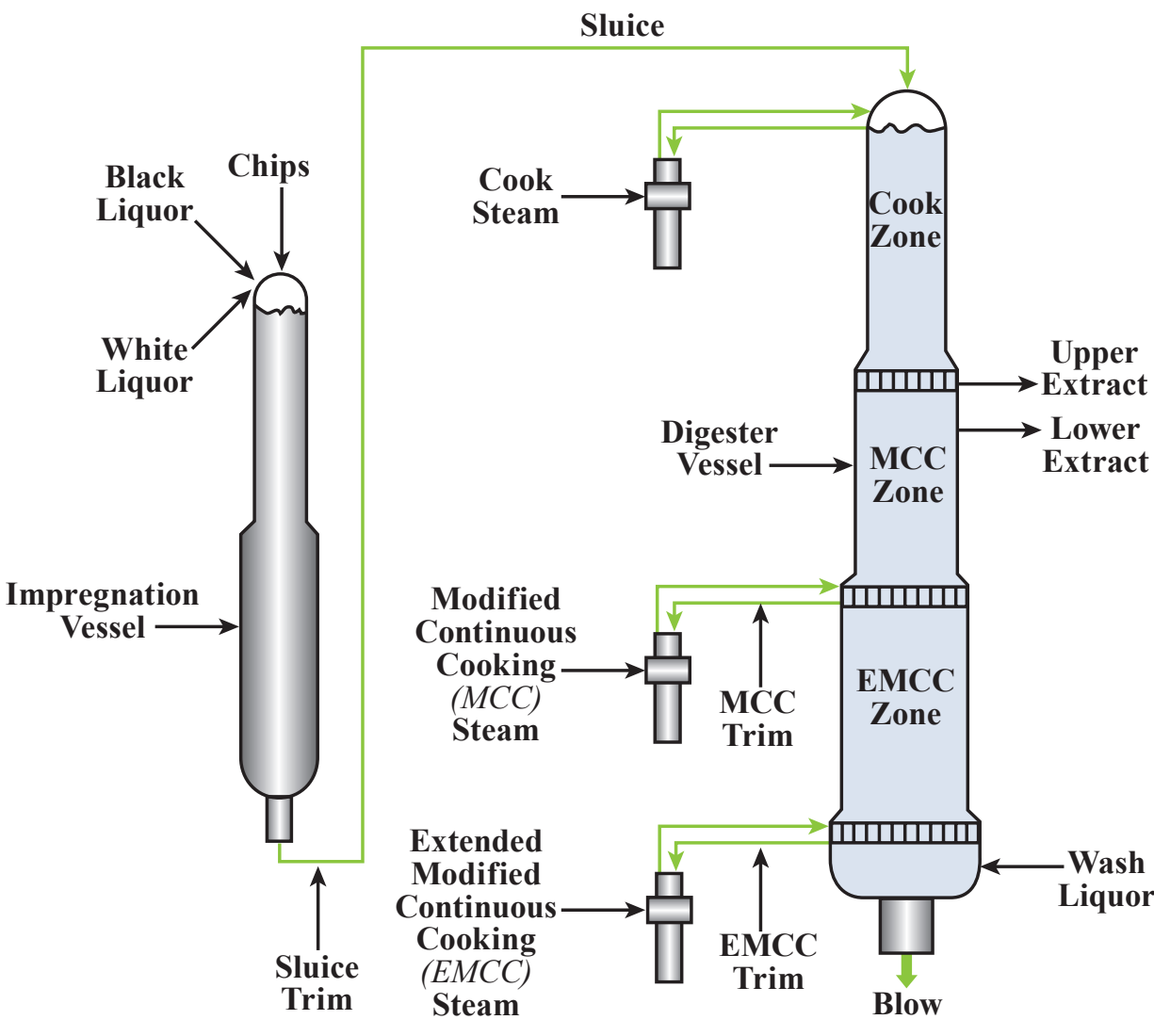

\section{Overview}

$\diamond$ Developed at the University of Delaware

$\checkmark$ Commercialized in 2003

Being marketed by IETEK (www.ietek.net)

\section{U.S. Energy Savings}

(Trillion Btu)

\begin{tabular}{|c|c|}
\hline Cumulative through 2010 & $\mathbf{2 0 1 0}$ \\
\hline 9.00 & 0.00 \\
\hline
\end{tabular}

\section{U.S. Emissions Reductions}

(Thousand Tons, 2010)

\begin{tabular}{|c|c|c|c|}
\hline Particulates & SO $_{\mathrm{x}}$ & NO $_{\mathrm{x}}$ & Carbon \\
\hline 0.0 & 0.0 & 0.0 & 0.0 \\
\hline
\end{tabular}

\section{Applications}

Can be used in all types of pulp digesters and provides the basis for developing more model-based methods of soft sensing, diagnostics, and control

\section{Capabilities}

$\checkmark$ Uses a computer model to evaluate the pulping process.

- Provides operational data through the model to identify process improvements.

\section{Benefits}

\section{Environmental Impact}

Minimizes the amount of chemicals used.

\section{Productivity}

Improves operator control, thus raising productivity and process reliability. Also improves system operability through rate and grade transitions.

Product Quality

Reduces pulp and paper quality variations. 


\section{Detection and Control of Deposition on Pendant Tubes in Kraft Chemical Recovery Boilers}

\section{Advanced Imaging System Improves Boiler Efficiency, Reduces Sootblowing Costs, and Improves Operational Safety}

The kraft chemical recovery boilers used for pulp processing are large and expensive and can be the limiting factor for mill capacity. Improvements in boiler efficiency with better control of deposits on heat transfer surfaces (e.g. pendant tubes) and reductions in boiler downtime (due to pluggage or slag impact) can improve boiler capacity and reduce operating costs.

With assistance from DOE's Inventions and Innovation Program, Enertechnix, Inc., has developed a hand-held infrared inspection system. Using the inspection system technology, they have also established the feasibility of and are developing a continuous integrated monitoring sootblower control system to detect and control buildup of deposits. The early detection of deposits can extend the intervals between boiler shutdowns. The resulting improved boiler operation and reduced maintenance provide energy savings and productivity improvements to the pulp processing industry.

Sootblowers use steam to clean the soot from the fire side of heat exchanger pendant tube surfaces. The hand-held inspection system has demonstrated reductions in sootblower steam use of up to $20 \%$ because the frequency of sootblower operation is reduced, sootblowers can be repositioned based on data obtained from the inspection, and sootblower malfunction can be detected. Reduced pluggage and deposition in the boiler have also led to improved heat transfer rates. The integrated observation camera and sootblower control system (under development) are expected to reduce sootblower steam usage by $30-35 \%$ and improve heat transfer efficiency by $20 \%$.

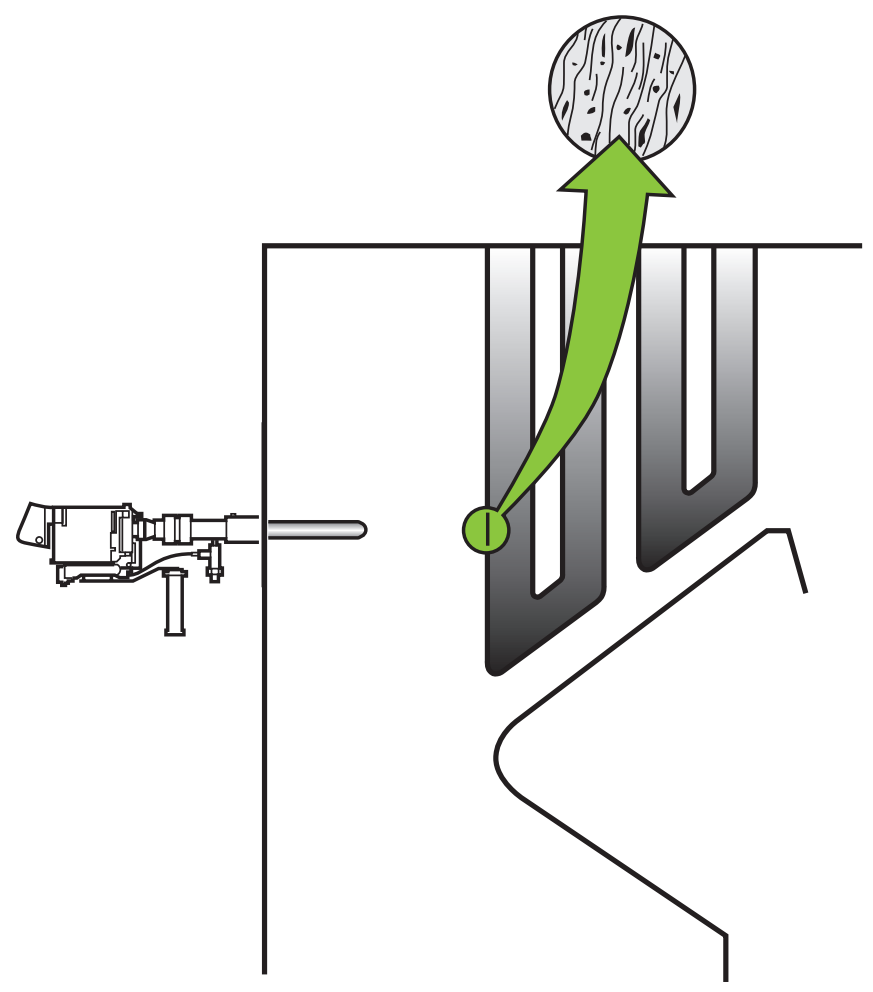

Hand-Held Inspection System on a Kraft Recovery Boiler

\section{Overview}

Developed by Enertechnix, Inc. (www.enertechnix.com)

Commercialized a hand-held device in 2002

181 units in use in 2010

\section{U.S. Energy Savings}

(Trillion Btu)

\begin{tabular}{|c|c|}
\hline Cumulative through 2010 & $\mathbf{2 0 1 0}$ \\
\hline 9.17 & 1.99 \\
\hline
\end{tabular}

\section{U.S. Emissions Reductions}

(Thousand Tons, 2010)

\begin{tabular}{|c|c|c|c|}
\hline Particulates & SO $_{\mathrm{x}}$ & NO $_{\mathrm{x}}$ & Carbon \\
\hline 0.015 & 1.16 & 0.307 & 43.3 \\
\hline
\end{tabular}

\section{Applications}

Can be used by kraft recovery boilers in the pulp and paper industry and also for boilers in the coal power, cement, steel, and glass industries

\section{Capabilities}

Produces clear video images of boiler interiors despite highly particle-laden environments.

- Produces images at distances up to 100 feet, enabling inspection anywhere in the combustion chamber including the convection pass and economizer.

\section{Benefits}

\section{Productivity}

Reduces boiler downtime through early detection of defective fixtures (tube leaks or damaged sootblower). Without shutting down the boiler, also detects slag formation at an early stage, preventing impact damage and enabling cleaning before deposits harden.

\section{Safety}

Enables early detection and elimination of sizable slag deposits on boiler internals, which can lead to severe damage and potential injury. 


\section{Advanced Sensor Detects Paper's Unique Spectral Signature at High Speed}

The primary challenge in recycling paper has been to obtain raw material with the highest purity. Ideally, creating a paper stream sorted by purity would facilitate a high-quality end product, thereby saving processing chemicals and energy. Unfortunately, previous manual sorting techniques were not effective in meeting this challenge. With financial assistance from AMO, North Carolina State University, Weyerhaeuser, and MSS Corporation developed sensors for automatically sorting grades of paper from a mixed stream at high speed for more efficient recycling. Using technology developed by North Carolina State University, MSS commercialized the MultiWave ${ }^{\mathrm{TM}}$ sensor in 2006, providing proprietary full spectrum color and near infrared (NIR) spectroscopy in one compact module at scanning speeds that are more than double those of other NIR sensor systems. The new sensor also provides gloss and lignin identification.

The new sensor provides manual recycling facilities, as well as paper and plastics processors, with a solution for automated optical separation at levels not possible before. At up to 15 tons $/ \mathrm{hr}$, the incoming stream is uniformly fed in a single layer on high-speed conveyors at velocities of $1,200 \mathrm{ft} / \mathrm{min}$ (6 meters/ sec). Besides increased speed, the sensor works in machine widths of up to 96" $(2440 \mathrm{~mm}$ ), which allows significantly higher throughput rates to be processed than any other sorting module available on the market - more than $160 \mathrm{ft}^{2}$ per second $\left(15 \mathrm{~m}^{2} / \mathrm{sec}\right)$.

The sensor starts the process by analyzing all items and classifying them according to specific "signatures." Then, the master computer processes the signals and fires compressed air jets. Depending on the setup, the targeted materials can be ejected together into one chute (upwards) or separately into two chutes (one upward, one downward). An auto-calibration feature ensures consistently high sorting accuracy. The result is a paper stream that is sorted by purity, thereby meeting the original challenge and reducing landfill waste.

\section{Overview}

$\checkmark$ Developed by North Carolina State University

Commercialized and marketed by MSS Corporation in 2006

(www.magsep.com)

\section{Applications}

Can be used for high-speed sorting of mixed recycled paper streams and gloss and lignin identification

\section{Capabilities}

- Works in machine widths up to 96 inches, up to 15 tons per hour.

Analyzes and classifies paper type at 1,200 feet per minute.

\section{Benefits}

\section{Profitability}

Sorts recycled paper using a high-speed machine instead of hand sorting.

\section{Waste Reduction}

Reduces rejected recycled pulp up to 5\%.

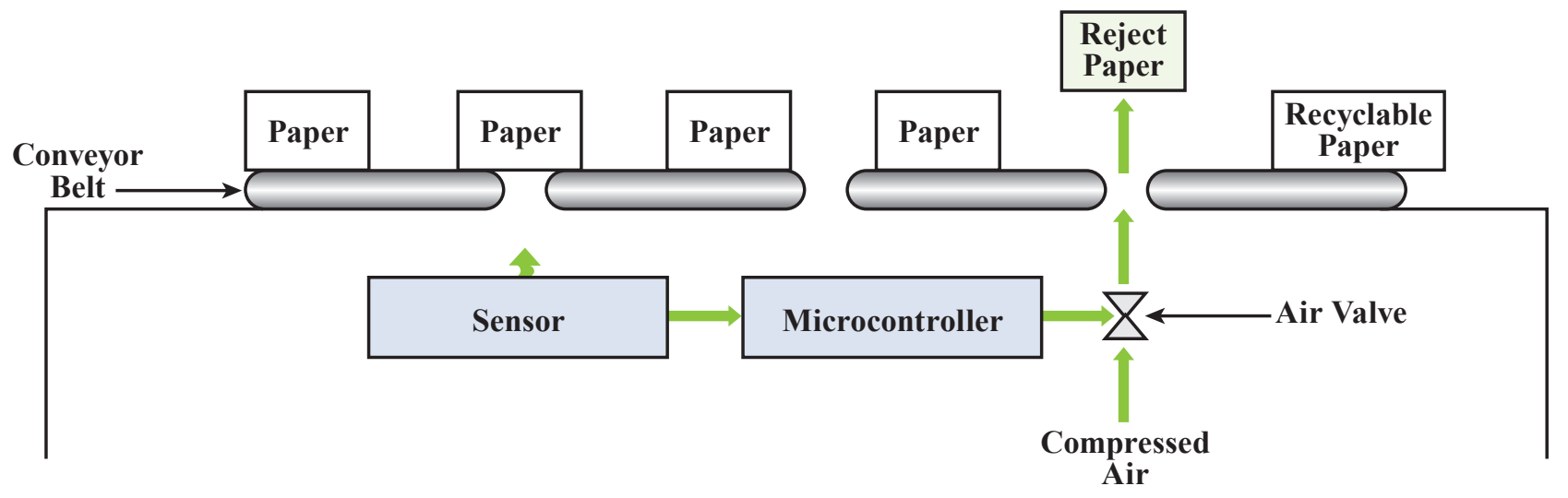

Paper Recycling Using the MultiWave Sensor System 


\section{Improving Recycled Paper Production Energy Efficiency}

Pressure-sensitive adhesives (PSAs) in recycled paper create a number of problems for the recycling process, including lost production and diminished product quality. Unlike conventional PSAs, a new adhesive material was developed at the University of Minnesota, with the assistance of AMO funding, that is effectively removed from the papermaking process during the furnish screening process. The new adhesive possesses properties that enhance its removal without impacting its performance in PSA products.

To develop the new adhesive materials, new screenable PSAs were synthesized and characterized, and performance measures were created. In addition, modified adhesive substrates were tested, and test methods were designed to gauge disintegration inhibition of adhesive labels and relative removal efficiencies of developed polymers. The new adhesives break down into larger, harder, nontacky particles that are more easily removed through conventional screening, and the cross linking reactions may be controlled through external stimuli allowing the reactions to be initiated during recycling.

The technology was commercialized in 2006 and is the industry's first $100 \%$ recyclable label. Currently, the Pinnacle Label Company is selling a portion of their labels under their recyclable label brand utilizing this technology. Using $100 \%$ recycled paper stock and a recyclable permanent adhesive, Pinnacle now has an environmentally friendly product. Pinnacle Label supplies the needs of its national customer base from its headquarters and production facility in Buffalo, New York, and other distribution centers around the nation.

\section{Overview}

Developed by Dr. Steven Severtson of the University of Minnesota in 2000

- Commercialized in 2006 and being marketed by H. B. Fuller Company (www.hbfuller.com)

\section{Applications}

Can be used for all press-on type labels and sticker products

\section{Capabilities}

$\checkmark$ Allows easier adhesive removal in paper recycling.

- Reduces machine downtime by reducing jams due to adhesives and reduces process chemical needs.

\section{Benefits}

\section{Energy Savings}

Improves the energy efficiency of recycled paper production.

\section{Productivity}

Reduces paper recycling re-manufacture processing downtime and lowers fiber loss.

\section{Waste Reduction}

Allows for the recycling of more postconsumer paper trash and reduces process chemical needs.

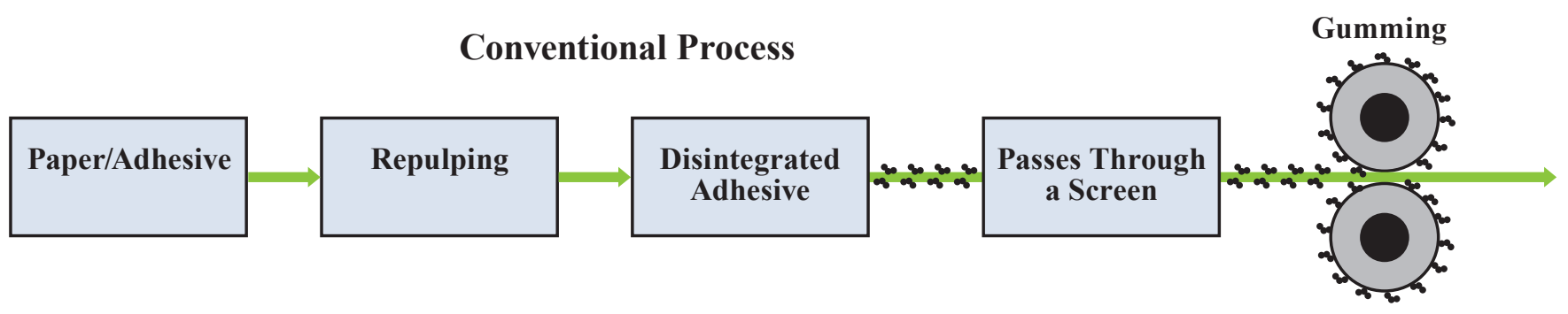

Screenable Process

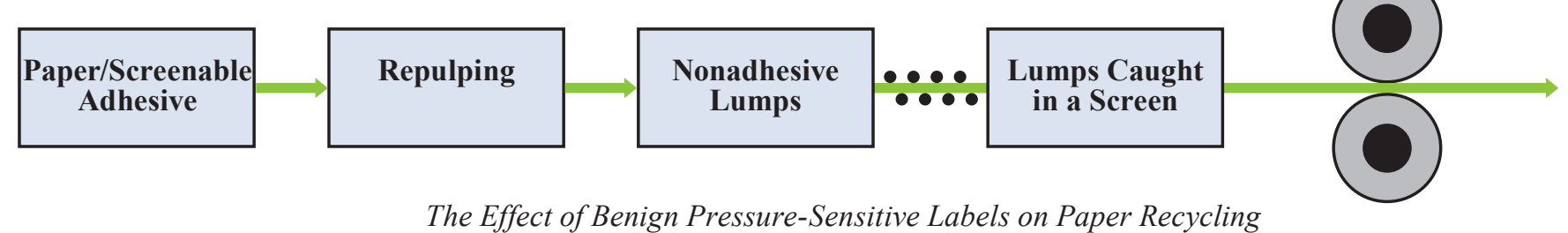

The Effect of Benign Pressure-Sensitive Labels on Paper Recycling 


\section{Thermodyne $^{T M}$ Evaporator - A Molded Pulp Products Dryer}

IMPACTS

\section{Thermodyne Evaporator-A Substantially Improved Molded Pulp Products Dryer}

With assistance from DOE's Inventions and Innovation Program, Merrill Air Engineers demonstrated that its Thermodyne dryer outperforms conventional molded pulp dryers. Unlike other dryers, the Thermodyne dryer reheats water vapor released from the product being dried to create superheated steam that is directed onto the material being dried. Conventional paper dryers exhaust this liberated water outdoors, causing a large visible plume and dumping valuable heat. The Thermodyne dryer is sealed so internal vapor (moisture) cannot escape into the insulated dryer walls. The retained water vapor passes through indirect integral heaters to raise its temperature to a level that allows for substantially faster drying rates than if drying in relatively dry air. An absence of oxygen in the dryer also means the drying temperature can be higher and the retained water vapor can help protect and evenly dry the material. Fires are prevalent with standard dryers, but lower oxygen levels in a Thermodyne dryer eliminates this hazard. The released water vapor also helps control internal temperatures by mixing with the superheated steam, dropping its temperature to a more desirable level. Finally, the system recovers heat and harmful volatile organic compounds (VOCs) from the dryer's condensate, substantially reducing the amount released into the atmosphere.

\section{Benefits}

\section{Productivity}

Promotes easier stacking and wrapping.

\section{Product Quality}

Suppresses oxygen, reducing the chance of scorching or burning the product under higher and faster drying temperatures; offers less warping, reduced case hardening, and no discoloration.

\section{Profitability}

Promotes lower shipping costs and lowers product losses.

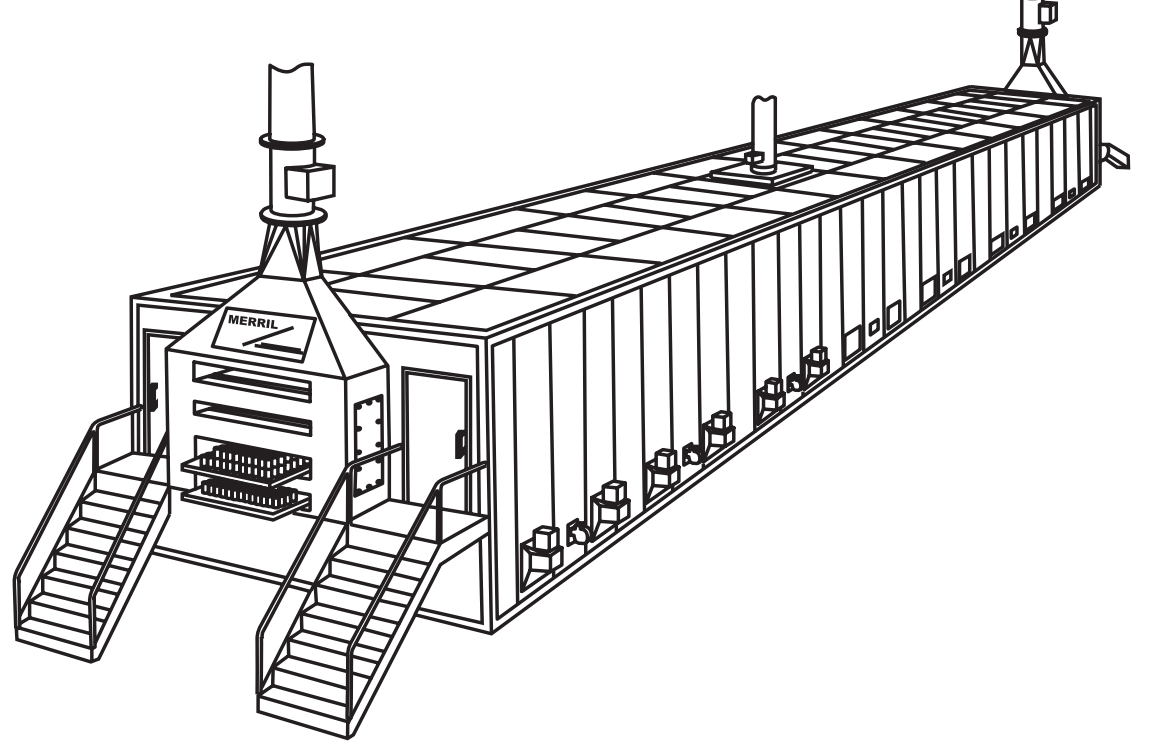

\section{Overview}

Developed by Merrill Air Engineers

Commercialized in 1997

Two units in service in the U.S., one in Ireland, and one in Columbia

\section{U.S. Energy Savings}

(Trillion Btu)

\begin{tabular}{|c|c|}
\hline Cumulative through 2010 & $\mathbf{2 0 1 0}$ \\
\hline 0.555 & 0.079 \\
\hline
\end{tabular}

\section{U.S. Emissions Reductions}

(Thousand Tons, 2010)

\begin{tabular}{|c|c|c|c|}
\hline Particulates & SO $_{\mathrm{x}}$ & NO $_{\mathrm{x}}$ & Carbon \\
\hline 0.0 & 0.0 & 0.009 & 1.25 \\
\hline
\end{tabular}

\section{Applications}

Can be used by the forest products industry for manufacturing molded fiber articles and for drying pulp, wood, cotton, cellulose, or torrefied wood and wood veneers

Thermodyne Evaporator-A Molded Pulp Products Dryer

\section{Capabilities}

$\checkmark$ Can replace conventional drying systems in the forest products industry.

Handles a wide variety of forest products and can be applied to agricultural applications. 


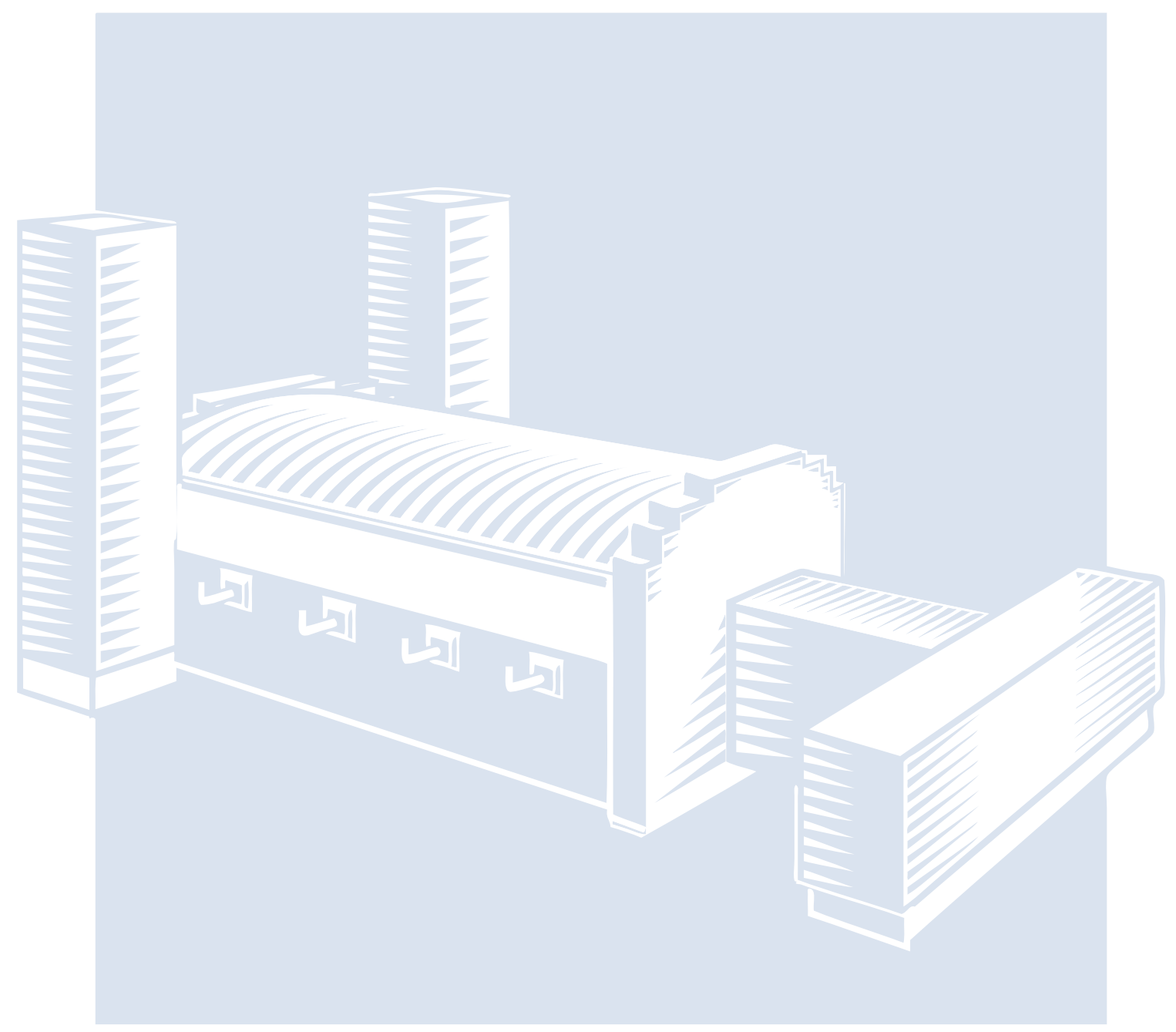




\section{High-Efficiency Burner Lowers Costs and Emissions in Oxy-Fuel Glass Melters}

Glass melters use combustion systems to produce molten glass. While significant progress has been made in developing oxy-fuel combustion systems, current technologies provide low flame luminosity and generate relatively high $\mathrm{NO}_{\mathrm{X}}$ emissions in the presence of even small mounts of nitrogen in the combustion process.

With the help of a grant from AMO, Combustion Tec Inc., now Eclipse, Inc., has developed an innovative burner that increases luminosity and radiant heat transfer in high-temperature glass furnaces. The burner improves performance by modifying the fuel prior to combustion and then forming and burning soot in the flame. The burner increases heat transfer rates while decreasing flame temperatures to improve furnace production rates and thermal efficiency.

The high-luminosity, low- $\mathrm{NO}_{\mathrm{x}}$ burner combines a preheating zone with two combustion zones. First, a small fraction of the natural gas is burned. The products of this combustion are then mixed with the main supply of natural gas, resulting in hydrocarbon soot precursors generated in an oxygen-free heating environment. Next, the preheated natural gas enters the first, fuelrich combustion zone in which soot forms in the flame. However, most of the combustion occurs in the second, fuel-lean combustion zone. The burning soot particles create a highly luminous flame that is more thermally efficient and cooler than a typical oxy-fuel flame.

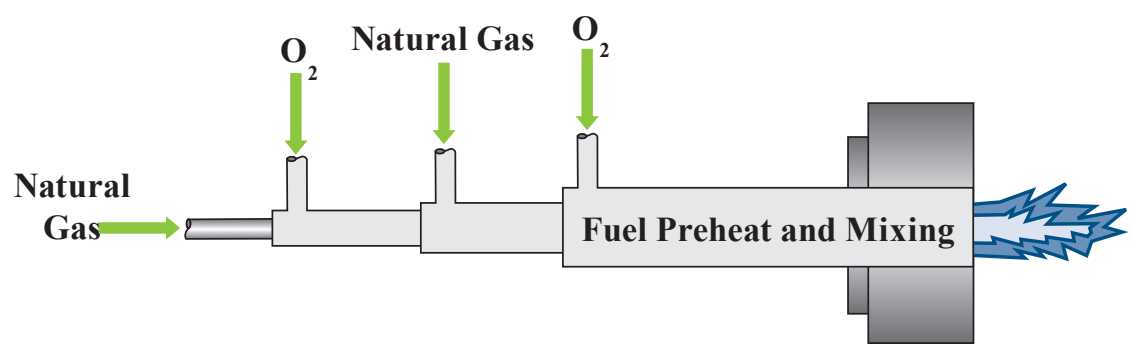

High Luminosity, Low-NO $O_{X}$ Burner Design

\section{Overview}

Developed and marketed by Eclipse, Inc. (www.eclipsenet.com)

Commercialized in 2002

- Operating in nine U.S. plants in 2010

\section{Applications}

Can be used in existing and new oxy-fuel glass melters, with the largest demand currently existing in the container, fiber, and specialty glass sectors of the glass industry

\section{Capabilities}

Can be used on new furnaces or retrofit to older ones.

- Improves furnace production rates as a result of a more than $12 \%$ increase in heat transfer rates.

\section{Benefits}

\section{Energy Saving and Pollution Reduction}

Reduces $\mathrm{NO}_{\mathrm{x}}$ emissions from glass melters up to $50 \%$ and improves thermal efficiency up to $20 \%$ over traditional oxygen fuel burners.

\section{Productivity}

Allows cost-effective compliance with emissions regulations and provides flexibility for compliance in existing furnaces without major modifications.

\section{Reliability}

Produces a lower flame temperature and lower exit temperatures, which could extend the furnace life. 


\section{High Throughput Vacuum Processing for Producing Innovative Glass/Photovoltaic Solar Cells}

IMPACTS

\section{Continuous Manufacturing Process Reduces Cost of Solar Power}

The sun has long been known to be a boundless source of energy. More solar energy hits the earth in one hour than is used by the entire world's population in one year. Unfortunately, the high manufacturing cost of solar photovoltaic (PV) modules has prevented solar from competing with other forms of electricity generation.

With assistance from DOE's Inventions and Innovation Program, Abound Solar, Inc., has developed an improved manufacturing process for producing thin-film cadmium telluride (CdTe) solar cells encapsulated with a protective layer of glass. The manufacturing process is dry, in-line, continuous, and fully automated. A glass panel enters the semiconductor chamber every 10 seconds, and emerges from the end of the line as a complete product module in less than two hours. Abound Solar's proprietary in-line semiconductor deposition tool significantly improves PV film quality, device efficiency, device stability, and product yield. Because the semiconductor layers are applied in a single piece of equipment, capital equipment costs, factory space, and manufacturing costs are reduced. In addition, the fast cycle time increases product volume per capital dollar invested.

The Abound Solar modules are ideally suited for solar installations ranging from commercial-scale (tens of kilowatts) to utility-scale (hundreds of megawatts). Designed for use worldwide in a variety of climates, the modules perform better than crystalline silicon PV under real-world conditions such as high temperatures and low or diffuse lighting.

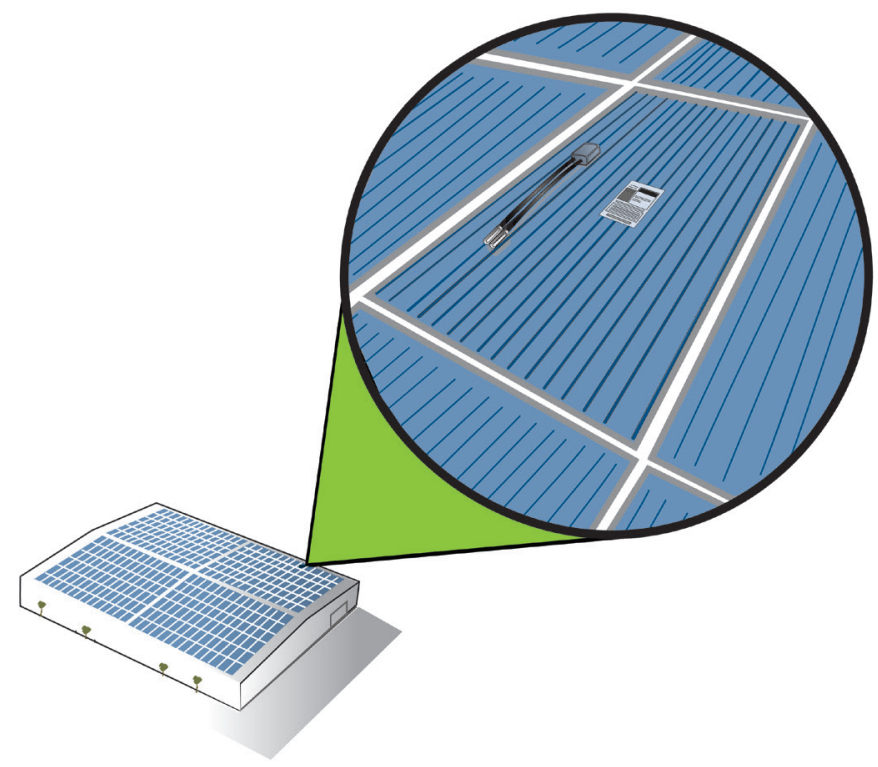

\section{Overview}

Developed and marketed by Abound Solar, Inc.

Commercialized in 2009 with one facility in Longmont, Colorado, selling commercial units in the U.S. and internationally.

\section{Applications}

Can be used to produce next-generation, thin-film PV modules that deliver a low levelized cost of electricity.

\section{Capabilities}

Produces completed solar modules in less than two hours.

Produces thin-film CdTe PV cells that have achieved efficiencies of $12 \%$ to $13 \%$.

\section{Benefits}

\section{Cost Savings}

Reduces costs by using continuous, highthroughput manufacturing techniques in a single piece of equipment.

\section{Emissions Reductions}

Reduces emissions of air pollutants and greenhouse gases by $92 \%$ to $98 \%$ compared with fossil-fuel-based electricity.

\section{Environmental}

Avoids disposal issues because Abound Solar pays for packaging and shipping of solar modules to be recycled at the end of their life. More than $95 \%$ by weight of each module is recycled.

\section{Product Quality}

Offers a 5-year materials and workmanship warranty, with power output guarantees of $90 \%$ of nominal output during the first 10 years and $80 \%$ over 25 years. 


\section{Process for Converting Waste Glass Fiber into Value-Added Products}

\section{New Process Reduces Glass Fiber Waste Stream to Landfills}

Solid wastes are generated at glass fiber manufacturing facilities. With the help of a grant from DOE's Inventions and Innovation Program, Albacem, LLC, developed a new process that converts these waste streams into VCAS ${ }^{\mathrm{TM}}$ (vitrified calcium alumino-silicate) pozzolans that can be used in cement and concrete applications. This technology can help divert up to 250,000 tons per year of discarded glass fiber manufacturing wastes for use in the concrete construction industry. This technology can also be used for processing glass fiber waste materials reclaimed from existing landfills at manufacturing facilities. Both sources can help supply over 500,000 tons per year of glass fiber waste for processing into value-added products.

In the new process, waste glass fiber is ground to a fine powder that effectively functions as a reactive pozzolanic admixture for use in Portland-cement-based building materials and products, such as concrete, mortars, terrazzo, tile, and grouts. Because the waste fiber from the glass manufacturing industry is vitreous, clean, and low in iron and alkalis, the resulting pozzolan is white and highly consistent in chemical composition. This white pozzolan is especially suited for white concrete applications, providing increased long-term strength and improved long-term durability. This new pozzolan is being manufactured and marketed by Vitro Minerals, Inc. While this additive is targeted towards white concrete applications, it can also be applied to other concrete applications where environmental benefits are desired.

\section{Conventional Process}

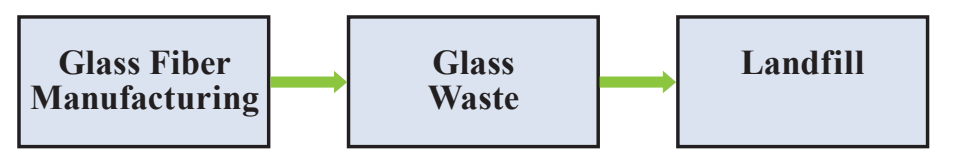

New Technology

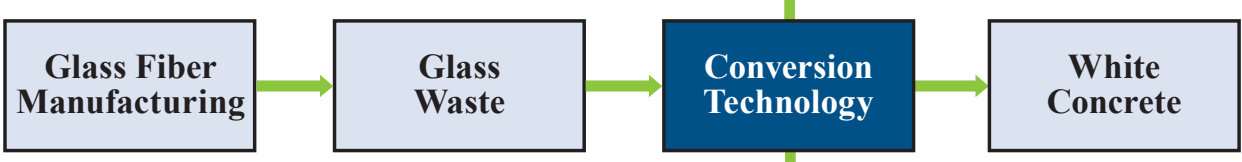

Tile

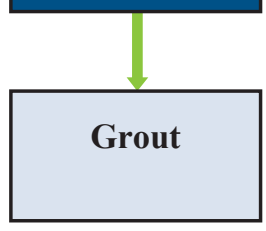

Glass Waste Conversion Process

\section{Overview}

Developed by Albacem, LLC

$\checkmark$ Commercialized and marketed by Vitro Minerals in 2006

(www.vitrominerals.com)

\section{U.S. Energy Savings}

(Trillion Btu)

\begin{tabular}{|c|c|}
\hline Cumulative through 2010 & $\mathbf{2 0 1 0}$ \\
\hline 0.525 & 0.140 \\
\hline
\end{tabular}

\section{U.S. Emissions Reductions}

(Thousand Tons, 2010)

\begin{tabular}{|c|c|c|c|}
\hline Particulates & SO $_{x}$ & NO $_{x}$ & Carbon \\
\hline 0.0 & 0.0 & 0.016 & 2.22 \\
\hline
\end{tabular}

\section{Applications}

Can be used for waste streams in the glass fiber industry and to replace part of the cement used in concrete

\section{Capabilities}

$\checkmark$ Decreases water used to cure concrete.

Imparts white color to concrete.

\section{Benefits}

\section{Energy Savings}

Decreases the amount of cement used in concrete and the amount of water needed to cure concrete while imparting white color to the concrete.

\section{Environmental}

Reduces the carbon footprint of a product when used as a cement additive.

\section{Waste Reduction}

Reduces the waste stream from current glass fiber manufacturing and reclaims glass fiber waste from old landfills. 
Die Casting Copper Motor Rotors. A-39

$\checkmark$ Improved Magnesium Molding Process (Thixomolding) A-40

Improvement of the Lost Foam Casting Process....... A-41

Low Permeability Components for Aluminum Melting and Casting. A-42

Titanium Matrix Composite Tooling Material for Aluminum Die Castings A-43

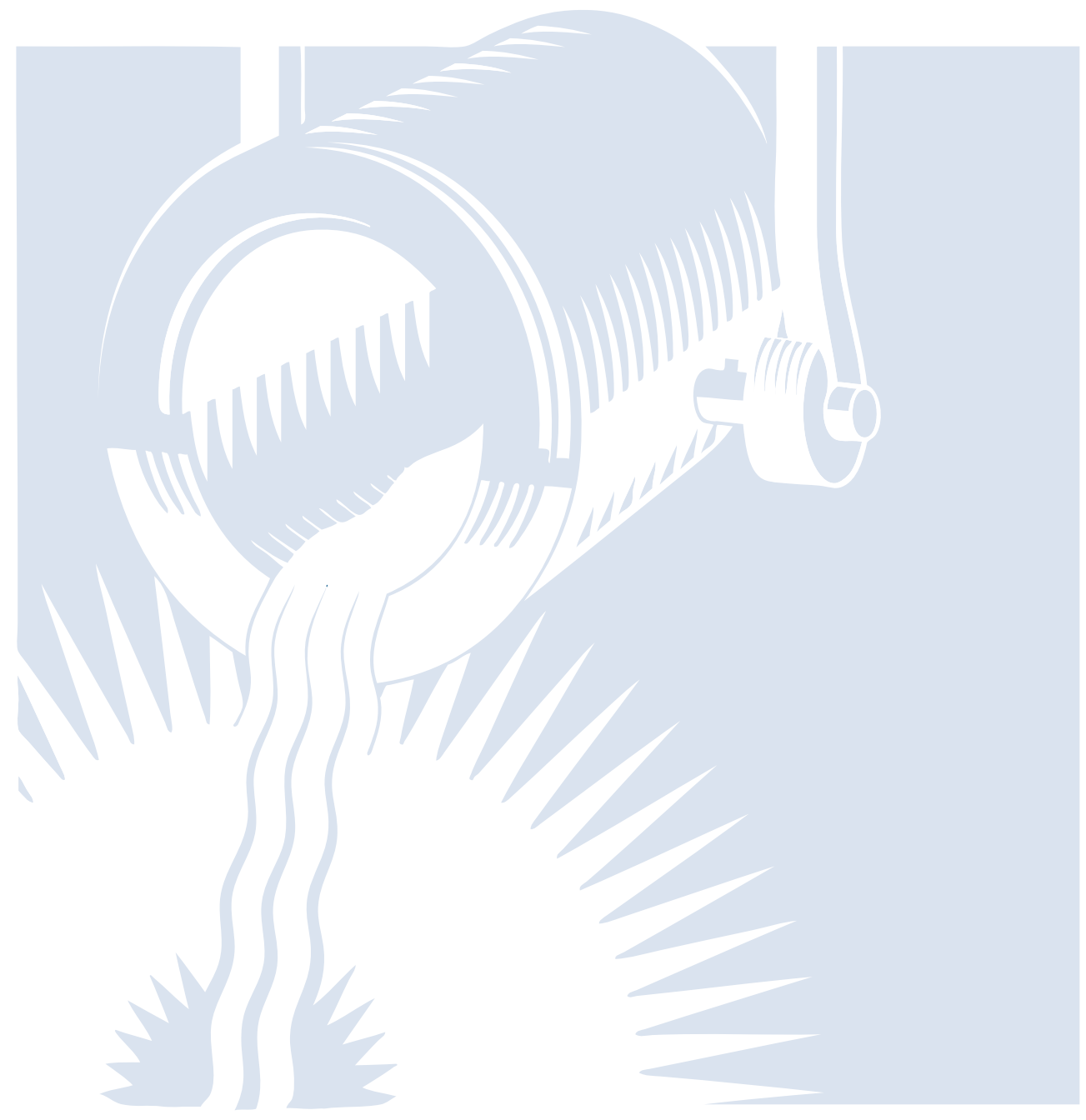




\section{New Modeling Program Provides Higher Quality Lost Foam Molds}

The lost foam casting process produces clean, high-quality castings with close tolerances. The most important advantage is that no cores (with binders) are required. One challenge in lost foam casting is maintaining the uniformity and quality of the expandable polystyrene (EPS) pattern. This has often been the cause of defects in casting. An estimated $80 \%$ or more of lost foam defects can be attributed to the pattern, or the so-called white side. Foam molds are complex, and beads must flow through complex passages to completely fill the mold. The process is further complicated by the expansion of the beads.

General Motors Powertrain and others in the metal casting industry have successfully used advanced computational fluid dynamics (CFD) tools to improve foundry processes. These efforts have yielded significant cost savings and improvements in the casting processes. The industry has recognized that mathematics-based tools are needed to design and build consistent, quality EPS patterns for lost foam casting.

Arena-flow, LLC, in conjunction with the American Foundry Society, AMO, and the metal casting industry, have extended existing flow modeling software to simulate the air-driven blowing of pre-expanded beads into a mold and the subsequent steaming (expansion) of beads as they form a lost foam pattern. They developed a CFD tool for improving design and development of EPS patterns for lost foam castings.

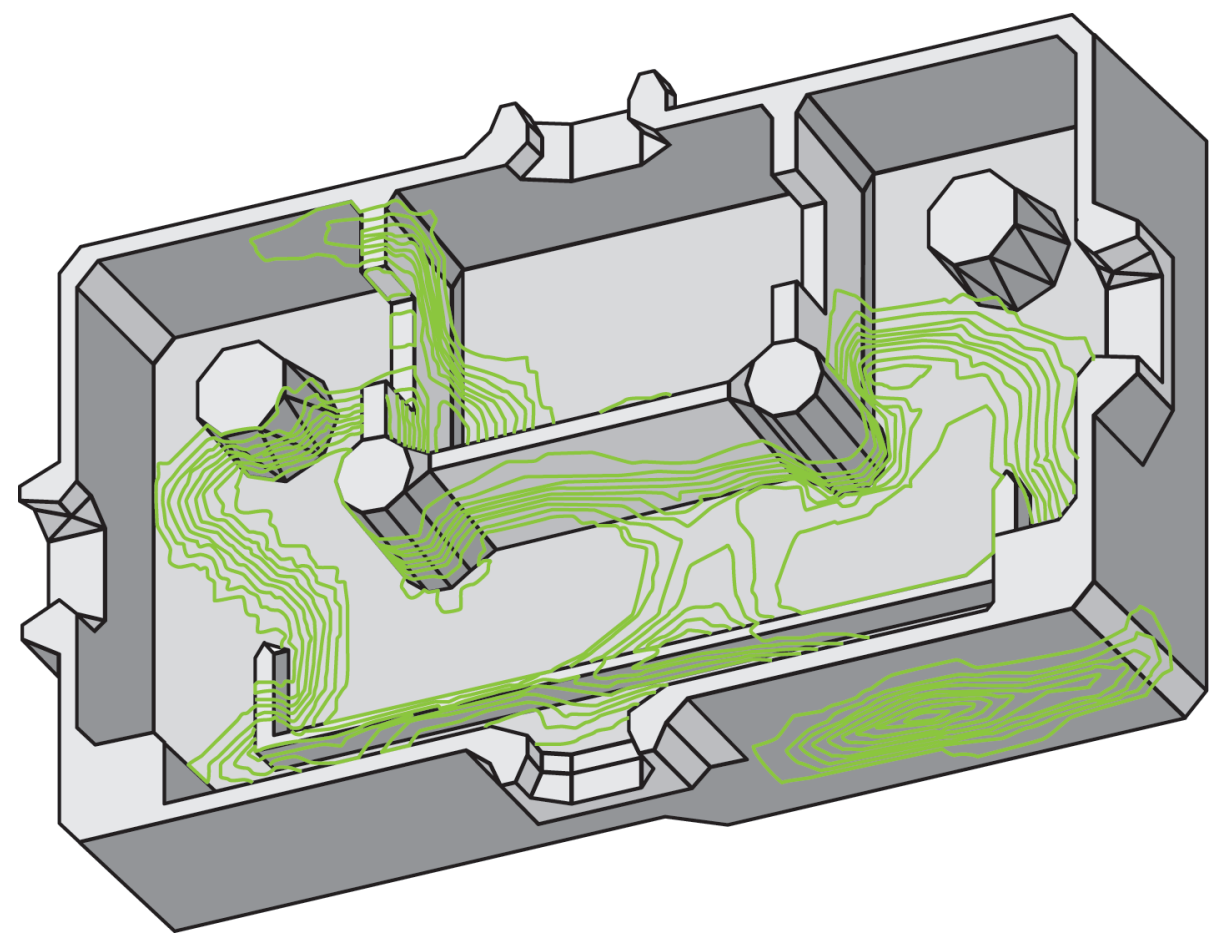

Expandable Polystyrene Pattern Volume Fraction During Filling of a General Motors Test Box

\section{Overview}

Invented by Arena-flow, LLC, and marketed by CPFD Software, LLC (www.cpfd-software.com)

Being used by 2 U.S. manufacturers in 3 locations

\section{Applications}

Can be used in modeling fluid/particle applications for mold creation in the lost foam casting industry

$\checkmark$ Can be used in analysis of other industrial fluid/particle processes, including cyclones or fluidized bed reactors

\section{Capabilities}

Provides visualization of the mold by using CFD modeling prior to the mold creation.

Optimizes pattern quality as affected by fill guns, beads, and tool venting.

\section{Benefits}

\section{Productivity}

Results in fewer casting defects, requires no cores, and produces higher-quality castings.

\section{Waste Reduction}

Reduces casting defects on the white side, caused by pattern difficulties. 


\section{Die Casting Copper Technique Improves Energy Efficiency of Electric Motors}

Though it conducts electricity less efficiently than copper, aluminum is the industry's preferred fabrication material in electric induction motor rotors. Traditional tool steel casting molds suffer thermal shock, shortening mold life and increasing operating costs when used for die casting copper rotors. ThermoTrex Corporation, with the assistance of a $\mathrm{NICE}^{3}$ grant, proposed a process for copper die casting using molds from high-temperature, thermal shock-resistant materials. The copper industry successfully tested these mold materials for copper die casting at higher temperatures (copper melts at $1083^{\circ} \mathrm{C}$, aluminum at $\left.660^{\circ} \mathrm{C}\right)$.

The copper die-casting technology developed by the copper industry is now in commercial use. The process replaces the tool steel molds used for the aluminum die casting with molds made from high-temperature die materials. In addition, the new process preheats the die inserts, reduces the temperature differential between the mold surface and the cooler interior, and avoids mold failure from thermal shock and thermal fatigue.

In 2003, SEW Eurodrive of Bruchsal, Germany, was the first company, worldwide, to bring the technology to market. A line of high-efficiency gear motors (1.1-5.5 kW) use copper rotors at a competitive price. Although traditional high-efficiency motors are larger than standard motors, gear boxes using copper rotor technology provide efficiency without increasing motor size. In 2004, FAVI S.A., a major French supplier of copper and copper alloy die castings, began offering custom-designed, copper-based rotors for squirrelcage electric motors in sizes ranging from fractional to $100 \mathrm{hp}$. Siemens Corporation began commercial production and sales domestically in 2006 in the 1 to $20 \mathrm{hp}$ range.

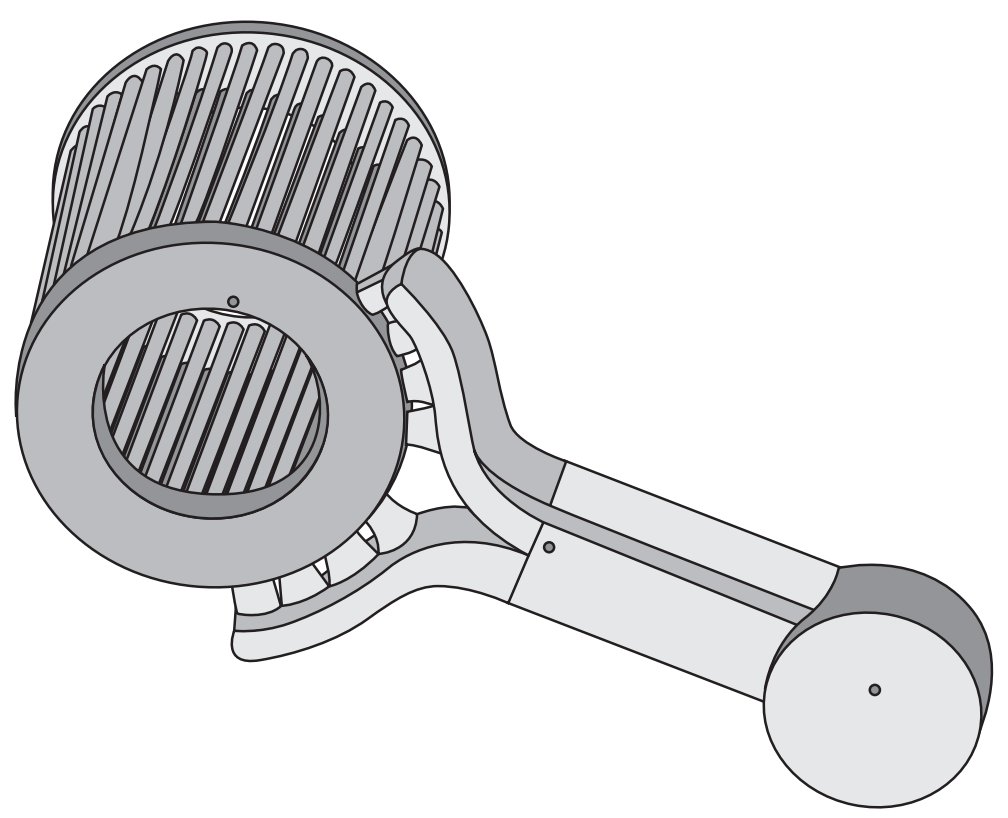

Squirrel-Cage Motor with Die Cast Copper Rotors

\section{Overview}

Invented by the ThermoTrex Corporation and commercialized by the Copper Development Association (www.copper.org)

$\checkmark$ Marketed by SEW Eurodrive, FAVI S.A, and Siemens Corp. with more than 295,000 in use in the U.S. in 2010

\section{U.S. Energy Savings}

(Trillion Btu)

\begin{tabular}{|c|c|}
\hline Cumulative through $\mathbf{2 0 1 0}$ & $\mathbf{2 0 1 0}$ \\
\hline 0.552 & 0.163 \\
\hline
\end{tabular}

\section{U.S. Emissions Reductions}

(Thousand Tons, 2010)

\begin{tabular}{|c|c|c|c|}
\hline Particulates & SO $_{x}$ & NO $_{x}$ & Carbon \\
\hline 0.001 & 0.035 & 0.026 & 3.20 \\
\hline
\end{tabular}

\section{Applications}

Can be used in electric motors throughout U.S. industry, which account for more than $60 \%$ of all electricity use in the nation.

\section{Capabilities}

Reduces electric motor total energy loss by $15 \%$ to $20 \%$.

Decreases operating costs compared with conventional motors.

\section{Benefits}

Productivity

Reduces production time and hand labor compared with former methods of producing copper motor rotors.

\section{Profitability}

Decreases operating costs compared with conventional motors. 


\section{Improved Die Casting Process Substantially Reduces Energy, Waste, and Operating Costs}

Traditionally, die-cast molding results in product yields of $50 \%$ and creates waste - scrap, slag, and dross. The Thixomolding process, developed and demonstrated by Thixomat, Inc., with the help of a NICE ${ }^{3}$ grant, improves product yields to $90 \%$ while eliminating waste and loss of product to melting. The process is worker and environmentally friendly and can be integrated into automated manufacturing processes to produce metal and metal/plastic assemblies.

In Thixomolding, room-temperature magnesium chips are fed through a volumetric feeder into the back end of a heated barrel that contains an argon atmosphere to prevent oxidation. Within the barrel, a rotating screw propels the material forward as the screw retracts. Resistance heaters on the outside of the barrel, arranged in 10 separately controlled zones, heat the material to the semi-solid region (approximately $560^{\circ} \mathrm{C}$ to $630^{\circ} \mathrm{C}$ ). Once the magnesium is heated, the screw rotation provides the necessary shearing force to divide the dendrites from the root solid particles. This action creates a thixotropic slurry consisting of spherical solid particles in a continuous liquid matrix. The slurry is forced through a non-return valve and into the accumulation zone. When the proper amount of slurry is in front of the non-return valve, the screw proceeds forward at a speed of 1.8 to $5 \mathrm{~m} / \mathrm{s}$, forcing the metal into a preheated metal mold to produce a net or near-net shape part requiring few, if any, secondary operations. The process offers numerous cost advantages over other production methods, including higher yield, increased die life, lower utility costs, consistency of process, tighter dimensional tolerances, and improved manufacturing agility.

\section{Benefits}

\section{Cost Savings}

Reduces operating costs by $20 \%$.

\section{Environmental}

Significantly reduces pollutant emissions and eliminates the use of sulfur hexafluoride. Eliminates slag and dross and their disposal problems.

\section{Waste Reduction}

Reduces scrap that must be recycled and subsequently reheated by $50 \%$.

\section{Overview}

Developed by Thixomat, Inc. (www.thixomat.com)

50 Thixomolding machines in use in 2010

\section{U.S. Energy Savings}

(Trillion Btu)

\begin{tabular}{|c|c|}
\hline Cumulative through 2010 & $\mathbf{2 0 1 0}$ \\
\hline 0.298 & 0.075 \\
\hline
\end{tabular}

\section{U.S. Emissions Reductions}

(Thousand Tons, 2010)

\begin{tabular}{|c|c|c|c|}
\hline Particulates & SO $_{x}$ & NO $_{x}$ & Carbon \\
\hline 0.0 & 0.0 & 0.009 & 1.18 \\
\hline
\end{tabular}

\section{Applications}

Can be used in automotive, electronics, communications, sports, and hand tool industries

\section{Capabilities}

Produces thinner, lighter, and stronger parts than possible with engineered plastics.

Provides excellent dimensional stability $(0.001 \mathrm{~mm} / \mathrm{mm})$, low porosity, tighter part tolerances, minimum shrinkage $(0.5 \%)$, low residual stress, and virtually no component distortion.

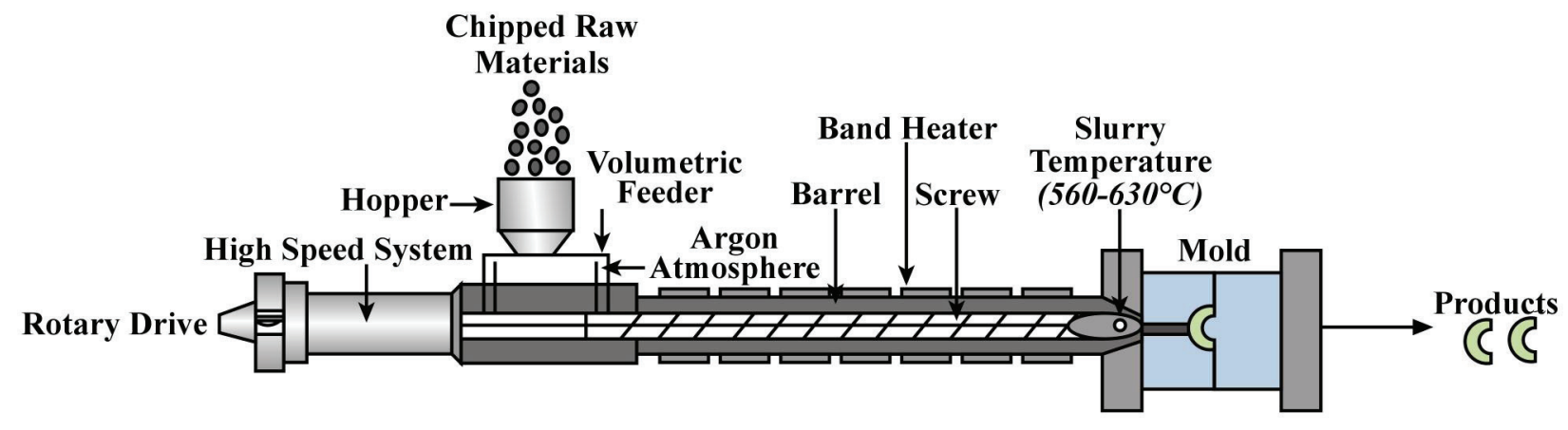




\section{Improved Process Reduces Energy Use, Waste and Emissions, While Lowering Product Defects and Costs}

Casting is an energy-intensive manufacturing process within the metal casting and aluminum industries, requiring natural gas to melt aluminum and electricity to run equipment. The higher-than-acceptable faults and scrap rates in the lost foam casting process for the complex L61 engine previously resulted from the inability to control and measure refractory coating thickness and to control particle size and the shape of the unbonded sand. Remelting defective castings adds to overall energy costs, emissions, and use of resources.

The lost foam casting process starts with a foam pattern of the desired endproduct made out of polystyrene beads. The foam pattern is coated with a thin refractory film and placed into dry, unbonded sand that is compacted by vibration. Molten metal, poured into the sand casting, evaporates and replaces the foam, producing a metal casting that is nearly identical to the foam pattern. The foam vapor passes through the pores in the refractory coating and the sand. This process enables the joining of several components within a single casting, thereby reducing downstream machining and assembly.

With the assistance of a NICE ${ }^{3}$ grant and the New York State Energy Research and Development Authority, General Motors Corporation has developed tools to precisely measure dried coating thickness and pore size distribution, more accurately measure the size and shape of sand used in casting, and better understand the rheology of coatings. Rheology affects both coating thickness and uniformity on foam patterns. Coating thickness controls the permeability of gaseous expanded polystyrene by-products, which is directly related to casting defects such as porosity and folds. Therefore, measuring the rheological properties of the lost foam coating is critical to minimizing casting defects.

\section{Benefits}

\section{Cost Savings}

Reduces costs for polystyrene beads, glue, coating, sand, aluminum, cleaning media, and labor by $\$ 900,000$ to $\$ 1.5$ million annually.

\section{Environmental}

Reduces harmful incinerator emissions and sand waste by 2.2 to 3.5 tons annually.

\section{Product Quality}

Improves product quality $5 \%$ to $8 \%$ over conventional lost foam casting and significantly reduces scrap rates.

\section{Overview}

Developed by General Motors Corporation (www.gm.com)

$\checkmark$ Commercialized in 2004

$\checkmark$ Employed at 1 General Motors casting facility

\section{U.S. Energy Savings}

(Trillion Btu)

\begin{tabular}{|c|c|}
\hline Cumulative through 2010 & $\mathbf{2 0 1 0}$ \\
\hline 2.45 & 0.163 \\
\hline
\end{tabular}

\section{U.S. Emissions Reductions}

(Thousand Tons, 2010)

\begin{tabular}{|c|c|c|c|}
\hline Particulates & SO $_{\mathrm{x}}$ & NO $_{\mathrm{x}}$ & Carbon \\
\hline 0.0 & 0.015 & 0.022 & 2.85 \\
\hline
\end{tabular}

\section{Applications}

Can be used in metal casting and aluminum industries

\section{Capabilities}

Significantly reduces aluminum and sand scrap rates during production of the complex General Motors L61 engine. 


\section{Low Permeability Components for Aluminum Melting and Casting}

\section{New Low Permeability Coating Improves Durability and Life of Aluminum Casting Components}

Materials for low-pressure casting operations typically have limited lifetimes. New, optimized coatings for ceramics and refractory components have been developed by Pyrotek, Inc., Oak Ridge National Laboratory, and the University of Missouri with support from AMO. The new materials exhibit low permeability to gases for applications involving low-pressure casting and contact with molten aluminum. The products treated with this new technology will have improved coatings, functionally graded materials, and monolithics that will hold gas pressure.

The new materials include enhanced combinations of properties, including resistance to thermal shock, erosion, corrosion, and wetting. As these materials are successfully deployed in aluminum smelting and casting operations, their superior performance and durability will achieve marked improvements in uptime, defect reduction, scrap/rework costs, and overall energy savings. Initial applications of this technology, labeled "XL" glaze, include riser tubes in low-pressure die casting of aluminum products. The reduced porosity of the new ceramic coating material improves the component's air tightness, which reduces tube failures. Testing shows that the improved tube coatings increase the life of the component 3-4 times the standard, depending on the application and coating material. Additional work is underway on a castable material system that will incorporate the benefits of the "XL" coating in the cast material itself. This product is expected to increase component life by up to 7 times the standard.

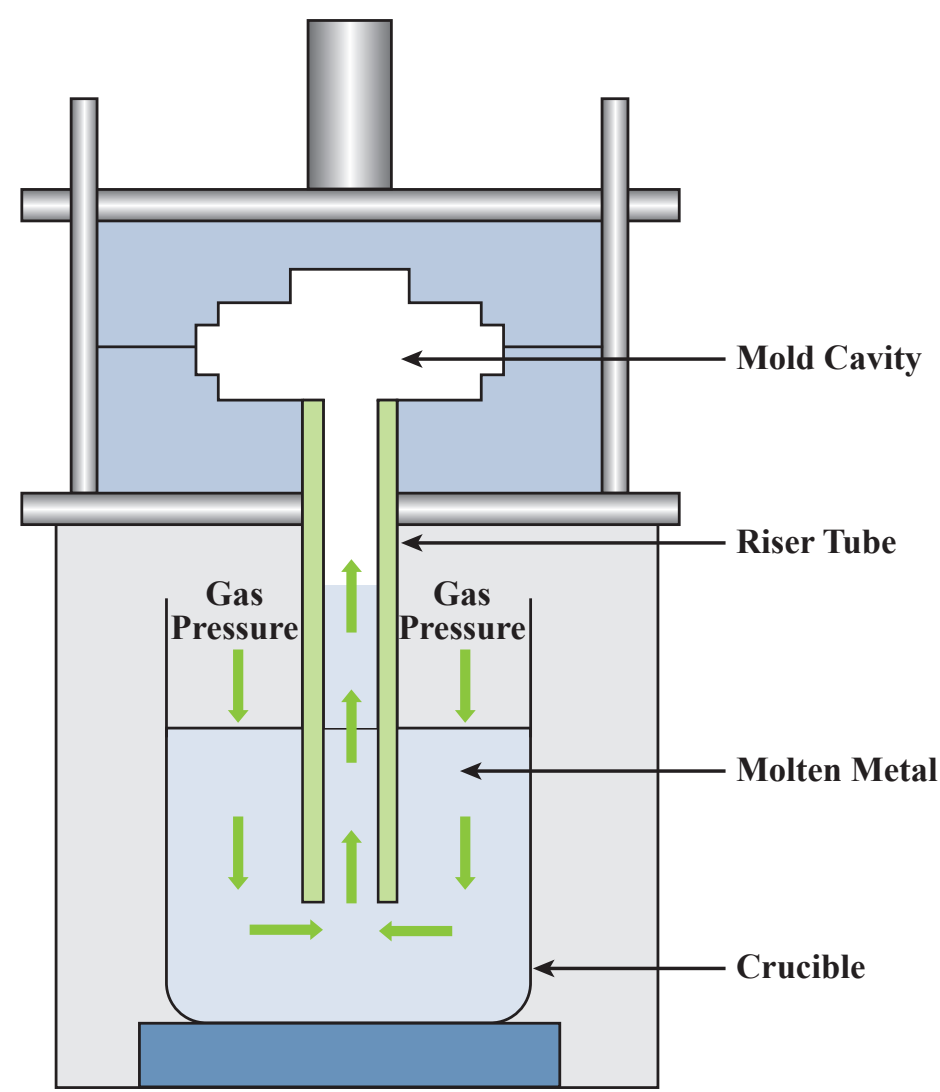

Aluminum Casting Riser Tube with Pyrotek's Low-Permeability Coating

\section{Overview}

$\checkmark$ Developed by Pyrotek, Inc. (www.pyrotek-inc.com)

Commercialized in 2005

\section{Applications}

Can be used in aluminum casting and chemical reaction processes where riser tube and other material flow components are subject to extreme temperatures or caustic chemical streams and replacement of process components is costly and timeconsuming

\section{Capabilities}

Extends tube component life 3-4 times.

$\checkmark$ Increases component reliability.

\section{Benefits}

\section{Energy Savings}

Eliminates reheating energy by reducing waste.

\section{Productivity}

Reduces production downtime because components have longer lifetimes.

\section{Product Quality}

Increases the life of process components. 


\section{Titanium Matrix Composite Tooling Material for Aluminum Die Castings}

\section{Innovative Material Saves Energy and Extends Product Life In Aluminum Die-Casting Components}

In aluminum die-casting, molten aluminum is forced under high pressure into a die cavity. First a "shot" of molten aluminum is ladled into a shot sleeve and the shot of molten aluminum is forced by a plunger through the shot sleeve into the die cavity. Shot sleeves are subject to severe conditions. For example, impingement of the shot can cause erosion at the surface across from the pour hole, and delivering and then expelling the shot can subject the shot sleeve to cyclical heating.

Currently, H-13 tool steel is used to fabricate shot sleeves and other aluminum die-casting components. However, the useful life of $\mathrm{H}-13$ is limited because molten aluminum adheres (called "aluminum soldering") to the surface of the steel, eventually causing the sleeve to fail. Also, H-13 has poor resistance to heat checking, thermal fatigue, erosion, and distortion. The poor performance of $\mathrm{H}-13$ results in frequent shot sleeve replacements.

With the help of a NICE ${ }^{3}$ grant, Dynamet Technology, Inc., developed $\mathrm{CermeTi}^{\circledR}$, a titanium-alloy metal matrix composite material that is used as a liner inserted into an $\mathrm{H}-13$ shot sleeve. This new technology has significant advantages over the conventional technology, especially in its resistance to aluminum soldering and erosion. In addition, the reduced thermal conductivity of the CermeTi liner reduces heat loss during the injection phase of the casting process. Slower cooling permits the use of lower pouring temperatures (less preheat energy) or slower plunger-tip speeds (less turbulence or surface impingement problems within the die). As a result, the useful life of the shot sleeve is dramatically improved, reducing downtime, improving product quality, and saving energy.

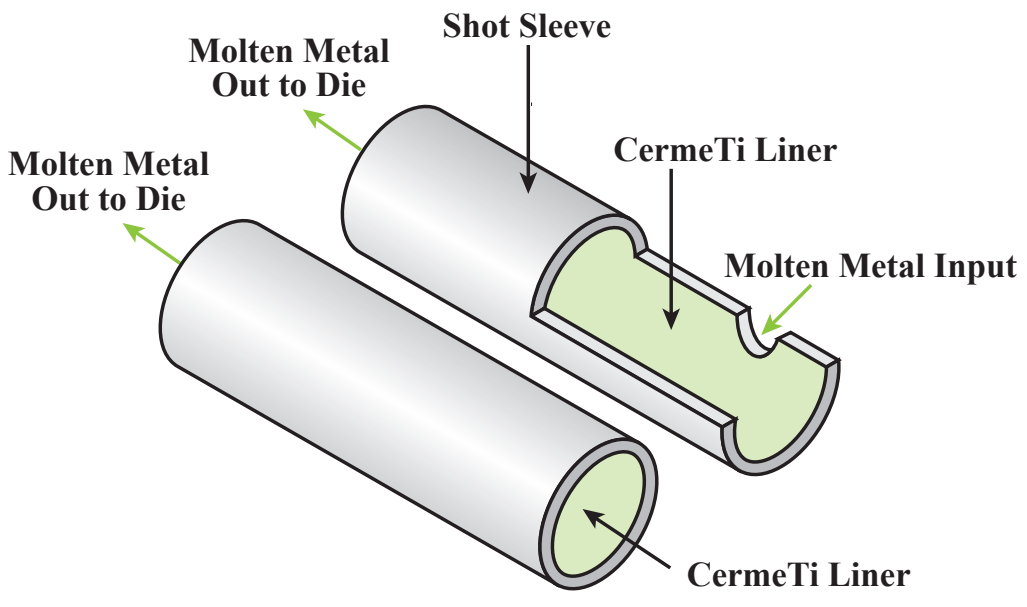

Aluminum Die-Casting Shot Sleeves with CermeTi ${ }^{\circledR}$ Liners

\section{Overview}

Developed by Dynamet Technology, Inc. (www.dynamettechnology.com)

$\checkmark$ Commercialized in 2005 and being used by 37 die-cast machines in the U.S.

\section{U.S. Energy Savings}

(Trillion Btu)

Cumulative through 2010

0.085

2010

0.019

\section{U.S. Emissions Reductions}

(Thousand Tons, 2010)

\begin{tabular}{|c|c|c|c|}
\hline Particulates & SO $_{\mathrm{x}}$ & NO $_{\mathrm{x}}$ & Carbon \\
\hline 0.0 & 0.0 & 0.002 & 0.299 \\
\hline
\end{tabular}

\section{Applications}

Can be used in metal casting applications currently using H-13 shot sleeves, including squeeze casting, conventional die-casting, and semi-solid processing

\section{Capabilities}

Enhances thermal shock resistance through excellent resistance to aluminum soldering and lower thermal conductivity than $\mathrm{H}-13$ steel.

Reduces the tendency of premature metal solidification that impedes the flow of molten metal needed to feed the casting properly.

\section{Benefits}

\section{Cost Savings}

Reduces total process costs by $3 \%$.

\section{Productivity}

Extends sleeve life by 4 to 10 times over H-13 steel, reduces downtime as a result of fewer shot sleeve changeovers, and enables longer plunger tip life. 


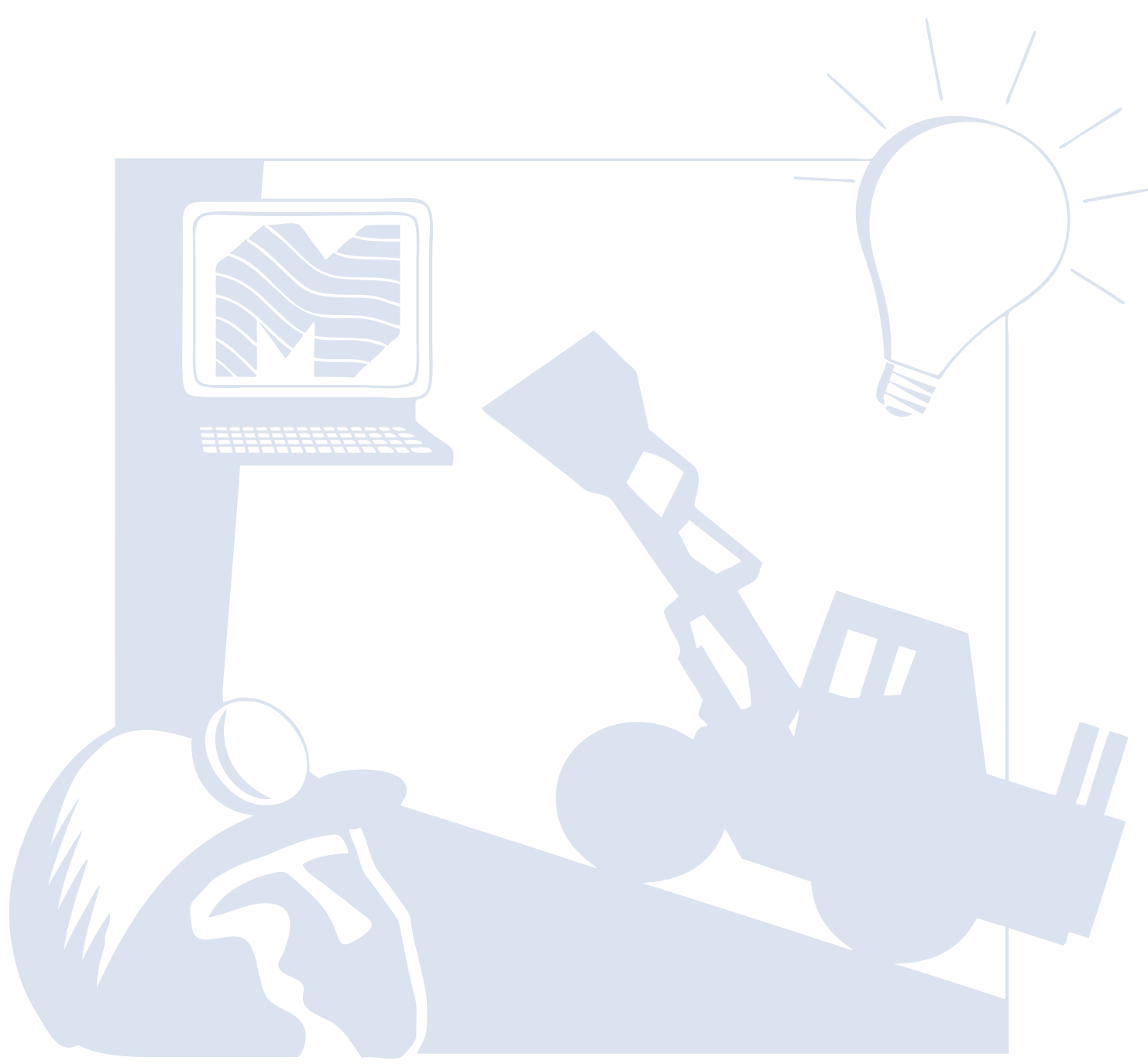




\section{Belt Vision Inspection System}

IMPACTS

\section{Low-Cost System Identifies Defects in Mining Conveyor Belts, Reducing Unscheduled Maintenance and Downtime}

Mining operations rely on conveyor belts to move mined material from the working face of the mine to a processing plant. When a conveyor belt breaks or stops for unscheduled maintenance, production generally halts because the belt is the only cost-effective way to carry material away from the mining unit and stockpiling is typically not available at the point of extraction. Longwall mining operations can produce revenue at $\$ 1000 /$ minute; a mainline belt break will stop production for a minimum of four hours, resulting in $\$ 240,000$ of lost revenue.

The Belt Vision system, developed by the Beitzel Corporation and Carnegie Mellon University's National Robotics Engineering Consortium, with support from AMO, uses high-speed line scanning cameras and a computer system to monitor mechanical splice deterioration in moving conveyer belts. The computer system, located on the belt or a remote desktop, digitizes and records continuous imaging of the belt and splices. Mine personnel can review live or historical images several times a day with minimal effort and take action before belt splices fail. The Belt Vision system helps eliminate costly repairs to conveyor belts, keeps production running, and helps reduce costs.

The Belt Vision system's hardware consists of cameras for imaging the belt, lighting for illuminating the belt, a computer for digitizing and analyzing the camera image, a flat panel touch screen display for a local user interface, and components for power distribution. Mines using the system can measure cost savings from avoided downtime, plan maintenance effectively, review the real time splice status of beltlines more easily, and plan action items for a splice.

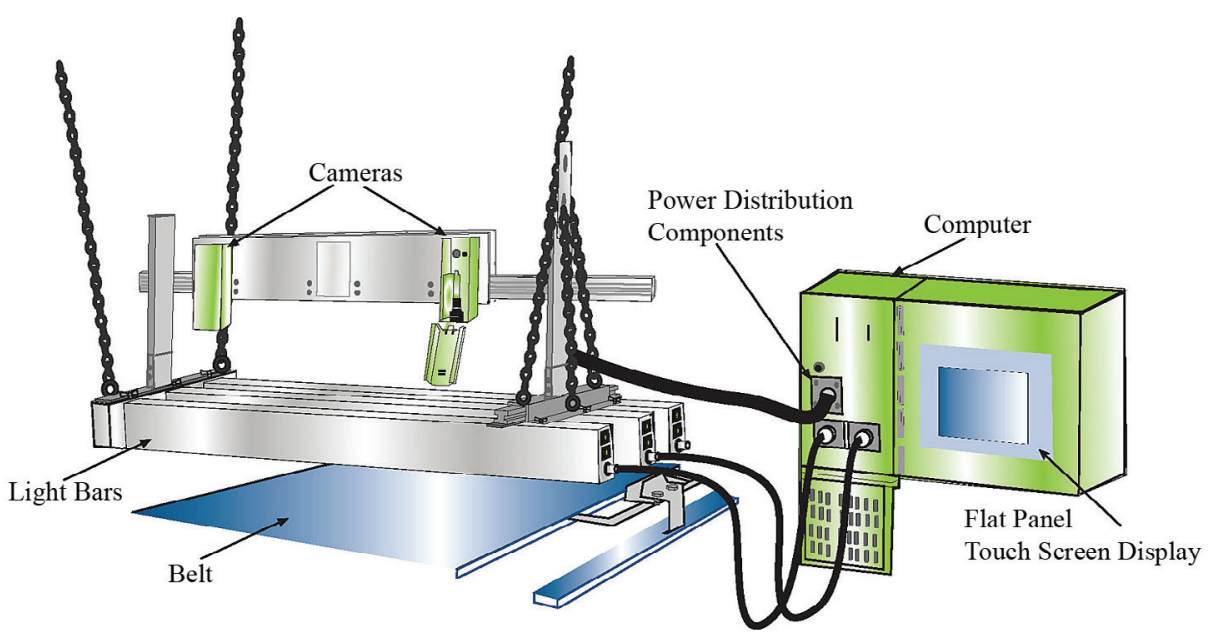

Components of Beitzel's Belt Vision System

\section{Overview}

$\checkmark$ Developed by the Beitzel Corporation (www.beitzelcorp.com)

Marketed by Pillar Innovations, LLC (www.pillarinnovations.com)

Commercialized in 2007, with more than 10 systems used in U.S. mines in 2010.

\section{Applications}

Can be used to provide images of the belt splices to mine personnel, who evaluate these images and take action before the belt splice fails

\section{Capabilities}

Allows mine personnel to monitor deterioration in operating conveyor belts in underground and surface mines.

Reduces deterioration in mining conveyance systems.

Provides a user interface for belt inspection at installation points using software that controls the cameras, collects encoder data, and captures images.

Stores images in a database and distributes them to a web server that can be accessed on a remote computer.

\section{Benefits}

\section{Cost Savings}

Helps eliminate costly repairs to conveyor belts by finding potential problem points before the belt fails.

\section{Productivity}

Keeps production running and eliminates the need for periodic manual shutdowns to inspect the belt's condition. 


\section{Digital Through-The-Earth Communication System}

IMPACTS

\section{System Provides Voice and Data Link for Surface to Subsurface Communications}

Traditional radio uses frequencies above $500 \mathrm{kHz}$ and does not penetrate any significant distance into typical underground rock masses. Hard-wired links such as phone lines, coaxial cables, mining car tracks, short-range radio links, or line-of-sight communication are commonly used, but these systems restrict the mobility of an underground worker and are typically more expensive to deploy from the surface to the underground site, if feasible at all. Lowfrequency magnetic waves penetrate deeply into the earth, but conventional low-frequency receivers are relatively insensitive to low-frequency magnetic waves.

Los Alamos National Laboratory, with assistance from AMO, has developed communication technology suitable for underground use. The Digital ThroughThe-Earth (TTE) Communication System, sold by Vital Alert Communication Inc., uses advanced digital communications techniques and very low frequency (VLF) transmission to provide reliable voice or data links through solid rock strata and other solid media. The TTE communication system can be used to provide communications links from either the surface to below ground or between two below-ground locations. The system can be used to provide realtime monitoring of equipment sensors or alarms and environmental or security conditions. The TTE system is compatible with a wide range of standard audio and data interfaces, allowing connection to a variety of external devices and networks. Applications include mines, subways, pipelines, and tunnels where obstructions like rock, concrete, and metal are common.

TTE can provide vital underground communications for the mining industry, urban first-responders, and others who frequently work underground. The system can increase underground mining production and safety through improved communications that can monitor orientation and position of individual miners and mining equipment. The TTE two-way communication system is provided with standard audio and data interfaces, allowing it to be connected to a wide variety of communications devices such as sensors and radio-frequency identification (RFID) tags. Vital Alert uses RFID readers to track assets, conducts sensor monitoring for various conditions such as heat and pressure, and allows emergency warning and disaster recovery communications.

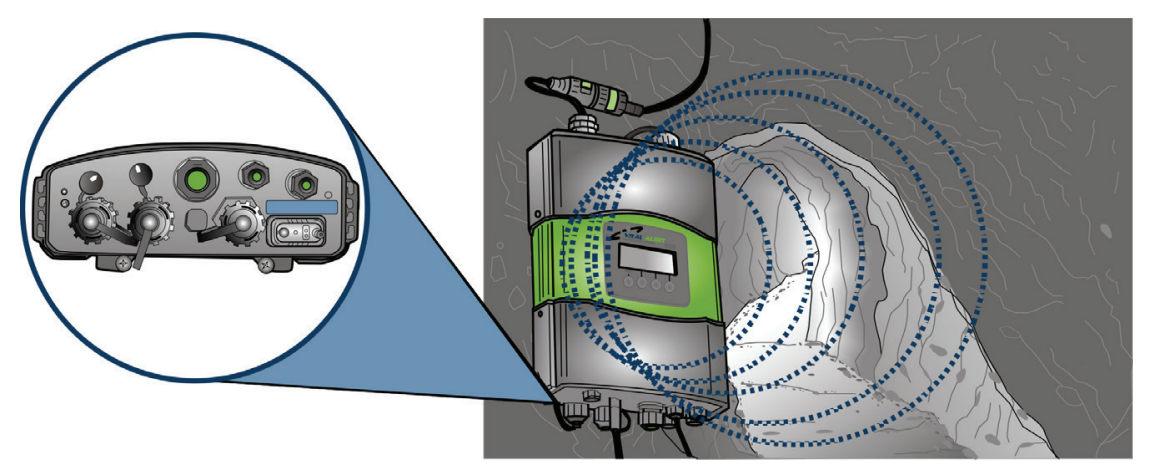

Vital Alert's Digital TTE Communications System

\section{Overview}

$\checkmark$ Developed by Los Alamos National Laboratory.

Commercialized in 2010

Distributed and marketed by Vital Alert Communication Inc.

(www.vitalalert.com)

\section{Applications}

Can be used in underground to surface communication applications, e.g. mining, subways, tunnels, garages, and other below ground sites. Can also be used between underground sites where cabling and lineof-sight wireless are not feasible.

\section{Capabilities}

- Provides portable communication for use in underground radio networks.

Provides portable two-way voice and data links through solid rock or concrete strata.

Provides short-range (1000 ft) audio for portable and wireless communications.

\section{Benefits}

\section{Cost Savings}

Offers a less expensive than alternatives, especially for temporary or migrating work sites (e.g., rescue shelters and emergency locations), and integrates with existing enduser handsets.

\section{Productivity}

Increases productivity within underground sites through a real-time, reliable communication link for requesting information, resources, and equipment without leaving the work site.

\section{Safety}

Increases underground worker safety by providing real time voice and data communications deep within mines, tunnels, and subways and by transmitting personnel tracker and gas sensor information to the surface. 


\section{Remote Sensing Cuts Coal and Other Minerals More Efficiently}

Future mining will be from deeper and thinner seams; profiles of deep coal seams reveal multiple levels of coal and sediment strata or layers. Some of these layers contain greater levels of pollutants than others, which results in more effort to clean the coal once it is removed from the ground and more emissions when it is burned for fuel.

With the aid of AMO, Stolar Horizon, Inc., developed the Horizon Sensor to distinguish between the different layers of coal. Miners can use this technology at remote locations to cut only the clean coal, resulting in a much more efficient overall process. The sensor, located inches from the cutting bits, is based on the physics principle of resonant microstrip patch antenna (RMPA). When it is in proximity of the rock-coal interface, the RMPA impedance varies depending on the thickness of uncut coal. The impedance is measured by the computer-controlled electronics and then is sent by radio waves to the mining machine. The worker at the machine can read the data via a graphical user interface, which displays a color-coded image of the coal being cut, and can direct the machine appropriately.

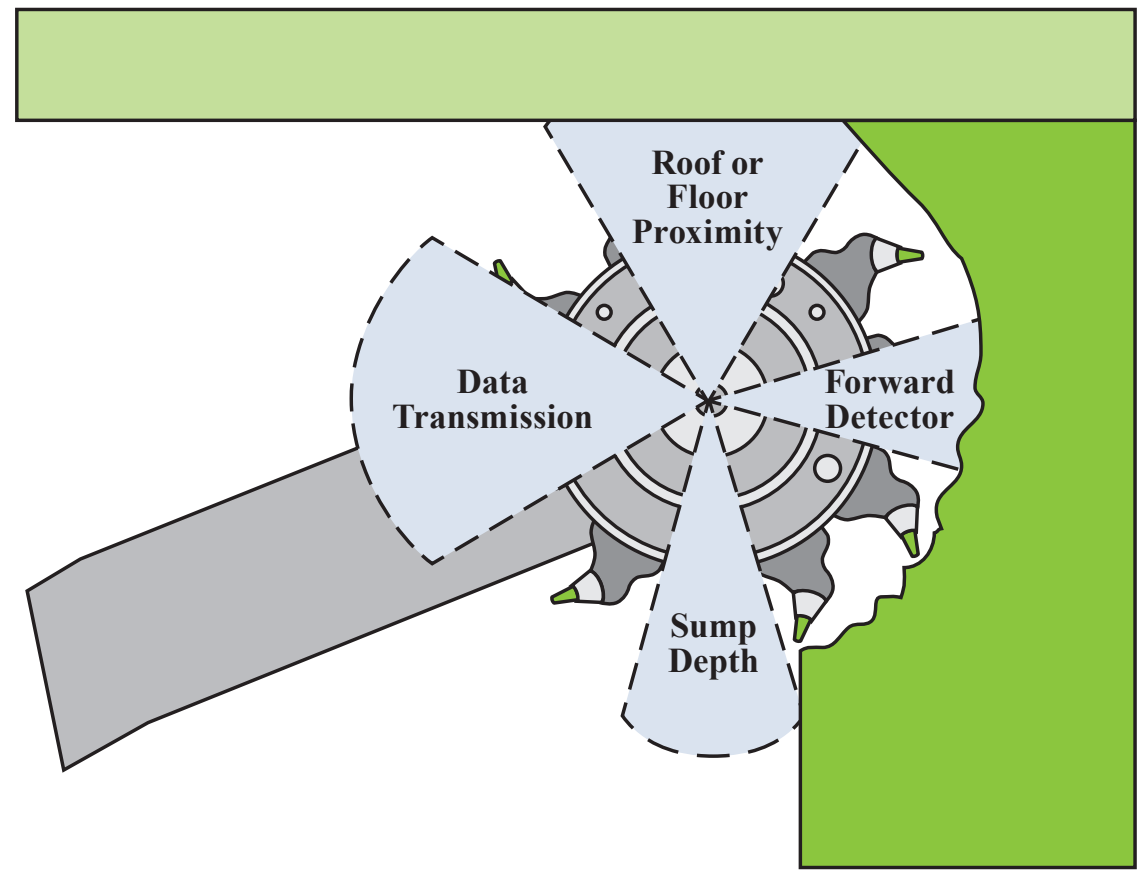

Functions Performed by the Horizon Sensor Mounted on the Cutting Edge of a Continuous Mining Machine

\section{Overview}

Developed by Stolar Horizon, Inc. (www.stolarhorizon.com)

Commercialized in 2002

Used in 10 different U.S. mines

\section{U.S. Energy Savings}

(Trillion Btu)

\begin{tabular}{|c|c|}
\hline Cumulative through $\mathbf{2 0 1 0}$ & $\mathbf{2 0 1 0}$ \\
\hline 0.251 & 0.000 \\
\hline
\end{tabular}

\section{U.S. Emissions Reductions}

(Thousand Tons, 2010)

\begin{tabular}{|c|c|c|c|}
\hline Particulates & SO $_{\mathrm{x}}$ & NO $_{\mathrm{x}}$ & Carbon \\
\hline 0.0 & 0.0 & 0.0 & 0.0 \\
\hline
\end{tabular}

\section{Applications}

Can be used in both underground and surface mining operations. Primarily used in the coal industry but is also used to mine trona and potash.

\section{Capabilities}

Improves the quality of coal extracted from mines.

Allows for deeper mining.

Is used remotely for miner safety.

\section{Benefits}

\section{Productivity}

Increases productivity by reducing or eliminating the cleaning step after extraction. Allows for deeper mining, resulting in more material obtained from one location and results in longer bit life keeping the cutting bits out of rock.

\section{Safety}

Allows workers to operate the machinery away from the hazards of cutting coal, including noise, dust and gases, and coal and rock splintering and outbursts. 


\section{Radio-Imaging Method (RIM ${ }^{\mathrm{TM}}$ ) Improves Mine Planning and Products}

Coal mining is becoming more difficult as machines must extract the coal from deeper, thinner, and more geologically complex coal beds. This type of mining also includes the need to reduce risk and costs.

To address these mining issues, Stolar Horizon, with support from AMO, redesigned and improved a technology developed twenty years ago. The Radio-Imaging Method (RIM) uses wireless synchronization between a transmitter and remote imaging receiver to detect geologic formations up to 1,800 feet ahead.

In layered sedimentary geology, a natural coal seam waveguide occurs because of the 10:1 contrast in conductivities between coal and surrounding materials. The electromagnetic wave sent by RIM through the rock reacts to these properties with a detectable change in magnitude because it is very sensitive to changes in the waveguide geology.

The information from RIM can be used to produce an image that maps out the dikes, faults, and paleochannels for more targeted mining. Areas of high signal loss represent geologic anomalies and can be imaged to high resolution using tomographic reconstructions similar to CAT scans.

\section{Benefits}

\section{Productivity and Profitability}

Reduces the risk of interrupting production because of adverse geologic conditions. When RIM is integrated into the planning of underground mining, forecasting production can improve 10 percent, which in turn increases profits.

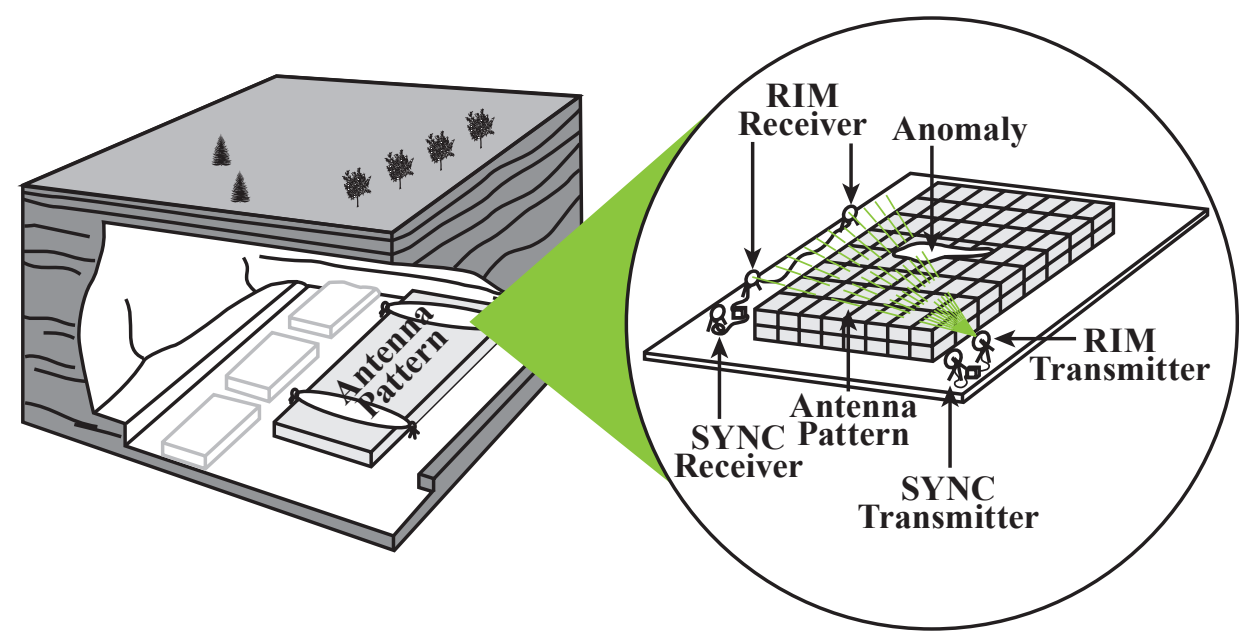

In-Mine RIM Detection System

\section{Overview}

Developed by Stolar Horizon, Inc. (www.stolarhorizon.com)

Commercialized in 2002

- Used in over 20 different mines in the United States through 2010

\section{U.S. Energy Savings}

(Trillion Btu)

\begin{tabular}{|c|c|}
\hline Cumulative through 2010 & $\mathbf{2 0 1 0}$ \\
\hline 7.14 & 0.000 \\
\hline
\end{tabular}

\section{U.S. Emissions Reductions}

(Thousand Tons, 2010)

\begin{tabular}{|c|c|c|c|}
\hline Particulates & SO $_{x}$ & NO $_{x}$ & Carbon \\
\hline 0.000 & 0.000 & 0.000 & 0.00 \\
\hline
\end{tabular}

\section{Applications}

Can be used in both underground and surface mining operations. Primarily used in the coal industry but has also been used for metalliferous mining, environmental research, and civil engineering applications. Also has been used to confirm the location of old and abandoned mine works and the integrity of barrier pillars.

\section{Capabilities}

Detects ore seams and geologic anomalies.

- Delineates ore bodies, monitors heap leaches, and detects voids in coal seams.

Detects voids and confirms geologic anomalies. 


\section{New Reagent System Improves Recovery, Reducing Energy Use and Air Emissions in the Mining Industry}

In the mining industry, flotation is a process that concentrates minerals from their ores prior to metal recovery. Current practice uses slurry $\mathrm{pHs}$ in excess of 10 , achieved by adding burnt lime $(\mathrm{CaO})$. However, lime production is an energy-intensive process that releases large quantities of carbon dioxide into the atmosphere. Furthermore, lime has several undesirable properties once it is in the flotation circuit. Lime produces scaling in piping and equipment, requiring the use of descaling reagents. It flocculates fine material and may occlude fine copper-sulfide particles. Lime increases the viscosity of the mineral slurry and tends to hinder aeration, slowing flotation kinetics. In addition, the calcium ion also has been shown to decrease recoveries of lead and molybdenum-sulfides and to reduce the recovery of free gold.

A new reagent system, developed by Versitech, Inc., with assistance from DOE's Inventions and Innovation Program, recovers copper minerals at a much lower $\mathrm{pH}$ than conventional reagents and avoids floating pyrite. The process reduces or even eliminates both the lime used in copper flotation and the accompanying carbon dioxide. The result is immediate cost, energy, and environmental savings along with improved recovery of copper and other minerals.

\section{Benefits}

\section{Cost Savings}

Reduces annual operating costs in a 50,000 ton per day plant by $\$ 1.3$ million.

\section{Productivity}

Improves mineral recovery in the mill

flotation processes and decreases

the amount of waste rock.

\section{Overview}

Developed by Versitech, Inc.

Commercialized in 2005

\section{U.S. Energy Savings}

(Trillion Btu)

\begin{tabular}{|c|c|}
\hline Cumulative through 2010 & $\mathbf{2 0 1 0}$ \\
\hline 5.84 & 0.973 \\
\hline
\end{tabular}

\section{U.S. Emissions Reductions}

(Thousand Tons, 2010)

\begin{tabular}{|c|c|c|c|}
\hline Particulates & SO $_{\mathrm{x}}$ & NO $_{\mathrm{x}}$ & Carbon \\
\hline 0.004 & 0.210 & 0.157 & 19.1 \\
\hline
\end{tabular}

\section{Applications}

Can be used in mining processes using a lime additive in the separation process

\section{Capabilities}

$\checkmark$ Reduces or eliminates lime and descaling reagents.

Increases the amount of copper recovered per ton of mined ore.

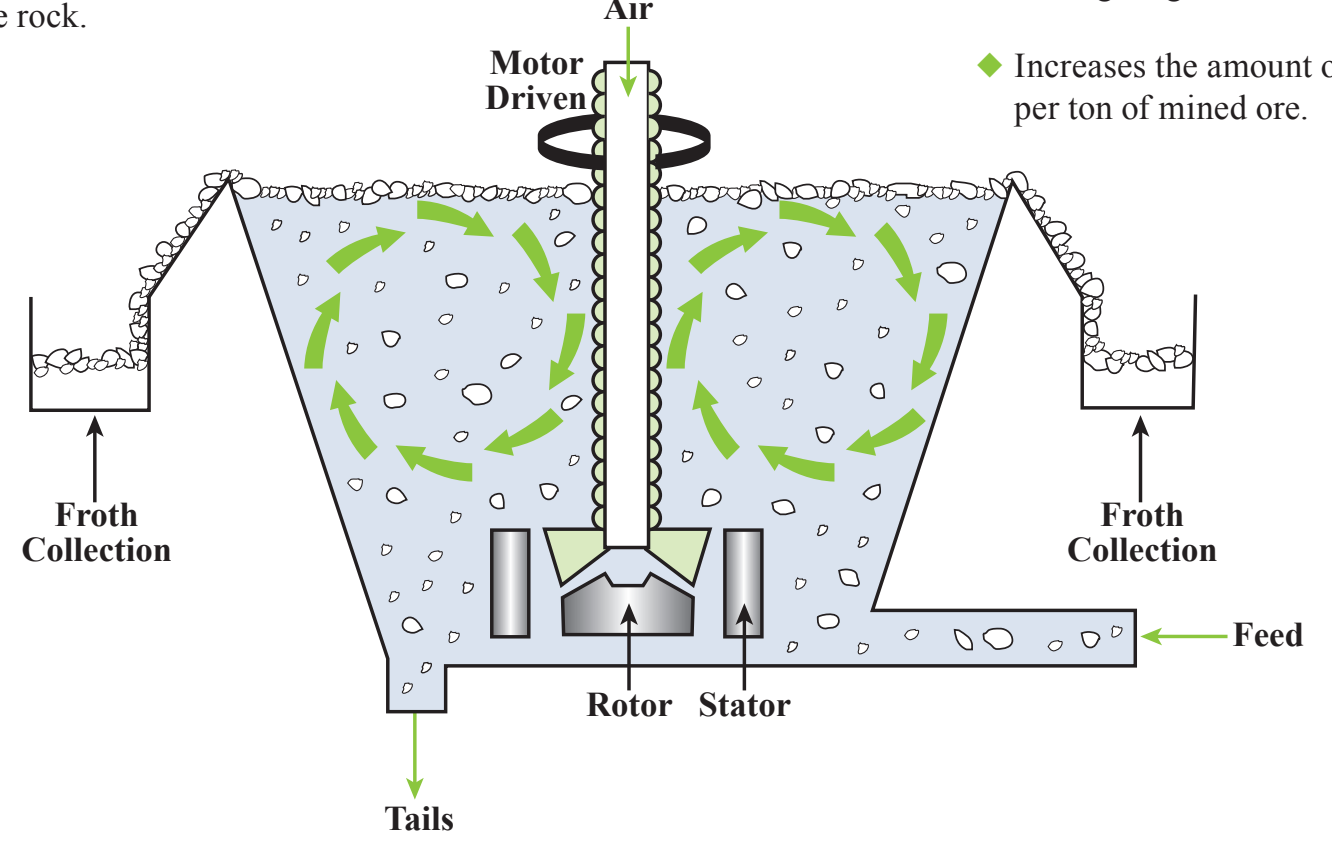

Copper Flotation Reagent System 
IMPACTS

Aluminum Bronze Alloys to Improve Furnace Component Life

A-52

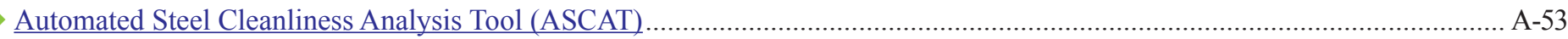

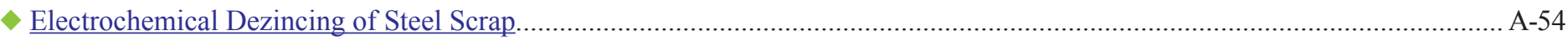

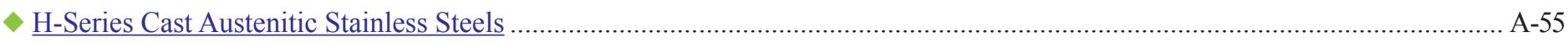

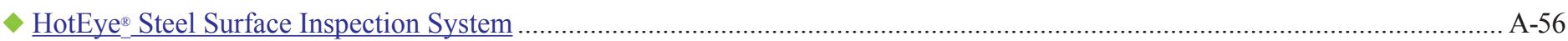

ITmk3: High-Quality Iron Nuggets Using a Rotary Hearth Furnace ........................................................................................ A-57

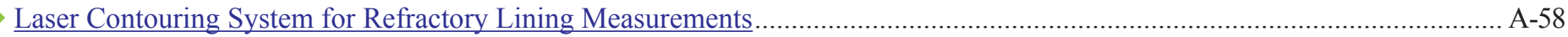

Life Improvement of Pot Hardware in Continuous Hot Dipping Processes......................................................................... A-59

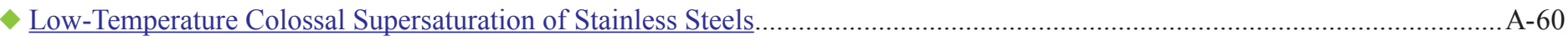

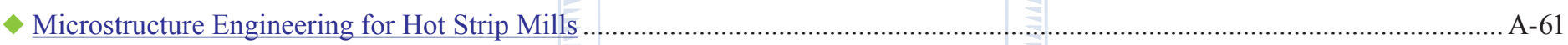

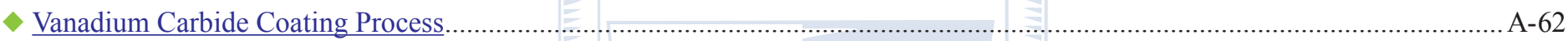

\begin{tabular}{l|l} 
DOE Advanced Manufacturing Office & A-51
\end{tabular} 
IMPACTS

\section{Improved System Increases Steelmaking Furnace Efficiency, Safety, and Productivity}

Hoods, roofs, and sidewall systems in basic oxygen furnaces (BOFs) and electric arc furnaces (EAFs) enable effluent gases in excess of $3000^{\circ} \mathrm{F}$ to be properly captured, cooled, and processed prior to delivery to the environmental control equipment. Traditionally, these carbon steel components have been considered standard "repair and replace" items by the industry. During the steelmaking process, large amounts of waste heat, particulates, and waste gases are generated in the furnace. The interaction of these waste streams with the carbon steel components of the furnace can result in metal failure from erosion, corrosion, and thermal stress cracking.

With AMO support, the Energy Industries of Ohio, Oak Ridge National Laboratory, Republic Engineered Products, and Amerifab, Inc., developed and installed several components of a BOF with aluminum bronze alloy material. Replacing carbon steel components with those manufactured from aluminum bronze alloy reduces metal failure, increases productivity, improves operating safety, and reduces energy consumption in the steel making process. Additionally, slag from the steel making process does not adhere to the aluminum bronze alloy, which eliminates all cleaning time, equipment damage, and operational difficulties associated with the accumulation of slag on the skirt.

\section{Environmental}

Reduces chance of air permit violations associated with improper skirt positioning in suppressed combustion furnaces, thereby optimizing primary capture of vessel emissions.

\section{Productivity}

Reduces maintenance on skirts, chutes, hoods, and other water-cooled steel furnace components. Environmental Control

$$
\text { and }
$$
Coolant (1)

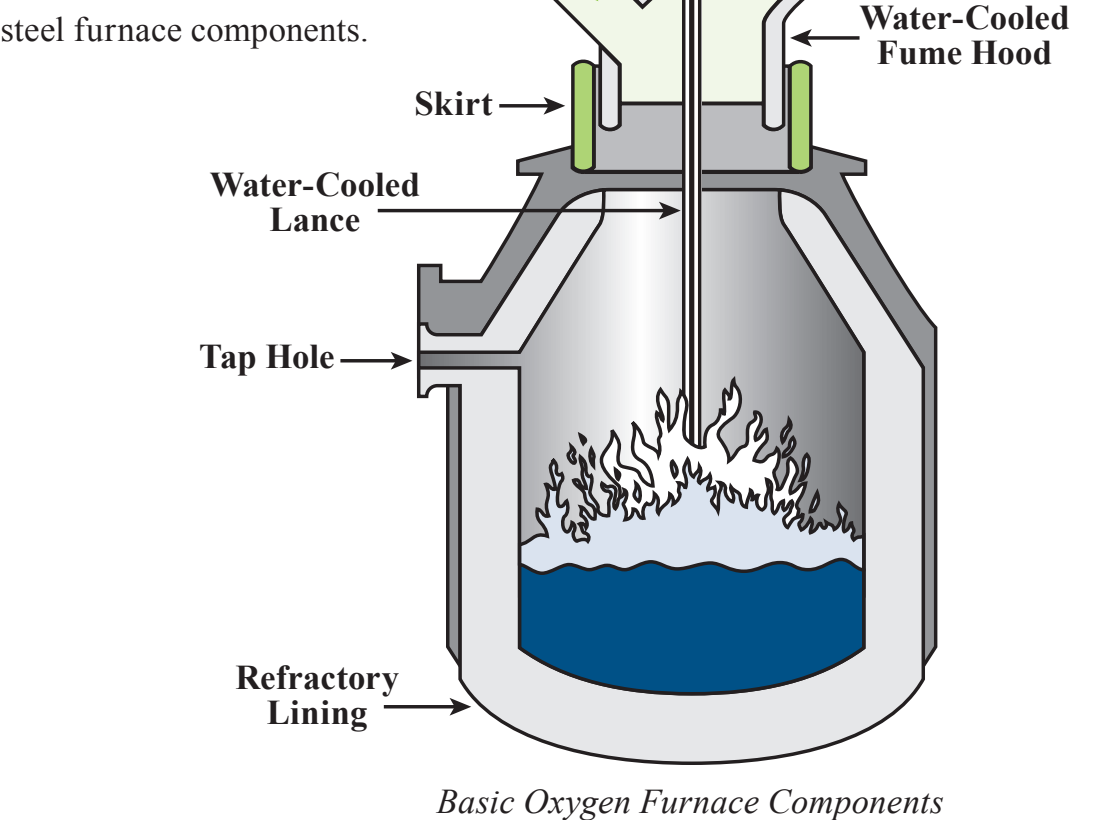

Fumes to

\section{Benefits}

\section{Overview}

Developed by AmeriFab, Inc., in 2002 (www.amerifabinc.com)

Commercialized in 2004

Components being used on eight furnaces in Ohio, Illinois, and Indiana

\section{U.S. Energy Savings}

(Trillion Btu)

\begin{tabular}{|c|c|}
\hline Cumulative through 2010 & $\mathbf{2 0 1 0}$ \\
\hline 0.075 & 0.006 \\
\hline
\end{tabular}

\section{U.S. Emissions Reductions}

(Thousand Tons, 2010)

\begin{tabular}{|c|c|c|c|}
\hline Particulates & SO $_{\mathrm{x}}$ & NO $_{\mathrm{x}}$ & Carbon \\
\hline 0.0 & 0.0 & 0.001 & 0.088 \\
\hline
\end{tabular}

\section{Applications}

Can be used for BOF/EAF hood, roof, and side wall systems that are exposed to aggressive heat, particulate, and corrosive waste gas from the steelmaking process

\section{Capabilities}

Provides superior performance compared with industry standard carbon, chromemoly, and weld overlayed steels.

Improves production throughput and limits energy consumption by reducing forced outages and downtime due to thermal fatigue, particulate erosion, and chemical corrosion.

Reduces issues related to slag buildup. 


\section{Automated Steel Cleanliness Analysis Tool (ASCAT)}

IMPACTS

\section{New Microscopy System Improves Steel Mill Performance and Allows Production of Higher Quality Steel}

Inclusions are particles of insoluble impurities formed during steelmaking and casting operations that are entrapped during solidification of metal. Characterizing inclusions is important because of an increasing demand for cleaner steels with low inclusion (defect) content. The composition, and therefore the properties, of the inclusions can be controlled through the chemistries of the metal and slag. Controlling the properties of the inclusions allows higher quality steel to be made. However, despite the major advances in inclusion control, no rapid and accurate method is available to determine the type, size, and number of inclusions present in steel samples.

RJ Lee Group, Inc., with AMO and steel industry support, has developed the ASCAT, an inclusion analysis tool based on a highly capable scanning electron microscope combined with specially developed hardware and software. The ASCAT provides a way to understand the complicated effects of inclusions in the steel making process and on the resulting properties of steel. The instrument uses an innovative state-of-the art silicon drift detector to acquire $\mathrm{x}$-ray composition information that is about an order of magnitude faster than previously used equipment. The ultimate goal is to develop the system so that analysis time is reduced to 10-15 minutes, which would enable the ASCAT to be used as an "on-line" analysis tool. The ASCAT uses "intelligent" software to emulate specialized knowledge that can be used to evaluate causes of clogging/erosion, slag treatment practices, castability, degasser circulation optimization, and slab disposition. One ASCAT system is now in use at the U.S. Steel Munhall Research and Technology Center.

\section{Benefits}

\section{Energy Savings}

Improves energy efficiency by minimizing steel rejection and subsequent remelting of the rejected steel.

\section{Productivity}

Increases production and reduces downgrades, with significant cost savings.

\section{Product Quality}

Allows for the increased production of high-grade steels and alloys.

\section{Overview}

$\checkmark$ Developed and being marketed by the RJ Lee Group, Inc. (www.rjlg.com)

Commercialized in 2007

Employed at the U. S. Steel Munhall Research and Technology Center

\section{Applications}

Can be used in the steel manufacturing process, including in castability of calcium treated steel; interstitial free degasser grade slag conditioning practice; tundish clogging and erosion minimization; degasser circulation and optimization; quality assessment/steel cleanliness; slab, billet, or bloom disposition; and alloy development.

\section{Capabilities}

Collects statistically meaningful data on inclusions in a steel sample and addresses a market need to monitor the effects of inclusions in the steel making process.

- Uses fast inclusion identification software with advanced statistical algorithms to automatically sort inclusions into meaningful classifications.

Provides intuitive graphics-based output, which can be integrated to plant control rooms and computer databases.

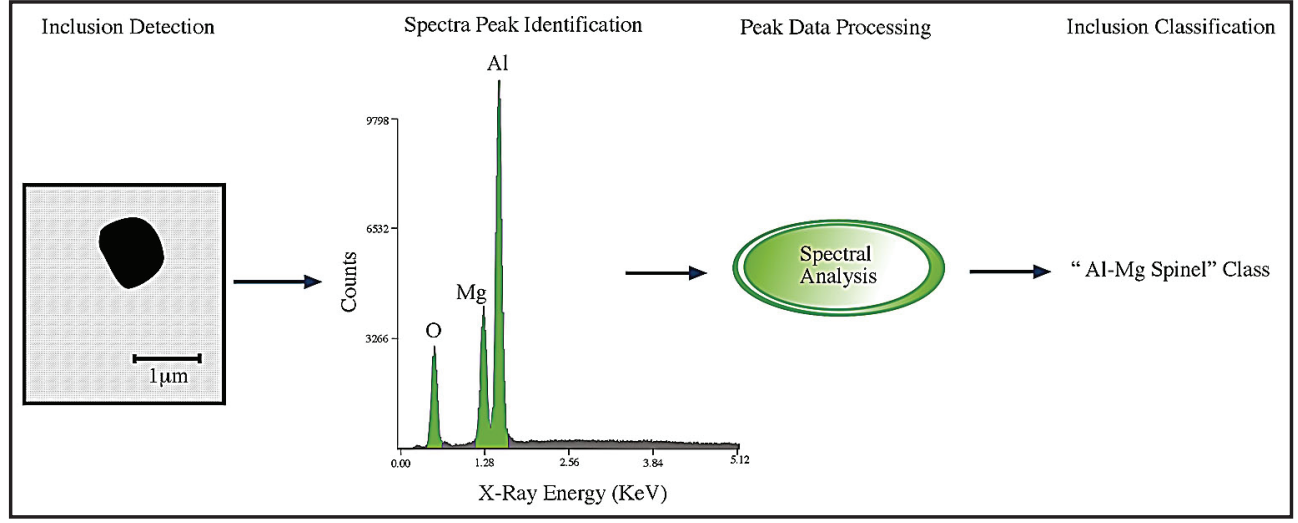

Classification of Steel Inclusions Using ASCAT 


\section{Electrochemical Dezincing of Steel Scrap}

\section{Dezincing of Steel Scrap Reduces Concerns of Recyclability and Waste Streams}

Half of the steel produced in the United States is derived from scrap. With zinc-coated prompt scrap increasing fivefold since 1980, steelmakers are feeling the effect of increased contaminant loads on their operations. The greatest concerns are the cost of treatment before disposal of waste dusts and the water associated with remelting zinc-coated scrap.

With financial assistance from AMO, Argonne National Laboratory with Metal Recovery Technologies, Inc., and CMA Corporation (formerly Meretec Corporation) have developed a technology that separates steel scrap into dezinced steel scrap and metallic zinc. The removal of zinc from steel scrap increases the recyclability of the underlying steel, decreases steelmaking dust, and decreases zinc in wastewater streams.

The process consists of two stages: dissolving the zinc coating from scrap in a hot, caustic solution and recovering the zinc from the solution electrolytically. Through a galvanic process, the zinc is removed from the steel and is in solution as sodium zincate ions rather than zinc dust. The steel is then rinsed with water and ready for reuse. Impurities are removed from the zinc solution, and then a voltage is applied in order to grow metallic zinc via an oxidationreduction reaction. All waste streams in this process are reused.

\section{Benefits}

\section{Pollution Reduction}

Decreases steelmaking dust released to the air as well as pollutants in wastewater streams. The process itself does not consume any chemicals, other than drag-out losses, and produces only a small amount of waste.

\section{Productivity}

Removing zinc prior to processing of scrap saves time and money in disposal of waste dusts and water. Without the zinc, this high-quality scrap does not require extra handling, blending, or sorting for remelting in steelmaking furnaces.

\section{Overview}

Developed by Argonne National Laboratory

Commercialized in 2003 by Meretec Corporation (now CMA Corporation) (www.cmacorp.net)

Steel scrap sold to several dealers, steelmakers, and foundries after dezincing

\section{U.S. Energy Savings} (Trillion Btu)

\begin{tabular}{|c|c|}
\hline Cumulative through $\mathbf{2 0 1 0}$ & $\mathbf{2 0 1 0}$ \\
\hline 0.407 & 0.036 \\
\hline
\end{tabular}

\section{U.S. Emissions Reductions}

(Thousand Tons, 2010)

\begin{tabular}{|c|c|c|c|}
\hline Particulates & SO $_{x}$ & NO $_{x}$ & Carbon \\
\hline 0.000 & 0.023 & 0.010 & 1.02 \\
\hline
\end{tabular}

\section{Applications}

Can be used primarily in the steel and foundry industries

\section{Capabilities}

Improves quality of steel scrap that steelmakers can use.

$\checkmark$ Produces $99.8 \%$ pure zinc for resale.

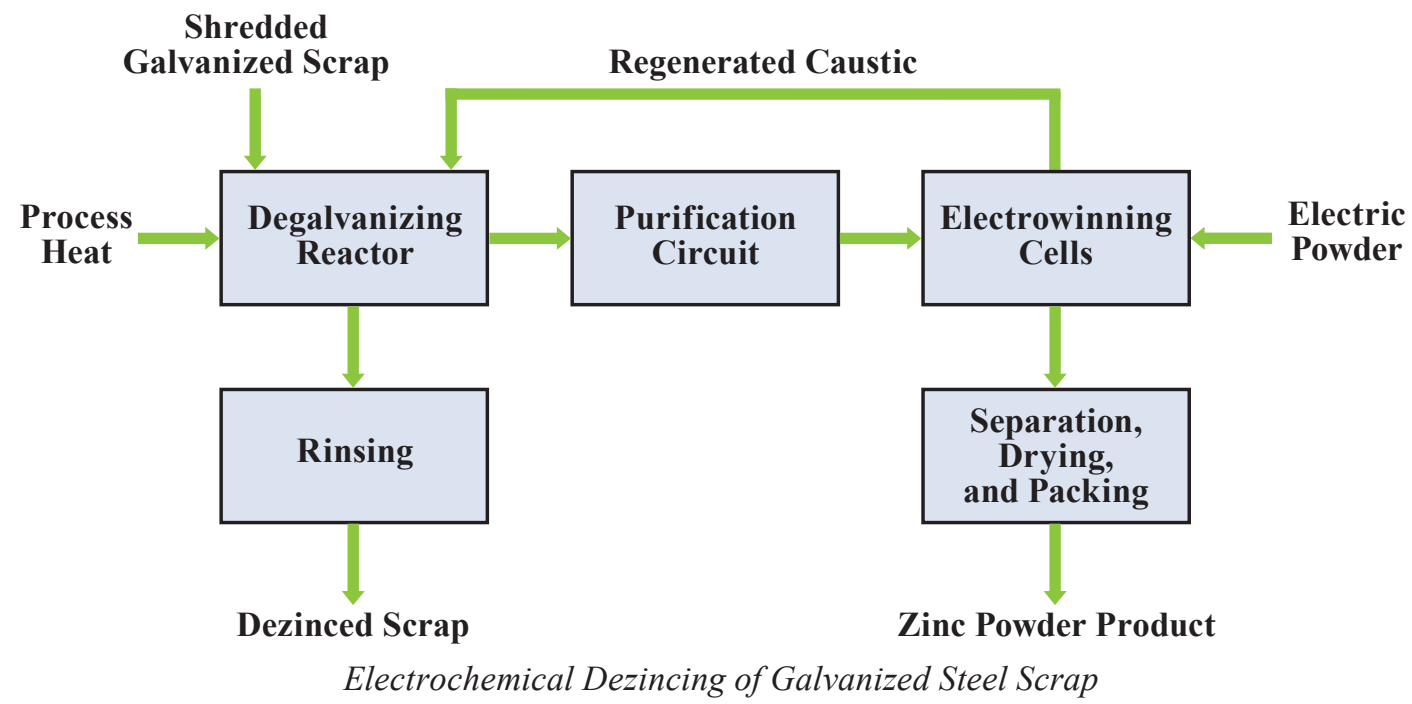




\section{Scientific Design Methodology Used to Develop Stronger Stainless Steels for High-Temperature Applications}

Cast H-Series austenitic steels are used extensively in several industries for a broad range of high-temperature applications. The H-Series stainless steels have evolved over many years of complex alloy development that added various alloying elements by trial-and-error methods. The native microstructure established in these austenitic alloys consists of dendritic structures of austenite matrix with finer dispersions of carbides. With the support of a grant from AMO, a combination of thermodynamic modeling, developed at the Oak Ridge National Laboratory, micro-structural characterization, and mechanical property measurements was used to derive composition-structure-property relationships for this class of alloys. With these relationships, Duraloy Technologies, Inc., successfully developed new alloy compositions with improved properties at higher temperatures.

The combined approach of micro-characterization of phases and computational phase prediction permits rapid improvement of a current class of alloy compositions and allows alloys to be customized across steel grades for specific applications. The results of this work increased the high-temperature creep strength and the upper-use temperature range of $\mathrm{H}$-Series stainless steel material, including HP and HK alloys. Application of these new products is best suited to radiant burner tubes for annealing furnaces in the steel heat treating industry, tubes for the chemical industry, and transfer rolls and kilns for various high-temperature furnace operations. Other applications in other industries would apply where high-temperature operations are required.

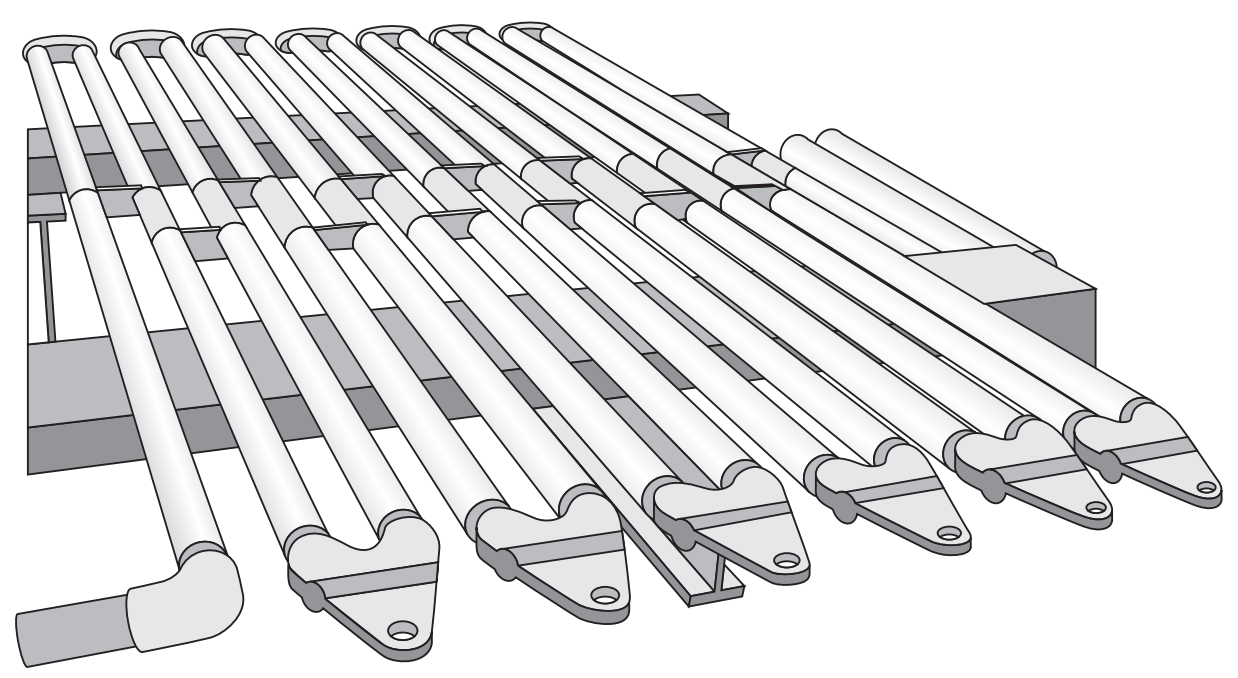

Chemical Processing Coils Composed of H-Series Stainless Steel

\section{Overview}

$\checkmark$ Developed by Duraloy Technologies, Inc. (www.duraloy.com)

Commercialized in 2003

$\checkmark$ As of 2010, 183 U.S. applications were operating in 8 processing plants

\section{Applications}

Can be used in the chemicals, forest products, heat treating, petrochemical, and steel industries, including burner tubes for heat-treating furnaces, transfer rolls for heat-treating furnaces, coiler drums and rolls for Steckel mills, and tubes for ethylene cracking and other processes

\section{Capabilities}

$\checkmark$ Offers superior toughness over standard H-series steel.

Applies to multiple heating processes.

\section{Benefits}

\section{Energy Savings}

Could save an estimated 35 trillion Btu/year and $\$ 185 \mathrm{M} /$ year by 2020 .

\section{Productivity}

Improved process efficiencies from higher operating temperatures reduces downtime of the production equipment, reduces replacement of components, and increases productivity with reduced rejection. 


\section{Unique Measurement System Enhances Process Control, Cuts Scrap by Half, and Saves Energy}

A new inspection system, the HotEye ${ }^{\circledR}$ Rolled Steel Bar (RSB) System, has been developed and demonstrated by OG Technologies (OGT) Inc., with the help of both a NICE ${ }^{3}$ grant and a project under the ITP Sensors and Automation Program. The HotEye RSB System is based on OGT's HotEye System and integrates it with a dynamic control plan (DCP) for hot steel processes. The HotEye System accurately and reliably measures a part's dimensions and detects its surface features, including defects, while it is still red hot, i.e., at temperatures of up to $1550^{\circ} \mathrm{C}$. Current measurement systems cannot be used until the parts cool down, which results in higher scrap rates once defects are detected. The DCP classifies some defects from production and identifies their root causes and corrective actions. The DCP's effectiveness depends on instruments that can detect quantitative quality information in real-time in a hostile operating environment. The HotEye RSB System provides real-time process control to increase yields $2.5 \%$ in continuous casting and hot rolling steel mills, saving energy, improving quality, and increasing productivity.

The HotEye RSB System consists of three HotEye imaging sensors, four powerful PCs, modulating devices for the lighting system, proprietary image processing software, the software version of the steel rolling DCP, and an enclosure to protect the hardware and software from the effects of the harsh operating environment in a steel mill. The HotEye RSB System will automatically (1) inspect $100 \%$ of the surface of the product in-line; (2) identify defects as small as $0.025 \mathrm{~mm}$; (3) analyze and record the size, nature, and location of the defects; (4) measure $100 \%$ of the dimensions of the product; and (5) generate process correction advice based on the DCP, while the product is at a temperature up to $1550^{\circ} \mathrm{C}$ and moving at a speed up to $100 \mathrm{~m} / \mathrm{second}$.

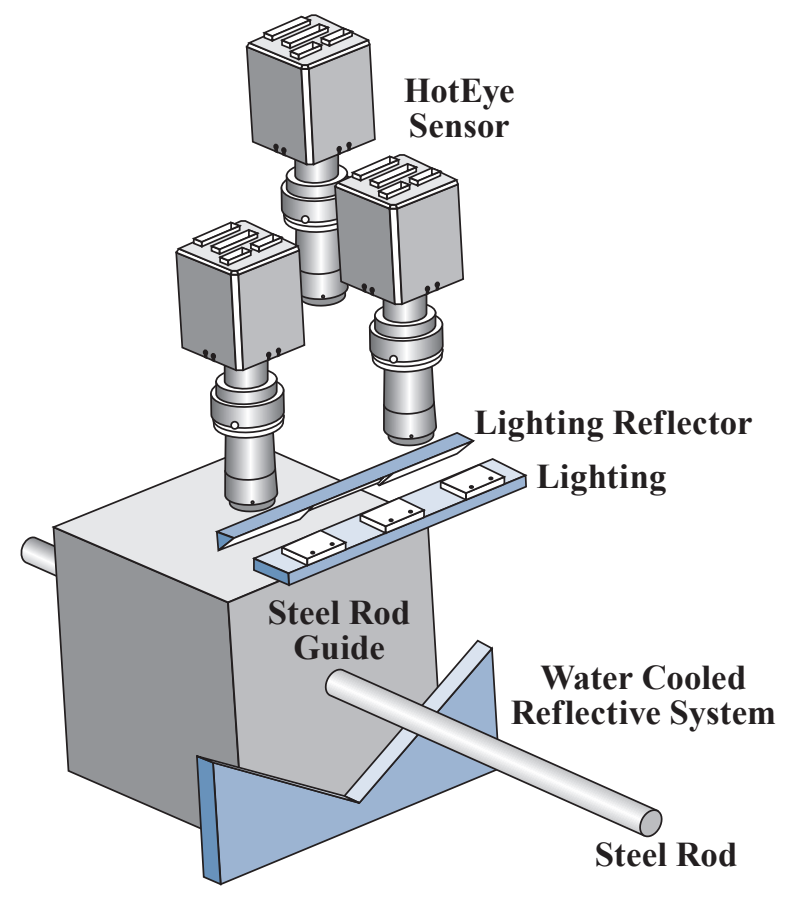

Design of the HotEye RSB Sensor System

\section{Overview}

- Developed by OG Technologies, Inc. (www.ogtechnologies.com)

Commercialized in 2004

Installed in four U.S. and multiple foreign steel mills in 2010

\section{U.S. Energy Savings}

(Trillion Btu)

\begin{tabular}{|c|c|}
\hline Cumulative through 2010 & $\mathbf{2 0 1 0}$ \\
\hline 9.82 & 1.53 \\
\hline
\end{tabular}

\section{U.S. Emissions Reductions}

(Thousand Tons, 2010)

\begin{tabular}{|c|c|c|c|}
\hline Particulates & SO $_{x}$ & NO $_{x}$ & Carbon \\
\hline 0.0 & 0.0 & 0.179 & 24.3 \\
\hline
\end{tabular}

\section{Applications}

Can be used in steel hot rolling mills and continued casting processes

\section{Capabilities}

Inspects $100 \%$ of product surface on-line.

Identifies defects as small as $0.025 \mathrm{~mm}$.

Performs inspections while the product is at temperatures of up to $1550^{\circ} \mathrm{C}$ and moving at $100 \mathrm{~m} / \mathrm{second}$.

\section{Benefits}

\section{Employee Safety}

Allows the inspection of parts at temperatures of up to $1550^{\circ} \mathrm{C}$ remotely, reducing employee burns.

\section{Profitability and Productivity}

Detects and identifies production flaws quickly and reduces the scrap rate from the process by $50 \%$. 


\section{ITmk3: High-Quality Iron Nuggets Using a Rotary Hearth Furnace}

IMPACTS

\section{Steelmaking Process with a One-step Furnace Operation Uses Less Energy}

The industrial sector consumes $30 \%$ of all U.S. energy consumption, of which about half (1.5 quad) is consumed by iron and steel production. Despite steadily increasing demand the iron and steel industry has reduced $\mathrm{CO}_{2}$ emissions and lowered energy consumption by $30 \%$ since the early 1990 's. To remain competitive, steelmakers must apply new technologies to produce high-quality steel at lower cost. Energy is one of the main cost components in iron and steelmaking operations. To produce steel, facilities use one of two processes: the basic oxygen furnace (BOF) or the electric arc furnace (EAF). In producing steel, both BOFs and EAFs require iron or iron-bearing materials; high-quality steel requires premium quality iron. Of the energy required to produce steel, $70 \%$ is consumed in producing iron.

Messabi Nugget, LLC, and industry partners, with assistance from AMO, has successfully begun producing iron nuggets using a new energy-efficient process for making hig- quality iron, the third-generation iron-making technology process or ITmk $3^{\circledR}$. The ITmk3 process uses an agglomerate of iron ore and pulverized coal, which undergoes reduction, melting, and slag removal in only 10 minutes. A first-generation or conventional blast furnace requires 8 hours of reduction time and higher temperature and uses more expensive coking coal instead of steaming coal. The ITmk3 process takes advantage of the separation of iron ore from slag at lower temperature, around $1400^{\circ} \mathrm{C}$, versus typical blast furnace temperature, around $2000^{\circ} \mathrm{C}$. The process has improved energy efficiency and emits $20 \%$ less $\mathrm{CO}_{2}$ and produces high purity iron nuggets ( $96 \%$ - $97 \%$ pure).

In 2009, Mesabi Nugget finished construction of the first plant to use the ITmk3 technology in Hoyt Lakes, MN. The plant began producing iron nuggets in January 2010 and has the capacity to produce 500,000 tonnes per year. The nuggets have been used by Mesabi's industry partner, Steel Dynamics, for producing various steel products, including flat-rolled steel, bar stock products, and rail. Mesabi is planning to reopen a nearby iron-ore mine to reduce material costs; Mesabi currently must purchase iron-ore from other mining operations. Material cost reduction is a key component to Mesabi's long-term success.

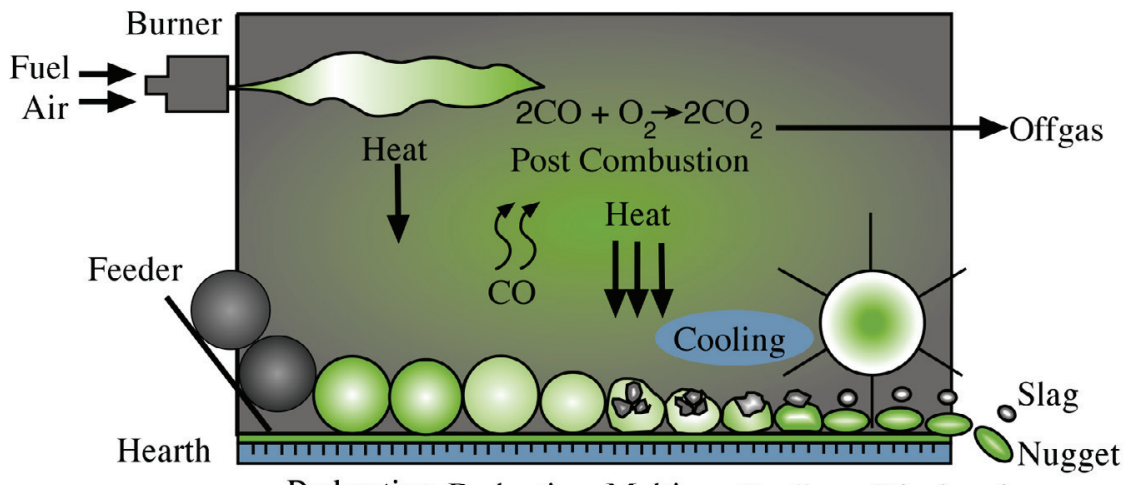

Preheating Reduction Melting Cooling Discharging

Mesabi Nugget ITmk3 Process Flow

\section{Overview}

- Developed and commercialized by Mesabi Nugget, LLC, in 2010

(www.mesabinuggetmn.com).

ITmk3 technology available from Midrex Technologies, Inc., a subsidiary of Kobe Steel Ltd. (www.midrex.com/).

Operating one plant in the United States.

\section{U.S. Energy Savings}

(Trillion Btu)

Cumulative through 2010

0.329

2010

0.329

\section{U.S. Emissions Reductions}

(Thousand Tons, 2010)

\begin{tabular}{|c|c|c|c|}
\hline Particulates & SO $_{\mathrm{x}}$ & NO $_{\mathrm{x}}$ & Carbon \\
\hline 0.000 & 0.000 & 0.000 & 0.000 \\
\hline
\end{tabular}

Applications

Can be used for processing iron ore into pig iron nuggets for steel making.

\section{Capabilities}

Produces high-quality pig iron nuggets (96\% - 97\% pure) using iron oxide fines of most grades.

Achieves one-step processing in 1/60th of the time compared with conventional blast furnaces.

Allows processing at lower temperatures and burns less costly fuels, including steaming coal.

\section{Benefits}

\section{Energy Savings}

Reduces energy consumption by over $22 \%$, $\sim 5$ Btu per tonne of iron nuggets compared with a conventional blast furnace.

\section{Environment}

Improves energy usage and processing efficiency, which reduces emissions by up to $20 \%$ compared with conventional blast furnaces. 


\section{Laser Contouring System for Refractory Lining Measurements}

IMPACTS

\section{Optical Sensor Provides Real-Time Process Control, Resulting in Reduced Costs and Improved Performance}

A suite of new robust sensors and control systems for base oxygen furnace (BOF) and molten steel transfer ladles makes possible dynamic process control and rapid assessment of the effectiveness of operations. With AMO support, Process Metrix and the American Iron and Steel Institute developed the Laser Contouring System (LCS) now being sold by Process Metrix. The LCS is a high-speed, laser-based technology that measures the refractory lining thickness of furnace vessels for manufacturing steel, copper, and aluminum. With a laser scan rate of over 8,000 points per second, the LCS provides exceptionally detailed contour resolution and accurate bath height determination. Moreover, measurement time ranges between 1 to 6 minutes or ten times faster than prior units. Quick on-line feedback eliminates downtime costs due to off-line inspection and unnecessary relining, increases equipment life, and ensures operational safety.

Contour maps of both vessel wall and bottom clearly illustrate lining thickness over the entire vessel interior. Thickness values are displayed both numerically and by color key, immediately revealing regions that might require attention. The report generator automatically prints all of the views and screens needed by the mill to make informed process decisions. New software releases, that include upgrades and feature requests from customers, are made twice annually.

Two principle objectives are emphasized in the mobile platform design: speed and simplicity. Fast measurement times are achieved using a laserbased navigation system. Working from three reflectors mounted on the building structure behind the cart, this system automatically measures the cart position relative to the $\mathrm{BOF}$ and reports position information directly to the LCS computer. The navigation system is completely automatic and updates 8 times per second. Process Metrix has also implemented a radio frequency (RF) link that continuously broadcasts the vessel tilt to a receiver located in the cart. The RF-link incorporates 2.4 gigahertz spread-spectrum technology for interference-free transmission. During the measurement, the RF receiver automatically reports the vessel tilt to the LCS computer. Together, the laser navigation system and RF link enable fast, error-free measurement of the vessel lining thickness. Single measurements can be made in 20-30 seconds. An entire map of the vessel interior, consisting of 4-6 measurements and 500,000+ data points, can be completed in less than 6 minutes.

Fixed position installation is available for converter and ladle applications. This type of installation, coupled with the high measurement speed of the LCS, enables measurements after every heat with little or no loss of process time.

\section{Overview}

$\checkmark$ Commercialized in 2001 by Process Metrix

(www.processmetrix.com)

- Nine units in operation at seven U.S. installations in 2010 and additional units in use overseas

\section{Applications}

Can be used for rapid measurements of vessel wall and bottom lining thickness in steel converters, ladles, electric arc furnaces, copper smelters - in short, any refractory-lined vessel that has line-of-sight optical access

\section{Capabilities}

$\checkmark$ Is available as a mobile platform or a fixed position installation.

Maps the entire vessel interior in less than 6 minutes.

Provides detailed contour resolution and vessel lining thickness with over 500,000 individual contour measurements.

\section{Benefits}

\section{Cost Savings}

Saves up to $\$ 1$ million per year for manufacturers.

\section{Energy Savings}

Reduces energy usage via rapid real-time measurements for process control and with no loss of process time.

\section{Productivity}

Reduces maintenance on BOF refractory via automated furnace inspection. 


\section{Life Improvement of Pot Hardware in Continuous Hot Dipping Processes}

\section{Improved Galvanizing Bath Hardware and Materials Result in Energy and Cost Savings}

Flat-rolled surface-coated steel, including galvanized and aluminized sheet, is one of the fastest growing, most profitable sectors of the U.S. steel industry. Coating steel sheets by continuous hot dipping in a molten metal bath of zinc and aluminum is an efficient and economical method of protecting most steel sheet compositions from corrosion. However, corrosion, wear, and dross buildup on bath hardware such as bearings, sink rolls, and stabilizing rolls can lead to frequent downtime of production lines and can significantly reduce energy efficiency.

West Virginia University, with support from AMO and numerous private sectors partners, developed a new generation of bath hardware components. The components are made with several entirely new materials, such as an iron-aluminum-cobalt alloy, which provide 10 times the corrosion and wear resistance in the $\mathrm{Zn} / \mathrm{Al}$ bath compared with baseline materials. The advanced bath hardware materials provide longer life in the corrosive galvanizing bath by minimizing crystal growth, corrosion attack, and bearing surface degradation, all of which can lead to surface impurities on the final product, lowering the market value of the finished galvanized steel.

Delivering new roll and bearing designs, along with bath hardware materials developed with these new alloys, has extended component life by an order of magnitude, while remaining cost effective at only $10 \%$ to $15 \%$ higher than comparable components.

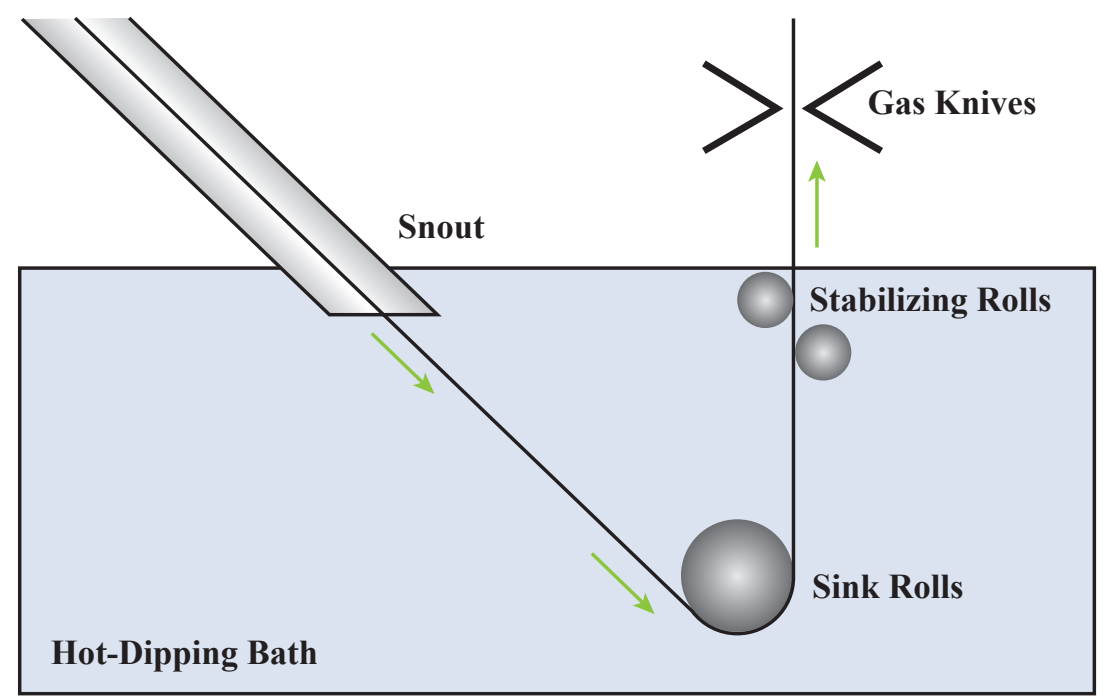

Steel Sheet Manufacturing Process

\section{Overview}

$\checkmark$ Developed by West Virginia University in partnership with numerous steel manufacturing support companies

$\checkmark$ Commercialized in 2006 by Pyrotek, Inc. (www.pyrotek-inc.com)

\section{Applications}

Can be used to improve the life of pot hardware, which applies to the 57 continuous hot dipping process lines in the U.S.

\section{Capabilities}

Provides up to 10 times the corrosion and wear resistance compared with baseline materials.

Reduces the potential for bearing instability due to improved hardware alloys.

Improves surface characteristics of sheet steel from reduced dross formation.

\section{Benefits}

\section{Cost Savings}

Reduces waste and process scrap volume by limiting the frequency of downtime in the galvanizing process.

\section{Environmental}

Reduces emissions from sheet steel manufacturing plants.

\section{Productivity}

Limits the formation of surface imperfections on the finished sheet steel. 


\section{Low-Temperature Colossal Supersaturation of Stainless Steels}

\section{New Process Improves Hardness and Corrosion Resistance of Stainless Steel Components}

Austenitic stainless steels in the 300 Series are the primary materials used for a very broad range of applications when corrosion resistance is needed in aqueous solutions at ambient temperatures. While austenitic stainless steels have excellent corrosion-resistance properties, they possess low hardness values and cannot be heat-treated to increase their hardness. In materials science, it has been generally understood that carbon atoms cannot be introduced into austenitic stainless steel through heat treatment without the formation of chromium carbides, which compromise the corrosion-resistant properties of the alloy. Until now, hardness and corrosion resistance have been typically regarded as tradeoffs.

With assistance from AMO and the Ohio Department of Development, Swagelok Company contributed to research using its patented heat treating process known as low-temperature colossal supersaturation (LTCSS). This process dramatically improves surface hardness without losing corrosion resistance. By contrast, the traditional methods of heat treating stainless steel promote the formation of chromium carbides that compromise the corrosionresistant properties of the alloy. LTCSS introduces carbon atoms into the austenitic, or face-centered-cubic, crystal structure without the formation of chromium carbides. Testing has shown the carbon absorption to be about 80,000 times greater than thermodynamics and kinetics would suggest being possible. At the same time, there is evidence of improved corrosion resistance, wear resistance, and increased fatigue strength.

Swagelok Company launched their LTCSS business by forming a subsidiary, Swagelok Technology Services Co., to treat steel parts supplied by their customers. Swagelok is pursuing individual licensing of the technology.

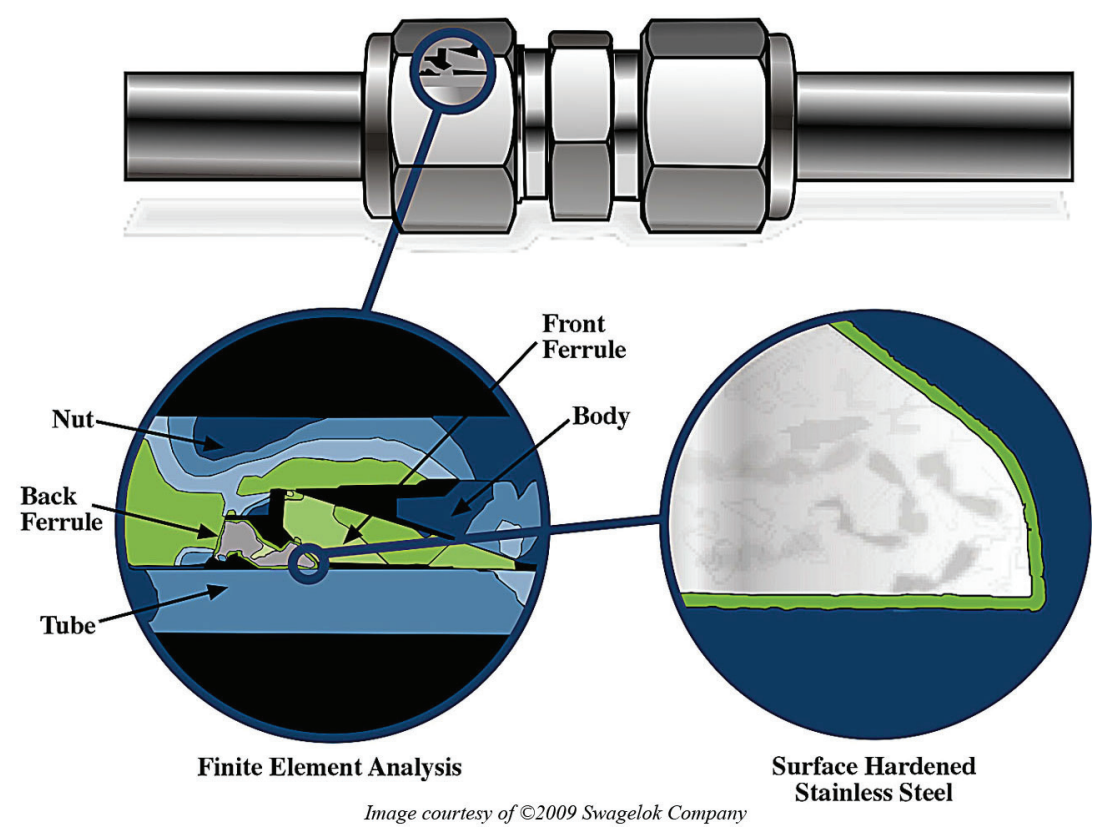

An Application of Swagelok's LTCSS to Tube Fittings

\section{Overview}

Developed by Swagelok Company (www.swagelok.com)

Research performed in conjunction with Case Western University, Energy Industries of Ohio, Oak Ridge National Laboratory, and Spirax Sarco, Inc.

Used by Swagelok since 1999 and commercialized to the public in 2007

Used by the U.S. Naval Research Lab for treating stainless steel components

\section{Applications}

Can be used anywhere stainless steel parts are used, e.g., pump and circulation equipment, industrial components, and medical devices

\section{Capabilities}

Imparts higher hardness to stainless steel components.

Provides nickel-like corrosion resistance for a part that will cost less than an expensive high-nickel alloy.

Allows sheet metal to be treated and still retain its ductility.

Treats finished components without distortion or change of dimension.

Avoids carbide formation.

\section{Benefits}

\section{Durability}

Increases the corrosion/erosion resistance of stainless steel components to levels previously attainable only by expensive high-nickel or high-molybdenum alloys.

\section{Product Quality}

Allows ordinary stainless steels to adopt performance characteristics of more expensive alloys. 


\section{Innovative Model Provides a More Detailed Insight into Mill Operations to Reduce Costs and Improve Quality}

Many hot rolled products must achieve strict strength and toughness requirements, making control of the microstructure critical. This causes these products to be difficult to make and requires many costly full production trials before the range of both chemical composition and hot strip mill processing parameters can be defined. The Hot Strip Mill Model (HSMM) is an invaluable tool to cost effectively assist in determining the optimum processing conditions to achieve the desired product properties. This model runs in an offline mode, thereby saving many tons of wasted product that might be scrapped in trying to identify the proper mill set-up.

The HSMM also provides additional savings in grade consolidation, control optimization for new grades, and improvement of mechanical and microstructure properties for downstream processing. The model can consolidate grades by allowing the user to develop different processing setups for the same steel grade that will then achieve the various mechanical properties needed for the different finished products. The HSMM can improve on-line control optimization for new grades by using what is learned from the HSMM to help set up the on-line models so they learn faster how to optimize the processing of the new grade. And finally, processing the steel to achieve the optimum or specific microstructure attributes further improves processing of the product in downstream operations.

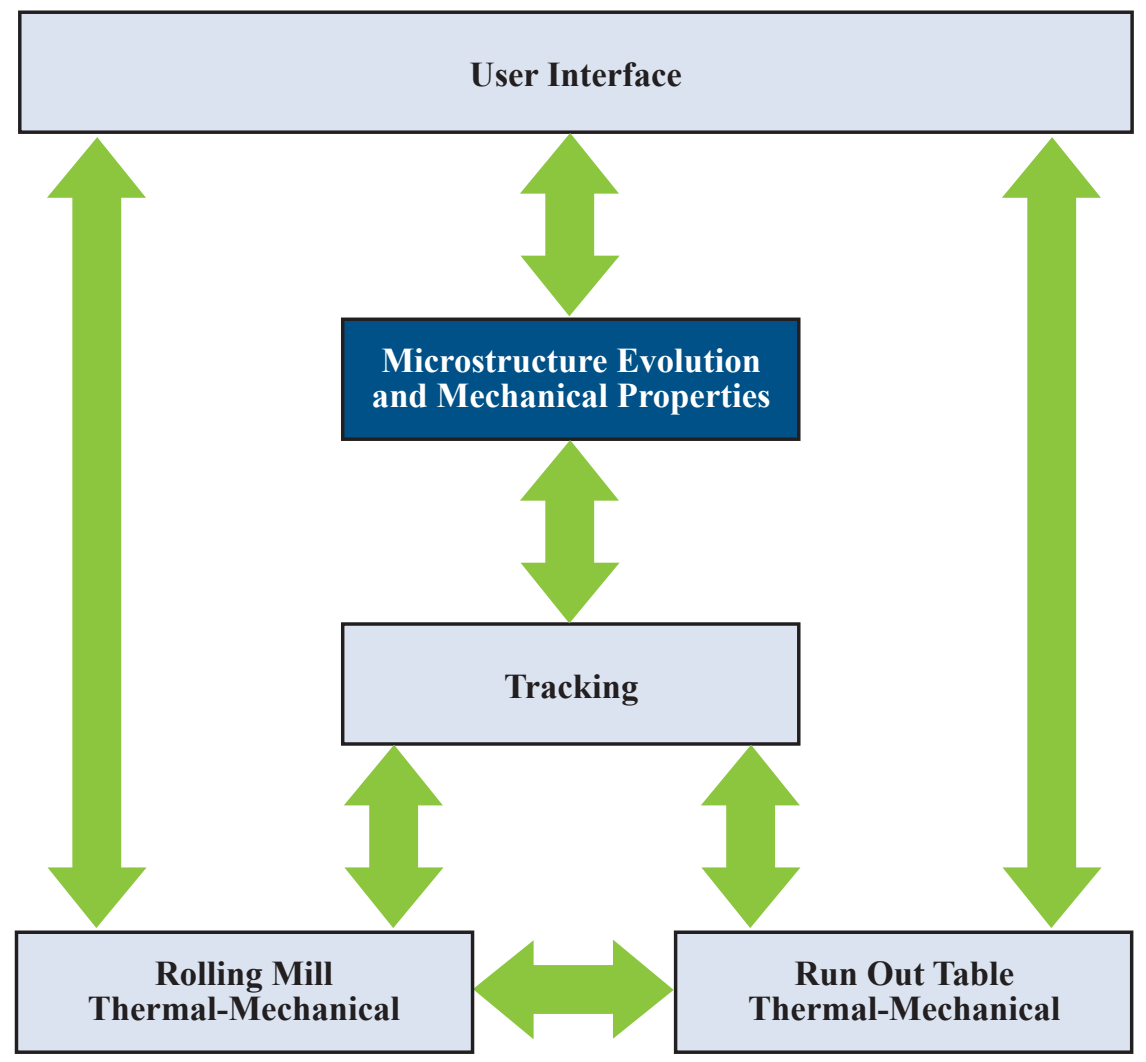

Components of the HSMM

\section{Overview}

$\checkmark$ Developed by The American Iron and Steel Institute as part of its Advanced Process Control Program

Marketed and sold by INTEG Process Group, Inc.

(www.integpg.com)

Acquired by 28 companies or universities around the world, including five U.S. steel companies

\section{Applications}

Can be used in any hot rolling mill that produces sheet or plate products (flat rolled material). The model can handle a variety of rolling mill configurations, including roughing mills, coil boxes, finishing mills, run out tables, and coilers

\section{Capabilities}

Allows the user to easily modify the mill configuration or processing parameters to see its impact on the end results of the product being rolled (simulated).

$\checkmark$ Can be used as a training tool, allowing operators to see the end result for different processing conditions or grades of steel.

\section{Benefits}

\section{Competitiveness}

Improves industrial competitiveness through product optimization and cost savings.

\section{Productivity}

Decreases product variability through the development of a predictive tool, which can quantitatively link the properties of hot rolled product to the operating parameters of the hot strip mills. 


\section{Vanadium Carbide Coating Process}

\section{Innovative Process Enhances Wear Resistance of Metals, Saving Energy, Waste, and Costs}

Traditional methods of coating steel surfaces with a layer of hard metal carbide require large capital investment, produce toxic and hazardous gases, are costly to operate, and require multiple heat-treatment steps during processing. Vanadium carbide (VC) coating technology provides a superior protective coating for steel surfaces and eliminates the need for multiple heat-treatment steps during processing, thereby eliminating harmful gas emissions.

The coating system, developed by Metlab-Potero with assistance from the $\mathrm{NICE}^{3}$ program, is based on a thermal diffusion technology, which forms a VC surface layer that can be made up to 15 microns thick in 12 hours. Process steps include cleaning, preheating, coating, cooling, or quenching, and subsequent tempering as required. Cleaned parts are preheated and then immersed in an environmentally benign fused salt bath in an $800^{\circ} \mathrm{C}$ to $1200^{\circ} \mathrm{C}$ furnace at ambient pressure until the required coating thickness is achieved. The work piece is then removed from the furnace for quenching, slow cooling, or additional hardening and tempering. The process protects steel surfaces with a thick, well-controlled layer of VC while eliminating the need for multiple heattreatment steps that increase energy use and the chance of production defects. Reducing the number of processing steps eliminates emissions, vacuum vessels, and the associated electrical heating system components.

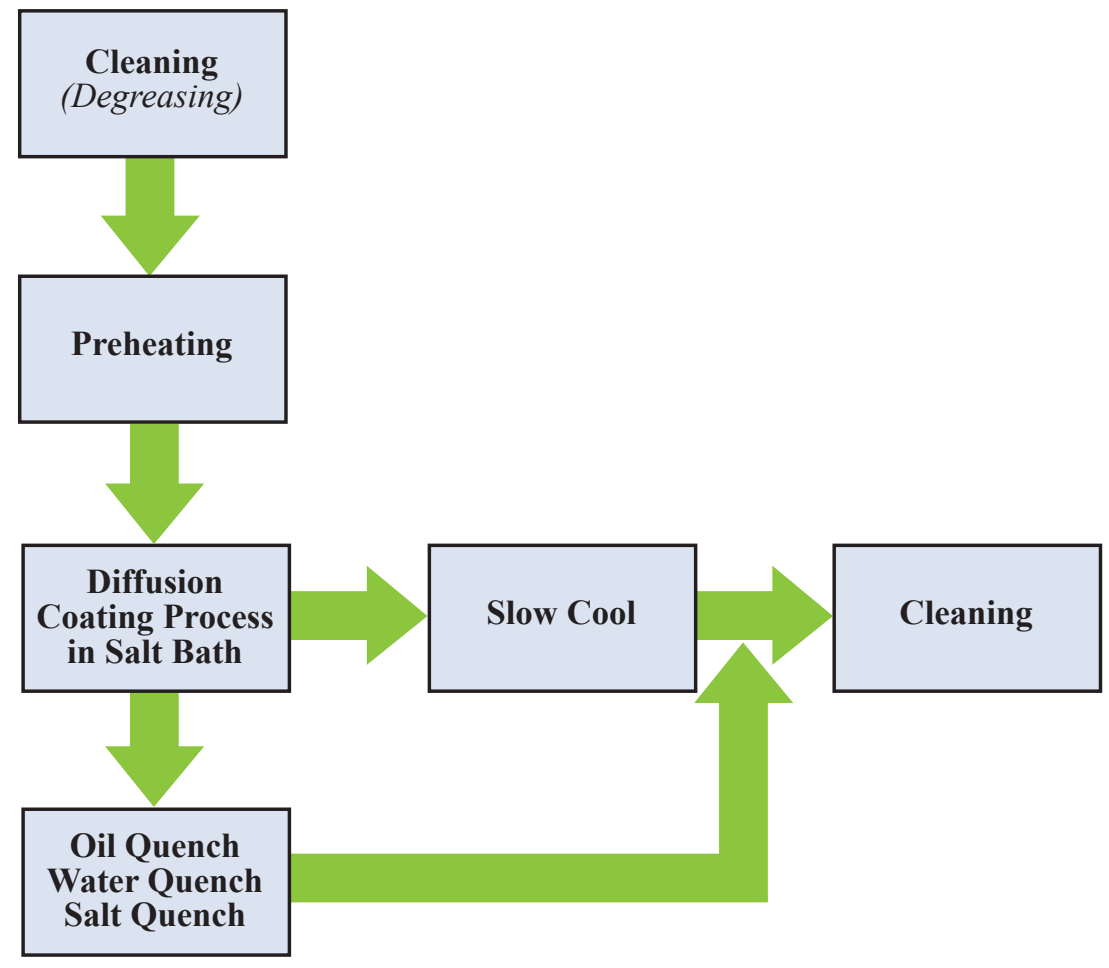

Vanadium Carbide Coating Process

\section{Overview}

Developed by Metlab-Potero (www.metlabheattreat.com)

$\checkmark$ Commercialized in 2005

\section{Applications}

Can be used for manufactured tools and dies requiring hardened, wear-resistant surfaces

\section{Capabilities}

Increases dimensional accuracy and creates wear-resistant surfaces without multiple heat-treatment steps.

\section{Benefits}

\section{Cost Savings}

Reduces process costs by $20 \%$.

\section{Environmental}

Reduces water usage by $20 \%$ to $50 \%$ and eliminates harmful gas emissions.

\section{Productivity/Quality}

Offers productivity gains of $10 \%$ to $30 \%$ and increases tool life 5 to 30 times compared with conventional wearresistance methods. 
IMPACTS

Adjustable-Speed Drives for 500 to 4000 Horsepower Industrial Applications

A- 65

Advanced Aerodynamic Technologies for Improving Fuel Economy in Ground Vehicles

A- 66

Advanced Diagnostics and Control for Furnaces, Fired Heaters, and Boilers

A-67

Advanced Reciprocating Engine Systems (ARES)

A-68

Aerogel-Based Insulation for Industrial Steam Distribution Systems

A-69

Autotherm ${ }^{\circledR}$ Energy Recovery System

A-70

Barracuda ${ }^{\circledR}$ Computational Particle Fluid Dynamics $\left(\mathrm{CPFD}^{\circledR}\right)$ Software

A-71

$\checkmark$ Callidus Ultra-Blue (CUBL) Burner.

A-72

Catalytic Combustion A-73

Composite-Reinforced Aluminum Conductor. A-74

Cromer Cycle Air Conditioner. A-75

Electrochromic Windows - Advanced Processing Technology.. A-76

$\checkmark$ Energy-Conserving Tool for Combustion-Dependent Industries A-77

Fiber-Optic Sensor for Industrial Process Measurement and Control. A-78

Fiber Sizing Sensor and Controller. A-79

Force Modulation System for Vehicle Manufacturing A- 80

$\checkmark$ Freight Wing ${ }^{\mathrm{TM}}$ Aerodynamic Fairings A- 81

Functionally Graded Materials for Manufacturing Tools and Dies.

A- 82

Ice Bear ${ }^{\circledR}$ Storage Module

$\checkmark$ In-Situ, Real Time Measurement of Elemental Constituents

A- 84

Materials and Process Design for High-Temperature Carburizing

A-85

Mobile Zone Optimized Control System for Energy-Efficient Surface-Coating

Nanocoatings for High-Efficiency Industrial Hydraulic and Tooling Systems

Novel Refractory Materials for High-Temperature, High-Alkaline Environments

Portable Parallel Beam X-Ray Diffraction System

Predicting Corrosion of Advanced Materials and Fabricated Components.

$\checkmark$ Pulsed Laser Imager for Detecting Hydrocarbon and VOC Emissions.

$\checkmark$ Self-Healing Polymeric Coatings

$\checkmark$ Sensor Network for Motor Energy Management .

- Simple Control for Single-Phase AC Induction Motors

Solid-State Sensors for Monitoring Hydrogen

SpyroCor ${ }^{\mathrm{TM}}$ Radiant Tube Heater Inserts

Three-Phase Rotary Separator Turbine.. 


\section{Crosscutting}

IMPACTS

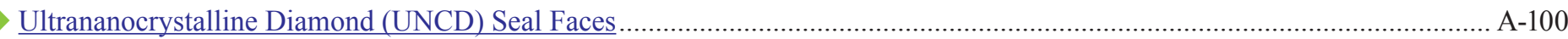

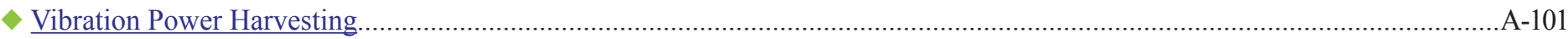

Wireless Sensors for Condition Monitoring of Essential Assets ......................................................................................... A-102

Wireless Sensors for Process Stream Sampling and Analysis ................................................................................................... A-103 


\section{Adjustable-Speed Drives for $\mathbf{5 0 0}$ to $\mathbf{4 0 0 0}$ Horsepower Industrial Applications}

IMPACTS

\section{New Drive System Saves Energy and Extends Variable Speed Control to Larger Motors}

MagnaDrive Corporation, with assistance from the $\mathrm{NICE}^{3}$ program and Washington State University's Cooperative Extension Energy Program, has developed a highly efficient adjustable speed drive (ASD) for various industrial applications. The MagnaDrive ASD has been successfully tested and used in industrial environments with motors up to 4,000 horsepower (hp). Over 5,000 units are currently in use in U.S. applications up to $2,500 \mathrm{hp}$, of which 72 are over $500 \mathrm{hp}$.

The ASD consists of two major components that never touch: (1) the copper conductor assembly, directly connected to the motor shaft; and (2) the magnet rotor assembly, directly connected to the load shaft. The torque is transmitted across a thin air gap that can be continuously adjusted to control the speed of the load. The actuation components are attached to the magnet rotor assembly on the load side of the ASD. Rare-earth permanent magnets are the key to the system's performance. The magnets are made of neodymium, iron, and boron $(\mathrm{NdFeB})$ and retain their magnetic properties for the life of the system.

The motor is started with the ASD system in a position that places the largest air gap between the magnet rotors and the copper conductors. The motor quickly comes to full speed in an unloaded condition. The magnet rotor is then actuated to adjust the rotors closer to the conductors. As the components approach each other, eddy currents are induced, allowing a smooth transfer of torque across the air gap until the distance between the magnet rotor and the copper assembly closes to about $1 / 8 \mathrm{inch}$. At this point the ASD reaches its maximum efficiency of up to $99 \%$ of the torque transferred between the motor and the load.

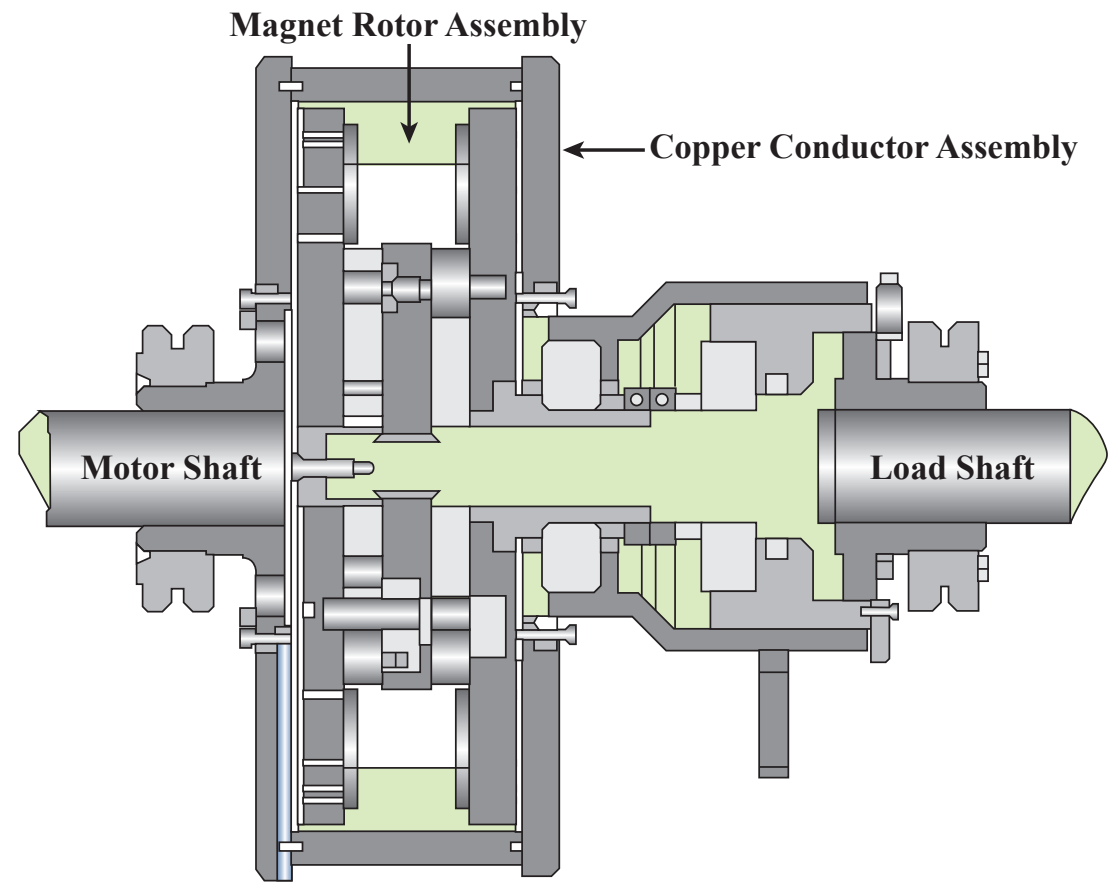

Adjustable-Speed Drive Components

\section{Overview}

Developed by MagnaDrive Corporation (www.magnadrive.com)

Commercialized in 2003

72 large and over 5000 smaller units operating in the United States in 2010

\section{U.S. Energy Savings}

(Trillion Btu)

Cumulative through 2010

2.20 2010

\section{U.S. Emissions Reductions}

(Thousand Tons, 2010)

\begin{tabular}{|c|c|c|c|}
\hline Particulates & SO $_{x}$ & NO $_{x}$ & Carbon \\
\hline 0.002 & 0.119 & 0.089 & 10.8 \\
\hline
\end{tabular}

\section{Applications}

Can be used in motor driven pumps, fans, blowers, and other processing/manufacturing equipment used in industry

\section{Capabilities}

Transfers torque from motors to driven equipment across an air gap without shaft-to-shaft physical connection.

Permits speed control by varying the air gap spacing, thereby controlling the amount of torque transmitted.

- Eliminates the transmission of vibration across the drive due to the air gap configuration.

\section{Benefits}

\section{Productivity}

Eliminates vibration, reduces noise, tolerates misalignment, provides overload protection, extends motor and equipment life, and reduces overall maintenance and operations costs.

\section{Product Quality}

Improves product quality and optimizes process rates. 


\section{Advanced Aerodynamic Technologies for Improving Fuel Economy in Ground Vehicles}

\section{Low-Cost Aerodynamic Drag Reduction Devices for Tractor-Trailer Trucks Reduce Fuel Consumption}

Heavy vehicles lose a tremendous amount of energy from wind resistance, braking, and rolling resistance. Such non-engine losses can account for about a $45 \%$ decrease in efficiency. The need for technologies to reduce these parasitic losses has gained significant attention as fuel costs have increased. The 21st Century Truck Program, an industry-government collaboration, has established an aerodynamic drag reduction goal of $20 \%$ for Class 8 tractor-trailer combinations.

With assistance from DOE's Inventions and Innovation Program, SOLUS Solutions and Technologies LLC has developed several low-cost aerodynamic devices that reduce drag and improve fuel economy for tractor-trailer trucks. In 2007 Silver Eagle Manufacturing Company began to produce and sell the SOLUS drag reduction devices. Wind tunnel and on-road testing demonstrated that these devices can provide a combined fuel savings of about $10 \%$ at $60 \mathrm{mph}$. The expected fuel savings from the inventions for an average tractor-trailer truck will exceed 2,000 gallons per year.

The geometric-based devices can be attached to the trailer's front face, sides and top surfaces, and the undercarriage. One device employs "trapped vortex" design technology to eliminate the drag due to flow in the gap region between the tractor and the trailer. The "vortex strakes" create a "boat tail" at the back of the trailer. A boat tail is a tapering protrusion mounted on the rear of a truck that reduces the aerodynamic base drag caused by the lowerpressure effect that occurs in the wake of a vehicle. The "skirt fairings" reduce drag caused by airflow underneath the trailer. The location of the aerodynamuc devices (trailer front, top, sides and undercarriage) does not interfere with door operation. Testing indicates that adding the SOLUS devices to trailers has no negative impact on either operational utility or maintenance requirements.

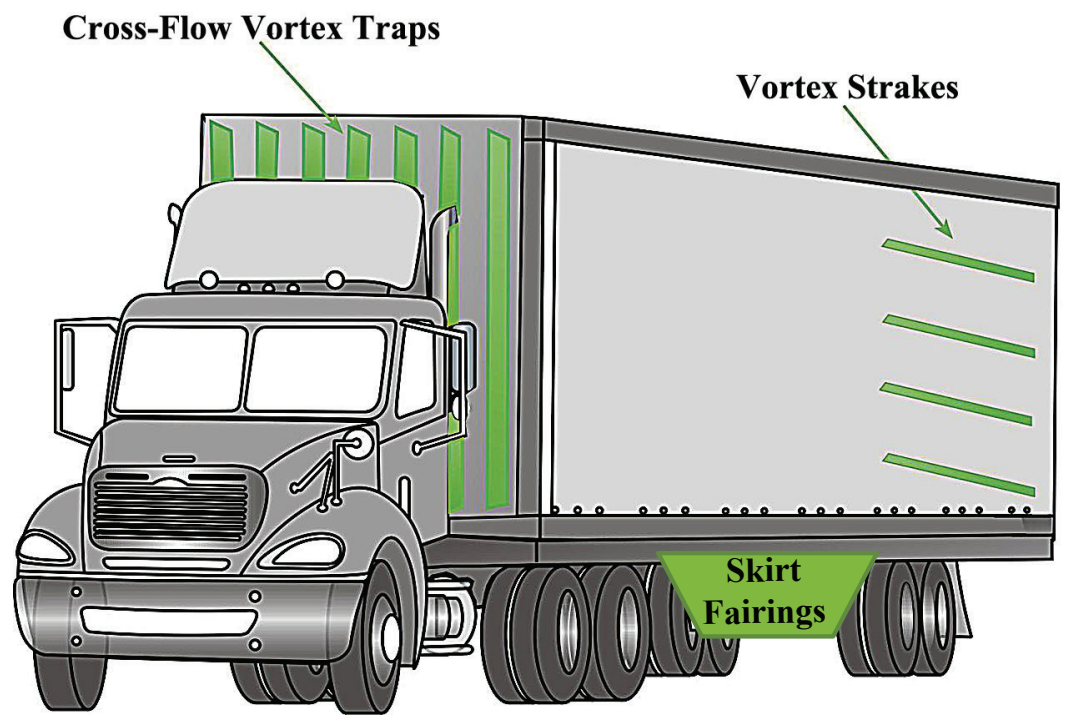

SOLUS Solutions and Technologies' Vortex Drag Reduction Devices

\section{Overview}

Developed by SOLUS Solutions and Technologies LLC in 2001

(www.solusinc.com)

Commercialized in 2007

Currently marketed by Silver Eagle Manufacturing Company (www.silvereaglemfg.com)

\section{U.S. Energy Savings}

(Trillion Btu)

\begin{tabular}{|c|c|}
\hline Cumulative through $\mathbf{2 0 1 0}$ & $\mathbf{2 0 1 0}$ \\
\hline 0.152 & 0.059 \\
\hline
\end{tabular}

\section{U.S. Emissions Reductions}

(Thousand Tons, 2010)

\begin{tabular}{|c|c|c|c|}
\hline Particulates & SO $_{\mathrm{x}}$ & NO $_{\mathrm{x}}$ & Carbon \\
\hline 0.0 & 0.034 & 0.009 & 1.28 \\
\hline
\end{tabular}

\section{Applications}

Can be used for all classes of heavy tractor trailers to reduce drag and improve fuel economy

\section{Capabilities}

$\checkmark$ Improves fuel economy of a tractor-trailer by $10 \%$ at $60 \mathrm{mph}$.

Improves vehicle stability and handling.

Reduces drag by up to $25 \%$ at all operational speeds.

\section{Benefits}

\section{Profitability}

Ensures low operation and maintenance costs and a return on investment in less than one year.

\section{Reliability}

Reduces wear on engine and braking assemblies and wear on the transmission. 


\section{Advanced Diagnostics and Control for Furnaces, Fired Heaters, and Boilers}

IMPACTS

\section{Diode Sensor Array and Control System Optimizes Combustion}

Pyrolysis of chemical feedstocks into basic chemicals is an important process for the petrochemical industry and consumes considerable quantities of energy. One of the prevalent unit operations associated with these industries occurs in the furnace, where fuel combustion is used to generate large amounts of heat/radiation required to convert feedstocks into the desired products. To increase the operating efficiency, fuel consumption needs to be optimized and the waste heat needs to be minimized by exhausting excess air out the stack to the atmosphere. The models currently used to optimize furnace operations require monitoring constraints such as $\mathrm{O}_{2}, \mathrm{CO}$, and $\mathrm{CH}_{4}$. Data acquisition can be difficult in these harsh and hazardous environmental conditions. Unreliable and inaccurate measurement data have been used for model inputs, yielding poor and inefficient control of furnace operation.

Dow Chemical Company and Yokogawa, with assistance from AMO, have optimized furnace operation using advanced combustion diagnostics and rapid Btu measurements during fuel combustion. These concepts have enabled more accurate input into current process optimization models, allowing the industry to use existing models and to leverage computational fluid dynamic modeling capabilities to model heat transfer. The key to this technology's success was the development of existing monitoring hardware by Yokogawa. Yokogowa's TDLS 200 tunable diode laser spectroscopy system operates in the infrared region of the electromagnetic spectrum. The system uses absorbance to measure furnace parameters such as $\mathrm{O}_{2}, \mathrm{CO}$, and $\mathrm{CH}_{4}$. The system hardware can perform real-time monitoring and analysis of furnace conditions and performance. The systems data output can be used to control the furnace at stoichiometric burn conditions for complete fuel combustion. The system reduces excess emissions and $\mathrm{O}_{2}$ content and achieves optimized lean burn furnace operation. The system can monitor and process multiple sensor input, which enables spatially resolved hot zone measurements, optimizing and tuning of furnace burners, improving heat transfer, and minimizing undesirable combustion by-products.

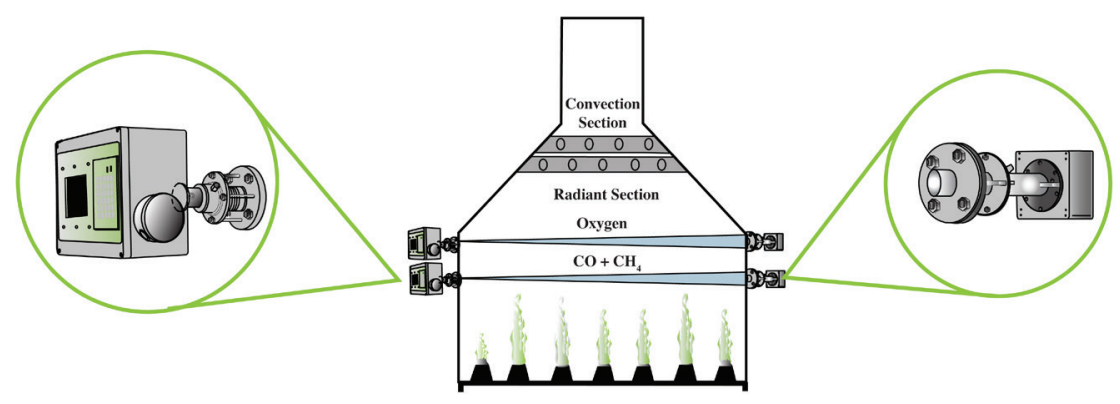

Yokogawa's TDLS 200 System for Furnace Control

\author{
Overview \\ Developed by Dow Chemical Company. \\ Commercialized in 2010 \\ $\checkmark$ Over 43 systems installed. \\ $\checkmark$ Distributed and marketed by Yokogawa \\ Corporation of America \\ (www.yokogawa.com/us/)
}

\section{Applications}

Can be used in a variety of industrial furnace, fired heater, and boiler applications.

\section{Capabilities}

$\checkmark$ Uses infrared absorbance spectroscopy for in-line process monitoring, analysis, and feedback control.

$\checkmark$ Enables optimizing furnace parameters for ideal stoichiometric burning conditions.

Provides CO sensitivity $<5$ ppm and $\mathrm{CH}_{4}$ sensitivity $<50 \mathrm{ppm}$ at start-up conditions.

Provides measurement capability of other chemical content, e.g., moisture, chlorine, and other hydrocarbons.

\section{Benefits}

\section{Cost Savings}

Reduces fuel costs by optimizing furnace burn conditions, maximizing usage return.

\section{Energy Savings}

Optimizes fuel burn rate, reducing process energy consumption.

\section{Environmental}

Reduces emissions through real-time control of furnace conditions and fuel input. 


\section{Advanced Natural Gas Reciprocating Engines Increase Efficiency and Reduce Emissions for Distributed Power Generation Applications}

Distributed energy (DE) technologies for on-site power generation are assuming a role of increasing importance for our nation's energy, environmental, and economic future. The use of DE technologies can lead to lower emissions and, particularly in combined heat and power (CHP) applications, improved efficiency. The reciprocating (piston-driven) engine is a widespread and well-known DE technology. Although diesel and gasoline-fueled reciprocating engines are commonly used for standby applications, they create significant pollution in terms of emissions and noise. The development of cleaner natural gas-fired engines is desired to address these concerns.

The U.S. Department of Energy's Advanced Reciprocating Engine Systems (ARES) program represents a cooperative effort by major engine manufacturers, DOE national laboratories, universities, and engine consultants to obtain maximum efficiency and minimum emissions from natural gas-fired reciprocating engines. The ARES program began in 2001 and consists of three phases, with each phase targeting specific progress benchmarks aimed at achieving the overall goals of the program. The program will result in engines with at least $50 \%$ brake thermal efficiency and NOx emissions no greater than $0.1 \mathrm{~g} / \mathrm{bhp}-\mathrm{hr}$.

Caterpillar, Inc. has successfully commercialized their G3500C and E series engines for Phase I of the ARES program. These engines employ several improvements for increased efficiency, including: advanced combustion, improved air systems, and dedicated control systems. In their current development stage (Phase II), Caterpillar is focusing on value-added aftertreatment and exhaust heat recovery. Cummins, Inc. selected a lean burn approach for achieving the targets of Phase I, which culminated with the successful release of their QSK60 engine. Phase II work is centered on a stoichiometric system with exhaust gas recirculation (EGR) and a threeway catalyst with advanced waste heat recovery. Dresser Waukesha developed its Advanced Power Generation (APG) 1000 engine in Phase I, focusing on combustion/controls technologies and application of the Miller Cycle to achieve its objectives. In Phase II, Dresser demonstrated 47\% efficiency without using exhaust energy recovery which will be used for CHP applications. In Phase III, Waukesha is exploring further advances in combustion, low friction technologies, and new controls technology to achieve further efficiency gains and emissions reductions.

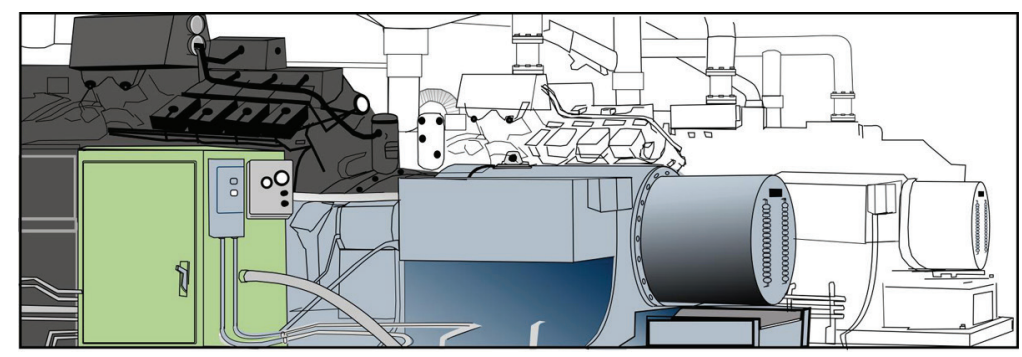

ARES Engines

\section{Overview}

Being developed in parallel by Caterpillar Inc., Cummins Inc., and Dresser Waukesha (www.cat.com) (www.cummins.com) (www.dresserwaukesha.com)

- Commercialized since 2003 and sold by all three engine manufacturers

Sold more than 500 engines in the U.S. and approximately 2000 sold internationally

\section{Applications}

Can be used for a wide range of distributed generation needs, including: backup to the electrical grid, combined heat and power, and combustion of landfill and digester biogases.

\section{Capabilities}

Increases combustion quality through use of improved spark plug ignition systems.

Reduces friction losses through modified piston rings and liners, without loss of sealing or component life.

Reduces frequency of maintenance through use of improved control systems, resulting in lower operating costs.

\section{Benefits}

\section{Cost Savings}

On-site power generation eliminates transmission costs associated with utilityprovided electricity.

\section{Emissions Reduction}

Reduces $\mathrm{NO}_{\mathrm{X}}$ and carbon monoxide emissions.

\section{Productivity}

Achieves higher power density and improved fuel efficiency compared with conventional reciprocating engines. 


\section{Aerogel-Based Insulation for Industrial Steam Distribution Systems}

\section{New Efficient Insulation for Pipes Allows for the Use of Less Material with High-Temperature Durability}

Thermal loss through industrial steam distribution systems accounts for a large part of total U.S. energy consumption. Traditional pipe insulation employs mineral wool, fiberglass, calcium silicate, perlite, and various foams. Annular shrouds of these materials are tightly wrapped around steam pipes and clad with sheet metal. As a highly efficient insulation material, flexible aerogel blankets can help reduce these losses when wrapped around hot piping, vessels, and equipment. This breakthrough technology provides the equivalent insulating properties of conventional insulation but with two to five times less material. A cost-effective method has been developed by Aspen Aerogels, Inc., with AMO assistance, to manufacture this industrial insulation product that has remarkable thermal performance, physical toughness, and water-resistant properties.

Aerogel has the lowest thermal conductivity of any known material. Recent processing developments allow this once boutique material to be manufactured cheaply in blanket form. The main attraction of aerogel insulation is that it significantly reduces the amount of material needed to achieve the same insulation value as bulkier traditional insulation. Aerogel is still more expensive to produce on a weight basis, but much less material is required, so the improved properties compensate for the difference in cost. Insulation designs and installation protocols were developed to allow for widespread adoption of aerogel-based pipe insulation by all industries that rely on steam distribution systems, with a focus on assemblies that are not currently costeffectively addressed by aerogel insulation, such as large diameter, complex, and/or high-temperature pipe systems.

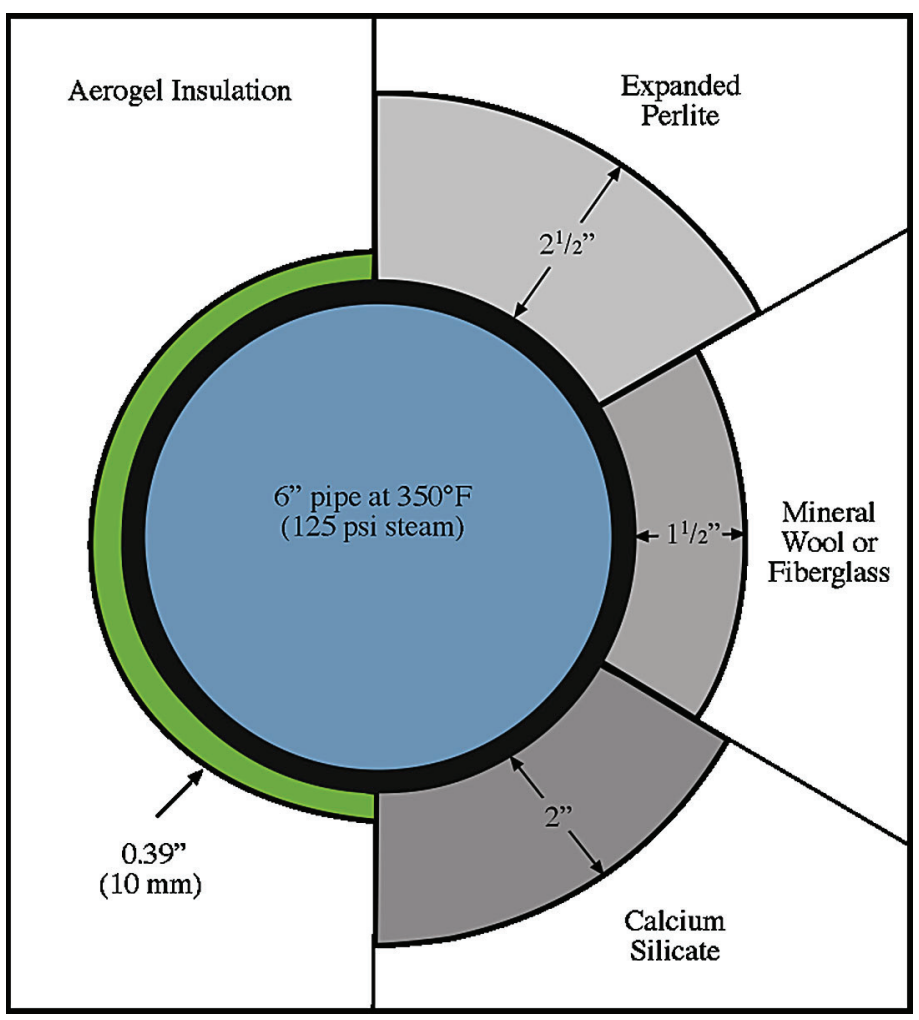

Thickness Comparison of Aspen Areogel's Insulation vs. Conventional Insulation with Equivalent Insulation Properties

\section{Overview}

Developed by Aspen Aerogels, Inc., in partnership with Air Liquide USA LLC (www.aerogel.com)

Commercially available since 2007

\section{U.S. Energy Savings}

(Trillion Btu)

\begin{tabular}{|c|c|}
\hline Cumulative through 2010 & $\mathbf{2 0 1 0}$ \\
\hline 0.537 & 0.374 \\
\hline
\end{tabular}

\section{U.S. Emissions Reductions}

(Thousand Tons, 2010)

\begin{tabular}{|c|c|c|c|}
\hline Particulates & SO $_{\mathrm{x}}$ & NO $_{\mathrm{x}}$ & Carbon \\
\hline 0.0 & 0.0 & 0.044 & 5.94 \\
\hline
\end{tabular}

\section{Applications}

Can be used for industrial steam distribution systems, enhancing high-temperature durability up to superheated steam at $1200^{\circ} \mathrm{F}$.

\section{Capabilities}

Enhances high-temperature durability of industrial insulation.

Reduces installation labor.

Offers long-term water resistance and corrosion protection because of the aerogel's hydrophobic properties.

Has very low thermal conductivity.

\section{Benefits}

\section{Efficiency}

Possesses a very low thermal conductivity and thickness compared with conventional insulation materials.

\section{Material Savings}

Reduces the amount of material needed to achieve the same insulation value as bulkier traditional insulation. 


\section{Innovative Technology Reduces Idling, Fuel Costs, and Emissions on Large Vehicles}

Historically, cab interiors are kept warm when a vehicle is stationary in the winter by either installing an expensive fuel-fired heater or idling the vehicle engine to keep hot water circulating to the cab heater. According to Argonne National Laboratory, larger vehicles can consume one gallon per hour of fuel simply to operate the heater. In most vehicles once the motor is turned off, within a few minutes, the vehicle interior is too cold to occupy comfortably because the engine driven pump is no longer recirculating water to the cab heater. With assistance from DOE's Inventions and Innovation Program, Autotherm developed a system that continues to supply heat stored in the engine to a vehicle cab when the engine is turned off. The easy-to-install design allows the vehicle to stay heated for up to several hours when the vehicle is turned off, eliminating both fuel consumption and emissions from the stationary vehicle.

Once the vehicle motor is turned off, the Autotherm system operates the vehicle's existing heater using a dash-mounted system control unit and a small electric recirculating pump, which is attached to the existing engine coolant system. The system is fully automatic and can maintain cab temperature with the driver present or absent from the vehicle. Operation stops automatically when the engine coolant drops to about $95^{\circ} \mathrm{F}$. The vehicle can be left securely locked, and if the driver returns within the heating period, the vehicle will be warm and snow-free.

\section{Benefits}

\section{Emissions Reductions}

Reduces $100 \%$ of the emissions from an idling vehicle by eliminating the need for the engine to run to maintain cab temperature.

\section{Profitability}

Reduces operating costs and has a payback of one heating season.

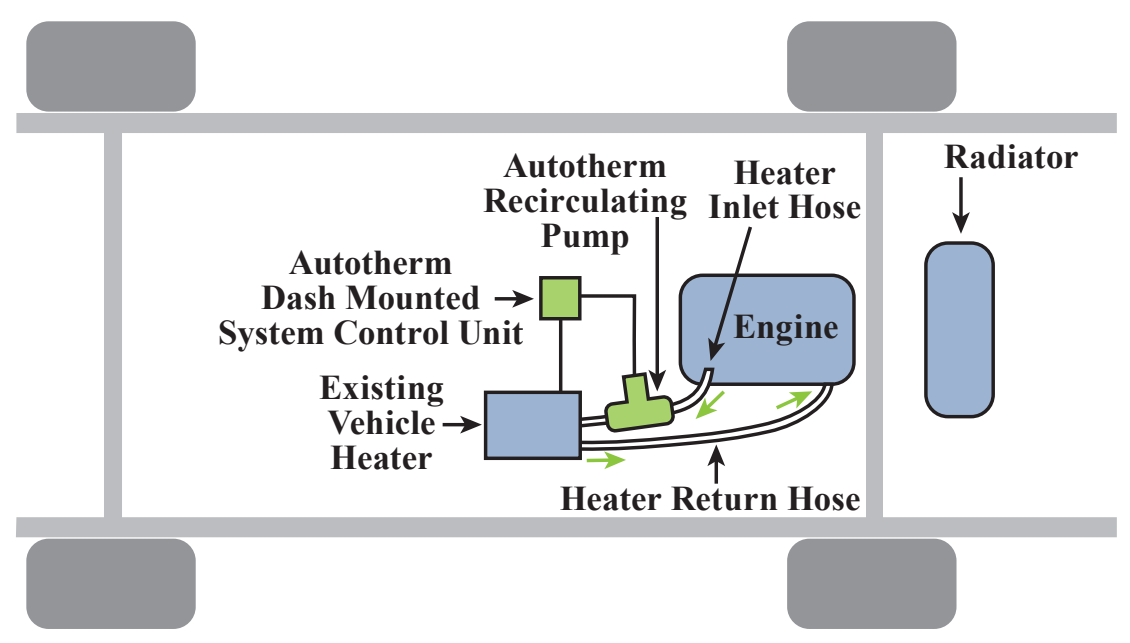

Autotherm Components

\section{Overview}

Invented by Frank Perhats in 1974 and refined using DOE funding

Commercialized in 2003 and being marketed by the Autotherm Division of Enthal Systems, Inc.

(www.autothermusa.com)

About 2050 units installed through 2010

\section{U.S. Energy Savings}

(Trillion Btu)

\begin{tabular}{|c|c|}
\hline Cumulative through 2010 & $\mathbf{2 0 1 0}$ \\
\hline 0.178 & 0.040 \\
\hline
\end{tabular}

\section{U.S. Emissions Reductions}

(Thousand Tons, 2010)

\begin{tabular}{|c|c|c|c|}
\hline Particulates & SO $_{x}$ & NO $_{x}$ & Carbon \\
\hline 0.0 & 0.023 & 0.006 & 0.875 \\
\hline
\end{tabular}

\section{Applications}

Can be used in any vehicle that is prone to idling, including small to large service vehicles and semi-trucks.

\section{Capabilities}

- Maintains a vehicle's interior temperature for several hours when the engine is off by recovering energy stored in the warm engine.

Automatically turns off when the engine coolant system drops to below $95^{\circ} \mathrm{F}$.

Alerts the driver to an approaching "low battery voltage" condition and shuts down the system before the battery is low. 


\section{Innovative Software Program Extends the Capabilities of CFD by Modeling Solid Particle Movement}

Invented at the Los Alamos Scientific Laboratory in the 1950s and ' 60 s, computational fluid dynamics (CFD) is a mathematical expression of the physics of the movements of fluids (liquids and gases). CFD computer software simulates real-world fluid-flow events, such as modeling the flow of air over an aircraft wing or predicting the flow of an oil spill in a river channel. Sand in an hour glass is said to "flow," and so for many years CFD computer codes were used to model and predict the movement of particles as well as fluids. However, because particles are solids, not fluids, modeling them as fluids is inherently limited and not completely accurate.

With assistance from AMO, a consortium of industrial partners led by CPFD Software, LLC, has developed and commercialized Barracuda CPFD software. The CPFD software models the behavior of particles as they move through process equipment. This gives industrial users the ability to design processes that are more energy-efficient and environmentally friendly.

The CPFD software is currently employed by major automotive and transportation manufacturers, as well as by major chemical, petrochemical, and power generation companies worldwide. CPFD Software, LLC, continues to expand the product's applications to meet today's critical energy challenges. These applications include making the supply of Canadian oil sands economically feasible, increasing clean coal energy production, and expanding solar photovoltaic deployment.

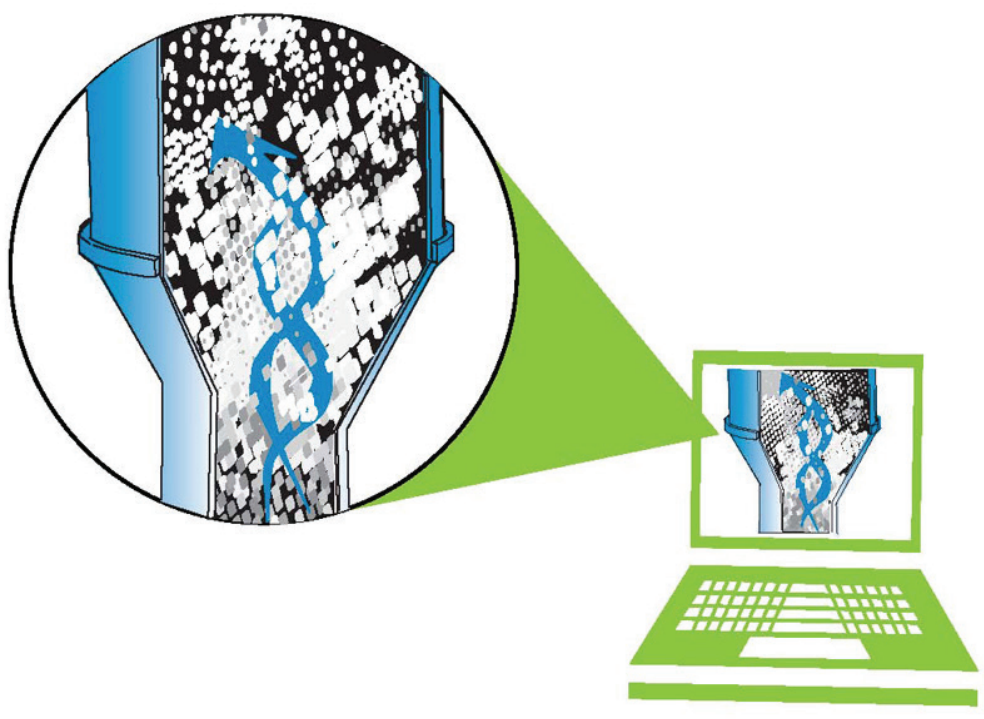

Industrial Process Modeled by Barracuda CPFD Software

\section{Overview}

$\rightarrow$ Developed through a collaborative effort between CPFD Software, LLC; ExxonMobil; Millennium Inorganic Chemicals, Inc.; and Sandia National Laboratories

$\checkmark$ Commercialized by CPFD Software, LLC (www.cpfd-software.com)

\section{Applications}

Can be used in any industrial application that requires accurate modeling of complex mixing and chemical reaction processes

\section{Capabilities}

- Allows the user to model threedimensional movement of a size distribution of particles.

Enables simulations to run for sufficient time to achieve meaningful quasi-steady behavior and allow for scenario analyses.

\section{Benefits}

\section{Cost Savings}

Saves time and reduces waste materials by optimizing existing processes.

\section{Emissions Reductions}

Reduces emissions by identifying more ecologically friendly retrofit technologies that can be applied to existing facilities.

\section{Energy Savings}

Prevents damaging outputs and inefficient energy use by modeling complex mixing and reacting processes. 


\section{Callidus Ultra-Blue (CUBL) Burner}

IMPACTS

\section{A New Generation of Smart, Integrated Burner/Fired-Heater Systems}

The refining and chemicals industries rely on process heaters to heat liquids and induce chemical reactions during production processing. Process heaters in these two industries generate over 235,000 tons of $\mathrm{NO}_{\mathrm{X}}$ emissions annually. The chemicals and refining industries are facing more stringent environmental regulations to reduce $\mathrm{NO}_{\mathrm{X}}$ emissions; for example, the state of Texas has ordered refiners in the Houston area to reduce $\mathrm{NO}_{\mathrm{X}}$ emissions by $80+\%$.

Callidus Technologies, along with funds and resources from AMO, Gas Research Institute (GRI), and Arthur D. Little Company, developed and demonstrated an ultra-low $\mathrm{NO}_{\mathrm{X}}$ emissions burner. The burner uses internal flue gas recirculation to reduce $80 \%$ of the $\mathrm{NO}_{\mathrm{X}}$ emissions, with many applications achieving reductions greater than 90\%. Callidus Technologies, with licensing rights from GRI, is manufacturing and marketing the Callidus Ultra-Blue Burner to the chemicals and refining industries, where potential $\mathrm{NO}_{\mathrm{X}}$ reductions of 200,000 tons/year are possible.

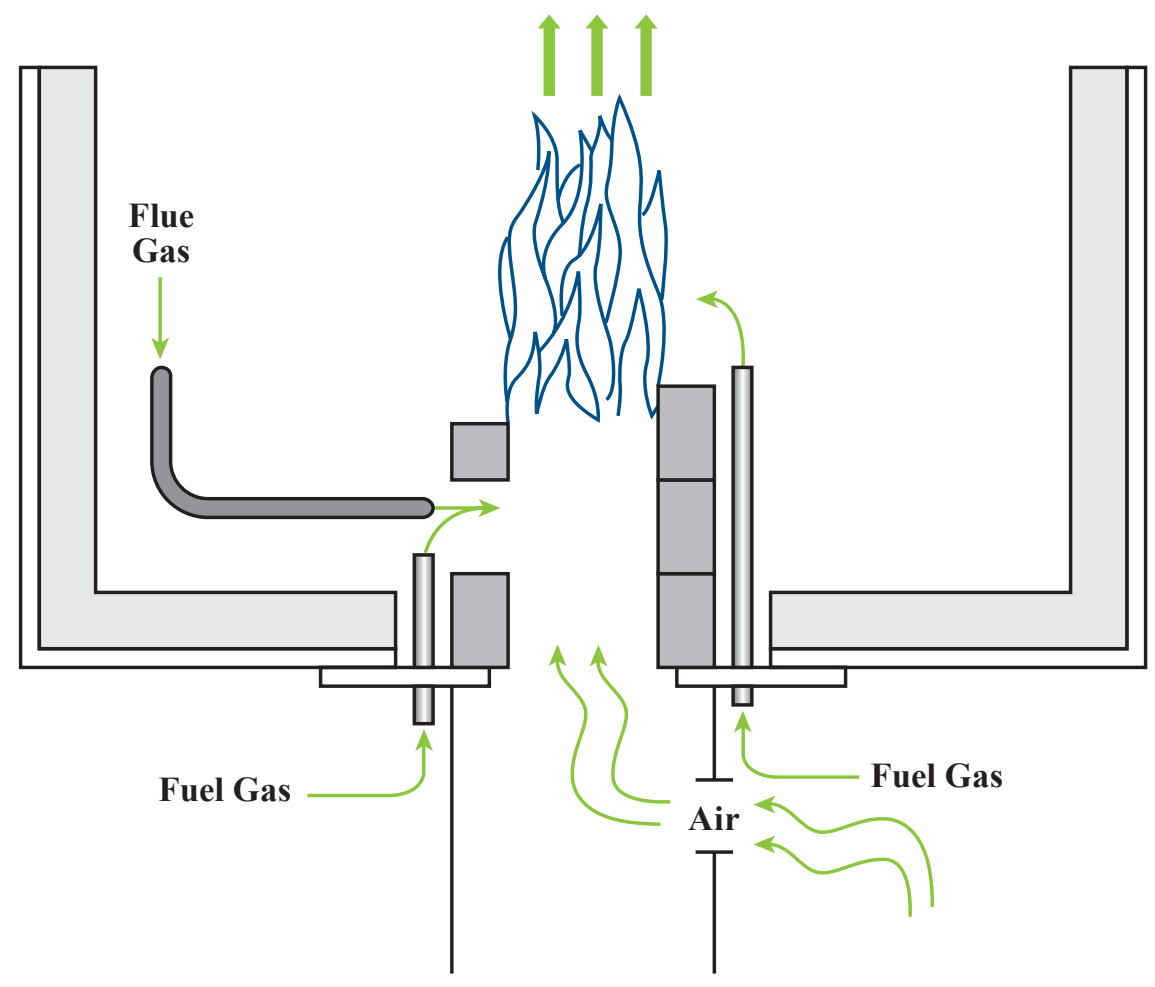

Callidus Ultra-Blue Burner

\section{Overview}

Developed by Callidus Technologies, Inc. (www.callidus.com)

$>$ Commercialized in 2000

Over 13,000 burner units installed by 2010

\section{U.S. Energy Savings}

(Trillion Btu)

\begin{tabular}{|c|c|}
\hline Cumulative through $\mathbf{2 0 1 0}$ & $\mathbf{2 0 1 0}$ \\
\hline 124 & 28.8 \\
\hline
\end{tabular}

\section{U.S. Emissions Reductions}

(Thousand Tons, 2010)

\begin{tabular}{|c|c|c|c|}
\hline Particulates & SO $_{x}$ & NO $_{x}$ & Carbon \\
\hline 0.0 & 0.0 & 3.37 & 457 \\
\hline
\end{tabular}

\section{Applications}

Can be used in the chemicals, petrochemicals, and refining industries

\section{Capabilities}

Works with natural or forced-draft operation; refinery fuel gas, natural gas, and high and low hydrogen content; and ambient and preheated air.

\section{Benefits}

\section{Emissions Reductions}

Reduces thermal $\mathrm{NO}_{\mathrm{X}}$ in the combustion zone by $80 \%$ to $90 \%$.

\section{Profitability}

Eliminates or reduces the need for expensive post-combustion emissionaltering equipment.

\section{Other}

Is designed to be user-friendly. 


\section{Catalytic Combustion}

IMPACTS

\section{Advanced Catalytic Combustion System Reduces $\mathrm{NO}_{x}$ Emissions}

Natural-gas-fired turbine systems currently require complex after-treatment systems to clean the exhaust of harmful emissions. Many of these emissions could be reduced by lower operating temperatures during the combustion process.

With the support and recognition from many organizations, including AMO, the California Air Resources Board, the California Energy Commission, and the U.S. Environmental Protection Agency, Catalytica Energy Systems, Inc., has developed an innovative system to reduce turbine emissions. The Xonon Cool Combustion ${ }^{\circledR}$ System uses a catalytic process instead of a flame to combust the fuel, thereby lowering the combustion temperature and significantly reducing the formation of $\mathrm{NO}_{\mathrm{x}}$.

While maintaining turbine efficiency, the technology has the potential to reduce the cost associated with achieving ultra-low emissions while generating electricity with gas turbines. With the growing need for electricity generation that produces less pollution, Catalytica Energy Systems' solution provides a cost-effective method to meet air pollution control standards through pollution prevention rather than cleanup. In its first commercial installation, the $\mathrm{NO}_{\mathrm{x}}$ output was reduced from approximately $20 \mathrm{ppm}$ to well below $3 \mathrm{ppm}$.

\section{Benefits}

\section{Emissions Reductions}

Reduces air pollutant emissions from gas turbine energy generation systems.

\section{Pollution Reduction}

Avoids the need for costly or burdensome exhaust cleanup systems that use toxic reagents such as ammonia.

\section{Productivity}

Maintains turbine efficiency, demonstrating operating reliability greater than $98 \%$.

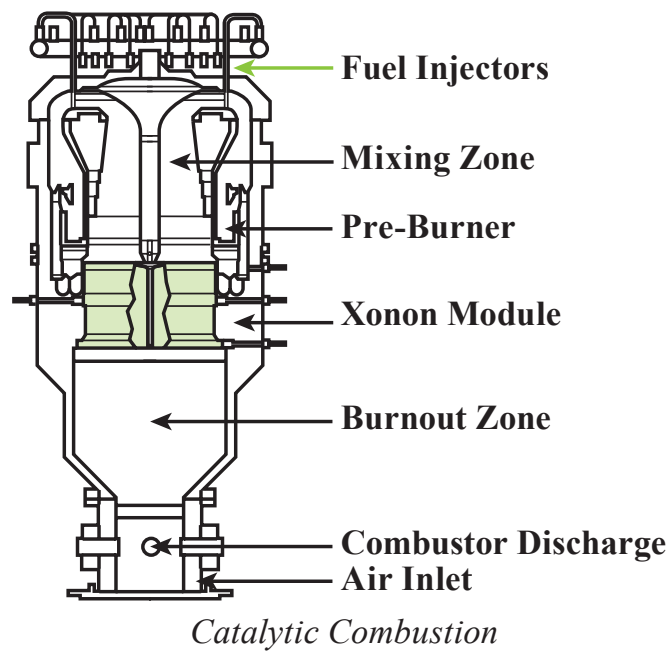

\section{Overview}

- Developed by Catalytica Energy Systems, Inc.

- Has accumulated over 18,000 hours of operation on the grid in field demonstrations

First commercial installation in 2002

$\checkmark$ Commercially available through Kawasaki Gas Turbines-America on its M1A-13X, a 1.4-MW gas turbine as part of the GPB $15 X$ cogeneration system (www.kawasakigasturbines.com)

Being actively developed in partnership with GE Power Systems for its GE10, a 10-MW gas turbine, and with Solar Turbines for its Taurus 70, a 7.5-MW gas turbine

\section{Applications}

$\checkmark$ Can be used for power generation turbine systems with low emission requirements or preferences, such as California installations, international systems, and systems with low pollution requirements

- Can also be applied to turbine generation systems with cogeneration to improve energy efficiency

\section{Capabilities}

$\checkmark$ Can be used in a broad range of turbine sizes and will not reduce the turbine efficiency.

Achieves emissions less than 3 ppm for $\mathrm{NO}_{\mathrm{X}}$ and less than $10 \mathrm{ppm}$ for $\mathrm{CO}$.

- Uses a catalyst rather than a flame to combust fuel. 


\section{New Aluminum Conductor Composite Core Cable Increases Transmission Efficiency and Installs Easily}

After nearly three years of intensive research and development, Composite Technology Corporation, in association with General Cable, introduced a new conductor type known as ACCC (Aluminum Conductor Composite Core). This new conductor uses a lighter-weight, high-strength carbon and glass fiber core embedded in a high-performance thermoset resin matrix, which is produced continuously using an advanced pultrusion process. The hybrid structural core is then helically wound with fully annealed trapezoidal-shaped conductive aluminum wires. Compared with a conventional steel core cable, the new core allows for up to $28 \%$ more conductive aluminum to be wrapped within the same outside diameter. The end product is of similar weight to conventional aluminum conductor steel reinforced cable, which allows existing structures to be used without modifications.

While the conductor was designed to perform efficiently at temperatures significantly higher than conventional steel-cored conductors, ACCC actually operates much cooler and more efficiently under equal power flow. Because the power flow capability, or "ampacity," is double that of a conventional conductor, the ACCC's improved efficiency can help reduce power generation costs and greenhouse gas emissions, while mitigating grid bottlenecks and the associated high costs of grid congestion.

The ACCC conductor's higher capacity can also improve grid reliability; if a parallel line fails, it can handle the extra current flow. When operated at higher temperatures (representing higher current flow), a normal conductor would tend to thermally expand and sag beyond safe limits - potentially grounding out to adjacent lines or structures - causing catastrophic outage. The ACCC conductor's reduced coefficient of thermal expansion prevents thermally induced line sag and would prevent that type of occurrence.

In addition to improving the weight and conductivity characteristics of utility transmission and distribution lines, the new ACCC allows for reductions in the number of structures by as much as $16 \%$ or more because of its thermal stability and $25 \%$ to $40 \%$ greater strength. The added aluminum content $(\sim 28 \%)$ greatly reduces resistance and line losses. One utility reported a reduction in line losses of approximately $35 \%$ on one of their ACCC lines, which also helped improve the overall efficiency of the system.

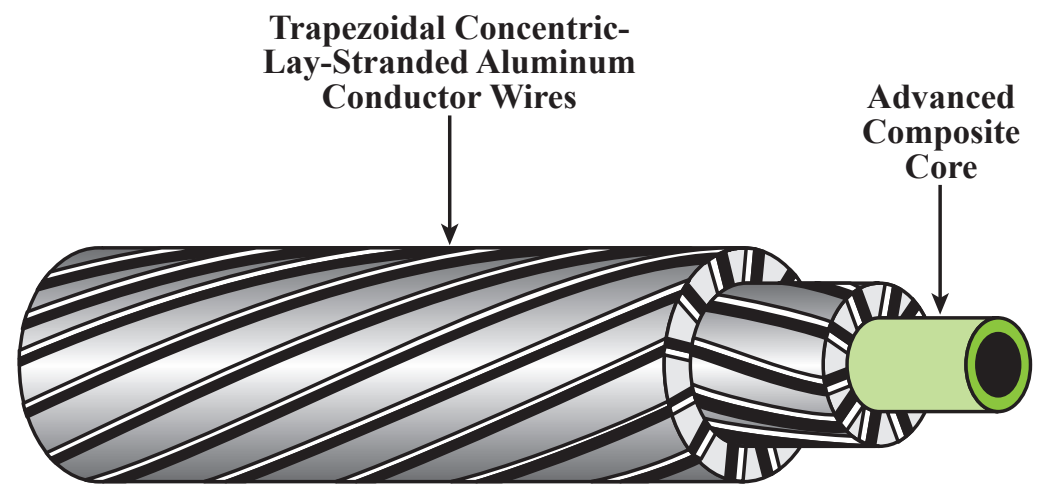

Aluminum Conductor Cable with Composite Core

\section{Overview}

$\checkmark$ Developed by Composite Technology Corporation (www.ctccable.com.com)

Commercialized in 2005

$\checkmark$ Over 648 miles of line installed in 13 U.S. states and much more in foreign countries

\section{Applications}

Can be used by the power industry to increase transmission efficiency and increase capacity for new and existing pathways. Is available in all the industry standard sizes ranging from 431 to 2727 kcmil.

\section{Capabilities}

Doubles the current carrying capacity of existing transmission and distribution lines.

$\checkmark$ Decreases the cost of new installations by reducing the number of structures required and related construction and maintenance costs.

Resists environmental degradation and improves reliability.

\section{Benefits}

\section{Productivity}

Uses conventional installation methods and tools, allows the existing transmission and distribution structures to be used without modifications, and reduces construction costs by using fewer support structures.

\section{Product Quality}

Virtually eliminates high-temperature cable sag and will not rust or corrode or cause electrolysis with aluminum conductors or other components.

\section{Profitability}

Doubles current-carrying capacity and reduces power generation and transmission costs.

DOE Advanced Manufacturing Office 


\section{Cromer Cycle Air Conditioner}

IMPACTS

\section{New Air Conditioning System Uses Desiccant to Transfer Moisture and Increase Efficiency and Capacity}

When cooling a space to a comfortable temperature, two types of heat energy must be removed: temperature-associated sensible heat and moisture-associated latent heat. An air-conditioner coil usually operates by performing about $25 \%$ moisture removal and $75 \%$ cooling. In a typical system, over-cooling must occur to meet the moisture-removal demands. These typical systems inefficiently add heat to the supply air (reheat), which consumes even more energy, to correct for the over-cooling. Latent-heat ratios often become higher than $25 \%$ in hot and humid climates, where introducing fresh air brings in significant levels of moisture, upsetting the temperature and moisture balance of interior spaces and reducing comfort levels. Excessive moisture in the air can also contribute to indoor air quality problems in buildings.

With assistance from DOE's Inventions and Innovation Program, the Cromer cycle air conditioner was developed to reduce energy consumption of the air conditioning while increasing the moisture-removal capacity of the airconditioner coil. In the Cromer cycle air conditioner, a desiccant wheel is used to transfer moisture continuously from the supply air stream to the return air stream before the cooling coil. This transfer enhances dehumidification of the coil without significantly reducing coil temperature, improving the efficiency of the refrigeration cycle. The drier air supplied to interior spaces increases comfort and indoor air quality. Trane incorporated the Cromer cycle into a new system called the Cool Dry Quiet $\left(\mathrm{CDQ}^{\mathrm{TM}}\right)$ desiccant dehumidification system. The first CDQ systems were sold in 2005 and by the end of the year 30 units had been installed, primarily in hospitals and museums. In 2006, Trane began to market the CDQ in roof top units and in applications for package units.

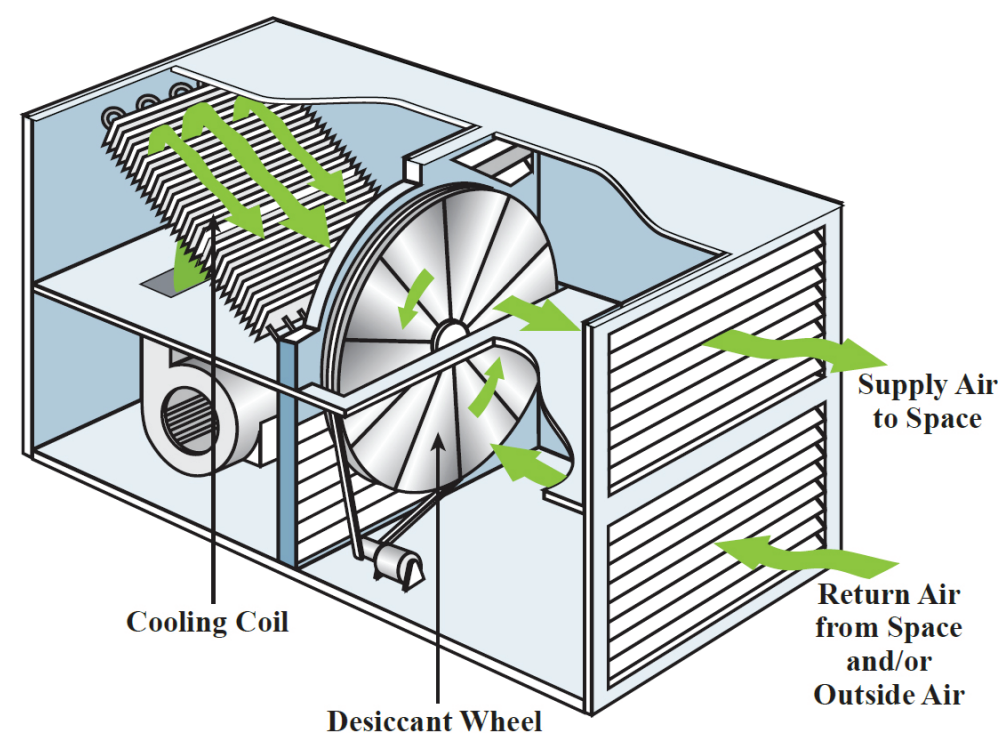

Trane Cromer Cycle Air Conditioner

\section{Overview}

$\checkmark$ Developed by Charles Cromer of the Solar Engineering Co.

Commercialized in 2005

Being produced and marketed by Trane (www.trane.com)

\section{U.S. Energy Savings}

(Trillion Btu)

\begin{tabular}{|c|c|}
\hline Cumulative through 2010 & $\mathbf{2 0 1 0}$ \\
\hline 1.67 & 0.541 \\
\hline
\end{tabular}

\section{U.S. Emissions Reductions}

(Thousand Tons, 2010)

\begin{tabular}{|c|c|c|c|}
\hline Particulates & SO $_{\mathrm{x}}$ & NO $_{\mathrm{x}}$ & Carbon \\
\hline 0.002 & 0.117 & 0.087 & 10.6 \\
\hline
\end{tabular}

\section{Applications}

Can be used in commercial, industrial, or residential HVAC systems needing dehumidification down to $25^{\circ} \mathrm{F}$ dew points

\section{Capabilities}

Reduces the amount of cooling, eliminating reheat used in many systems to dehumidify, and improves the efficiency of the cooling needed by maintaining higher evaporator coil temperatures than standard systems.

- Requires minimal maintenance of the desiccant wheel for the life of the air conditioning system.

\section{Benefits}

\section{Productivity/Comfort}

Improves humidity control for more comfortable working or living environments, resulting in improved productivity.

\section{Waste Reduction}

Avoids the need for stand-alone dehumidification equipment or dedicated outdoor air units; uses return air to regenerate the desiccant versus the hightemperature heat used with other desiccant systems. 


\section{Electrochromic Windows - Advanced Processing Technology}

IMPACTS

\section{'Smart Glass' Technology Reduces Solar Heat Gain in Buildings}

Windows are often the most inefficient part of a building envelope and are responsible for heat loss in cold months and solar heat gain in warm months. Sunlight entering a home can increase cooling loads by up to $20 \%$. In some instances, glare from the sun can make it difficult to see a computer or other LCD screen, requiring the blinds to be pulled, negating the benefits of natural light. Sunlight can also fade furniture, carpets, and drapes, increasing building owners' maintenance costs.

SAGE Electrochromics, Inc., with assistance from DOE's Inventions and Innovation Program, developed SageGlass ${ }^{\circledR}$ product technology to create windows and skylights that switch from clear to dark with the push of a button. Within 5-10 minutes, the electrochromic (EC) glass completely changes, depending on the size and temperature of the pane. The variable tint feature of the glass prevents glare, fading, and heat gain without the loss of a view. Without the drawbacks of traditional glass, this technology allows architects the freedom to design with daylighting, creating well-lit, comfortable buildings.

This EC glass modulates light transmission and solar heat gain by sending an electrical charge through the glass. The glass is made up of five separate layers of ceramic materials; when voltage is introduced, the glass lightens or darkens as needed. The electricity used to operate 1,500 square feet of SageGlass window is less than a 60 -watt light bulb. The glass can be altered manually via a wall switch or as part of an integrated building management system so that windows can be programmed to tint depending on input from timers, motion sensors, or similar controls.

\section{Overview}

$\checkmark$ Developed by SAGE Electrochromics, Inc. (www.sage-ec.com)

Commercialized in 2003

\section{U.S. Energy Savings}

(Trillion Btu)

\begin{tabular}{|c|c|}
\hline Cumulative through 2010 & $\mathbf{2 0 1 0}$ \\
\hline 0.004 & 0.002 \\
\hline
\end{tabular}

\section{U.S. Emissions Reductions}

(Thousand Tons, 2010)

\begin{tabular}{|c|c|c|c|}
\hline Particulates & SO $_{\mathrm{x}}$ & NO $_{\mathrm{x}}$ & Carbon \\
\hline 0.0 & 0.0 & 0.0 & 0.033 \\
\hline
\end{tabular}

\section{Applications}

Can be used in any building with windows or skylights, including homes and large public buildings; is particularly appropriate for hospitals, schools, libraries, data centers, clean rooms, etc.

\section{Capabilities}

$\checkmark$ Reduces solar energy by up to $81 \%$ in its fully tinted state.

Prevents sunlight from damaging artwork, furniture, and carpet.

Reduces glare so windows do not have to be shaded or blocked.

\section{Benefits}

\section{Adaptability}

Can be configured to operate by a wall switch or as part of a building's automation system and is appropriate for both residential and commercial applications.

\section{Energy Savings}

Reduces annual cooling loads in commercial buildings by $20 \%$ and peak electricity demand in most of the United States by $19 \%$ to $26 \%$. 


\section{Energy-Conserving Tool for Combustion-Dependent Industries}

IMPACTS

\section{MultiGas $^{\mathrm{TM}}$ Analyzer Provides On-Line Feedback Resulting in Lower Energy Use and Emissions}

Using a NICE ${ }^{3}$ grant, Advanced Fuel Research (AFR), Inc., has developed and demonstrated a new system to improve continuous emissions monitoring (CEM) and on-line process tuning of combustion-dependent systems such as boilers and turbines.

Many existing combustion-monitoring techniques are unable to effectively and efficiently monitor all combustion gases, including difficult-to-separate hydrocarbons such as formaldehyde and emission control reactants such as ammonia. Typical CEM systems monitor a limited number of gases using an expensive collection of single-gas analyzers. These systems require a temperature-controlled room and a substantial ongoing investment to maintain operation and calibration of the facility.

The new multi-gas analyzer technology is portable, low-cost, and energyefficient and combines advanced Fourier transform infrared spectroscopy with advanced electronics and software. This system provides CEM and on-line feedback for operational tuning of combustion-based industrial processes. The system allows for real-time measurement of criteria emissions and pollutants, including pollutants that are not usually monitored such as formaldehyde and ammonia. The improvements in dependability and efficiency and the lack of need for expansive temperature-controlled space result in lower operations, energy, and labor costs.

\section{Benefits}

\section{Environmental}

Measures criteria and hazardous air pollutants that are not typically monitored on-site in real-time, such as formaldehyde and ammonia.

\section{Productivity}

Reduces maintenance and performance verification time, resulting in labor savings of up to $80 \%$.

\section{Overview}

$\checkmark$ Developed by Advanced Fuel Research, Inc.

Commercialized in 2001

Manufactured and sold by MKS

Instruments

(www.mksinst.com)

$\checkmark 90$ units operating in the U.S. in 2010

\section{U.S. Energy Savings}

(Trillion Btu)

\begin{tabular}{|c|c|}
\hline Cumulative through 2010 & $\mathbf{2 0 1 0}$ \\
\hline 0.029 & 0.007 \\
\hline
\end{tabular}

\section{U.S. Emissions Reductions}

(Thousand Tons, 2010)

\begin{tabular}{|c|c|c|c|}
\hline Particulates & SO $_{x}$ & NO $_{x}$ & Carbon \\
\hline 0.0 & 0.002 & 0.001 & 0.138 \\
\hline
\end{tabular}

\section{Applications}

Can be used in systems and processes requiring combustion of fuels in engines, boilers, incinerators, and turbines

\section{Capabilities}

- Achieves higher combustion efficiencies through closely monitored and controlled combustion.

Reduces emissions through verified efficient operation.

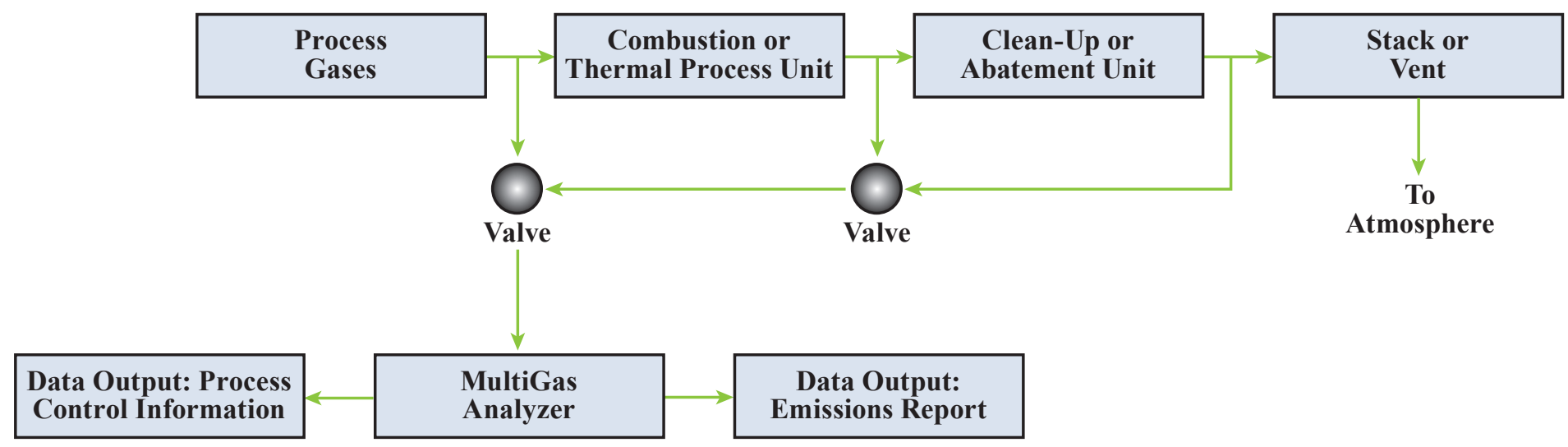

MultiGas Analyzer System 


\section{Fiber-Optic Sensor for Industrial Process Measurement and Control}

\section{Reliable Advanced Laser Sensor Helps Control High Temperature Gas Combustion}

Through a marketing agreement with MetroLaser Inc., Bergmans Mechatronics LLC is offering the LTS-100 sensor to the aerospace and industrial markets. This new sensor will help reduce the cost and improve the performance of traditionally difficult temperature measurements. A separate marketing agreement with LaVision $\mathrm{GmbH}$ of Germany has been entered into in which a version of this sensor is marketed to the pharmaceutical industry for leak detection.

Many existing industrial process sensors have limited accuracy in applications involving highly corrosive gases at elevated temperature and pressure because they require extractive sampling systems that introduce variations in the temperature, pressure, and composition of the probed gases. Moreover, sampling systems introduce a lag resulting in $>1-10$ second response times, require frequent servicing, and may be subject to unexpected failures because of their complexity. Using advanced tunable diode laser absorption spectroscopy (TDLAS) sensors for closed-loop process control affords a direct, quantitative measure of the species concentration in the probed region. In addition, by monitoring two or more transitions, the temperature along the optical path can also be determined.

Near-infrared diode lasers are attractive light sources for sensing applications because they are rapidly tunable, small and lightweight, low-cost, efficient, and robust. They operate at near-ambient temperatures and produce narrow bandwidth radiation over a broad wavelength range. These on-line sensors can be combined with process optimization control strategies to significantly improve plant throughput, increase product quality, and reduce energy consumption and waste.

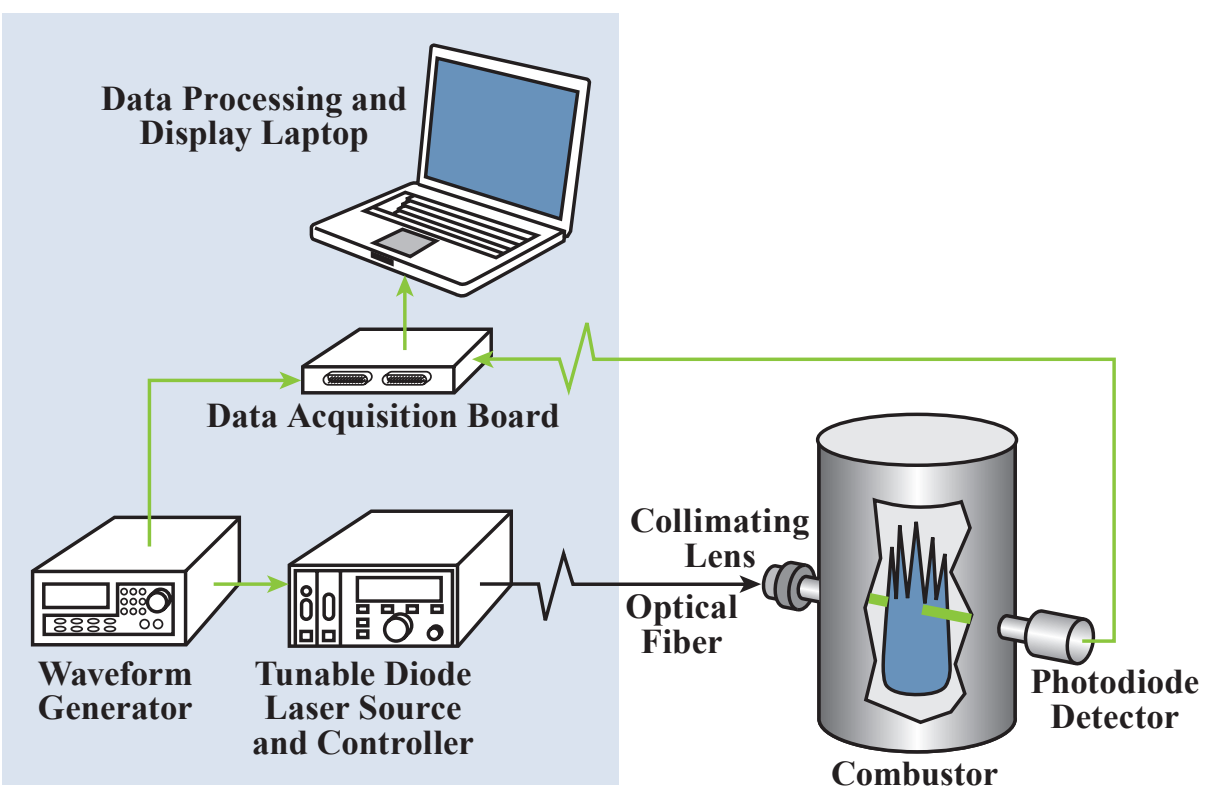

\section{Overview}

Developed by MetroLaser Inc., Irvine, CA

Commercialized in 2003

Being provided as a service in the United States by MetroLaser (www.metrolaserinc.com)

Applying a derivative of this technology as a leak detection system for pharmaceutical production lines

\section{Applications}

Can be used in coal-fired power plants to achieve accurate real-time temperature measurements, in solid propellant combustion to enhance the capabilities of the next generation of solid-fuel vehicles, and in leak detection for pharmaceutical production

\section{Capabilities}

Monitors high-temperature gas combustion in process control applications.

Monitors vacuum leaks in pharmaceutical vials using non-intrusive measurements.

\section{Benefits}

\section{Profitability}

Reduces maintenance costs and minimizes slag buildup heat-transfer losses in coalfired power plants by precisely controlling furnace temperature and startups.

\section{Reliability}

Performs measurements regardless of vibration, flame luminosity, temperature, pressure extremes, and particle interferences.

LTS-100 Processing Unit 


\section{Revolutionary Optical Technology Provides Rapid Measurement of Large Samples of Fiber Diameters}

Fiber size (or denier) has a significant effect on the performance of fiberbased products, such as filters, insulation, and composites. Fiber samples are generally characterized by optical or electron microscopy. Flow resistance of a sample of fibers (e.g., by the Micronaire ${ }^{\mathrm{TM}}$ technique) is also used to estimate the mean fiber size. However, these methods require sampling and are time consuming, and microscopic measurements are usually based on a small number of fibers selected from an image of a collection of fibers and may not be statistically reliable. Rapid measurement of fiber size, based on a large sample, is desirable for quality control of fiber-based products, development of new fiberizing processes, or basic research on fiber generation. With assistance from DOE's Inventions and Innovation Program, Powerscope, Inc., developed FibrSizr ${ }^{\mathrm{TM}}$, which provides rapid measurements for both on-line and off-line fiber characterization. The sample size is large and usually consists of hundreds of fibers.

FibrSizr consists of a laser instrument developed for the accurate real-time and in-situ determination of fiber diameter distributions. This device can be used to monitor nonwovens and glass fibers during production and to rapidly measure fiber size distribution in a web sample. This technique is applicable across a wide range of polymers, production methods, and fiber sizes.

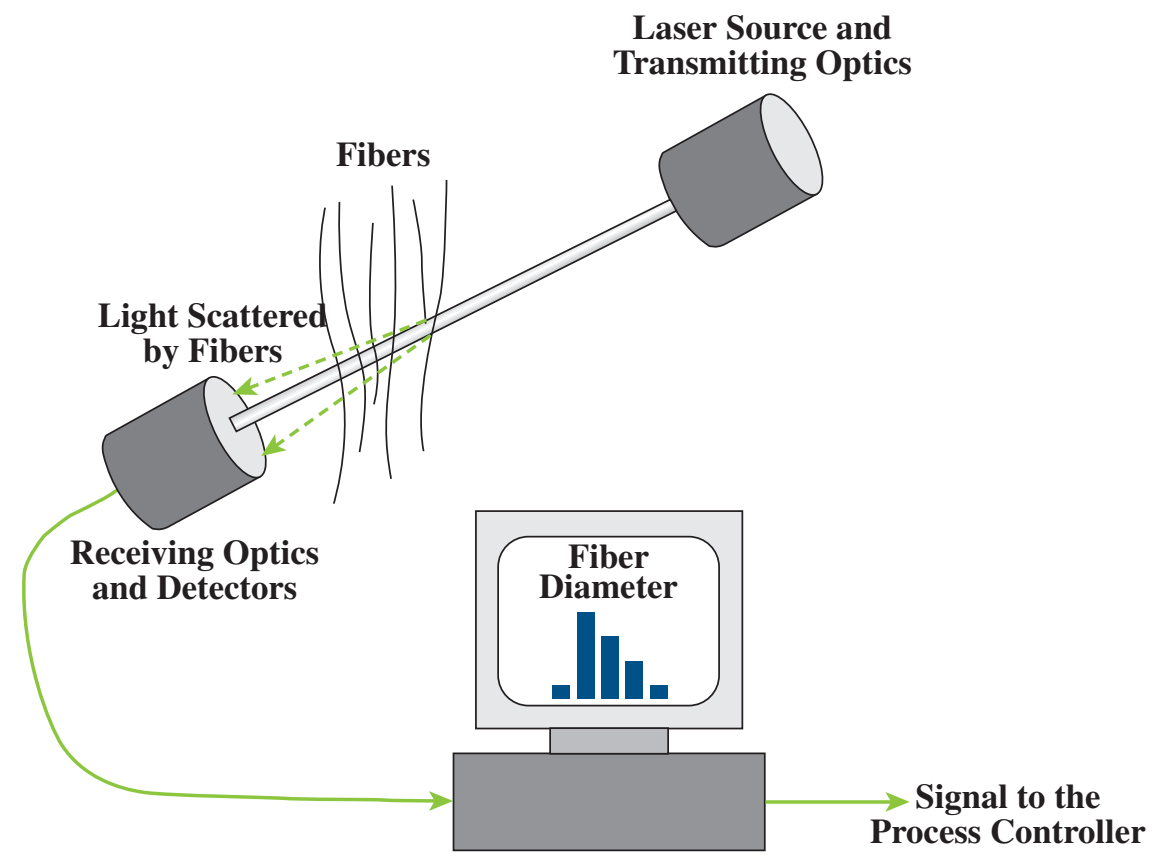

Fiber Sizing Sensor/Controller Using Ensemble Laser Diffraction

\section{Overview}

Developed and commercialized by Powerscope, Inc., in 2004

Completed sales, lease arrangements, and contract measurements for several major U.S. fiber manufacturers

\section{Applications}

Can be used in off-line and on-line process control of fibers on a variety of production/ treatment methods such as meltblown, spunbond, meltspun, carded, chemical bonded, needlepunched, spunlaced, stitchbonded, thermal bonded, and rotary fiberizing

\section{Capabilities}

$\checkmark$ Offers a new model that uses violet laser, instead of red laser, for better resolution of fine fibers as small as 0.7 micron in mean size.

Provides a detachable transmitter and receiver for applications with limited physical access.

Covers a wide range of fiber sizes (denier) and fiber densities using adjustable laser power and detector gain.

\section{Benefits}

\section{Energy Savings}

Eliminates events, such as sudden shutdowns, which result in waste of energy and material, by close monitoring of the process.

\section{Pollution Reduction}

Minimizes release of pollutants such as $\mathrm{CO}_{2}$ from the pertinent combustion processes by operating the fiberizers at near optimal conditions.

\section{Product Quality}

Measures and controls fiber size distribution, which is a critical element in producing nearly all value-added fiber products. 


\section{Novel Technology Enables Energy-Efficient Production of High-Strength Steel Automotive Parts}

Recent U.S. automobile sales show a growing demand for more fuel-efficient and environmentally-friendly vehicles, including hybrids. The U.S. auto industry is pursuing at least two parallel paths to address these market evolutions. The first path involves design changes in the engine plant, such as improved internal combustion engines, hybrids, and alternate fuel engines. The second method focuses on changes in the materials used to build vehicle frames and bodies, thereby reducing weight and improving fuel efficiency. Researchers have found that work-holding capabilities in excess of 600 tons are required to form the higher strength steels. Conventional press systems with nitrogen-based cylinders suffer from excess shock loading and an inability to control individual cylinders. A system is needed that offers improved vehicle component forming capability under heavy loads.

With assistance from DOE's Inventions and Innovation Program, Metalforming Controls Corporation has developed Force Modulator ${ }^{\mathrm{TM}}$ cylinder technology.

The Force Modulator system is built around a series of interconnected hydraulic cylinders. Each cylinder has a proprietary control device that allows for changing resistance throughout the stroke. In short, stroke tonnage can be controlled at any point in the stroke. This capability allows each cylinder to start with virtually no resistance tonnage (the equivalent of preacceleration), increase tonnage rapidly to set the bead, and decrease tonnage during part formation. Any other tonnage profile is also possible. When the press upstrokes, the initiation of system re-pressurization and the timing of re-pressurization allow the piston and binder return to be controlled. This system also allows for zone control. If required, the tonnage profile of each cylinder can be independently controlled, allowing press operators to increase or decrease tonnage at each point on the binder ring. Zone control is exerted through the control device found in each cylinder.

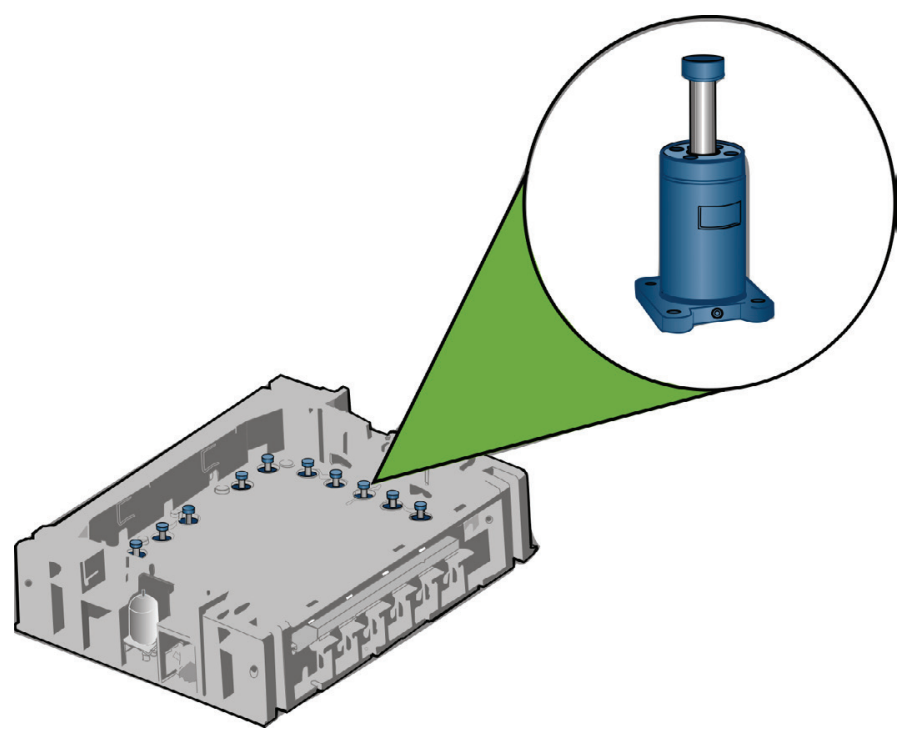

Metalforming Controls Corporation's Force Modulator Hydraulic Cylinder System

\section{Overview}

Developed and marketed by Metalforming Controls Corporation (www.mfcontrols.com)

Commercialized in 2009, with two cushion units operating in the U.S. and multiple units operating internationally.

\section{U.S. Energy Savings}

(Trillion Btu)

\begin{tabular}{|c|c|}
\hline Cumulative through 2010 & $\mathbf{2 0 1 0}$ \\
\hline 0.045 & 0.029 \\
\hline
\end{tabular}

\section{U.S. Emissions Reductions}

(Thousand Tons, 2010)

\begin{tabular}{|c|c|c|c|}
\hline Particulates & SO $_{\mathrm{v}}$ & NO $_{\mathrm{v}}$ & Carbon \\
\hline 0.0 & 0.008 & 0.005 & 0.612 \\
\hline
\end{tabular}

\section{Applications}

Can be used in the stretch-forming of standard and high-strength steel components for lightweight vehicle frames and bodies.

\section{Capabilities}

- Uses a die-mounted hydraulic cylinder system, which allows a soft hit, tonnage control throughout the press stroke, and a controlled return during the press stroke.

Reduces shock loading of presses by $20 \%$ or more compared with conventional nitrogen-based systems.

\section{Benefits}

\section{Energy Savings}

Reduces the amount of work required by the compressor via regenerative use of the working fluid's potential energy.

\section{Product Quality}

Produces high-strength steel components, which reduce vehicle weight and increase safety. 


\section{Freight Wing ${ }^{\text {TM }}$ Aerodynamic Fairings}

IMPACTS

\section{Innovative Aerodynamic Fairings Minimize Drag on Box-Shaped Semi-Trailers}

A great deal of scientific research has demonstrated that streamlining boxshaped semi-trailers can significantly reduce a truck's fuel consumption. However, significant design challenges have prevented past concepts from meeting industry needs. Freight Wing, Inc., was formed to improve the fuel efficiency and profitability of trucking fleets through innovative aerodynamic devices. Freight Wing was initially funded through a grant from DOE's Inventions and Innovation Program to develop rear-fairing technology and has since expanded the company's products to a complete line of aerodynamic solutions. Their initial research focused on developing a practical rear fairing that would not interfere with the truck's operation and on investigating other means to reduce aerodynamic drag on box-shaped semi-trailers. Freight Wing market research soon revealed that the industry was not very interested in the rear fairing because that area is extremely prone to damage and durability is a primary concern. Consequently, the company has since focused on developing designs for front or gap fairings and undercarriage or belly fairings.

Freight Wing generated prototypes of all three fairing designs with their manufacturing partner, ASAP Metal Fabricators, in early 2004. In May 2004, Freight Wing tested all three fairing prototypes at the independently owned Transportation Research Center (TRC) in East Liberty, Ohio. TRC tested the fairings using the industry standard Society of Automotive Engineers/ Technology \& Maintenance Council (SAE/TMC) J1321 fuel consumption procedure Type II test. A 7\% fuel savings was demonstrated on trailers equipped with all three fairings. The product was marketed starting in the fall of 2004, and soon thereafter the company made its first sale of two belly fairings. Additional research was conducted to develop second-generation designs using different materials and aerodynamic concepts. The resulting second-generation belly fairing product produced a $7.4 \%$ fuel savings alone in SAE tests and in fleet operation. Partnerships with major trailer manufacturers have been developed to offer Freight Wing products on new trailers with factory installation. In 2010, 8,323 fairings were sold, demonstrating a significant increase in product demand and industry acceptance of the technology.

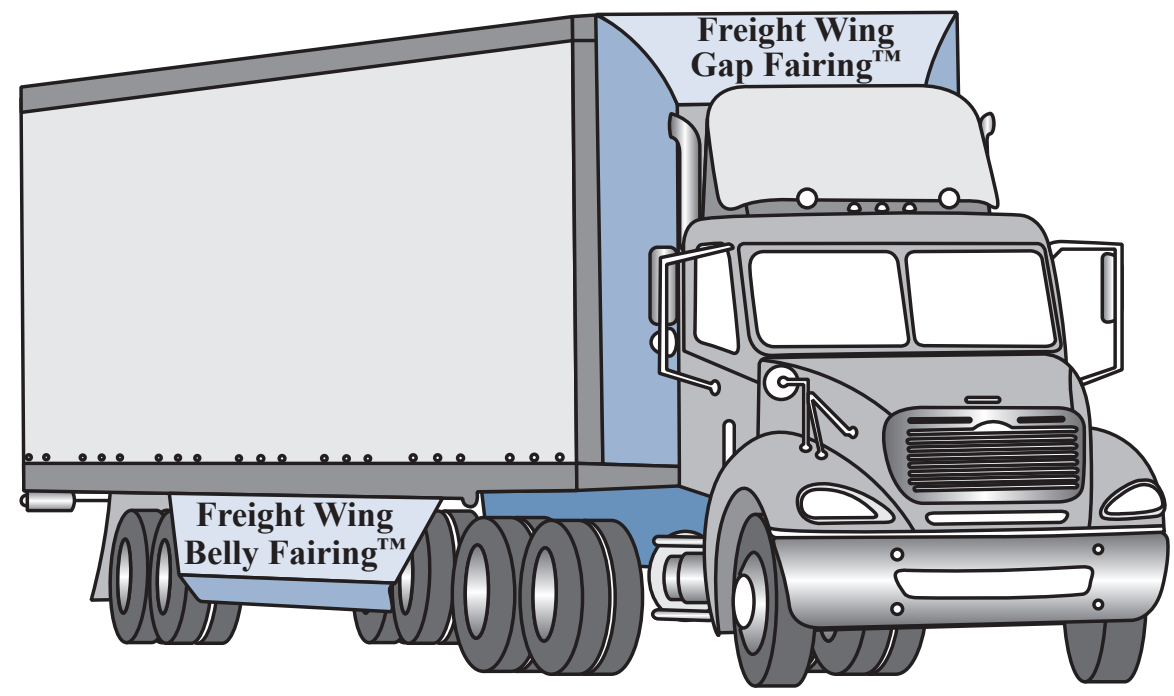

Freight Wing Fairings Installed on a Semi-Trailer

\section{Overview}

Developed and marketed by Freight Wing, Inc. (www.freightwing.com)

Commercialized in 2004

Currently used by over 400 trucking fleets in the United States and Canada

\section{U.S. Energy Savings}

(Trillion Btu)

\begin{tabular}{|c|c|}
\hline Cumulative through $\mathbf{2 0 1 0}$ & $\mathbf{2 0 1 0}$ \\
\hline 2.23 & 1.51 \\
\hline
\end{tabular}

\section{U.S. Emissions Reductions}

(Thousand Tons, 2010)

\begin{tabular}{|c|c|c|c|}
\hline Particulates & SO $_{x}$ & NO $_{x}$ & Carbon \\
\hline 0.011 & 0.882 & 0.234 & 33.0 \\
\hline
\end{tabular}

\section{Applications}

Can be used on trucks or semi-trailers to reduce the effects of aerodynamic drag

\section{Capabilities}

Reduces aerodynamic drag on semitrailers.

Retrofits on existing or new semi-trailers.

\section{Benefits}

\section{Energy Savings}

Reduces fuel consumption by $7 \%$ with use of second-generation belly fairing alone.

\section{Emission Reduction}

Reduces emissions of combustion products, including particulates, $\mathrm{SO}_{\mathrm{x}}, \mathrm{NO}_{\mathrm{x}}$, and $\mathrm{CO}_{2}$. 


\section{New Material Processes Improve the Performance and Lifetime of Tools and Dies}

Tools, dies, and process equipment currently used in the metal casting, forging, and glass manufacturing industries are generally composed of thick-sectioned monolithic $\mathrm{H} 13$ or other tool steels. Although the starting materials are relatively inexpensive, the conventional tool manufacturing process results in low material yields, significant machining time, long lead times, and high overall cost. When the dies contact either hot/molten metals or glass, as appropriate, significant degradation of the surfaces occurs due to soldering, heat checking, and/or physical erosion. Damaged dies lead to part surface imperfections, dimensional tolerance issues, high part reject rates, and die repair downtime.

With assistance from AMO, Carpenter Powder Products, Inc., has developed functionally graded materials (FGM) to produce more robust tools and dies. The techniques of laser powder deposition and solid-state dynamic powder consolidation result in FGM tools and dies with increased wear resistance and superior performance at elevated temperatures.

Functionally graded materials provide many benefits to the industrial process user. The tools and dies perform better, which leads to shorter process cycle times and a reduction in waste scraps from parts manufacturing. In addition, FGM parts have a longer lifetime than traditional tools and dies, which reduce replacement costs.

\section{Benefits}

\section{Adaptability}

Allows properties of functionally graded tools to be customized to meet the requirements of a particular application.

\section{Cost Savings}

Increases tool and die lifetimes, thereby reducing the cost to replace parts.

\section{Overview}

- Developed by Carpenter Powder Products, Inc. (www.cartech.com)

Commercialized in 2007

Used by multiple U.S. metal forging and die casting companies in 2010

\section{Applications}

Can be used in the aluminum, forging, glass, metal casting, and steel industries

\section{Capabilities}

- Improves elevated-temperature properties of tools and dies.

$\checkmark$ Reduces die surface degradation.

Increases wear resistance and dimensional stability of tools and dies.

Reduces process cycle times.

\section{Waste Reduction}

Reduces scrap and waste in tool and die parts manufacturing.

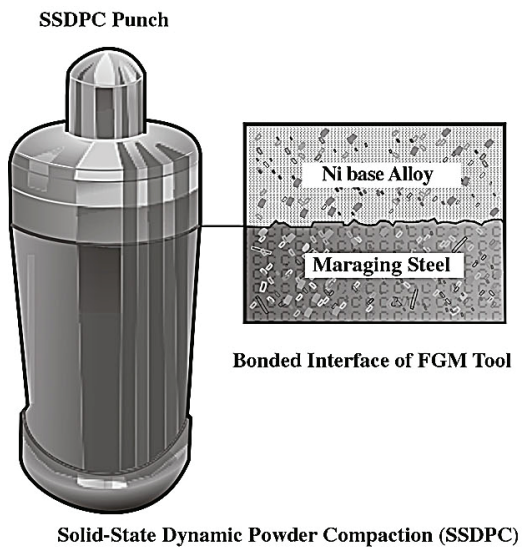

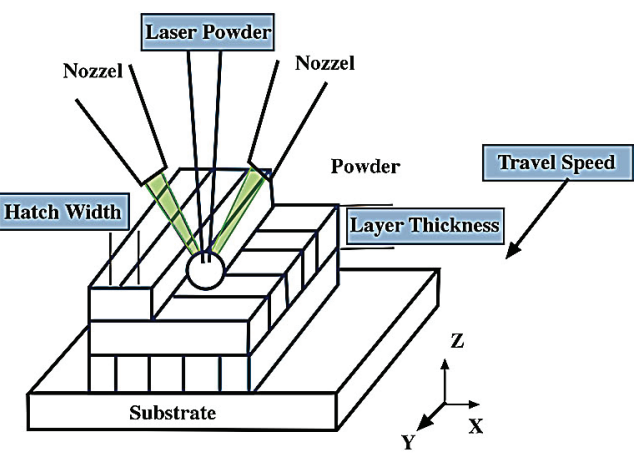

Laser Powder Deposition (LDP) 


\section{Thermal Energy Storage for Light Commercial Refrigerant-Based Air Conditioning Units}

The Ice Bear ${ }^{\circledR}$ storage technology was initially developed by Powell Energy Products, with assistance from DOE's Inventions and Innovation Program and commercialized by Ice Energy ${ }^{\circledR}$, Inc. The Ice Bear storage module was engineered to complement new or existing air conditioning (AC) equipment to shift energy use from peak to off-peak periods. The Ice Bear unit is designed for use with rooftop or split system AC equipment. The Ice Bear unit with an air-cooled condensing or rooftop unit operates during off-peak hours to store energy as ice. During peak daytime cooling, the Ice Bear unit functions as the condenser, circulating ice-condensed refrigerant with a low-power refrigerant pump. Total energy use is only 300 watts to provide 7.5 tons of cooling for 6 hours.

The Ice Bear unit consists of a heat exchanger made of helical copper coils placed inside an insulated polyethylene storage tank filled with normal tap water, a patented refrigerant management system, a low-power refrigerant pump, and the CoolData ${ }^{\circledR}$ controller. To provide AC, the Ice Bear uses a lowpower pump to circulate refrigerant to the evaporator coil in the air handler. By using the condensing or rooftop unit to produce ice during the night and the refrigerant pump to supply condensed liquid refrigerant to the evaporator coil during the day, the Ice Bear effectively transfers the majority of load requirements to nighttime hours or levels energy loads. In both of these applications, the Ice Bear reduces humidity levels, which helps meet indoor air quality standards.

The Ice Bear unit is designed to meet retrofit, replacement, and new construction requirements in commercial or industrial AC applications.

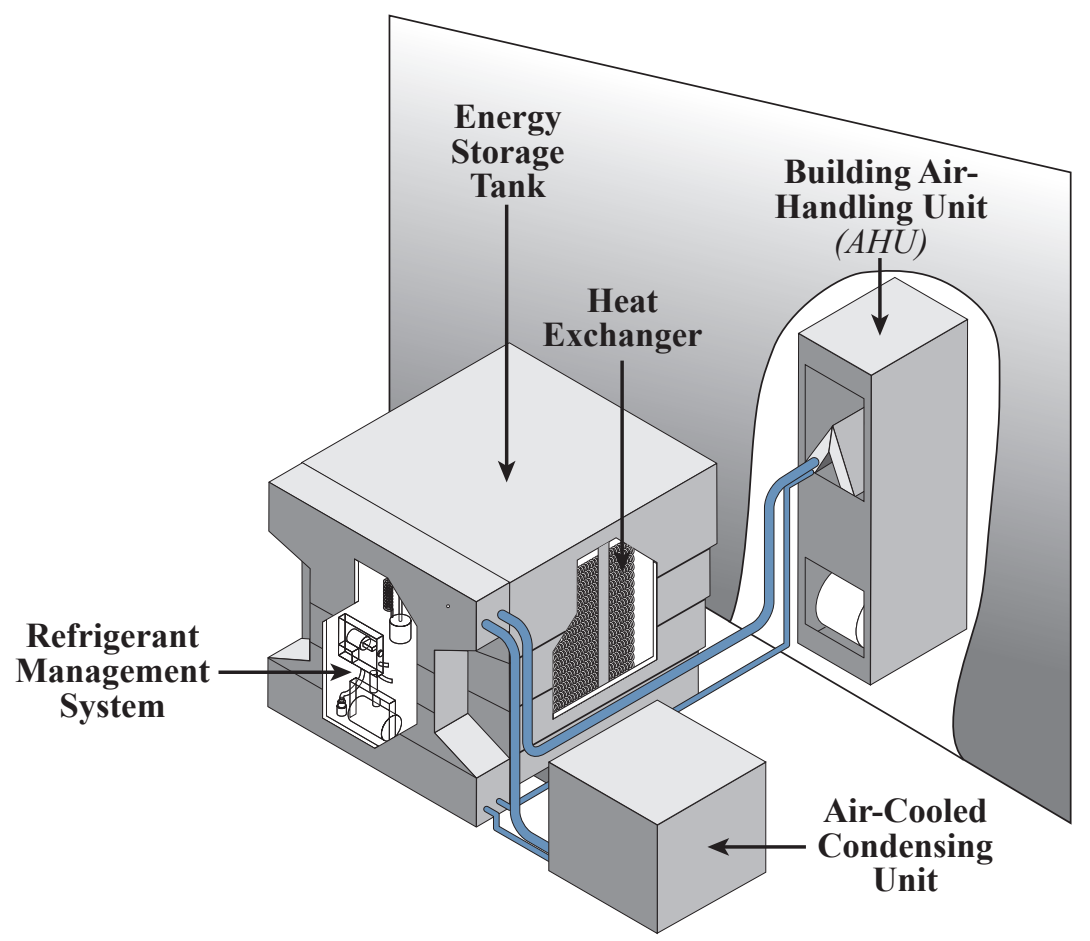

Ice Bear Storage Module

\section{Overview}

$\checkmark$ Base technology developed by Powell Energy Products, Inc., and patents acquired by Ice Energy, Inc. in 2003

$\checkmark$ Commercialized by Ice Energy, Inc. in 2005

(www.ice-energy.com)

\section{U.S. Energy Savings}

(Trillion Btu)

\begin{tabular}{|c|c|}
\hline Cumulative through 2010 & $\mathbf{2 0 1 0}$ \\
\hline 0.004 & 0.001 \\
\hline
\end{tabular}

\section{U.S. Emissions Reductions}

(Thousand Tons, 2010)

\begin{tabular}{|c|c|c|c|}
\hline Particulates & SO $_{\mathrm{x}}$ & NO $_{\mathrm{x}}$ & Carbon \\
\hline 0.0 & 0.0 & 0.0 & 0.026 \\
\hline
\end{tabular}

\section{Applications}

Can be used in conjunction with 3.5-to20 ton AC units in markets such as small to big-box retail, industrial, data centers, office buildings, restaurants, banks, fire stations, libraries, schools, and community centers

\section{Capabilities}

- Shifts $95 \%$ of AC load from peak to offpeak periods.

$\checkmark$ Offers energy storage capacity of 45-ton/ hr, up to 7.5 tons of cooling for 6 hours.

\section{Benefits}

\section{Cost Savings}

Substantially reduces electrical bills in loadshifting applications where peak and offpeak price differentials exist by reducing demand by $95 \%$. 


\section{In-Situ, Real Time Measurement of Elemental Constituents}

IMPACTS

\section{New Laser System Provides Real-Time Measurements for Improved Product Quality Control}

A probe uses laser-induced breakdown spectroscopy (LIBS) to determine the elemental constituents in ferrous and non-ferrous metals, ceramics, or glass. This probe measures continuously and in-situ at any point in the melt, thus providing spatial and temporal real-time data. The probe uses a pulsed (5-10 ns duration) Nd:YAG laser at $1064 \mathrm{~nm}$ that is focused, through a fiberoptic cable. In the molten aluminum application, the probe is immersed into the melt, generating high-temperature plasma consisting of excited neutral atoms, ions, and electrons. Any chemical compounds present in the sample are rapidly separated into their constituent elements. The laser-generated plasma is allowed to cool several microseconds after the laser pulse, and then a spectrometer collects and disperses optical emissions from neutral and ionized atoms. The line radiation signal provides the concentration of each element present.

The probe has several applications in the ferrous and non-ferrous metals, ceramics, or glass industries. For example, the probe can be used for in-line alloying to measure chemical content during a pour and for continuous and semi-continuous furnace operations to minimize the current practice of offline sampling and measurement. In other applications, the probe can perform in-line monitoring of impurity removal from the melt, such as removing magnesium from molten aluminum, and can provide real-time data to validate computer simulations and model furnaces.

\section{Benefits}

\section{Product Quality}

Providing data for use in a feedback control loop to control the furnace operation in real time increases product quality.

\section{Productivity and Profitability}

Eliminates the aluminum and steel furnace idle time now required for off-line measurement of melt constituents. The payback has been shown to be less than one year.

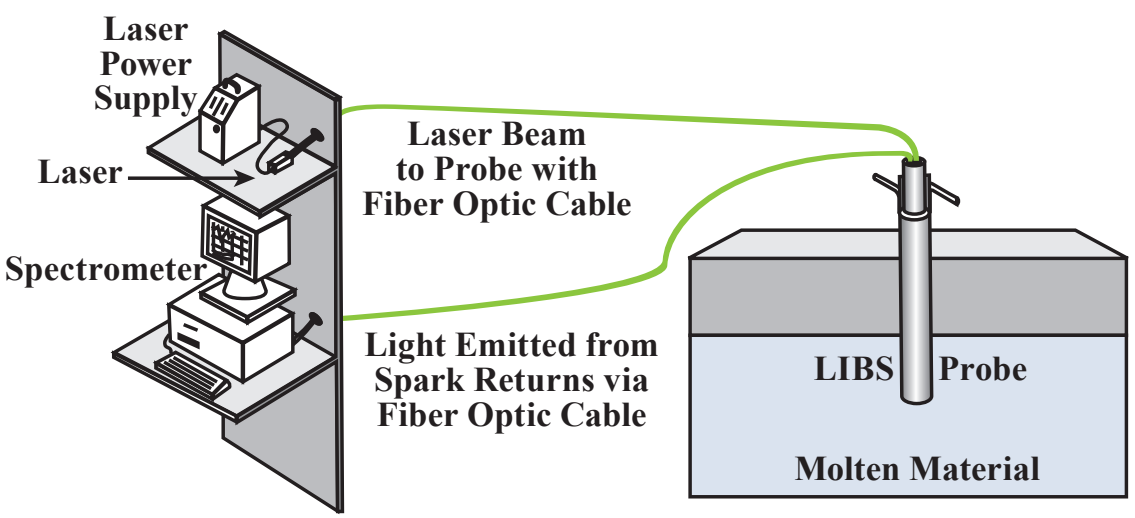

Example of LIBS System Applied to Molten Material

\section{Overview}

$\checkmark$ Developed and marketed by Energy Research Company

(www.er-co.com)

5 units installed in the U.S., with 3 units currently operating.

\section{U.S. Energy Savings}

(Trillion Btu)

\begin{tabular}{|c|c|}
\hline Cumulative through 2010 & $\mathbf{2 0 1 0}$ \\
\hline 0.927 & 0.000 \\
\hline
\end{tabular}

\section{U.S. Emissions Reductions}

(Thousand Tons, 2010)

\begin{tabular}{|c|c|c|c|}
\hline Particulates & SO $_{\mathrm{x}}$ & NO $_{\mathrm{x}}$ & Carbon \\
\hline 0.0 & 0.0 & 0.0 & 0.0 \\
\hline
\end{tabular}

\section{Applications}

Can be used to identify elemental constituents in ferrous and non-ferrous metals, ceramics, and glass melts during the fabrication process; to identify elemental constituents of wet or dry, solid or gaseous raw materials via close non-contact; and to characterize coal sample constituents to determine coal quality

\section{Capabilities}

Measures aluminum melt constituents with $5 \%$ accuracy and a $0.002 \%$ minimum detection limit.

- Monitors trace alkali metal content in electronic glass compositions.

Analyzes material being conveyed prior to processing, potentially eliminating energy use and emissions from using "off-spec" material. 


\section{New Class of High-Performance Carburized Steels Saves Energy and Increases Productivity}

Various project partners have integrated an optimization of process and materials that will enable a broad usage of high-temperature carburization. The unique capabilities of high-temperature carburizing were exploited to access new levels of steel performance, including the distortion-free, highperformance gear and bearing materials for the transportation sector. Emphasis was placed on creating a new class of thermally stable, ultra-durable, deep case-hardened steels that could ultimately extend case hardening to tool and die steels. Case hardening would enable major productivity gains in the forging, forming, and die casting of aluminum and steel.

With assistance from AMO, a consortium of project partners used their carburization simulation tools and fundamental calibration data to gain reliable control of high-temperature carburizing of their new class of high-performance gear steels. One of the partners, QuesTek Innovations LLC, used the technology to successfully commercialize the new gear steels by demonstrating both higher gear performance and acceptably reduced manufacturing variation.

\section{Benefits}

\section{Energy Savings}

Reduces the U.S. annual energy consumption for carburizing.

\section{Environmental}

Reduces greenhouse gases compared with conventional gas carburizing technology.

\section{Productivity}

Reduces scrap and eliminates the need for hard chromium plating in many applications; offers increased durability and higher performance when it replaces conventional steel.

\section{Overview}

Developed by a consortium of project partners including the Center for Heat Treating Excellence, Metal Processing Institute - Worcester Polytechnic Institute, Northwestern University, and QuesTek Innovations LLC

$\checkmark$ Commercialized by QuesTek in 2003 (www.questek.com)

\section{Applications}

Can be used in high-performance gear and bearing applications for the transportation sector and in new deep-case applications, that include ultra-durable die materials for forging and forming of steel and aluminum and for die casting of aluminum

\section{Capabilities}

Establishes sufficient control of hightemperature carburizing to greatly expand applications.

$\checkmark$ Creates a new class of steels with particular emphasis on novel deep-case applications.

$\checkmark$ Demonstrates accelerated materials and process development through the emerging technology of computational materials design.

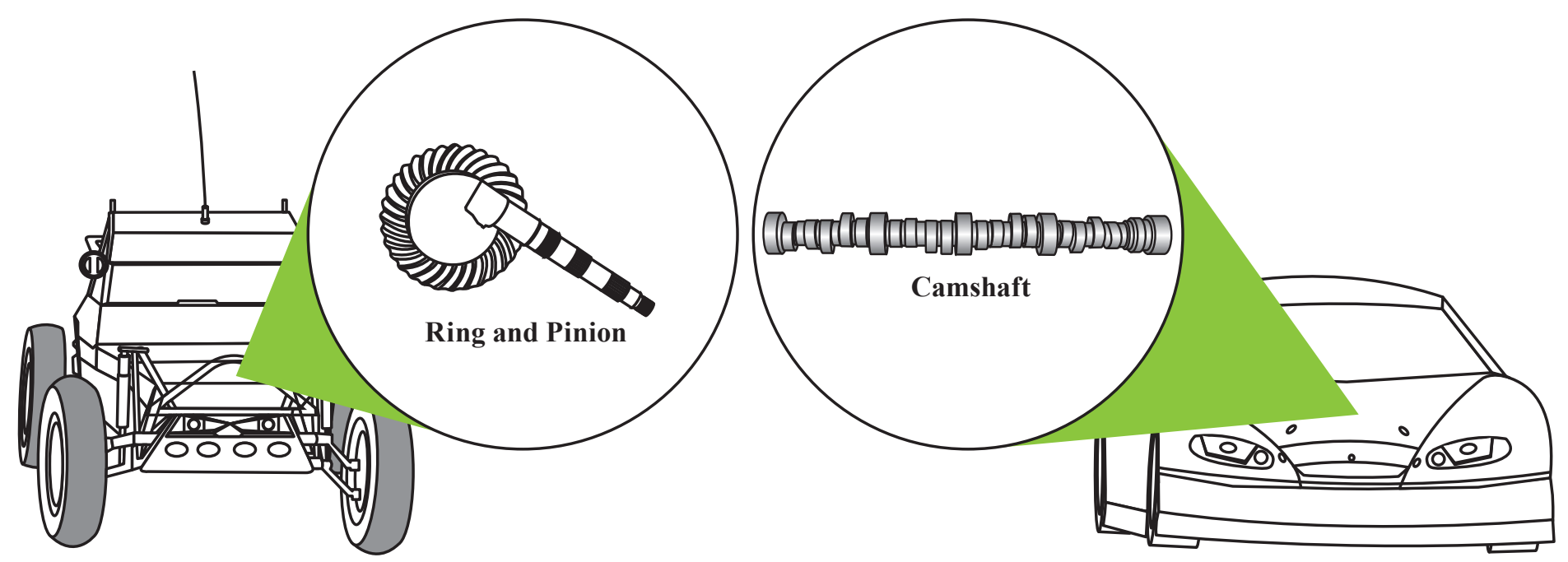

New Gear Steel Products Created Using High-Temperature Carburizing 


\section{New Surface-Coating Ventilation System Reduces Air Pollution and Energy Use}

Volatile organic compounds (VOCs) are released during the application of spray coatings in paint enclosures, exposing workers to toxins, creating air pollution emissions, and creating fire or explosion hazards. To meet safety and environmental regulations, paint booths are usually ventilated with $100 \%$ outside air, which is then heated or cooled to maintain useable work temperatures. Ultimately, the amount of ventilating air entering the spray booth (usually expressed as cubic feet per minute) determines the energy usage and scale of the pollution problem.

A new spray booth technology developed by Mobile Zone Associates, with the help of a grant from the EPA and DOE's Inventions and Innovation Program, greatly reduces the amount of energy needed to heat and cool ventilation air during surface coating operations by reducing the quantity of ventilating air consumed. The Mobile Zone system separates the human painter from the contaminated air of the spray booth by providing the painter with a separate, mobile work platform or cab during spray coating operations. The cab is flushed with fresh air, while the rest of the spray booth uses recirculated air. The design meets OSHA regulations and National Fire Protection Association (NFPA) guidelines. Excluding robotic painting operations, the Mobile Zone installation is the only successful example of substantial ventilating air reduction in the United States and possibly the world. It represents superior process containment and is a first step before consideration of air-to-air heat exchange or VOC pollution-control equipment. The technology is currently being used by the U.S. Army at Fort Hood, Texas, for consideration of system wide use.

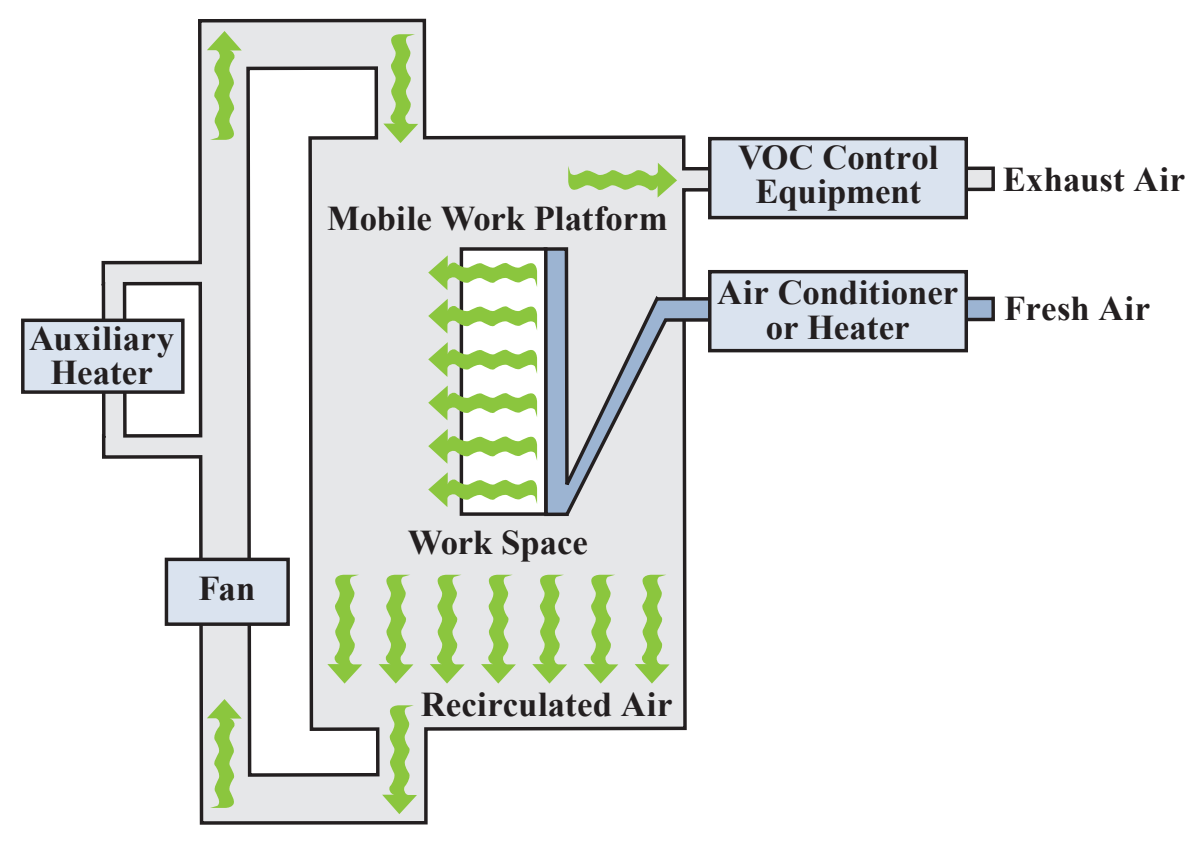

Air Flow in Paint Spray Booth with Mobile Zone System

\section{Overview}

$\checkmark$ Developed by Mr. Clyde Smith and Mr. William Brown of Mobile Zone Associates (www.mobilezonepaintbooth.com/ aboutus.html)

- One installation operating in the United States in 2010

\section{U.S. Energy Savings}

(Trillion Btu)

\begin{tabular}{|c|c|}
\hline Cumulative through 2010 & $\mathbf{2 0 1 0}$ \\
\hline 0.065 & 0.007 \\
\hline
\end{tabular}

\section{U.S. Emissions Reductions}

(Thousand Tons, 2010)

\begin{tabular}{|c|c|c|c|}
\hline Particulates & SO $_{\mathrm{x}}$ & NO $_{\mathrm{x}}$ & Carbon \\
\hline 0.0 & 0.001 & 0.001 & 0.120 \\
\hline
\end{tabular}

\section{Applications}

Can be used to apply sprayed surface coatings to chairs, tables, motorcycles, tractors, railroad cars, aircraft, and other painted products in either side-draft or down-draft booths

\section{Capabilities}

Reduces the ventilation, heating and cooling requirements by directing a sufficient, but small, amount of fresh air to the painter and recirculated air to the remaining unoccupied space within the spray booth. Meets existing OHSA, EPA, and NFPA standards for worker conditions.

\section{Benefits}

\section{Productivity/Product Quality}

Maintains or improves production speed and quality.

\section{Profitability}

Reduces the size of heating, cooling, and pollution control equipment between $60 \%$ and $98 \%$, which offers significant savings in associated capital and energy costs. 


\section{Nanocoatings for High-Efficiency Industrial Hydraulic and Tooling Systems}

\section{Surface Coatings Enhance Wear Resistance of Metals, Saving Energy and Increasing Component Life}

Industrial energy efficiency is directly linked to the wear and degradation of materials used in processing applications such as pumps and tooling components. The preferred route to minimizing wear is to apply a protective, hard coating to contacting surfaces so that the surfaces generate less friction and resist wear. With lower friction between contacting surfaces, less energy is required to overcome frictional forces during start-up and operation, thereby increasing energy efficiency. While the energy savings per component may be modest, substantial cumulative benefits are possible due to the large number of pumps and machining tools currently in operation.

With assistance from AMO, Eaton Corporation is developing a new family of "superhard" (greater than $40 \mathrm{GPa}$ ) composites in which the hardness is derived from microstructural engineering of the constituent phases. The coatings combine high hardness with a low coefficient of friction and have been shown to substantially reduce tool wear in lathe turning tests. This project is focusing on materials degradation resistance for two distinct industrial applications: tooling systems and industrial hydraulic components.

Widespread use of the new superhard coatings will increase energy efficiency through diminished friction losses and increased seal reliability in hydraulic pumps. Further savings are possible through an extended lifetime of optimum cutting performance in machine tooling. Increased system reliability coupled with decreased downtime and replacement costs also results in economic benefits. Environmental benefits include reduced pollutant leakage through pump seals and reduced emissions due to increased equipment energy efficiency.

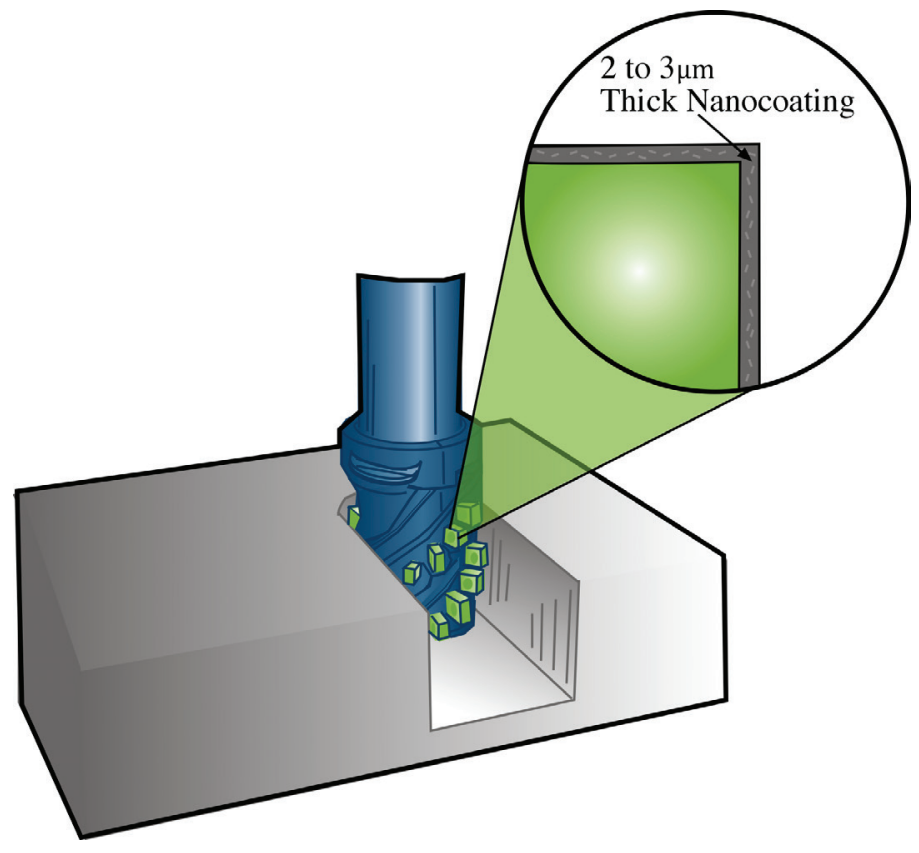

Eaton Corporation's Nanocoatings Protecting the Blades of an Aerospace Industry Titanium Machining Tool

\section{Overview}

- Developed by Eaton Corporation, in partnership with Greenleaf Corporation, Oak Ridge National Laboratory, and Iowa State University. (www.eaton.com)

Commercialized in 2009 and being sold by New Tech Ceramics, Inc.

\section{Applications}

Can be applied to any metal surface where increased wear resistance and reduced friction are desired, including industrial and mobile hydraulics, cutting and grinding tools, and mechanical seals used in pumps and compressors.

\section{Capabilities}

Increases operating efficiency of hydraulic systems.

Reduces heat loss from sliding friction along mechanical interfaces

Improves wear performance and extends component life.

\section{Benefits}

\section{Durability}

Reduces friction along mechanical interfaces, thus reducing wear associated with extended service time.

\section{Emissions Reduction}

Reduces pollutant leakage and emissions by improving pump seal performance and increasing the equipment efficiency.

\section{Productivity}

Enhances torque response in hydraulic motors. Reducing torque at startup yields greater power density, minimizing the necessary motor size. 


\section{Novel Refractory Materials for High-Temperature, High-Alkaline Environments}

\section{New Refractory Material Improves Durability and Performance in Harsh}

Applying new, highly durable materials in harsh industrial environments could save almost $\$ 400$ million annually. Harsh process conditions often reduce throughput and efficiency. The extreme thermal and corrosive nature of industrial processes impacts equipment worthiness and reliability and increases maintenance costs, affecting energy consumption and emissions. The use of conventional refractory materials is limited by factors that reduce process energy efficiency, such as chemical reactions, mechanical degradation by the service environment, temperature limitations, and costly installation and repairs. Degraded refractory insulation increases process heat loss, and frequent maintenance requires cooling and reheating of the furnace or refractory, which further increases energy losses and reduces productivity.

With assistance from AMO, Oak Ridge National Laboratory (ORNL), in collaboration with their industrial and academic partners, has developed a new family of refractory compositions tailored for use in high-temperature, highalkaline industrial environments. These materials are based on novel alumina and magnesia/alumina spinel materials, which use new aggregate materials, bond systems, protective coatings, and phase formation techniques. Both refractory development experience and computer modeling techniques were used to design these new materials. New application techniques and systems were developed for optimizing installation, maximizing lining properties, and facilitating hot installation and repair.

The technologies developed in the laboratory are being produced and marketed by MINTEQ. Successful trial results from commercial dross furnaces and a grain dryer have been presented at various academic and industrial meetings. The results are expected to open up additional sites for in-plant trials and other applications of the technology in related industries not currently targeted.

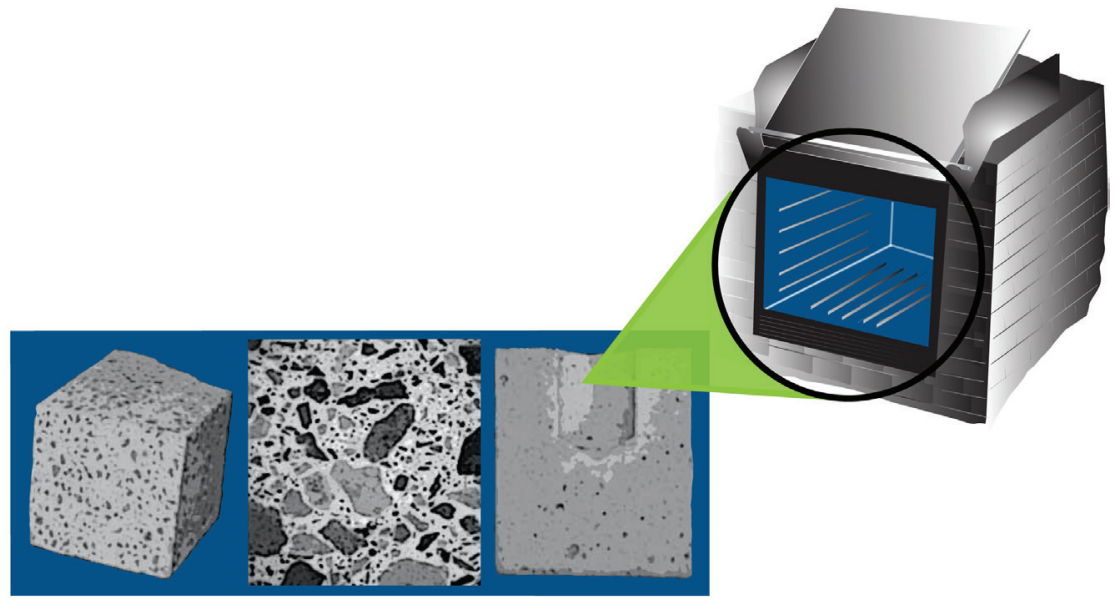

\section{Overview}

Developed by ORNL, MINTEQ International, Inc., and Missouri University of Science and Technology.

Commercialized in 2010

$\checkmark$ Distributed and marketed by MINTEQ (www.minteq.com)

\section{Applications}

Can be used in high-temperature, highalkaline furnaces and process vessels found in aluminum, chemical, forest products, glass, and steel industries.

\section{Capabilities}

Improves thermal efficiency by up to $20 \%$.

Increases resistance to degradation from harsh environments.

Reduces installation and repair costs.

\section{Benefits}

\section{Emissions}

Reduces $\mathrm{CO}, \mathrm{NO}_{\mathrm{x}}$, and volatile organic compound emissions through increased efficiency of refractory applications.

\section{Energy Savings}

Reduces energy loss using improved materials in harsh chemical and thermal environments.

\section{Productivity}

Reduces downtime and energy loss from repairing and replacing refractory linings. 


\section{New, Low Power System Reduces Energy Consumption and Improves Process Efficiency}

Real-time, nondestructive, in-line measurements of material properties are needed for process control in metallurgical manufacturing. With AMO support, X-Ray Optical Systems, Inc., developed the X-Beam ${ }^{\circledR}$, a portable x-ray diffraction (XRD) system that can be used to identify structural phases, determine grain size, and measure stress and texture of materials in line. $\mathrm{XRD}$ is widely used in laboratories to determine these material properties, but conventional XRD techniques usually cannot be used for in-line monitoring because they require sophisticated sample preparation, weigh hundreds of pounds, require water cooling, and consume several kilowatts of power (8 to 24 $\mathrm{kW})$.

The X-Beam provides real-time material characterization capability, is portable, weighs no more than 50 pounds, and uses about 50 watts of power. The X-Beam uses polycapillary x-ray optics to collect x-rays over a large solid angle from a low-power X-ray source and to form an intense quasi-parallel beam. This system eliminates the problem of misalignment and provides significantly more diffraction intensity than current Bragg-Brentano XRD systems. The parallel beam geometry also eliminates the instrument error functions that contribute to asymmetric peak shape broadening: flat specimen, axial divergence, sample displacement, and sample transparency.

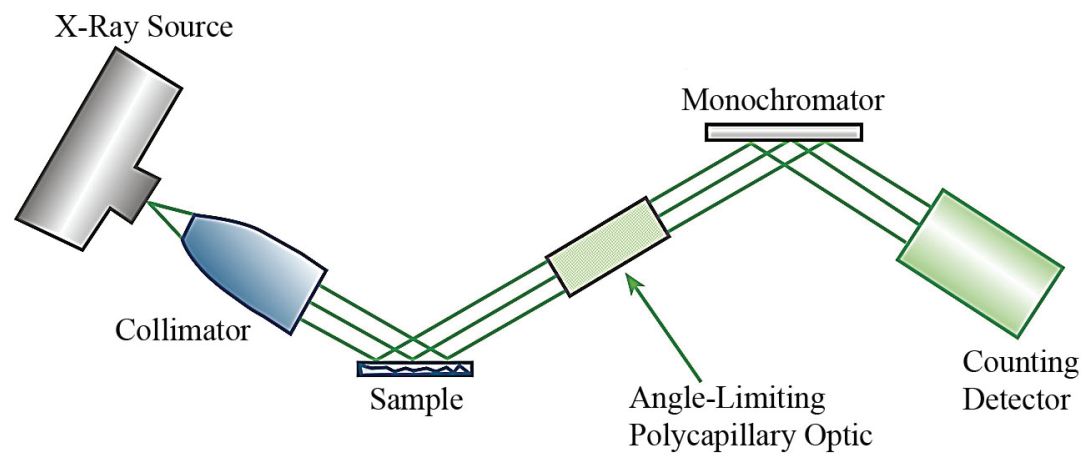

X-Ray Optical System's Parallel Beam XRD Process

\section{Overview}

$\diamond$ Developed by LTV Steel Technology Center and X-Ray Optical Systems, Inc.

$\diamond$ Commercialized in 2007

Marketed by X-Ray Optical Systems, Inc., with over 180 units sold worldwide (www.xos.com)

\section{Applications}

$\checkmark$ Can be used wherever elemental analysis is required, including protein crystallography

$\checkmark$ Can be used by industrial sectors, including steel, aluminum, cement, pharmaceutical, and semi-conductor

\section{Capabilities}

Provides continuous in-line monitoring of phase, grain size, grain orientation (texture), and residual stress of steel.

Provides real-time, nondestructive, inline measurements of material properties using XRD or X-ray fluorescence.

\section{Benefits}

\section{Energy Savings}

Uses $90 \%$ less energy then the standard rotating anode $\mathrm{x}$-ray system and operates without a water cooling loop.

\section{Portability}

Decreases measurement system weight compared with the current XRD systems (from 200 to $1,000 \mathrm{~kg}$ to $20 \mathrm{~kg}$ ) and volume from the current $2 \mathrm{~m}^{3}$ to $0.04 \mathrm{~m}^{3}$.

\section{Productivity}

Allows process control in the steel, pharmaceutical, nano-material, and plastics and polymer industries. 


\section{Corrosion Prediction Software Tool Facilitates Selection and Development of Corrosion-Resistant Alloys}

Based on the fundamental understanding of corrosion phenomena, OLI Systems, Inc., with assistance from AMO, developed the CorrosionAnalyzer, a methodology that simulates the electrochemical reactions and associated physical processes responsible for corrosion at the metal/aqueous solution interface. The simulation methodology predicts the susceptibility of fabricated components to localized corrosion as a function of alloy composition, fabrication procedures, and external environmental conditions.

To predict the occurrence of localized corrosion, the system relies on the computation of the corrosion and repassivation potentials as functions of solution chemistry and temperature. The corrosion potential is calculated from a mixed-potential model that has been verified by calculating corrosion rates in mixed acids and corrosion potential as a function of $\mathrm{pH}$ and concentration of oxidizing species. The repassivation potential is calculated from a separate model that quantitatively considers competitive processes at metal/salt film/ solution interfaces in the limit of repassivation. This model has been shown to be accurate for reproducing the repassivation potential for mixtures containing both aggressive and inhibitive ions. The combined predictive methodology has been extensively validated for engineering alloys using both laboratory and plant data.

This system combines fundamental understanding of mechanisms of corrosion with focused experimental results to predict the corrosion of advanced, base, or fabricated alloys in "real-world" environments encountered in the chemical industry. Users are able to identify process changes, corrosion inhibition strategies, and other control options before costly shutdowns, energy waste, and environmental releases occur. These innovative corrosion mitigation measures can be tested in a virtual laboratory without risking the plant. The "useful remaining life" can be predicted based on operating experience and projected operating conditions so that catastrophic failures can be avoided and well-planned corrosion control and maintenance actions can be proactively scheduled.

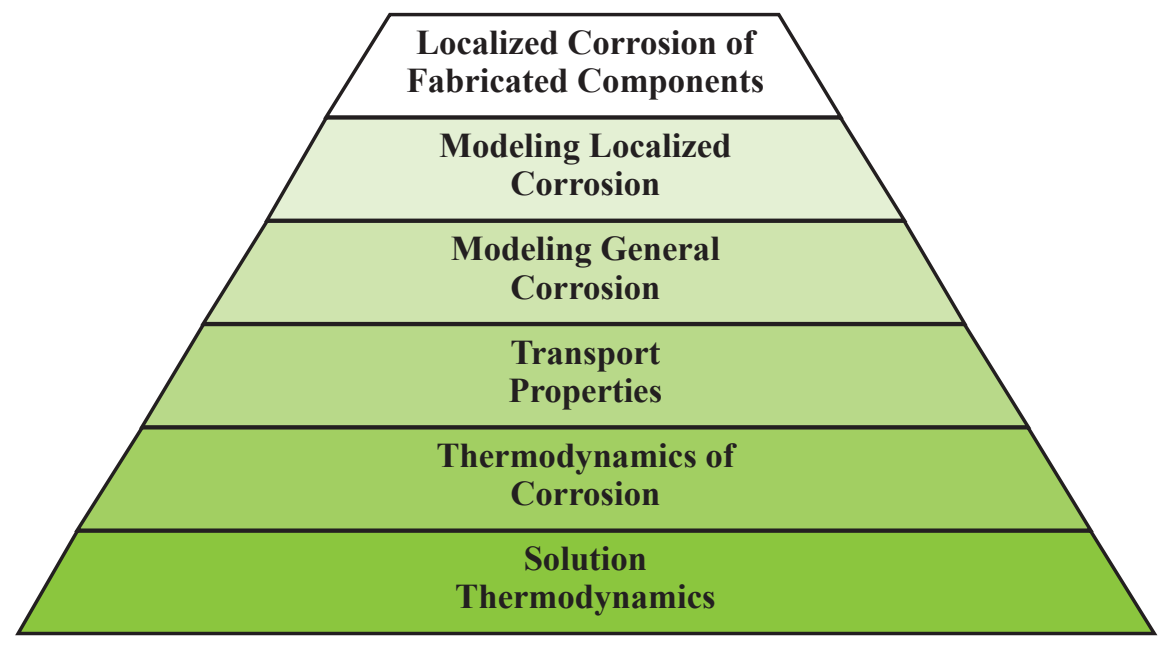

Structure of Corrosion Prediction Model

\section{Overview}

$\checkmark$ Developed and marketed by OLI Systems, Inc. (www.olisystems.com)

Commercialized in 2005

45 companies leasing the CorrosionAnalyzer in the United States and 55 outside the United States

\section{Applications}

Can be used in industries where fabricated components are exposed to corrosive environments, including chemicals, forest products, and petroleum industries

\section{Capabilities}

Predicts the tendency of alloys to corrode as a function of environmental conditions.

Predicts the tendency for localized corrosion and corrosion damage as a function of time.

\section{Benefits}

\section{Efficiency}

Reduces waste and environmental damage, and improves risk management.

\section{Energy Savings}

Reduces process losses, improves thermal efficiencies due to more optimum design of components, and reduces heat transfer losses attributable to corrosion and corrosion by-products.

\section{Productivity}

Improves component life and reduces unscheduled downtimes. 


\section{New Particle-Size and Concentration Monitor Leads to Efficient Use of Lower-Quality Fuels}

While both gas turbines and power-recovery expanders used in petroleum power generation are efficient energy-conversion devices, fuel quality limits the application of these technologies. Widely available low-cost fuels generally contain more contaminants, which can lead to system fouling and wear as well as downtime for repair and cleaning. Without continuous monitoring for particulate contamination and feedback control, systems must be set for unknown conditions, so the more-efficient gas turbines and power-recovery expanders are not installed or, if installed, operate at lower efficiency.

With assistance from AMO, and a grant from DOE's Inventions and Innovation Program, Process Metrix LLC developed a real-time laser-optical process particle counter/sizer (PPC). The PPC can be used as a short-term or automated long-term sensor and control system for dust monitoring of expanders/gas turbines and process stacks. The PPC uses optical technology with fixed alignment to provide a continuous, real-time, robust, standalone particulate monitor that allows expanders and gas turbines to operate closer to optimum conditions. Such conditions improve efficiency while protecting turbines, allowing use of lower-quality fuels.

\section{Benefits}

\section{Durability}

Protects turbines from high particulate concentrations that lead to blade wear.

\section{Emissions Reductions}

Decreases emissions by improving power-generation efficiency.

\section{Energy Savings}

Could save 20 billion Btu of natural gas per installation annually.

\section{Productivity}

Allows high-efficiency turbines to be installed in more applications and reduces production downtime from failures caused by particulate contamination.

\section{Overview}

$\checkmark$ Developed and being marketed by Process Metrix, LLC (formerly Insitec) (www.processmetrix.com)

$\checkmark$ Commercialized in 2004

- Seventeen units being used in the United States in 2010

\section{Applications}

Can be used in petroleum power generation both for existing power-recovery expanders and in situations where power-recovery expanders have not been used because of unreliable fuel quality and return on investment concerns

\section{Capabilities}

Monitors gas-phase particle contamination at low concentration using single particle counting.

Measures size, concentration, and velocity of gas particles in real-time.

$\checkmark$ Operates in-situ at industrial high temperatures/pressures.

Uses diffraction light scattering with minimum shape and refractive index sensitivity.

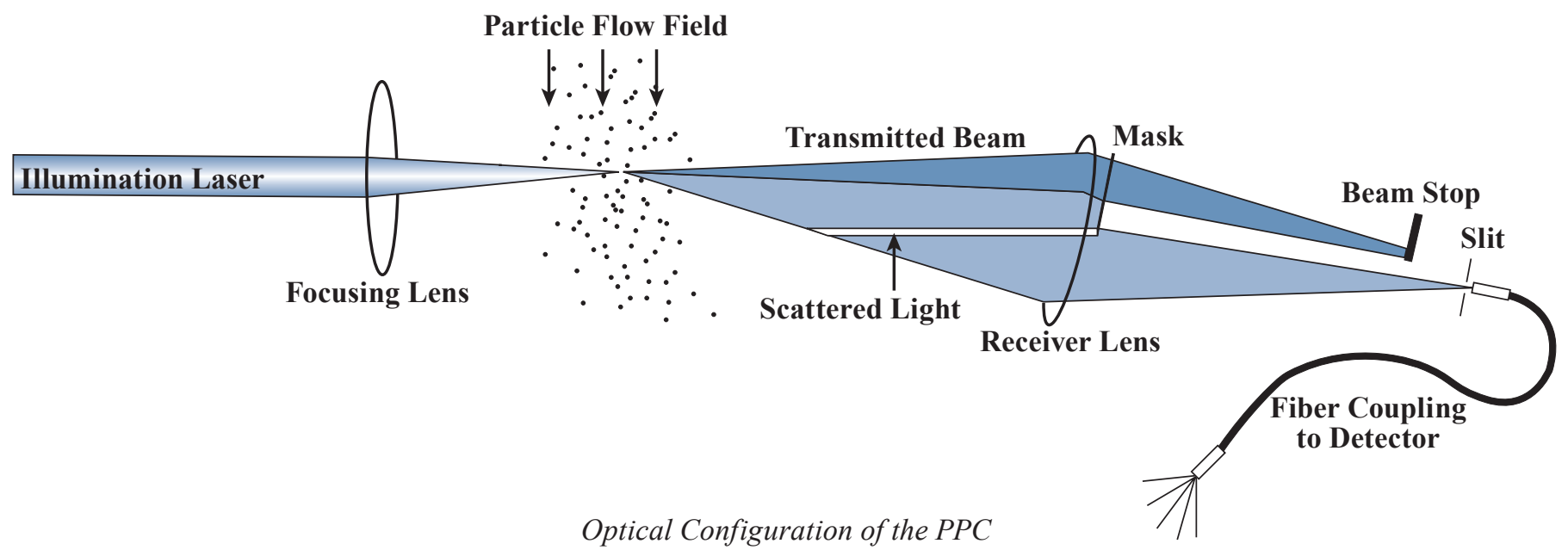




\section{Pulsed Laser Imager for Detecting Hydrocarbon and VOC Emissions}

IMPACTS

\section{Advanced System Safely and Effectively Detects Leaks and Emissions Without Requiring an Air Sample}

With assistance from DOE's Inventions and Innovation Program, LaSen, Inc., developed the Airborne Lidar Pipeline Inspection System (ALPIS ${ }^{\circledR}$ ). ALPIS is a helicopter-based, mid-infrared, Differential Absorption Lidar system that detects leaks in natural gas and hazardous liquids pipelines. The laser beam is transmitted downwards from the sensor to illuminate the area above and around the buried pipeline. When the laser beam passes through an emitted plume of hydrocarbon gas, some of the beam's energy is absorbed (i.e., removed from the beam) by the gas molecules in the plume. As a result, the amount of light reflected from the ground back towards the sensor is diminished. The amount of attenuation is measured by special detectors inside the sensor and can be used to determine the intensity of gas in the beam's path. This basic principle is at the heart of laser-based gas detection systems.

ALPIS is operated at a safe distance of 50 to 150 meters above the inspection site. Once a volatile organic compound (VOC) is detected, the GPS coordinates are recorded and an estimate of the leak size and a high resolution video image of the location are simultaneously recorded and delivered to the customer the day after the inspection flight. This remote capability provides better information for response teams to effectively maintain their pipeline. LaSen is offering ALPIS as a service to U.S. pipeline companies.

\section{Benefits}

\section{Efficiency}

Delivers complete survey results on a secure online database, which includes GPS coordinates of the indications, maps, and digital and satellite imagery of the right-of-way within 1 to 12 hours of inspection.

\section{Safety}

Offers a safe, fast and reliable remote detection system that eliminates human error and uses an eye safe laser.

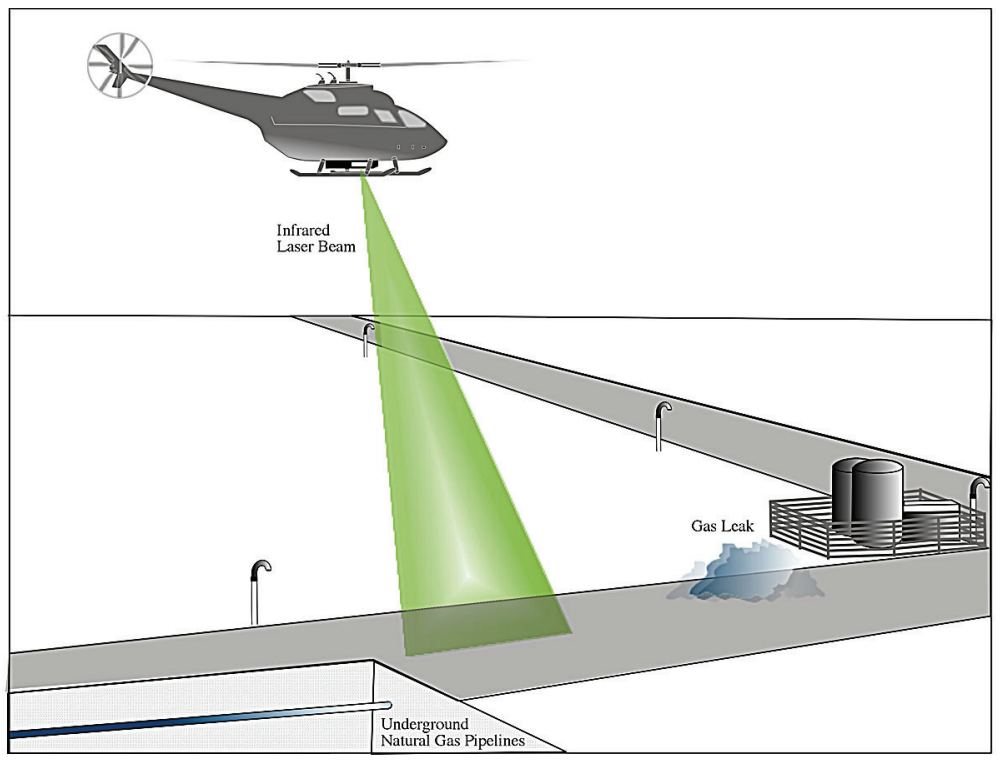

LaSen's ALPIS Used to Detect Underground Pipeline Leaks

\section{Overview}

Developed and being offered as a service by LaSen, Inc.

(www.lasen.com)

$\checkmark$ Commercialized in 2005

Currently used by 17 major U.S. oil and gas companies

\section{U.S. Energy Savings}

(Trillion Btu)

\begin{tabular}{|c|c|}
\hline Cumulative through 2010 & $\mathbf{2 0 1 0}$ \\
\hline 2.30 & 0.535 \\
\hline
\end{tabular}

\section{U.S. Emissions Reductions}

(Thousand Tons, 2010)

\begin{tabular}{|c|c|c|c|}
\hline Particulates & SO $_{x}$ & NO $_{x}$ & Carbon \\
\hline 0.0 & 0.0 & 0.063 & 8.49 \\
\hline
\end{tabular}

\section{Applications}

Can be used in the oil and gas industry to monitor and maintain the integrity of their pipeline systems from the wellhead to the end user

\section{Capabilities}

Inspects over ten times faster compared with ground surveys.

- Provides high sensitivity in remote hydrocarbon detection.

- Provides easy access to rough terrain and private land.

Provides high-resolution digital photography of the entire survey route.

Provides real time detection of benzene, propane and other volatiles. 


\section{Coatings Heal Cracks and Surface Deformations of Polymer Coatings}

Materials used for industrial and consumer applications are usually coated to improve their appearance and protect them from the damaging effects of weathering (e.g., ultraviolet light and acid rain), corrosion, and mechanical wear. Typical coatings used are paints, stains or sealers, waxes, and other chemical treatments. Inevitably, this protection weakens and microscopic damage occurs, leading to more extensive damage or eventual failure, which requires recoating or replacement.

NEI Corporation, with assistance from AMO, has developed self-healing nanocomposite polymeric-based coatings. Polymer coatings impart two important functions to the underlying substrate: the aesthetic function, which gives the substrate a good appearance, and the protective function, which prevents mechanical and chemical damage. Routine use generates surface scratches and micro-cracks, which eventually leads to macroscopic damage and the coating losing its aesthetic and protective functions. Corrosion protection coatings on metals are especially intolerant to crack formation since cracks will expose the underlying metal to corrosive environments, thereby shortening its service life. To increase longevity, when heat is applied to NEI's patented coatings, they self-repair or self-heal minor surface scratches and relatively deep cracks. The coatings allow for multiple healings, increasing service life and reducing cost and environmental impact from emissions and waste. The self-healing ability of the nanocomposite coating is partially the result of the morphology of the polymer coating and can be used in other applicationspecific polymer systems to provide self-healing capability.

NEI's patented coating technology has been used for repeatable self-healing on a solvent borne polyurethane coating systems. The coating industry is moving towards solvent and volatile-organic-compound-free, waterborne, and ultraviolet curable coatings. NEI is currently developing "greener" coatings with self-healing capabilities.

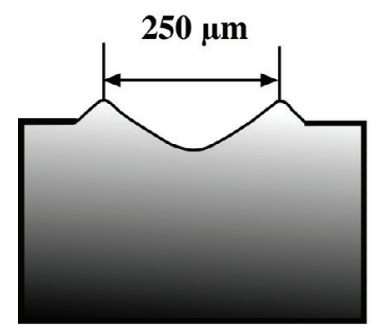

2 - 4 mil thick

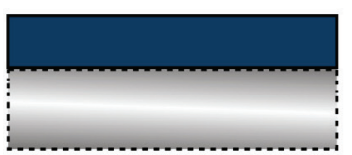

Metal

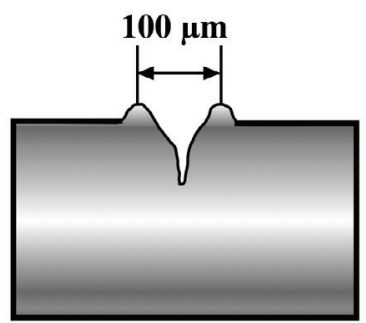

1 mil thick

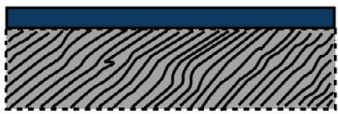

Wood

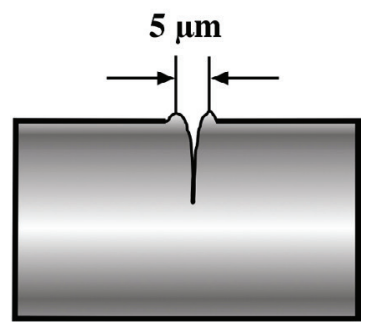

4 - 10 mil thick

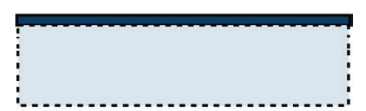

Plastic
NEI's Coating Thickness and Self-healing Capabilities on Various Substrates

\section{Overview}

Developed by NEI Corporation.

Commercialized in 2010

Distributed and marketed by NEI (www.neicorporation.com)

\section{Applications}

Can be used for coating metal, wood, and polymer surfaces in residential, commercial, military, and industrial applications.

\section{Capabilities}

Can be used as a complete coating solution or as an additive for other coating formulations.

Achieves self-healing of coating surface and subsurface damage.

Allows repeatable healings.

\section{Benefits}

\section{Cost Savings}

Reduces raw material, labor, and energy cost of repainting or recoating.

\section{Durability}

Increases the service life of coatings by preserving their aesthetic and protective functions.

\section{Environmental}

Minimizes the environmental costs and societal impact of repainting (e.g., waste disposal and volatile-organic-compound emissions).

\section{Maintenance}

Eliminates the need to frequently repaint or replace damaged coatings. 


\section{Remote Sensing Electric Motor Operation Optimizes Maintenance and Energy Efficiency}

Electric motor-driven systems used in industrial processes consume an estimated 23\% of all U.S. electricity sold. Energy use by large motors ( $>200$ horse power [hp]) has been reduced using advanced monitoring and diagnostic systems served by conventional field-wired sensors. Deploying monitoring systems on smaller motors $(<200 \mathrm{hp})$ would reduce motor energy use by up to another $18 \%$ but would not be cost-effective with conventional wiring eliminating potential energy savings and the additional benefits of optimized preventative maintenance and improved uptime.

Eaton Corporation, with assistance from the U.S. Department of Energy's AMO, has developed and successfully deployed an electric motor overload and monitoring solid-state relay, Motor Insight ${ }^{\mathrm{TM}}$. Motor Insight provides real-time line, load and motor protection, and control. In addition to monitoring electric motor health, the technology provides line conditioning for improved motor reliability and reduced maintenance downtime. Users can configure the system locally or with a variety of standard industrial communication protocols, allowing for integration into supervisory control and data acquisition, programmable logic control, and distributed control systems. Motor Insight's control circuits and registers allow the data to initiate action locally or at system level. Instantaneous power consumption and motor efficiency monitoring enables real time optimization of energy usage required for the motor load condition. The technology is easily retrofitted and provides flexibility and expandability to accommodate plant complexity.

Eaton has demonstrated the capability of the Motor Insight system at multiple customer sites in various industries. For example, at a regional wastewater facility the Motor Insight technology prevented costly equipment failures and wasted energy consumption. Savings based on avoidance of equipment failure, reduced maintenance, and energy reduction totaled nearly $\$ 15,000$ for a system consisting of three $60 \mathrm{hp}$ pumps. Combined with reduced process and equipment downtime, these savings resulted in repeat sales from the end user.

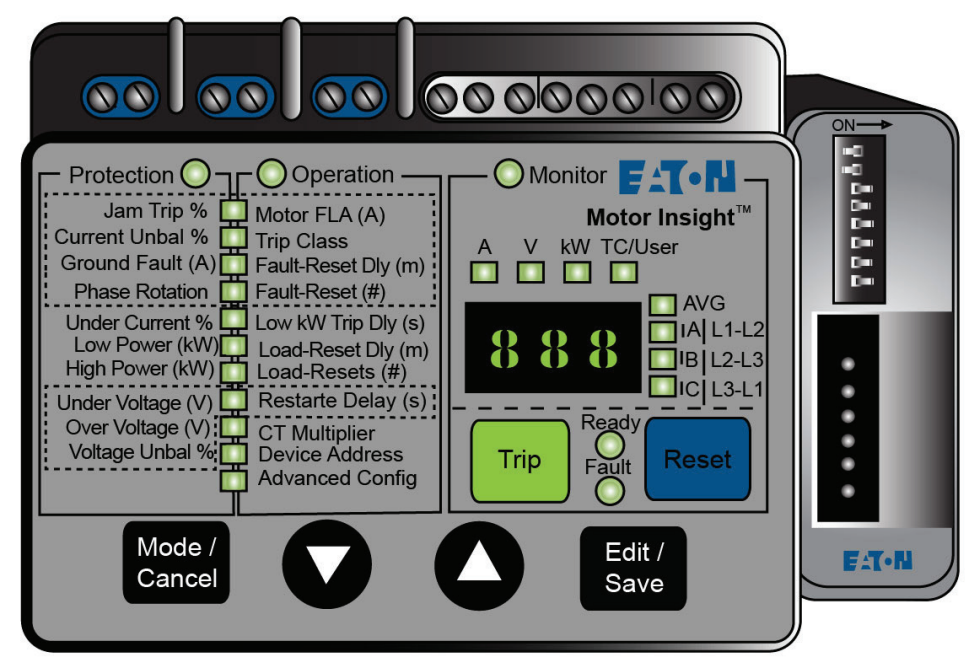

Eaton's Motor Insight Sensor Technology

\author{
Overview \\ Developed by Eaton Corporation. \\ Commercialized in 2010 \\ Distributed and marketed by Eaton \\ Corporation \\ (www.eaton.com)
}

\section{Applications}

Can be used to monitor, control, and protect electric motors.

\section{Capabilities}

Provides configurable motor, load, and line protection in addition to power monitoring and diagnostic capabilities.

Provides compatibility with industrial communication protocols.

Meets multiple domestic and international industry standards and certifications including lead free compliance.

\section{Benefits}

\section{Cost Savings}

Reduces installation and infrastructure cost by up to $84 \%$ compared with conventionally wired systems.

\section{Energy Consumption}

Reduces abnormal and inefficient operation using real time communication and control of motor operation.

\section{Flexibility}

Can be used in most process power system applications using electric motors.

\section{Maintenance}

Provides intelligent load, motor, and line quality monitoring and eliminates unnecessary fault finding inspections. 


\section{Simple Control for Single-Phase AC Induction Motors}

IMPACTS

\section{New Motor Controller Reduces Noise and Increases Efficiency}

A new approach to electric motor control removes the need for complex, high-frequency, high-voltage digital controllers that are motor and application specific. With the help of a grant from DOE's Inventions and Innovation Program, Opto Generic Devices, Inc. (OGD), developed an optical programmable encoder and controller combination that offers continually adaptive/variable-speed, optimized commutation, dynamic vector control, real-time feedback, application tuning, and signal enhancement for operating AC motors. Based on this technology, OGD's subsidiary, OGD V-HVAC, Inc., developed a new technology, the Adaptive Climate Controller (ACC), using optical programming that controls single-phase motors. While this controller has many uses with small motors, its most common applications provide climate control and healthy indoor air quality with energy efficiency, noise reduction, relative humidity control, and moisture control for mold abatement. Air filtration systems function more effectively with gradually changing air flow than with abrupt off-on fan cycling that accelerates harmful particles and organisms through mechanical and electronic filters.

In addition to providing a second, analog input for low DC voltage, the factorysupplied temperature sensor provides feedback for the controller to maintain temperature in the human comfort zone by gently mixing room air to avoid the extremes of cold air near the floor and warm air near the ceiling. If comfort demands suddenly change, such as when additional people enter a classroom or conference room, the ACC ramps up airflow as the mechanical system supplies heated or chilled air at temperatures above or below the human comfort zone, responding quickly to the changing room needs. Gradually ramping up fan speeds, instead of turning fans on fully whenever the thermostat calls for heated or chilled air, conserves energy by using only the electrical and thermal energy necessary to satisfy the demand. In systems such as fan coils, where thermal energy is transferred from heated or chilled coils into the air, the ACC enhances thermal energy exchange from the coils as it gradually ramps down fan speed in response to the actual supply air temperature as it settles into the setpoint temperature even after the thermostat has closed the valve that brings in heated or chilled water. Thus, the coil thermal energy transfer with the room continues even after the water valve has closed, allowing for additional electrical savings in chillers and fuel savings in boilers.

\section{Benefits}

\section{Ease of Installation}

Allows control upgrades to be easily installed on existing systems within minutes.

\section{Energy Savings}

Adaptively varies air flow to only what is needed.

\section{Product Quality}

Reduces noise for workers or occupants in businesses, hospitals, hotels, schools, etc.

\section{Overview}

Developed by Opto Generic Devices, Inc. (www.ogd3.com)

$\checkmark$ Commercialized in 2005 with thousands of installed units

\section{Applications}

Can be used to control small single-phase motors up to 240 VAC and 10 amps full load, including HVAC and other system motors found in data centers, hospitals, residences, hotels, nursing homes, schools, and other institutions. Also can be used to control fan coils, packaged terminal air conditioners, unit ventilators, and exhaust fans.

\section{Capabilities}

Accepts one or two analog inputs, including, but not limited to, temperature and low DC voltage from a sensor or building management system.

Adaptively varies motor speed for the discharge air flow across fan coils to control indoor climate.

Reduces system noise.

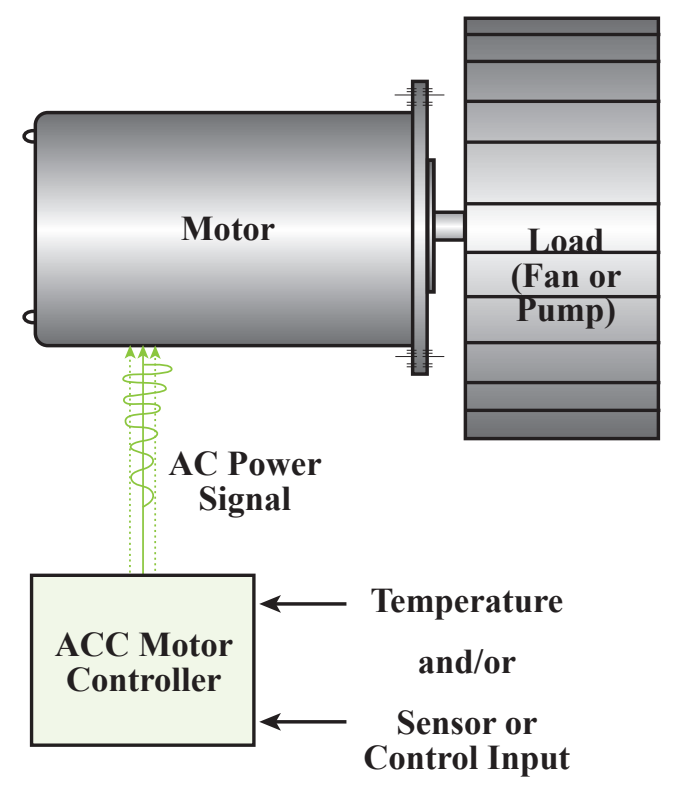

OGD Electric Motor Control 


\section{New Sensors Rapidly and Accurately Detect Hydrogen, Improving Industrial Safety and Efficiency}

Molecular hydrogen, $\mathrm{H}_{2}$, is a combustible gas that is produced in large quantities by many industries and has a broad range of applications. When $\mathrm{H} 2$ is an undesirable contaminant, a monitor must be able to detect concentrations on the order of parts per million (ppm). In other cases a monitor must be usable in nearly pure hydrogen. Although gas chromatography and mass spectrometry are widely used for detecting $\mathrm{H}_{2}$, these methods require bulky, expensive equipment.

Using solid-state technology developed at Sandia National Laboratory, $\mathrm{H}_{2} \mathrm{scan}$ LLC is now commercializing hydrogen-specific sensing systems that can detect hydrogen against virtually any background gases. These hydrogen-sensing devices can detect hydrogen in 1 to 10 seconds, thus allowing the devices to be used in control systems. Currently, $\mathrm{H}_{2}$ scan offers three hydrogen-sensing system configurations: a hand-held portable leak detector, a fixed-area monitoring system, and an in-line real-time concentration analyzer.

The advantages of the $\mathrm{H}_{2} \mathrm{Scan}$ hydrogen sensors are in their operating parameters. The sensors have a low hydrogen sensitivity of about $5 \mathrm{ppm}$ in air and less than $1 \mathrm{ppm}$ in nitrogen. They are hydrogen specific with no cross-sensitivity to other gases. The upper range of the sensor is $100 \%$ with an extremely fast speed of response. They operate between $-40^{\circ} \mathrm{C}$ to $150^{\circ} \mathrm{C}$, making them attractive for virtually all sensor applications.

\section{Benefits}

\section{Energy Savings}

Saves substantial energy by avoiding improper monitoring.

\section{Productivity}

Detects hydrogen in 1 to 10 seconds, which is suitable for interfacing to control systems. Using the device to monitor hydrogen in feedstock of a refinery feed hydrogen/carbon monoxide facility could improve overall performance by up to $\$ 250,000$ per year per plant.

\section{Profitability}

Can be mass-produced, making them much less expensive than competing sensors. Small sensor dye produces a system that is much smaller than traditional sensors.

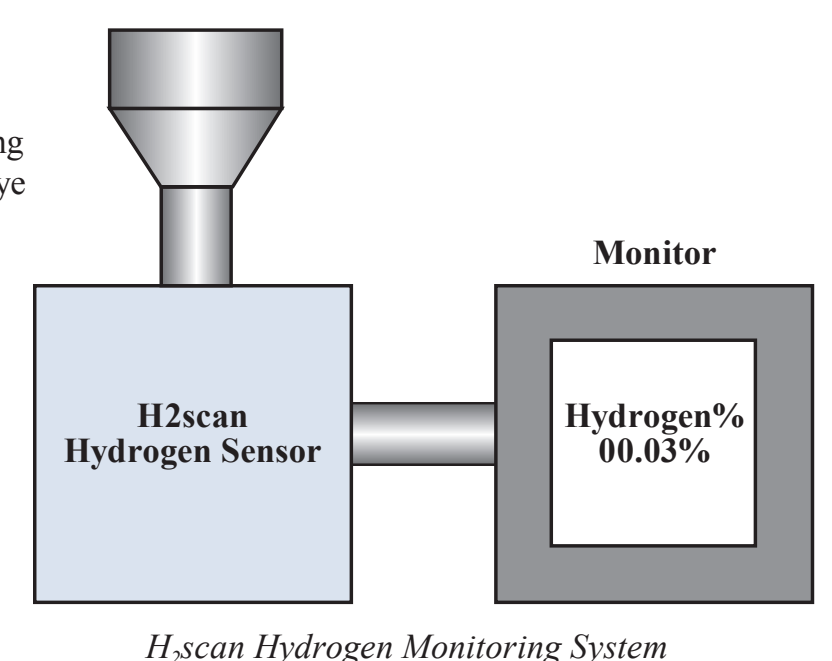

\section{Overview}

- Developed by Sandia National Laboratory and $\mathrm{H}_{2}$ scan LLC (www.h2scan.com)

$\checkmark$ Commercialized in 2003

3120 units sold through 2010

\section{Applications}

Monitoring trace levels of $\mathrm{H}_{2}$ in highpurity feed gases for chemical processes

Monitoring hydrogen production from methane and refinery offgases, where hydrogen is often mixed with $\mathrm{CO}$

Monitoring hydrogen levels in transformer oil to detect when the oil starts breaking down

Measuring the hydrogen given off from lead acid batteries due to overcharging to stop a buildup of hydrogen and reduce the threat of either a fire or explosion

Monitoring and control of hydrogen, which are crucial to obtain the correct molecular-weight distributions in the gasphase polymerization of polyethylene and polypropylene

Analyzing fugitive hydrogen emissions in ambient plant environments or in materials subjected to high-energy radiolysis, which is crucial for safety in those environments

Measuring hydrogen levels to control the efficiency of fuel cell reformers

\section{Capabilities}

$\checkmark$ Can be used over a wide range of hydrogen concentrations with minimal interference from other gases.

Provides rapid response time of 1 to 10 seconds, allowing the sensors to be used for process control. 


\section{SpyroCor ${ }^{\mathrm{TM}}$ Radiant Tube Heater Inserts}

IMPACTS

\section{Unique Twisted Design of Ceramic Insert Saves Energy for Metal Heat-Treating Furnaces}

Radiant tube heaters are typically used in metal heat-treating furnaces. The heaters are long tubes, often in a U shape, which have natural-gas fired burners at one end of the tube (the burner leg) to produce a flame and heated gas that flows through the tube to produce heat for conditioning metals (e.g., strengthening them or otherwise changing some of their properties). In a traditional radiant tube, the burner leg releases $30 \%$ more energy than the exhaust leg because of convection and radiation heat transfer in the burner leg.

With the help of a grant from DOE's Inventions and Innovation Program, STORM Development LLC and Sycore, Inc., optimized the SpyroCor, a ceramic (silicon-carbide) insert for the exhaust leg of the tube heater. The patented twisted design of the SpyroCor produces nonturbulent, high convection flow that produces the highest possible rate of uniform heat transfer. As a result, the SpyroCor reduces heat loss and the energy demands of the process or application by $15 \%$ to $20 \%$. A typical furnace contains 10 radiant tubes, which use an average of 3 SpyroCors per tube. Through 2010, 492 furnaces have been equipped with SpyroCors for a savings of 10.0 trillion Btu.

\section{Benefits}

\section{Ease of Installation}

Can be quickly and easily inserted into existing heater tubes without overhauling the entire furnace.

\section{Productivity}

Allows the furnace user to increase the amount of metal treated for the same amount of energy used or to reduce the amount of energy used for the same output.

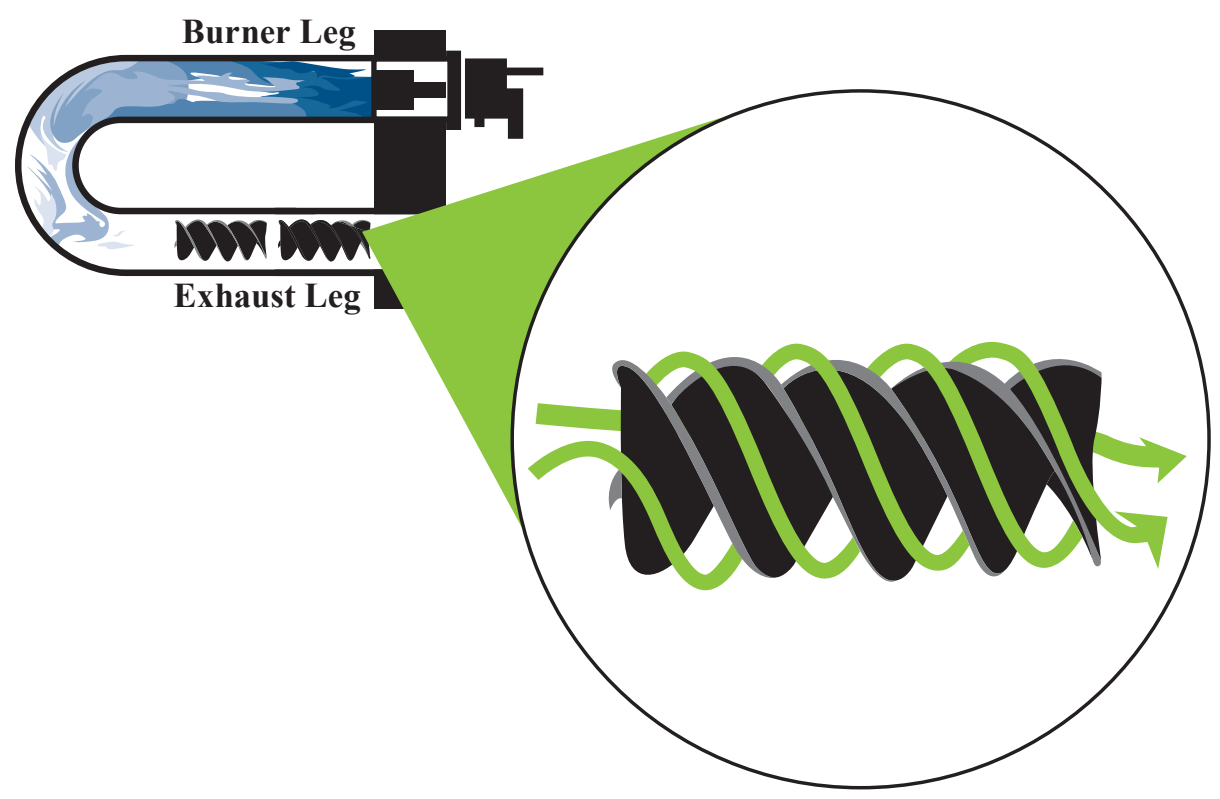

SpyroCor Installed in a Radiant U-Tube Heater

\section{Overview}

$\checkmark$ Developed by STORM Development LLC and SyCore, Inc.

Commercialized and being marketed by Spinworks LLC

(www.spin-works.com)

$\checkmark$ Sold more than 19,000 units through 2010

\section{U.S. Energy Savings}

(Trillion Btu)

\begin{tabular}{|c|c|}
\hline Cumulative through 2010 & $\mathbf{2 0 1 0}$ \\
\hline 10.0 & 2.59 \\
\hline
\end{tabular}

\section{U.S. Emissions Reductions}

(Thousand Tons, 2010)

\begin{tabular}{|c|c|c|c|}
\hline Particulates & SO $_{\mathrm{x}}$ & NO $_{\mathrm{x}}$ & Carbon \\
\hline 0.0 & 0.0 & 0.302 & 41.0 \\
\hline
\end{tabular}

\section{Applications}

Can be used in radiant tube heaters typical in metal heat-treating furnaces that use natural gas burners or in industrial radiant tube space heaters

\section{Capabilities}

- Produces nonturbulent, high convection flow in the radiant tube.

Doubles the amount of surface area available for heat transfer.

Balances the heat transfer throughout the radiant tube, allowing more energy to be available to the load. 


\section{New Turbine Efficiently Separates Gas, Oil, and Water While Generating Electricity from Waste Energy}

Using a NICE ${ }^{3}$ grant, Douglas Energy Company and Multiphase Power and Processing Technologies (MPPT) demonstrated a three-phase rotary separator turbine (RST3) at a land-based production field and on an offshore production platform. The device introduces a highly efficient and compact method for separating gas, oil, and water during production operations, while generating substantial power from previously wasted process energy.

Traditional oil and petroleum separator systems use a centrifuge or gravity separator. The centrifuge system requires outside energy to power the motors that propel a centrifugal drum, where oil and water are separated. After separation occurs, solids remain inside the drums and require costly periodic cleaning. The gravity separators use huge vessels that rely on gravity to perform the separations. However, the separations are often incomplete and require secondary energy-consuming systems.

The RST3 effectively separates solid waste, oil, gas and water, while harnessing expansion energy from the pressure reduction that occurs after the oil, gas, and water mixture is brought to the surface from offshore wells. This creates a clean power source that accelerates the rotating portion of the RST3 unit, where the mixture is separated more efficiently than by traditional methods. The new process often creates net energy for other offshore oil platform operations, reducing the need for electricity produced from natural gas turbine generators.

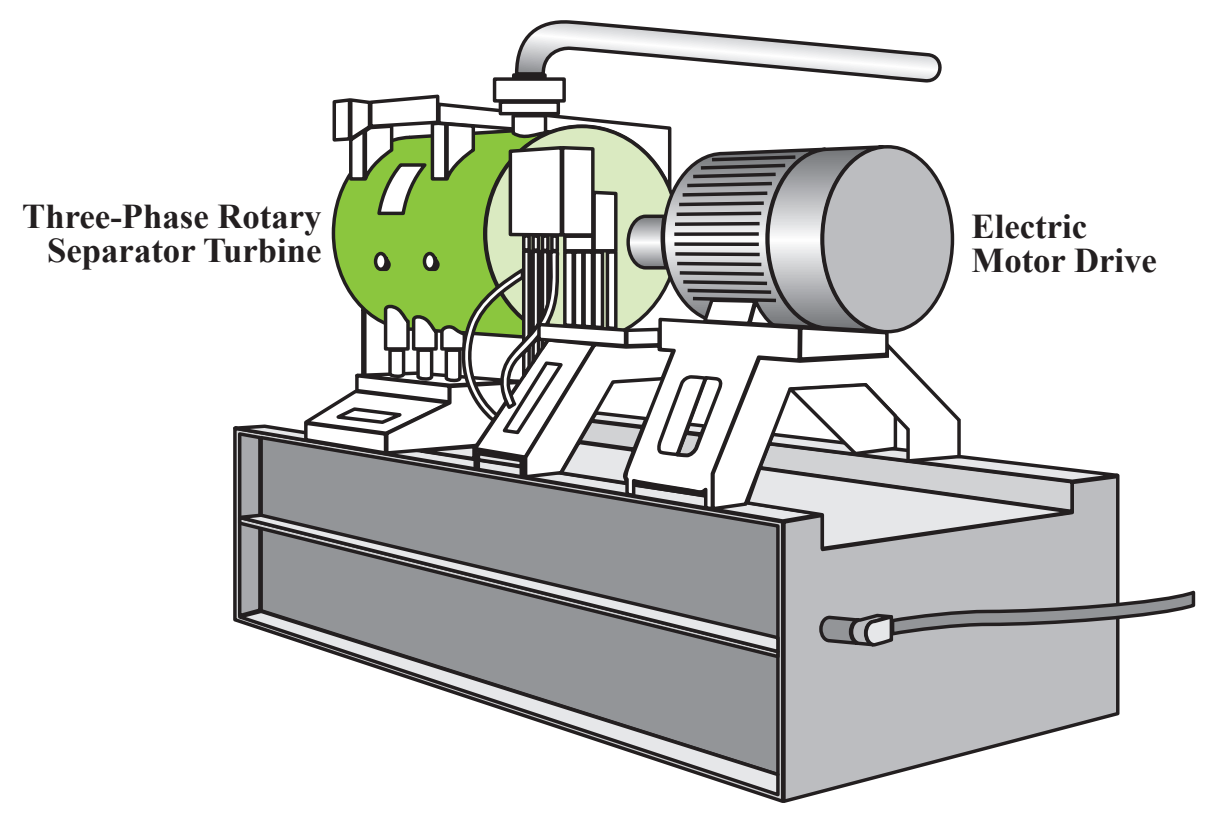

Three-Phase Rotary Separator Turbine

\section{Overview}

Developed by Douglas Energy Company Inc.

Commercialized in 2003 with 2 units previously operating in the U.S.

Currently being revamped by DresserRand Group, Inc. (www.dresser-rand.com)

\section{U.S. Energy Savings} (Trillion Btu)

\begin{tabular}{|c|c|}
\hline Cumulative through $\mathbf{2 0 1 0}$ & $\mathbf{2 0 1 0}$ \\
\hline 0.036 & 0.000 \\
\hline
\end{tabular}

\section{U.S. Emissions Reductions}

(Thousand Tons, 2010)

\begin{tabular}{|c|c|c|c|}
\hline Particulates & SO $_{\mathrm{x}}$ & NO $_{\mathrm{x}}$ & Carbon \\
\hline 0.0 & 0.0 & 0.0 & 0.0 \\
\hline
\end{tabular}

\section{Applications}

Can be used to replace traditional separation technologies used in petroleum and chemical industries

\section{Capabilities}

Creates its own source of clean shaft power, reducing electrical input requirements.

Weighs 10 times less than a typical gravity three-phase separator and has a much smaller footprint.

\section{Benefits}

\section{Cost Savings}

Substantially reduces the size and cost required for offshore platforms, enabling a low-cost production system for marginal oil and gas fields and increasing supply.

\section{Environmental}

Purifies the process water without adding harmful chemicals commonly used in traditional separators. 


\section{Reduction of Burner $\mathrm{NO}_{\mathrm{x}}$ Production with Premixed Combustion}

Industries that are dependant on combustion processes are faced with more stringent environmental regulations to reduce $\mathrm{NO}_{\mathrm{x}}$ emissions. Some states require $\mathrm{NO}_{\mathrm{x}}$ emissions reductions as great as $90 \%$ for chemical and refining industries. The recently developed M-PAKT ${ }^{\mathrm{TM}}$ Ultra-Low $\mathrm{NO}_{\mathrm{x}}$ Burner uses lean premixed combustion gases and low swirl flow of combustion gases to achieve $\mathrm{NO}_{\mathrm{X}}$ emissions levels $<10 \mathrm{ppm}$ (an $\mathrm{NO}_{\mathrm{X}}$ reduction of $80 \%$ to $90 \%$ ).

The research for this technology originated at Lawrence Berkeley National Laboratory with funding from the DOE Office of Science Experimental Program and AMO. This new burner's distinct characteristic is a detached flame that is lifted above the burner, providing the capability for more complete combustion with less emissions. This burner concept can be applied to a wide range of combustion systems including furnace and boiler applications, gas turbines, and liquid process heaters for the chemical and refining industries. The burner can be operated with natural gas, biomass gas, and pre-vaporized liquid fuels. The burner is scalable and simple in design with no need for costly materials for manufacturing and installation. Maxon Corporation has licensed the technology for industrial process heaters used in many industrial baking and drying ovens. Applications have also been successfully tested in smallerdiameter domestic heater units.

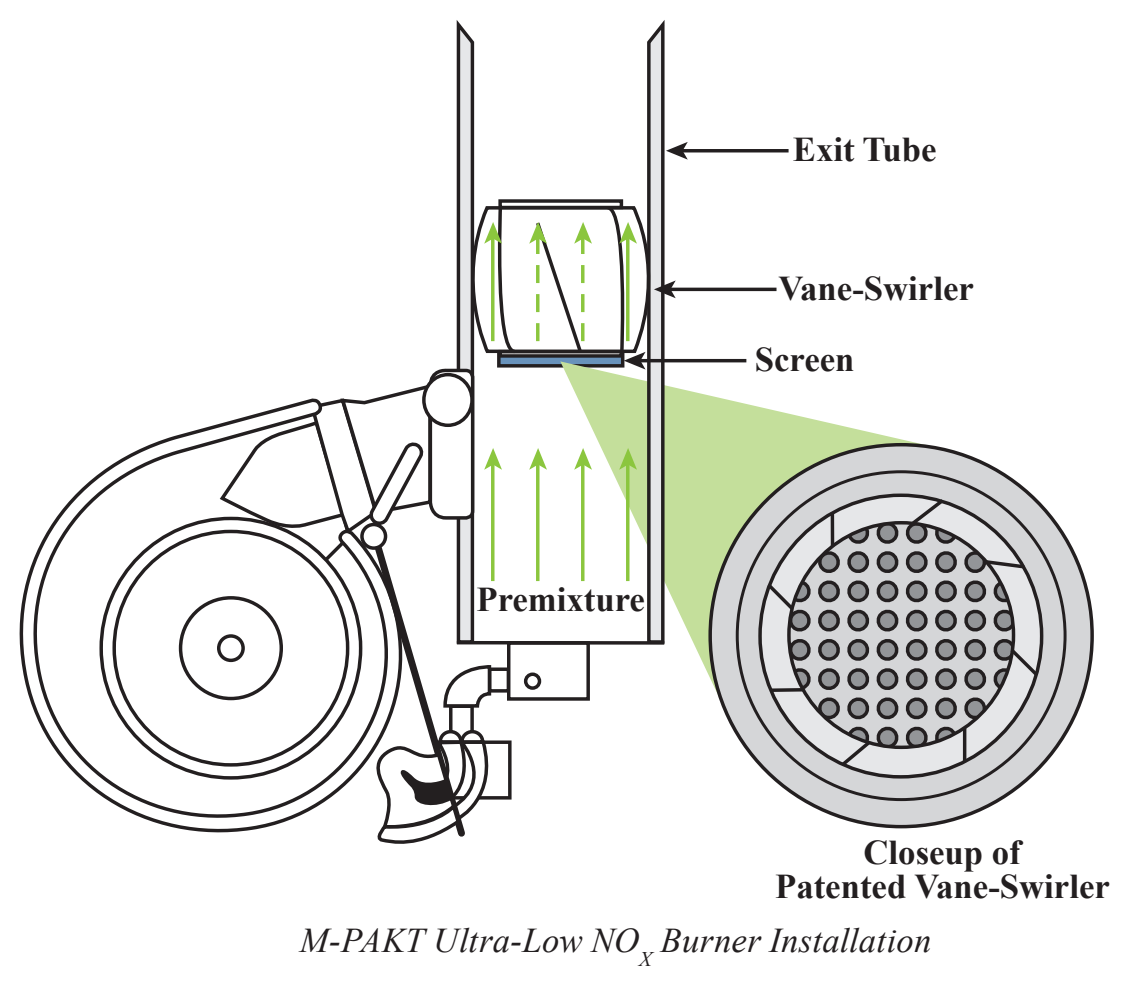

\section{Overview}

$\checkmark$ Developed by LBNL with two patents issued

Installed in the U.S. and overseas

- Technology licensed to Maxon Corporation and sold as the M-PAKT burner

(www.maxoncorp.com)

- Over 1366 burners estimated to reduce $\mathrm{NO}_{\mathrm{X}}$ by over 1.504 million pounds in 2010

\section{Applications}

Can be used on a wide range of combustion systems: furnaces and boilers, chemical and refining industry process heaters, and gas turbines

\section{Capabilities}

Reduces thermal $\mathrm{NO}_{\mathrm{x}}$ in the combustion zone.

\section{Benefits}

\section{Adaptability}

Burns different gaseous fuel types and blends. Can be scaled to different sizes of units and adapted to different orientations and sizes of various flue configurations.

\section{Low Cost}

Offers low cost for manufacturing compared with traditional low $\mathrm{NO}_{\mathrm{X}}$ solutions because the components are simple and are made from conventional materials.

\section{Pollution Reduction and Energy Efficiency}

Typically reduces $\mathrm{NO}_{\mathrm{x}}$ to less than $10 \mathrm{ppm}$ without compromising energy efficiency. 


\section{New Diamond Coatings Reduce Friction and Improve Performance of Mechanical Seals}

Mechanical seals are used to reduce friction and prevent product leakage in a variety of industrial rotary equipment such as pumps and mixers. Traditional seal ring pairs employ a hard material such as silicon carbide ( $\mathrm{SiC}$ ) and a soft material such as carbon to achieve the best possible hardness and frictionresistant properties. However, these seals exhibit significant wear in extreme environments such as abrasive slurry pumping. In addition, heat generated from friction between the two ring faces quickly leads to seal failure. An improved material is needed to address these concerns and improve seal performance.

Advanced Diamond Technologies, Inc., with assistance from AMO, has commercialized Utrananocrystalline Diamond (UNCD) technology to improve mechanical seals. Using a patented chemical vapor deposition process, thin UNCD coatings are applied to the seal face of a silicon carbide ring. Unlike commercially available diamond-like carbons, UNCD is a phase-pure (sp3) diamond-bonded carbon. The unique microstructure, comprised of nanometersized diamond grains, results in seals with exceptionally low friction, superior wear resistance, and chemical inertness.

UNCD provides a solution for applications requiring a metal-to-metal seal face combination that risks dry run damage. UNCD faces that are paired with silicon carbide have shown tolerance for dry running in conventional ANSI pumps, whereas conventional hard pairs generated so much heat that seal failure quickly occurred. UNCD provides improved wear resistance over $\mathrm{SiC}$, enabling seals to last longer in applications involving abrasive slurries, other erosive environments, or poor lubricating conditions. The exceptionally low friction results in a cooler face temperature, making UNCD suitable for temperature-sensitive media. The chemically inert, corrosion-resistant surface is ideal for handling food and pharmaceutical chemicals where media contamination and the reduction of friction-generated reactions at the seal face are critical.

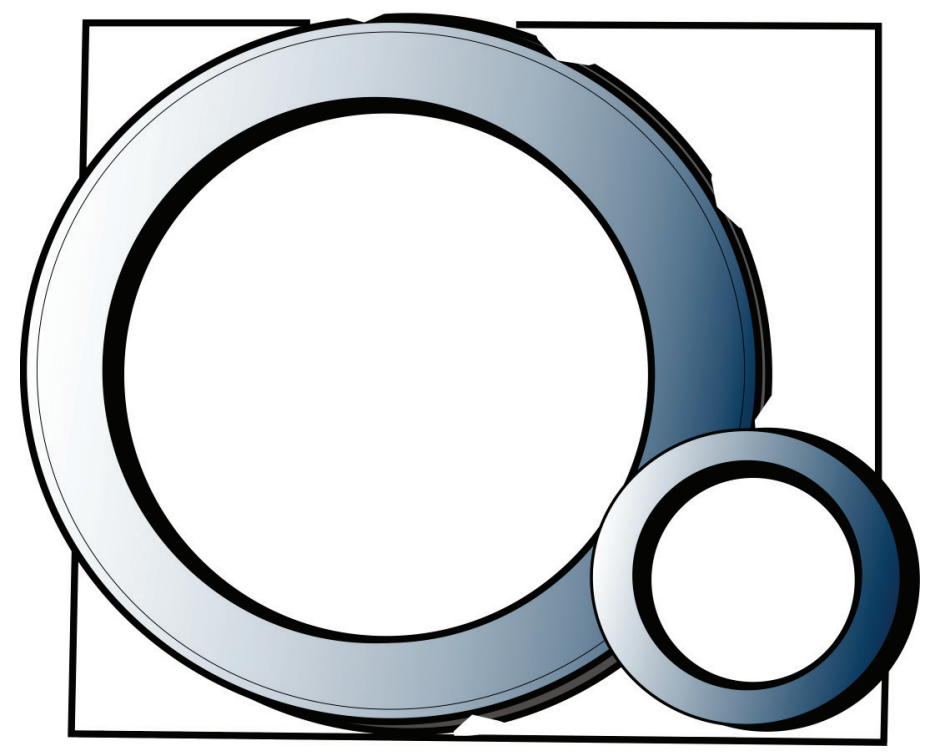

Advanced Diamond Technologies' UNCD Seal Faces

\section{Overview}

$\rightarrow$ Developed by Argonne National Laboratory, with assistance from John Crane, Inc., and Advanced Diamond Technologies, Inc.

Commercialized in 2008 and sold by Advanced Diamond Technologies, Inc. (www.thindiamond.com)

\section{Applications}

Can be used in a wide variety of industrial pumping applications, especially in harsh environments involving high wear and poor lubrication

\section{Capabilities}

Improves wear resistance compared with silicon carbide seal faces to increase seal life when handling abrasive slurries or other erosive fluids.

Increases energy efficiency by reducing friction between seal faces.

- Reduces seal face temperature to allow hard faces to be used when pumping thermally sensitive media.

\section{Benefits}

\section{Cost Savings}

Reduces operation and maintenance costs from process downtime when worn-out seals are replaced.

\section{Durability}

Enables dry running of metal-to-metal seal faces where conventional hard seal pairs fail due to excess heat generated from friction.

\section{Versatility}

Enables sensitive food, biological, and pharmaceutical media to be handled because of the corrosion-resistant, chemically inert diamond surface. 


\section{New Technology Captures Freely Available Vibration Energy to Power Wireless Sensors}

The industrial market for wireless sensors is growing rapidly but is constrained by implementation costs and compatibility with existing wireless networks. Typical wireless sensors and transmitters depend on batteries, which require periodic maintenance to change the battery. Maintenance costs for battery use in wireless sensor applications are estimated at $\$ 80$ to $\$ 500$ per replacement, including labor, which exceeds the sensor's cost.

With assistance from an SBIR grant, KCF Technologies, Inc., has developed vibration power harvesting devices that eliminate the need for battery change. Available as part of KCF's Power Harvesting Demonstration Pack, the device converts vibration energy to regulated DC power, supplying sufficient power to the wireless sensor for up to 15 years without needing any maintenance time or expenses. The technology is not overly sensitive to vibration frequency, amplitude, or other environmental characteristics.

KCF Technologies' innovation was recognized with a "Best of Sensors Expo" Award in 2008. The harvester-powered sensor was honored as one of the most promising and exciting technologies on display out of nearly 200 products at the annual Sensors Expo \& Conference in Rosemont, Illinois. These devices are expected to greatly expand the use of wireless sensors throughout U.S. industry.

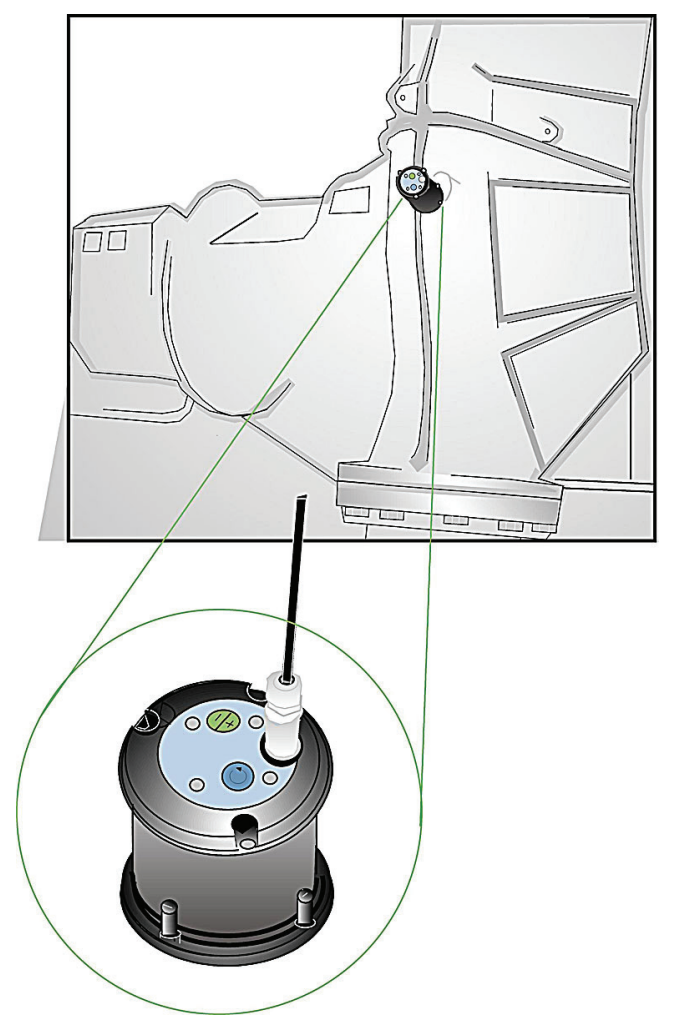

KCF Technologies' Vibration Power Harvesting Unit Installed on a Large Motor

\section{Overview}

Developed by KCF Technologies, Inc., in 2006

(www.kcftech.com)

Commercialized in 2007

Formed strategic partnerships with Johnson Controls, Omega Piezo Technologies, Pennsylvania State University, and RLW, Inc.

\section{Applications}

Can be used wherever wireless sensor networks are deployed, including refrigeration and HVAC systems, pulp processing and paper printing, conditionbased maintenance, and power generation facilities

\section{Capabilities}

- Increases data transmission capabilities for wireless sensors in high-vibration settings.

Is compatible with existing wireless sensors.

Enables sensor placement in infrequently accessed locations.

\section{Benefits}

\section{Cost Savings}

Eliminates downtime and costs associated with battery maintenance.

\section{Safety}

Expands sensing capabilities for machinery and equipment to increase safety and security. 


\section{Wireless Sensors for Condition Monitoring of Essential Assets}

\section{New Technology Provides Cost Savings and Flexibility for Monitoring Motor-Driven Industrial Equipment}

Conventional permanent systems for monitoring industrial electric motordriven assets (pumps, fans, compressors, etc.) suffer from the complexity and costs associated with running the necessary hardwiring for signal and power. Monitoring is especially difficult in remote locations or areas of a plant where access is hazardous. The traditional alternative to permanent systems is a hand-held portable monitoring strategy. However, using technicians in the field can be both costly and time-consuming and valuable monitoring information can be lost between data collection trips through the plant.

With assistance from AMO, GE has developed a wireless condition monitoring solution to economically monitor the performance of motor-driven equipment assets. The Essential Insight.meshTM solution contains all the hardware necessary to deploy 16 dynamic points of reliable and secure wireless monitoring throughout a plant and can be expanded to thousands of points throughout a site. A sensor mesh network enabled through wireless sensor interface module nodes provides this rapid deployment and flexibility. Each sensor node supports four input ports that can be any combination of vibration transducers or thermocouples.

The Essential Insight.mesh system allows equipment anomalies to be detected with clear diagnostic messaging. The package allows the user to configure collection rates to obtain information daily for general long-term trending and more often for static data transmissions. Advanced options include the availability of a dual power source for the sensor nodes. Power is available from a battery or from energy harvester technology. Energy harvester technology is an innovative new feature that allows the machine's vibration itself to serve as a power source via a miniature moving-coil generator. In addition, users can select magnetic or conventional threaded mounting studs for the sensor nodes.

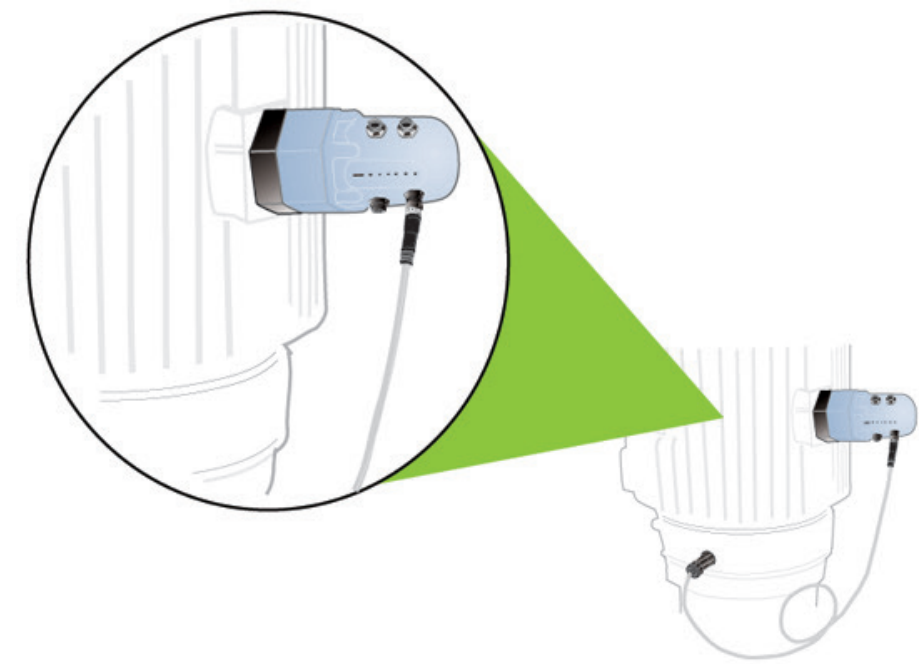

Essential Insight.mesh Wireless Sensor Transmitting Data from Critical Motor

\section{Overview}

$\checkmark$ Developed by GE.

Commercialized in 2008 by GE Energy (www.ge-energy.com/bentlywireless)

\section{Applications}

Can be used across all industries that employ motor-driven process equipment

\section{Capabilities}

Allows the user to configure the rate of data acquisition.

Allows a greater volume of data to be collected for analysis and interpretation compared with conventional systems.

Provides information critical to maintaining high productivity and preventing costly equipment failure.

\section{Benefits}

\section{Adaptability}

Can be powered via battery or energy harvester technology, which uses a machine's vibrations as the power source.

\section{Cost Savings}

Reduces outage times and the number of unplanned outages, thereby lowering the costs of these events.

\section{Safety}

Increases safety by remotely monitoring assets in areas that are unsafe for humans to enter. 


\section{Wireless Sensors for Process Stream Sampling and Analysis}

IMPACTS

\section{Advanced New Wireless Sensor Meets Demanding Requirements of Industrial Production Lines}

Sensing and controlling manufacturing present unique problems with effective sampling in harsh environments and with real-time control. The demanding requirements of industrial control of manufacturing processes need to be met while maintaining maximum security, battery life, and reliability. Wireless sensors for sampling and analyzing process streams allow monitoring in remote locations, but research is needed to determine how they satisfy the key considerations of operational reliability, sustained performance in harsh environments, invulnerability to interference, security, bandwidth efficiency, and other factors that are critical for the ultimate wide-spread deployment of robust wireless sensor networks in manufacturing.

With AMO support, Honeywell International, through its Wireless Sensors for Process Stream Sampling and Analysis project, developed and successfully commercialized a wireless system that meets all the operational considerations. The critical component of this production line measurement and control system is the Frequency Hopping Spread Spectrum board. In addition to production line measurement and control, the technology's anticipated low cost will enable wireless sensors to be used to determine energy and environmental-related process parameters that are not traditionally monitored. Industrial power and cogeneration plants can use the sensors to balance generation demands, operational efficiencies, and regulatory constraints. By implementing these sensors with advanced energy solutions, plants can reduce heat and power production costs, increase effective boiler operation range, reduce flue gas emissions, optimize production capacity utilization, extend production asset's life, and reduce maintenance.

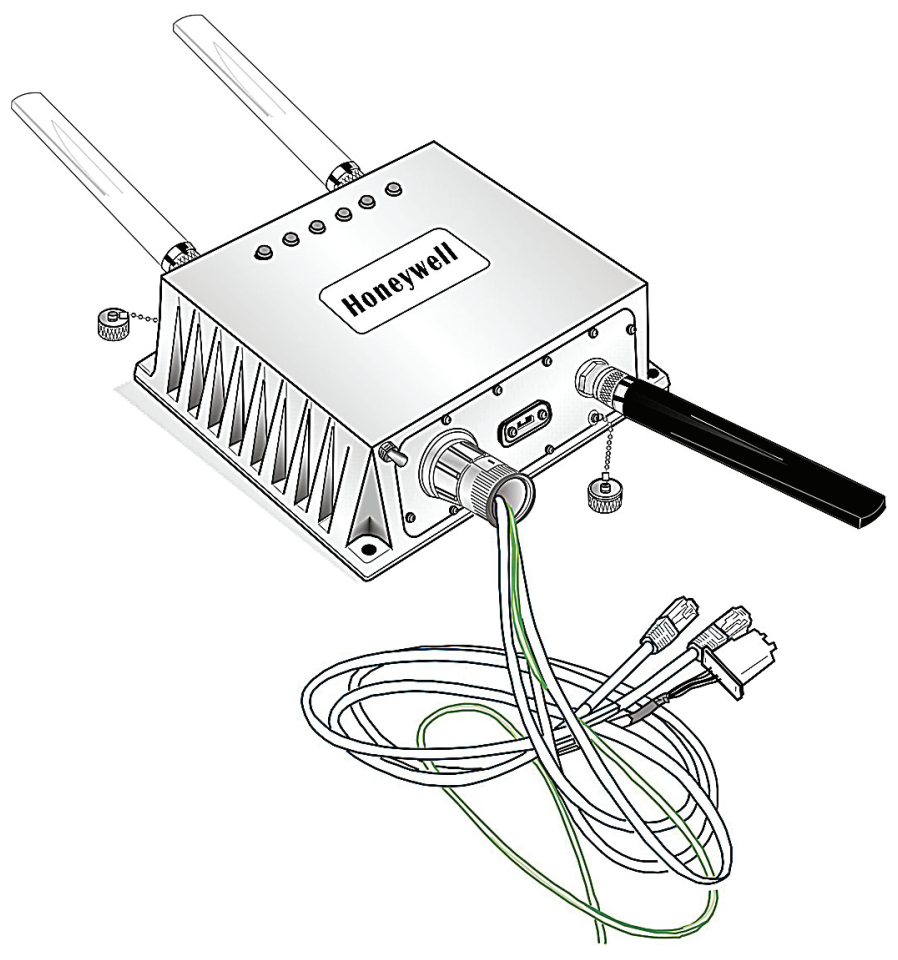

Honeywell International's Wireless Sensor

\section{Overview}

$\downarrow$ Developed by Honeywell International

$\checkmark$ Commercialized and marketed by Honeywell International in 2007 (www.honeywell.com)

- Sold about 3000 to 5000 units in the United States in 2010

\section{Applications}

$\checkmark$ Can be used for process control and monitoring in remote locations and for monitoring equipment health

\section{Capabilities}

Provides cost-effective sample validation.

$\checkmark$ Is certified for use in hazardous environments.

Collects additional process and equipment health data.

$\checkmark$ Is easily installed.

\section{Benefits}

\section{Profitability}

Offers low cost and easy deployment, increasing the number of measurements that can be used to improve process efficiency. Minimizes the energy needed to heat or cool down a process resulting in energy and cost savings.

\section{Reliability}

Has been tested extensively in severe production environments such as steel mills.

\section{Versatility}

Allows remote installation without running additional wires. 
IMPACTS

Advanced Membrane Devices for Natural Gas Cleaning.

A-106

Data Center Transformer from "Always On" to "Always Available"

A-107

Deep Discharge Zinc-Bromine Battery Module.

A-108

Energy-Efficient Cooling Control Systems for Data Centers ..................................................................................................... A-109

High-Efficiency, Wide-Band Three-Phase Rectifiers and Adaptive Rectifier Management .........................................................A-110

High-Intensity Silicon Vertical Multi-Junction Solar Cells...................................................................................................... A-111

Long Wavelength Catalytic Infrared Drying System …….....................................................................................................A-112

Low-Volume Server for Reduced Energy Use and Facility Space Requirements.....................................................................A-113

Management Technology for Energy Efficiency in Data Centers and Telecommunications Facilities.........................................A-114

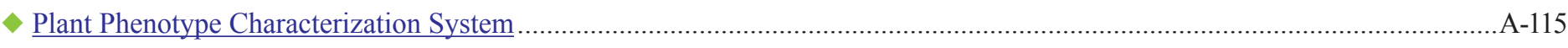

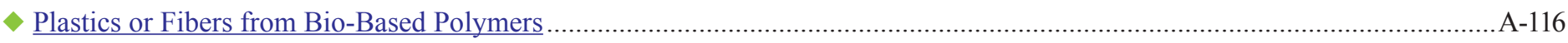

$\begin{array}{ll}\text { DOE Advanced Manufacturing Office } & \text { A-105 }\end{array}$ 


\section{New Membrane Cost Effectively Upgrades Sub-Quality Natural Gas}

Carbon dioxide $\left(\mathrm{CO}_{2}\right)$ is a common impurity that must be removed in natural gas to improve the gas's heating value or to meet pipeline specifications. Hydrogen sulfide $\left(\mathrm{H}_{2} \mathrm{~S}\right)$ often prohibits natural gas from being used to generate power and drive compressors at remote locations such as oil and gas production sites. Production companies are faced with choosing among shutting in a well, overhauling engines frequently, or dealing with logistical challenges associated with routing other fuels to the site.

With AMO support, Air Products \& Chemicals, Inc., through its Advanced Membrane Devices project, developed and successfully commercialized PRISM $®$ membranes for upgrading sub-quality natural gas. These semipermeable polymeric membranes can be used as gas scrubbers for natural gas, removing $\mathrm{CO}_{2}$ and $\mathrm{H}_{2} \mathrm{~S}$ from natural gas.

PRISM membranes, based on simple process designs, provide a low-cost alternative to traditional amine systems that are used to upgrade natural gas. The membranes can also be used as a bulk-removal device to minimize the size of an amine system. The benefits become even more pronounced as the industry produces natural gas from very remote locations. Fuel-gas conditioning systems that incorporate PRISM membranes provide oil and gas production companies with an economical solution to an otherwise often enormous problem. The membrane device can be used to make low-grade natural gas with high $\mathrm{CO}_{2}$ and $\mathrm{H}_{2} \mathrm{~S}$ content into a pipeline-grade gas for domestic and industrial consumption.

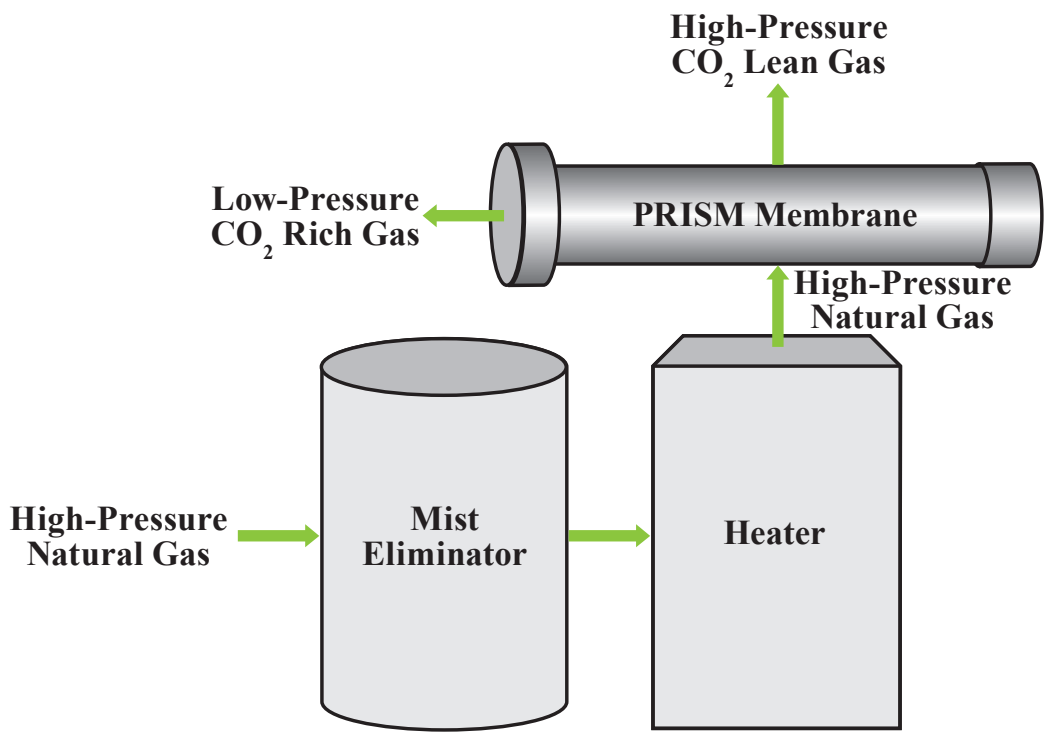

Example $\mathrm{CO}_{2}$ Removal Process Using the PRISM Membrane System

\section{Overview}

Developed by Air Products \& Chemicals (www.airproducts.com)

Commercialized in 2001

$\checkmark 110 \mathrm{CO}_{2}$-removal units operating in the United States in 2010

\section{Applications}

Recovers $\mathrm{CO}_{2}$ from associated gas in enhanced oil recovery programs

$\checkmark$ Removes acid gas from natural gas

Separates nitrogen from air while also yielding an oxygen-rich byproduct

Separates hydrogen from process gas

\section{Capabilities}

Reduces impurities to allow natural gas to meet pipeline specifications.

\section{Benefits}

\section{Environmental Quality}

Avoids use of any hazardous chemicals such as amines, which can cause environmental complications.

\section{Ease of Installation}

Offers lightweight and compact units, thus facilitating their transportation and installation.

\section{Profitability}

Is ideal for remote locations with limited utilities and sour natural gas.

\section{Reliability}

Requires no moving parts, reducing maintenance costs. 


\section{Data Center Transformer from "Always On” to "Always Available"}

IMPACTS

\section{Data Center Monitoring System for Controlling Power Utilization Reduces Energy Usage}

About $25 \%$ of a company's information technology (IT) costs results from electricity consumed by data centers because of the "Always On" operation of the data center. Typically, data centers are built to meet peak demand but don't have the ability to predict when peak demands occur. During off-peak periods, when the full capacity of the data center servers is not needed, $70 \%$ of the maximum electrical load is still being used. Today's servers, even the newest and most efficient, can only vary their electrical load between $60 \%$ and $100 \%$ based on demand, while the actual load can vary between $5 \%$ and $75 \%$. From a facility standpoint, the data center most likely is being over cooled because most use fixed, single-speed computer room air-conditioning units, which contribute further to unnecessary energy consumption.

Power Assure, Inc., with assistance from AMO (as part of the American Recovery and Reinvestment Act), has developed a system comprised of power management software and monitoring modules that are integrated into the infrastructure of the data center equipment. Power Assure's EM/4 software collects, synthesizes and analyzes the equipment status and energy consumption data from the data center facility. In real-time the software determines the power utilization, server demand, and other key performance indicators for the data center, enabling automated optimization of energy efficiency for the requested server demand. By operating the data center in this way, "Always Available" versus the conventional "Always On" mode, power consumption is reduced by up to $50 \%$ on average. The Power Assure $\mathrm{EM} / 4$ platform is easily integrated into existing equipment and is scalable across multiple data center facilities. Both facility and IT resource allocation can be optimally controlled, including multi-site redundancy and dynamic load shedding and shifting. The EM/4 platform targets data center operation that will meet actual customer demand with the computing supply needed to guarantee expected service levels. This means reliability or availability is maintained and needless energy consumption is reduced.

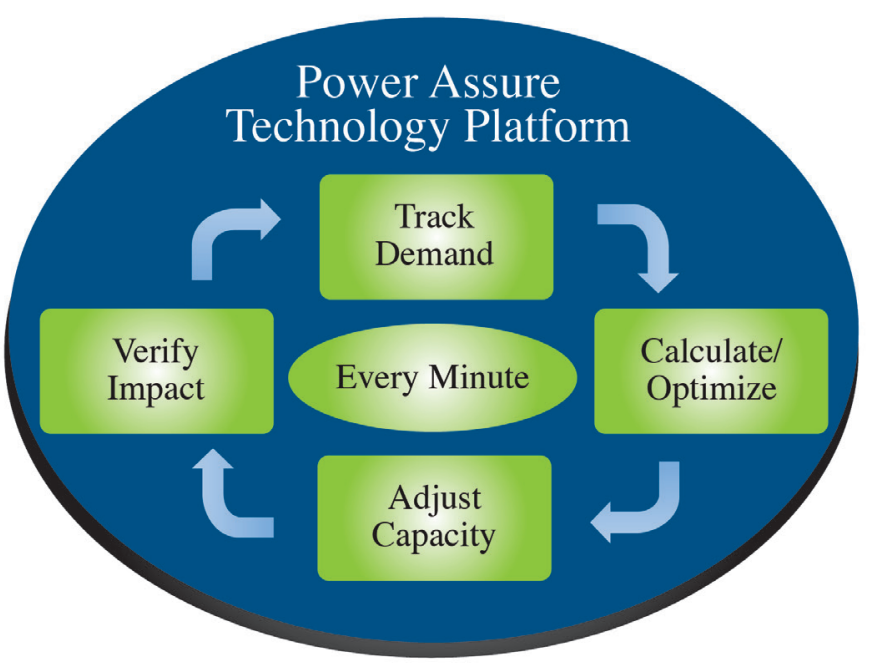

Power Assure's EM/4 Flowchart for Real-Time Utility Monitoring

\section{Overview}

Developed by Power Assure, Inc.

Commercialized in 2010

Distributed and marketed by Power Assure

(www.powerassure.com).

\section{Applications}

Reduces impurities to allow natural gas to meet pipeline specifications.

\section{Capabilities}

Achieves and average 50\% reduction in ongoing power consumption.

Provides automated responses to both expected and unexpected events.

Provides real-time status and analysis of data center power, capacity, and performance.

Maximizes use of available space and power to reveal hidden capacity and shift demand loads within and across sites.

\section{Benefits}

\section{Accuracy}

Provides accurate measurements and ratings for capacity planning and consolidation; reduces cost.

\section{Functionality}

Provides integration with real-time external data on power pricing, availability, usage, and utility alerts for aggregation, contract management, monetization. and disaster prevention.

\section{Performance}

Extends the useful life of the data centers by improving data center efficiency and utilization. 


\section{Deep Discharge Zinc-Bromine Battery Module}

\section{Long-Lasting Electrical Energy Storage Module Allows Off-Peak Power Generation}

Electricity consumption during peak demand can overload utilities, forcing them to acquire more generation, transmission, and distribution capacity to meet customer demand. Also, the available generation, transmission, and distribution capacity is not fully used most of the time because peak loads need to be met even though the amount of time they are used is limited. Equipment running at low loads (less than full capacity) is less efficient. ZBB Energy Corporation, with financial assistance from DOE's Inventions and Innovation Program and another EERE Program, has developed a longlasting, high-energy density zinc energy storage system (ZESS) module that can store energy generated during off-peak hours for use during peak hours. This provides the additional capacity during peak times without adding new generation, transmission, and distribution infrastructure and increases the overall operational efficiency of the complete electrical system or industrial plant.

The ZESS regenerative fuel cell consists of an electrochemical reactor through which electrolyte is circulated from external storage tanks and where the electrodes do not take part in the chemical reaction and thus are not degraded or consumed over time. Power characteristics of the ZESS can be modified by changing the electrolyte composition. The ZESS is made from cost-competitive materials, which reduce manufacturing and disposal costs compared with traditional battery types. The battery modules offer up to 3 times the energy density of lead-acid batteries. They can be $100 \%$ discharged thousands of times with minimal degradation of round-trip charge/discharge efficiency. The capacity rating of a ZESS battery module remains constant over the service life (20+ years), but the charge required to achieve the rated capacity degrades consistently (1 to $2 \%$ efficiency loss/year) with typical (daily) usage. The 'active electrode' layer in the cell stacks is what 'wears out' requiring the periodic (5+ year) replacement of the module's cells stacks.
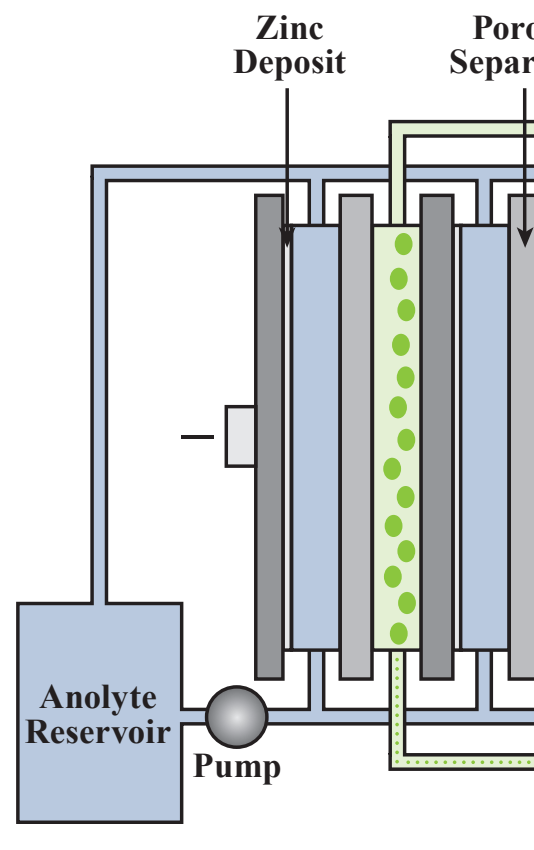

Schematic of Zinc-Bromine Battery Module

\section{Overview}

Developed by ZBB Energy Corporation (www.zbbenergy.com)

Commercialized in 2006

\section{Applications}

Can be used for power control and energy storage in renewable and remote-area power systems.

\section{Capabilities}

Allows storage of off-peak electricity for use during peak hours.

Achieves up to $100 \%$ battery discharge with no damage.

Achieves shorter recharge times; 4 to 5 hours vs. 8 to 12 hours for lead-acid battery.

\section{Benefits}

\section{Adaptability}

Adapts to various system configurations to suit application; $25 \mathrm{MW}$ to $2 \mathrm{MW}$ power output and $50 \mathrm{MWh}$ to $8 \mathrm{MWh}$ energy storage capacities.

\section{Cost Savings}

Achieves cost savings by eliminating liquid fuel use off-grid or during grid outages, by integrating renewable power sources or stored off-peak power to supplement power demand during peak hours.

\section{Operation and Maintenance}

Requires no maintenance and can be fully discharged indefinitely with no damage.

\section{Pollution and Waste Reduction}

Requires only the recyclable cell stack to be replaced which eliminates disposal and cost concerns that are associated with lead-acid batteries. 


\section{Energy-Efficient Cooling Control Systems for Data Centers}

IMPACTS

\section{Novel Data Center Cooling and Control Save Energy and Optimize Utility}

U.S. energy consumption from information technology (IT) equipment has risen by $\sim 36 \%$ since 2005 , an increase driven by the growth of internet usage by individuals and businesses. Data centers provide the IT infrastructure, which totals millions of servers and computing devices for data processing and storage. The electricity consumed in these data centers is mainly by the equipment (50\%) and HVAC $(25 \%-40 \%)$ to maintain the computer room environment or computer room air-conditioners (CRACs). The increasing efficiency of computer equipment design and higher equipment densities has increased demand for CRAC cooling. Lack of knowledge about the efficiency of the cooling system's behavior and efficiency has typically resulted in overcooling, primarily to prevent equipment failure, which leads to wasted energy and poor power usage effectiveness.

Vigilent Corporation, formerly Federspiel Controls, Inc., developed a data center energy management system that monitors and controls data center system cooling power consumption and cooling efficiency in real time. Vigilent, with assistance from the U.S. Department of Energy's AMO (as part of the American Recovery and Reinvestment Act), recently demonstrated the effectiveness of intelligent energy management in eight State of California data centers. The system uses a network of wireless sensors, hardware, and software to automatically and intelligently control the data centers' cooling operation provided by air handling units (AHUs) and CRAC units.

The Vigilent system provides a visualization of the facility layout and graphical displays showing real-time thermal conditions, and the actual effect of each HVAC/AHU's operation on temperatures throughout the facility. The system analyzes and optimizes cooling by enabling dynamic adaptive cooling control and load balancing. Vigilent has successfully demonstrated its data center cooling management technology solutions at multiple high-profile sites, including Verizon as well as the State of California sites. The case study at the California sites resulted in annual energy savings of over 2.3 million $\mathrm{kWh}$. Other Vigilent customers's report even larger savings at their installations.

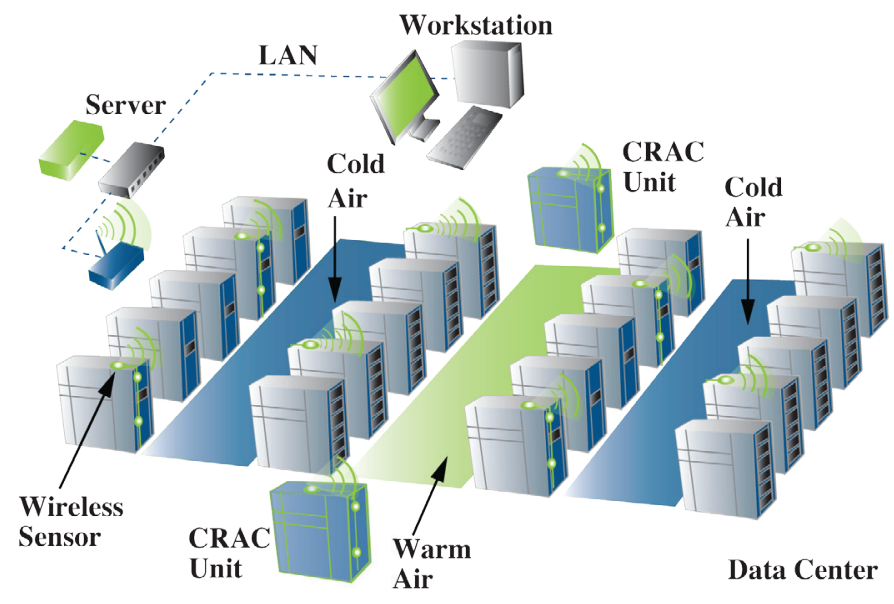

Vigilent Data Center Management Technology

\section{Overview}

Developed by Vigilent Corporation, formerly Federspiel Controls, Inc.

Commercialized in 2007

Distributed and marketed by Vigilent (www.vigilent.com)

Installed at numerous customer sites worldwide.

\section{Applications}

Can be used to monitor and control data center cooling in real time.

\section{Capabilities}

Provides monitoring, visualization, analysis, and feedback control of data center facility AHUs and CRAC units.

- Provides predictive maintenance, energy usage optimization, and future facility expansion analysis capabilities.

Provides secure web-based interface for remote access.

\section{Benefits}

\section{Cost Savings}

Reduces data center cooling energy consumption by up to $40 \%$.

\section{Installation}

Provides simple nondisruptive installation and retrofits into existing data center equipment.

\section{Reliability}

Improves cooling system effectiveness, extends equipment lifetime, and protects data center from damaging overtemperature events.

\section{Scalability}

Provides a modular system, which can be expanded to accommodate increased data center capacity. 


\section{High-Efficiency, Wide-Band Three-Phase Rectifiers and Adaptive Rectifier Management}

\section{Higher-Efficiency Power Conversion and Managed Supply Improve Energy Utilization}

Information technology (IT) and telecommunications facilities consume $\sim 48$ billion kWh of electricity in the United States. Energy consumption within IT data center facilities could be improved in three key areas: equipment and software, power supply chain, and cooling. The power supply chain represents $25 \%$ of the energy consumed in IT facilities. The alternating current electricity supply must be rectified into a direct current to operate nearly all of the equipment used in IT centers. Many of the rectifiers currently in use have low peak efficiencies (88\%-92\%) and offer much lower efficiencies when operated outside of their peak operating range.

Lineage Power, with assistance from the U.S. Department of Energy's AMO (as part of the American Recovery and Reinvestment Act), has developed a rectifier with improved peak efficiency and a flat efficiency curve. Lineage Power has also developed software that operates each rectifier in a system at or near its peak efficiency level. The software essentially selects rectifiers that can operate at lower demand levels and maintain a higher load demand on the conventional rectifying equipment.

Lineage Power's new switching mode rectifier (SMR) technology combines low-voltage synchronous rectification with true three-phase, bridgeless power factor correction. This approach reduces conduction and switching losses in the circuit to improve efficiency to $96 \%$ compared with current product efficiency of $91 \%$ and legacy equipment efficiency of $88 \%$. The new rectifier design is plug-compatible with its previous version and has a small footprint enabling easy retrofit applications. In addition to overall rectifier efficiency and performance improvement, Lineage Power's new technology has a reduced footprint or utility size requirement. The reduced utility size enables otherwise avoided capacity upgrade opportunities.

\section{Overview}

Developed by Lineage Power and acquired in 2011 by GE Industrial Solutions

Commercialized in 2011

Distributed and marketed by GE Power Electronics, Inc. (www.lineagepower.com)

\section{Applications}

Can be used for power rectification and supply in data center and telecommunications facilities.

\section{Capabilities}

Achieves up to $50 \%$ reduction in rectifier losses compared with conventional rectifiers.

Provides constant adjustment to plant operation to optimize efficiency regardless of rectifier type (SMR or Ferro).

\section{Benefits}
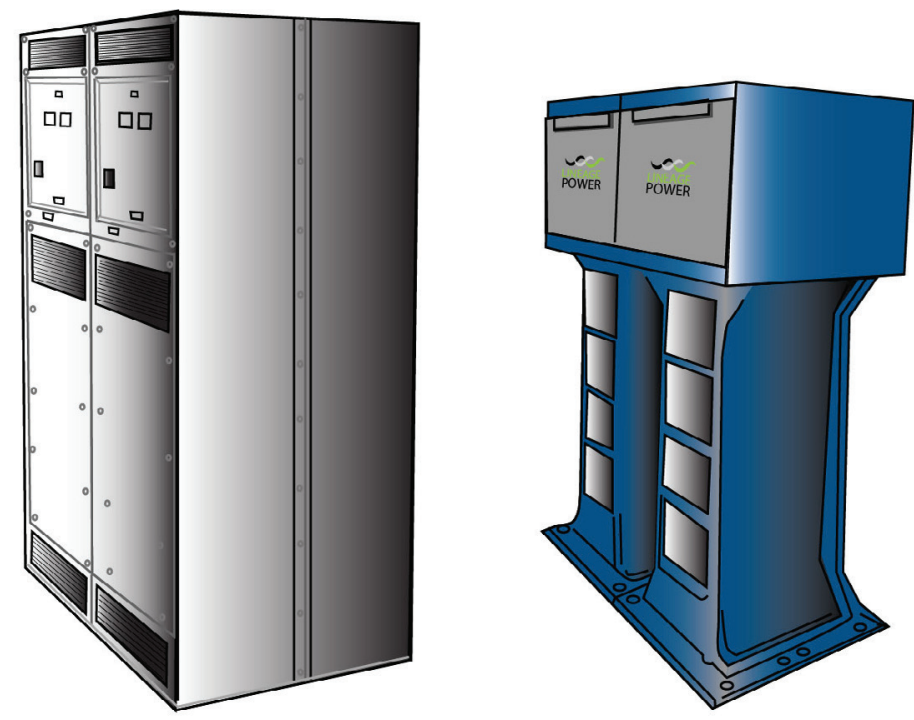

\section{Cost Savings}

Provides end-user value through short payback periods and immediate return on investment from decreased energy consumption.

\section{Energy Savings}

Improves energy utilization in power rectification and indirectly reduces energy required for equipment cooling.

\section{Retrofitable}

Provides easy installation in existing IT equipment rooms and is upgradable to suit future facility expansions.

Linage Power's SMR System (right) compared with Conventional Ferro-based Rectifier (left) 


\section{High-Intensity Silicon Vertical Multi-Junction Solar Cells}

IMPACTS

\section{Improved Solar Cell Reduces Cost of CPV Systems}

Solar photovoltaic (PV) technologies accounted for less than $1 \%$ of the nation's energy supply in 2009, despite their environmental benefits compared with electricity generation from combustion of fossil fuels. The high capital cost and low efficiency of PV systems are key barriers that prevent the technology from being widely adopted. Conventional flat PV panels also require large surface areas to generate a significant amount of electricity, making them less desirable in applications where ground or rooftop space is limited.

The efficiency and cost of solar PV can be improved with concentrating photovoltaic (CPV) systems, which use mirrors or lenses to concentrate sunlight on the solar cells. To maximize the cost-effectiveness of CPV systems, the solar cells must be low-cost, durable, and designed to perform well under high sunlight intensity. With assistance from DOE's Inventions and Innovation Program, GreenField Solar Corporation developed the PhotoVolt ${ }^{\mathrm{TM}}$ solar cell for use in its StarGen ${ }^{\mathrm{TM}}$ CPV system. The PhotoVolt is a series-connected array of silicon unit cells with vertical junctions and contacts. This configuration optimizes current collection and minimizes sheet resistance, current crowding, and blockage of illumination. The PhotoVolt has an extremely durable electrical, thermal, and mechanical configuration, which enables high packing densities with easy interconnecting of electrical output leads in high-powerdensity systems. The series connection of silicon unit cells provides highvoltage, low-current operation for optimum compatibility with most power processing loads. An active cooling system in the StarGen solar concentrator removes heat from the PhotoVolt cells, thereby increasing cell efficiency and capturing solar thermal energy.

Designed for operation at high intensities, the PhotoVolt uses 1/1000th of the silicon semiconductor used in conventional flat PV panels for a given power output. This innovation significantly reduces both the installed price and levelized cost of electricity of solar energy systems. The PhotoVolt cell's design simplicity and use of widely available silicon (instead of other semiconductor materials) enables high-volume production at low cost.

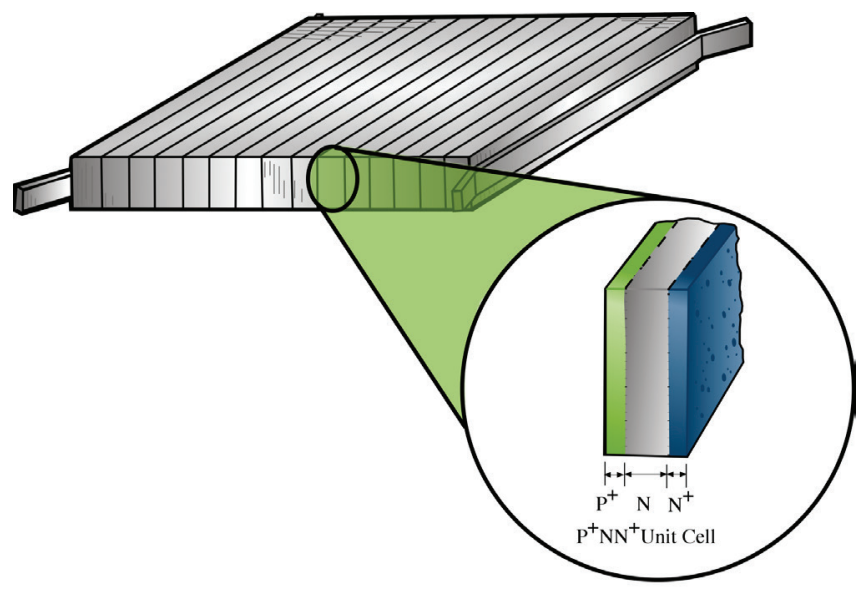

GreenField Solar Corporation's PhotoVolt Solar Cell

\section{Overview}

$\checkmark$ Developed and marketed by GreenField Solar Corporation. (http://greenfieldsolar.com/)

Commercialized in 2009 with 15 U.S. commercial installations.

\section{Applications}

Can be used to provide electrical and thermal energy for utilities and large commercial applications.

\section{Capabilities}

- Produces up to $1.5 \mathrm{~kW}$ of electricity and $15,000 \mathrm{Btu} / \mathrm{hr}$ of thermal energy per StarGen system.

- Uses a sun-tracking parabolic array of mirrors to concentrate high-intensity sunlight on PhotoVolt cells.

- Operates at a sunlight intensity of 300 to 900 times greater than conventional flat PV panels.

Facilitates use of "dense array" CPV design approach by offering side contacts and high-voltage output, and avoiding the need for bypass diodes.

\section{Benefits}

\section{Cost Savings}

Reduces costs by using 1/1000th of the silicon semiconductor used in conventional flat PV panels for a given power output.

\section{Emissions Reductions}

Reduces consumption of electricity generated from combustion of fossil fuels.

\section{Versatility}

Can be used in ground-mounted and roofmounted deployments. 


\section{New Infrared Drying System Removes Moisture More Efficiently Without Heating Surrounding Air}

Conventional drying systems for wood particulates, typically in the form of sawdust or chips, currently employ a rotary drum dryer that shoots a raw flame through a 20' to $30^{\prime}$ rotating drum while tumbling the wood product. Product scorching and air emission problems, particularly with carbon, $\mathrm{NO}_{\mathrm{x}}$, and volatile organic compounds (VOCs), are prevalent because the rotary drum operates at up to $1,000^{\circ} \mathrm{F}$.

An infrared drying system was developed by Catalytic Drying Technologies, Inc. (CDT), with the support of a DOE NICE ${ }^{3}$ grant. The long wavelength catalytic infrared drying system uses infrared energy from 3 to 7 microns to transfer energy directly to the water, activating it to a gaseous form at temperatures from $135^{\circ} \mathrm{F}$ to $220^{\circ} \mathrm{F}$. Highly efficient and tightly controlled infrared radiant energy is delivered to the product as it travels along a conveyor engineered to uniformly expose the product to the radiant energy.

A large prototype unit was constructed and tested with sawdust, wood chips, and a variety of agricultural products. The CDT system was proven to dehydrate forest and agriculture products efficiently. A conveyance system distributes the product evenly throughout the dryer to achieve consistent drying. While equipment costs are comparable to conventional heating systems, lifecycle costs are reduced. However, the CDT system can greatly reduce drying/ heating times using flameless catalytic infrared energy, resulting in smaller equipment or more throughput (or both). Reducing the moisture content with infrared drying by transferring energy directly to the moisture instead of heating the air and surrounding metal structure requires less energy, reduces air emissions and dries the product more thoroughly than conventional drying.

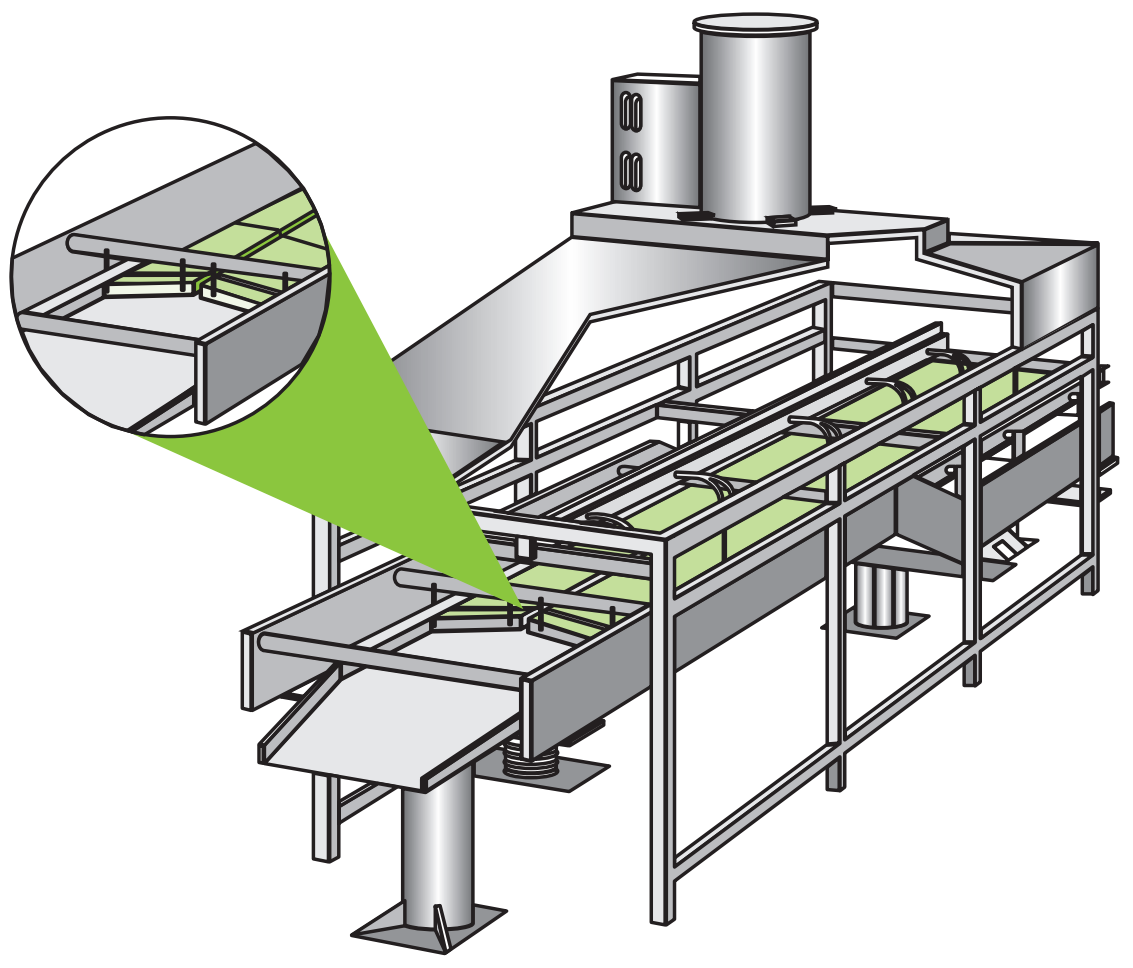

Catalytic Infrared Drying System

\section{Overview}

- Developed and marketed by Catalytic Drying Technologies, Inc.

(www.catalyticdrying.com)

Commercialized in 2005

Three units operating in the U.S. in 2010 in a rice drying facility, a powdered egg production plant and a flax seed processing plant

\section{U.S. Energy Savings}

(Trillion Btu)

\begin{tabular}{|c|c|}
\hline Cumulative through 2010 & $\mathbf{2 0 1 0}$ \\
\hline 0.015 & 0.003 \\
\hline
\end{tabular}

\section{U.S. Emissions Reductions}

(Thousand Tons, 2010)

\begin{tabular}{|c|c|c|c|}
\hline Particulates & SO $_{\mathrm{x}}$ & NO $_{\mathrm{x}}$ & Carbon \\
\hline 0.0 & 0.0 & 0.0 & 0.046 \\
\hline
\end{tabular}

\section{Applications}

Can be used by various industries such as forest products, agriculture, chemical processing, brewing and distilling, animal products, and horticulture

\section{Capabilities}

Uses infrared energy from 4 to 7 microns to transfer energy directly to water.

Drives off water at temperatures from $135^{\circ} \mathrm{F}$ to $220^{\circ} \mathrm{F}$.

Avoids the need for direct flame, which could damage the product.

\section{Benefits}

\section{Cost Savings}

Reduces operating and life-cycle costs compared with conventional dryers.

\section{Productivity}

Reduces residence time in the dryer and the amount of scorched (wasted) product. 


\section{Low-Volume Server for Reduced Energy Use and Facility Space Requirements}

IMPACTS

\section{Server Architecture and Software Improves Energy Consumption and Utilization}

Information technology (IT) and telecommunications facilities account for $\sim 3 \%$ of all U.S. electricity consumption. In data centers, volume servers account for $68 \%$ of the power consumed. The U.S. Department of Energy (DOE) identified the main areas where energy use or loss within information and communications technology facilities could be improved: equipment and software, power supply chain (and back-up power), and cooling. These areas are interdependent; power is supplied to the equipment and software; the heat given off by these components generates the need for cooling (as most of the energy used is converted into heat). Ultimately, major energy-efficiency gains that may be achieved in the equipment and software will decrease the demand for power and therefore also the demand for cooling.

SeaMicro, Inc., with assistance from DOE's AMO (as part of the American Recovery and Reinvestment Act), investigated and identified volume server energy consumption inefficiencies and developed technology to improve energy efficiency. SeaMicro developed the SM10000 product line of servers that use $75 \%$ less power and take $75 \%$ less space than the best available server on the market. The new server addresses the shortcomings of using larger higher processing power central processing units (CPUs). SeaMicro's new server architecture uses many small power efficient CPUs, and SeaMicro invented technology that eliminated $90 \%$ of the components in a server, allowing them to shrink the motherboard to 2" x 3", about the size of a credit card. The new server adopts a "supercomputer" style architecture where hundreds of mini motherboards are linked together with integrated switching for load balancing to meet computing demand. SeaMicro's servers reduce power consumption by $75 \%$ when compared with a traditional volume sever that consumes $200 \mathrm{~W}$ and is cost competitive at this level of server performance.

\section{Overview}

Developed by Seamicro, Inc., a subsidiary of Advanced Micro Devices, Inc.

Commercialized in 2010 and distributed and marketed by Seamicro (www.seamicro.com)

Installed hundreds of units worldwide at major web-based email and social media sites

\section{Applications}

Can be used to improve power consumption and use of IT and telecommunications facilities.

\section{Capabilities}

Provides equivalent conventional server capacity using one-fourth the power and space.

Provides "fail in place" architecture and hot swappable components.

Improves power consumption and utilization.

\section{Benefits}

\section{Energy Savings}

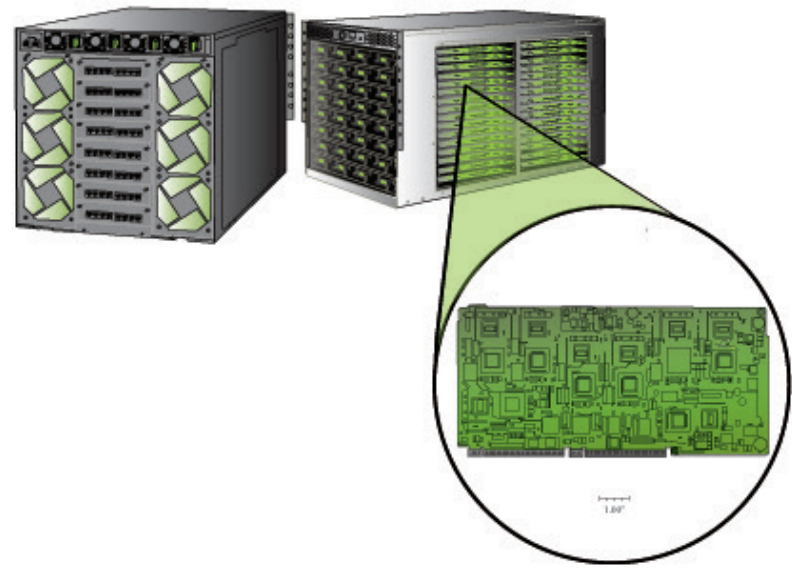

Reduces energy consumption by $75 \%$, which with widespread market adoption, could potentially save up to $900 \mathrm{MW}$ per year.

\section{Flexibility}

Easily integrates with existing IT equipment infrastructure and enables load balancing to meet computing capacity demand. 


\section{Management Technology for Energy Efficiency in Data Centers and Telecommunications Facilities}

\section{Technologies Optimize System Cooling and Power Demand}

Globally, demand for computing and data interconnectivity continues to rise, which in turn has increased the size of the data center infrastructure and its energy consumption. Between 2005 and 2010, U.S. data center electricity consumption increased by $36 \%$ or almost $2 \%$ of all electricity used. Information technology (IT) infrastructure requires energy for power and thermal management of the IT equipment. Inefficient energy use may result from using older ineffective server technologies and ineffective facility design, preventing adequate airflow for cooling. In most cases, facilities and IT management are organizationally separated, which increases the challenge to monitor and manage facility effectiveness and energy conservation.

IBM, with assistance from AMO (as part of the American Recovery and Reinvestment Act), has developed Measurement and Management Technologies (MMT) for evaluating and managing the effectiveness of data center energy consumption and energy usage. MMT can provide detailed evaluations using sensor networks and state-of-the-art assessment tools that measure energy consumption, airflow, and other necessary metrics combined with thermal imaging of the equipment to identify critical areas or hotspots. The analysis identifies operational inefficiencies and enables visualization, analysis, and optimization of the data center's energy consumption and utilization. The evaluation also provides facility installation plans for existing equipment and future expansion.

MMT has been productized through the IBM Tivoli Monitoring ${ }^{\mathrm{TM}}$ and Maximo ${ }^{\mathrm{TM}}$ solutions and is an important part of IBM's "Smarter Planet" campaign and strategy. The software solutions allow all assets across the data center to be managed, visualized, and optimized. The system has been successfully deployed internally at several IBM facilities and high profile sites at the Metropolitan Museum of Art, New York City; Syracuse University, NY; Toyota Motor Car Sales, U.S.A. Inc., CA; The Kroger Company, OH; and Highmark Blue Cross Blue Shield, PA. IBM is also a member of the Green Sigma ${ }^{\mathrm{TM}}$ Coalition, an industry alliance with key leaders in metering, monitoring, automation, data communications, software, and analytics to provide smart solutions for managing energy, water, waste, and greenhouse gas.

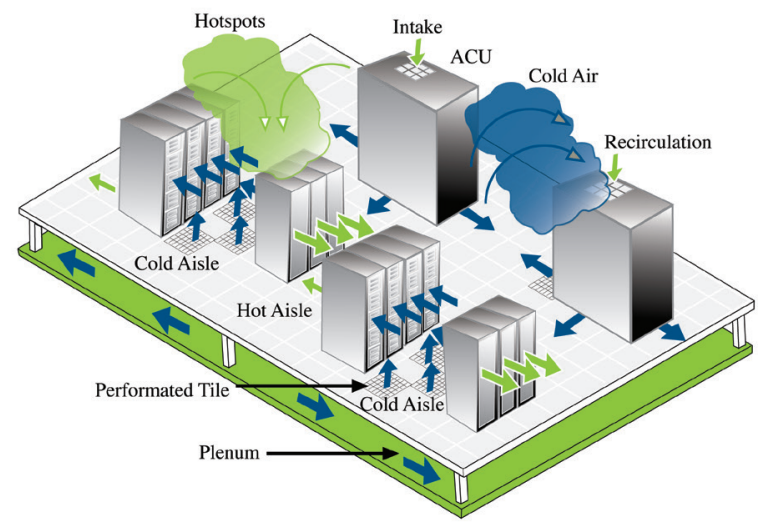

IBM's MMT Thermal Imaging and Evaluation Output

\section{Overview}

Developed by IBM Corporation (www.ibm.com).

Commercialized in 2010

Over 75 MMT systems installed in the United States with over 150 systems worldwide.

\section{U.S. Energy Savings}

(Trillion Btu)

\begin{tabular}{|c|c|}
\hline Cumulative through 2010 & $\mathbf{2 0 1 0}$ \\
\hline 0.154 & 0.154 \\
\hline
\end{tabular}

\section{U.S. Emissions Reductions}

(Thousand Tons, 2010)

\begin{tabular}{|c|c|c|c|}
\hline Particulates & SO $_{\mathbf{x}}$ & NO $_{\mathbf{x}}$ & Carbon \\
\hline 0.0 & 0.000 & 0.000 & 0.000 \\
\hline
\end{tabular}

\section{Applications}

Can be used for building facility monitoring, asset management, and preventive maintenance.

\section{Capabilities}

Provides real-time monitoring and optimization of data center energy efficiency and thermal management.

Improves energy consumption and utilization of data center operations.

- Provides comprehensive facility evaluation and analysis.

Achieves an optimized installation plan for current and future equipment expansion.

\section{Benefits}

\section{Cost Savings}

Reduces installation and floor space costs by optimizing equipment effectiveness and thermal management.

\section{Energy Savings}

Achieves typical annual energy savings $>15 \%$.

DOE Advanced Manufacturing Office 


\section{New X-Ray Technology Accelerates Plant Research}

The ability to analyze plant root structure and function in a timely, costefficient manner is critical to meeting DOE Biomass Program goals. Plant root characterization technologies traditionally cannot handle high throughput. Additionally, it has been difficult to analyze the same plant more than once due to destructive analysis methods.

With funding from DOE's Inventions and Innovation Program, the Phenotype Screening Corporation has developed a high-throughput, high resolution, and non-destructive system to image and characterize plant roots. The effect of the application of this technology will be to accelerate progress in a wide range of genetic improvement programs, including biomass feedstock (poplar, switchgrass, corn, and soybeans). Research acceleration may produce overall improvements in the range of $30 \%$.

The system is based on low-voltage digital x-ray radiography, used with special growth substrate material, plant containers, and image processing algorithms. Low-density polymer substrates and containers are used because they are suitable for low energy x-ray radiographic imaging. The project will primarily enable "output trait" and "value-added trait" improved products.

\section{Both Container and Substrate are Virtually Transparent to X-rays.}

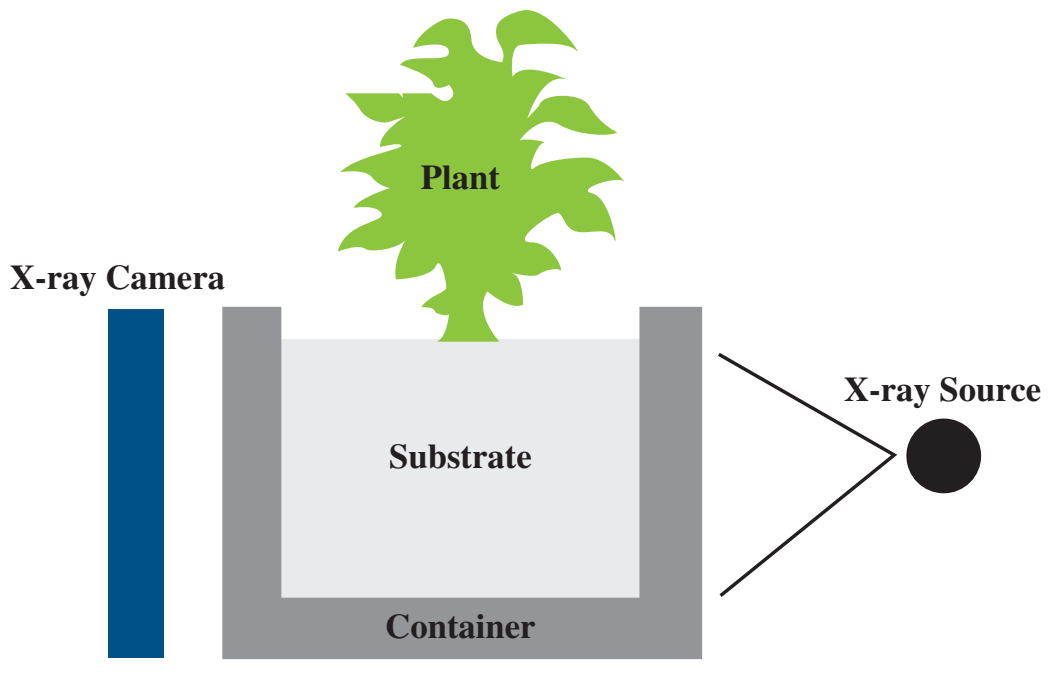

Non-Invasive Root Characterization System

\section{Overview}

\author{
$\checkmark$ Developed by Phenotype Screening \\ Corporation \\ (www.phenotypescreening.com) \\ Commercialized in 2006 \\ Used by universities and other research \\ organizations
}

\section{Applications}

Can be used in noninvasive root characterization studies to compare different plants' growth or a single plant's growth over time. Stressors may be introduced to see how the plants react; detailed analysis and characterization can show traits that can't be seen by the unaided eye.

\section{Capabilities}

Allows detailed plant root measurements without destroying the plant.

$\checkmark$ Can be customized to allow varied studies.

\section{Benefits}

\section{Productivity}

Accelerates research by about $30 \%$, contributing to reduced research time and costs, and therefore higher productivity.

\section{Waste Reduction}

Allows measurements to be made on the same plant so fewer plants have to be grown to conduct an analysis, using less growing medium, water, and plant containers. 


\section{Plastics or Fibers from Bio-Based Polymers}

IMPACTS

\section{Plastics from Renewable Resources Offer Significant Commercial and Environmental Benefits}

Each year, 60 billion pounds of thermoplastics are produced from imported and domestic oil to make industrial and consumer products. Because oil is an increasingly limited resource with negative impacts on the environment, reducing dependence on oil in all areas is important, including product manufacturing.

Polylactide (PLA), derived from annually renewable bio-based resources, can be used in place of petroleum-based thermoplastics in many applications such as compostable packaging, film, and fibers for apparel, carpeting, and other fabrics while greatly reducing $\mathrm{CO}_{2}$ emissions. With financial assistance from AMO, the National Renewable Energy Laboratory (NREL) along with Cargill Dow LLC and the Colorado School of Mines, developed and refined a process to use PLA in manufacturing. Substituting PLA for petroleum-derived polymers reduces fossil energy use by $62 \%$ to $68 \%$. Projections are that $10 \%$ of the U.S. nonrenewable plastics packaging can be replaced with polylactide polymer.

This project assisted in expanding the PLA market by developing two new processing technologies. Both technologies yield semi-crystalline PLA particles that have improved physical properties. Other project tasks helped to better understand the relationship between polymer molecular structure and physical properties, which is useful information for improving process control.

\section{Benefits}

\section{Energy Savings and Pollution Reduction}

Consumes up to $68 \%$ less energy in the form of fossil resources compared with producing products from petroleum. Emits less $\mathrm{CO}_{2}$ than petroleum-based products because the carbon comes from plants that extracted $\mathrm{CO}_{2}$ from the atmosphere.

\section{National Security}

Reduces the nation's dependence on foreign resources and oil to produce necessary products such as clothing, food packaging, and carpets.

\section{Overview}

$\checkmark$ Developed by NREL with Cargill Dow LLC and Colorado School of Mines

Commercialized in 2003

Produced at Nature Works LLC's Blair, NE facility with a capacity of 300 million pounds per year

(www.natureworksllc.com)

\section{U.S. Energy Savings}

(Trillion Btu)

\begin{tabular}{|c|c|}
\hline Cumulative through $\mathbf{2 0 1 0}$ & $\mathbf{2 0 1 0}$ \\
\hline 0.142 & 0.018 \\
\hline
\end{tabular}

\section{U.S. Emissions Reductions}

(Thousand Tons, 2010)

\begin{tabular}{|c|c|c|c|}
\hline Particulates & SO $_{x}$ & NO $_{x}$ & Carbon \\
\hline 0.0 & 0.011 & 0.003 & 0.394 \\
\hline
\end{tabular}

\section{Applications}

Can be used by plastics and textile industries, replacing certain packaging, films, and fibers used for apparel, carpeting, and other fabrics

\section{Capabilities}

$\checkmark$ Competes in a market based on price and performance, with a better environmental profile than today's plastics.

Currently could replace $10 \%$ of packaging with PLA, with more research being conducted to infiltrate the market further.

$\checkmark$ Offers potential to use a wide variety of bio-based materials.

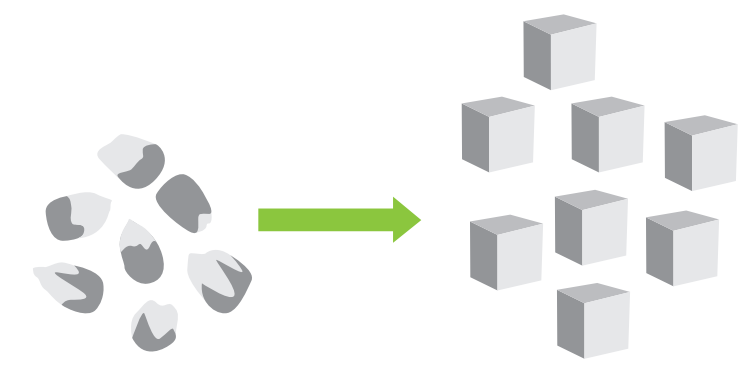

Bio-Based Materials
Fermentation Products

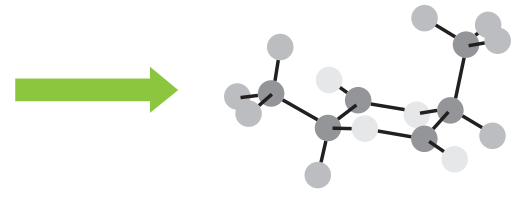

Lactide Formation

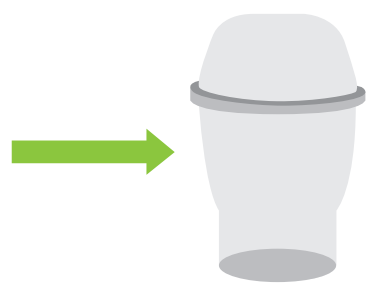

Plastic Products

Process for Producing Plastic Using Renewable Resources 


\section{Appendix B: AMO Emerging Technologies}

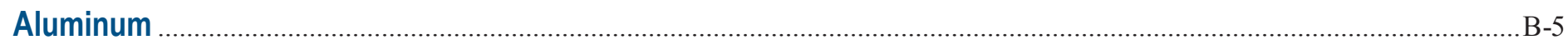

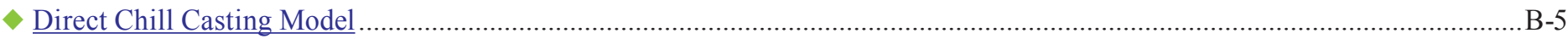

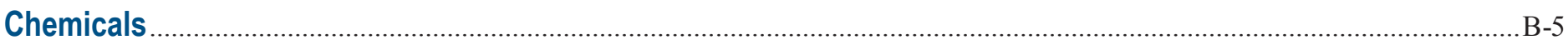

Acetic Acid Manufacture by the Selective Photocatalytic Oxidation of Ethane ........................................................................ B-5

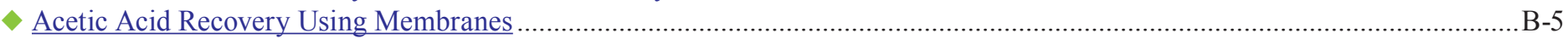

Affinity Ceramic Membranes with $\mathrm{CO}_{2}$ Transport Channels ..............................................................................................

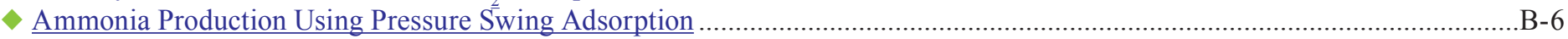

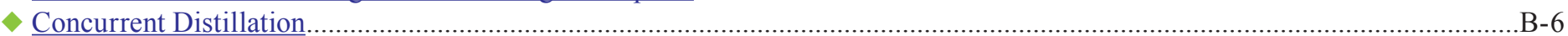

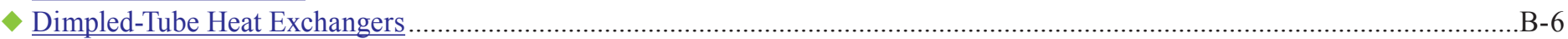

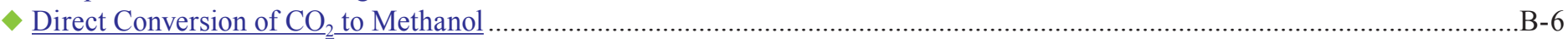

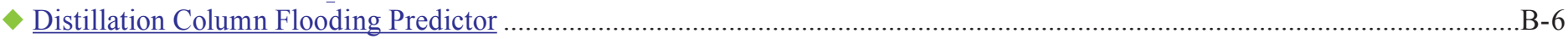

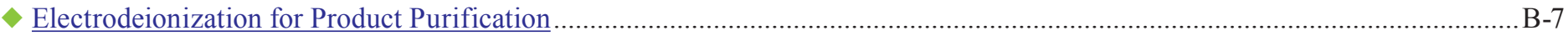

Fuel-Flexible Combustion System for Refinery and Chemical Plant Process Heaters ................................................................... B-7

Heat Integrated Distillation Using Microchannel Technology .................................................................................................

High Octane Fuel-Stocks via Engineered Solid Acid Catalysts ............................................................................................. B-7

Low Cost Chemical Feedstocks Using a Natural Gas Liquid (NGL) Removal Process ............................................................. B-7

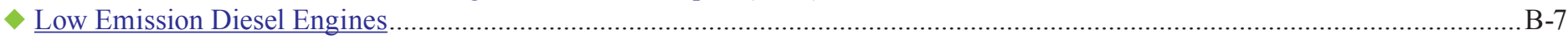

Microchannel Reactor System for Hydrogen Peroxide Production...........................................................................................B-8

New Design Methods and Algorithms for Multi-Component Distillation Processes ..................................................................B-8

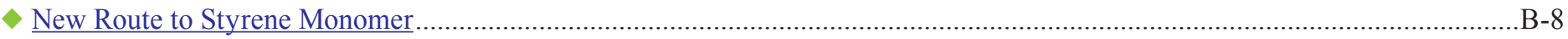

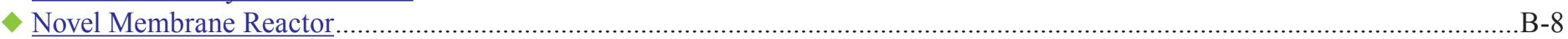

Process Intensification Through Multifunctional Reactor Engineering ...................................................................................8

Purification Process for Purified Terephthalic Acid (PTA) Production...................................................................................

Reduction of Distillation Usage in Manufacturing Ethanol by Reactive Water Separation .......................................................... B-9

Scalable Production of Fermentation-Derived Acetic Acid.................................................................................................... B-9

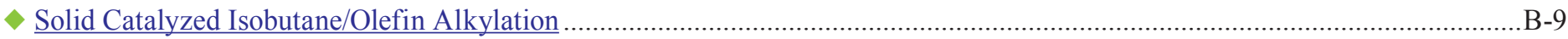

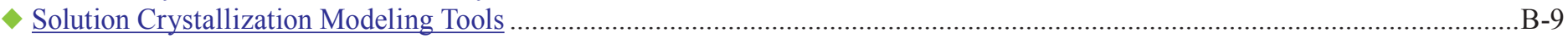

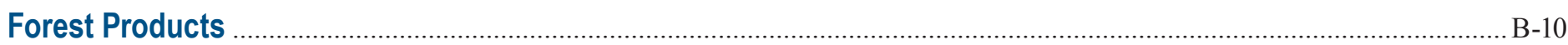

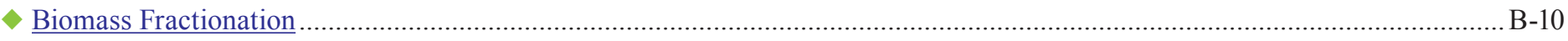

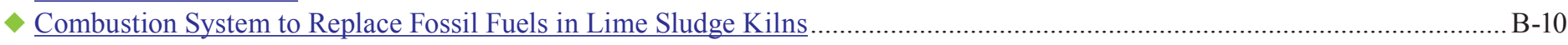

Decontamination of Process Streams through Electrohydraulic Discharge …….................................................................... B-10

Direct Causticizing for Black Liquor Gasification in a Circulating Fluidized Bed ................................................................... B-10

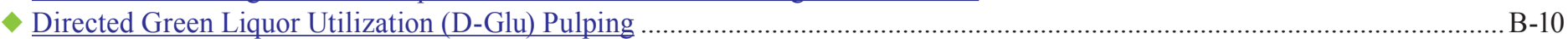

Fibrous Fillers to Manufacture Ultra-High Ash/Performance Paper ........................................................................................ B-11

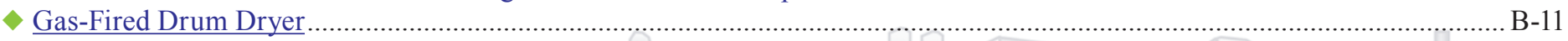

Innovative Back Surface Reflector for High-Efficiency Infrared Paper Drying ................................................................... B-11

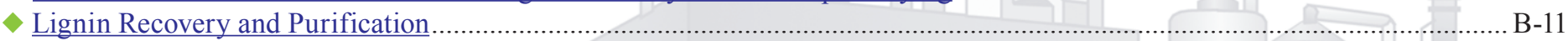

Low Temperature Plasma Technology for Treating VOC Emissions ................................................................................ B-11

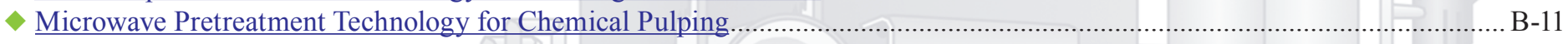

Novel Isocyanate-Reactive Adhesives for Structural Wood-Based Composites ........................................................................ B-12

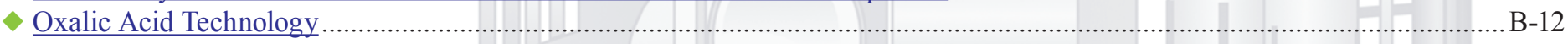

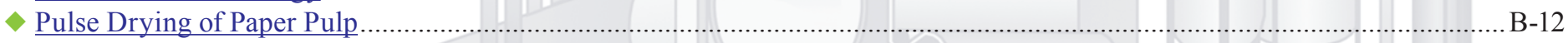

Screenable Water-Based Pressure Sensitive Adhesives.......................................................................................................... B-12

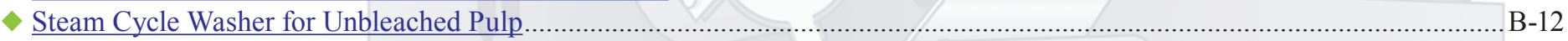

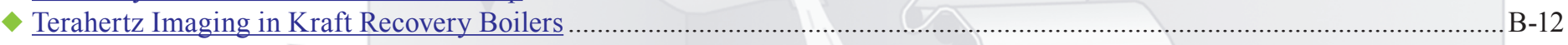


Advanced Combustion Space Model for Glass Melting .................................................................................................... B-13

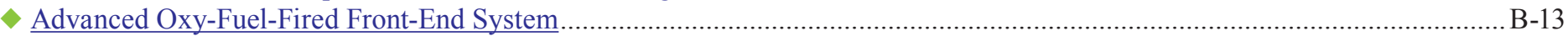

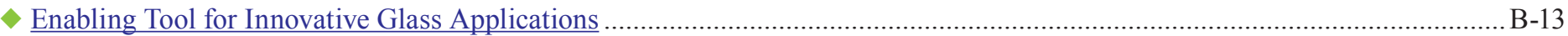

Energy Saving Glass Lamination via Selective Radio Frequency Heating ........................................................................... B-13

High-Intensity Plasma Glass Melter ………………...................................................................................................... B-13

Manufacturing Ceramic Products from Waste Glass ........................................................................................................ B-13

Submerged Combustion Melting....................................................................................................................................... B-14

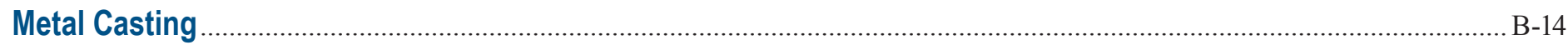

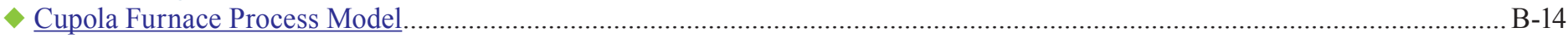

In-Situ Real Time Monitoring and Control of Mold Making and Filling Processes................................................................... B-14

Process to Recover and Reuse Sulfur Dioxide in Metal Casting Operations.............................................................................. B-14

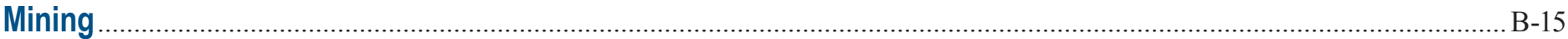

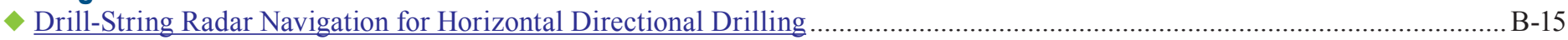

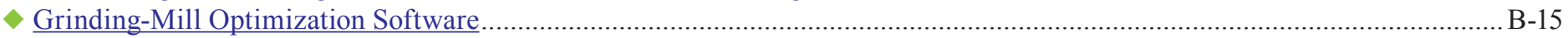

Soft (Unfired) Ceramic Particles via Dynamic Cyclone Classification...................................................................................... B-15

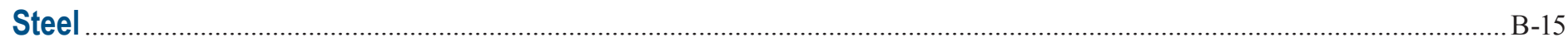

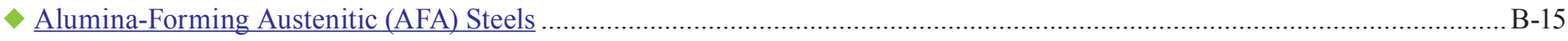

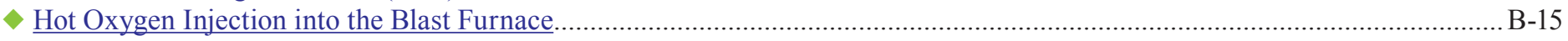

Imaging-Based Optical Caliper for Objects in Hot Manufacturing Processes ……................................................................. B-15

Metallic Iron Nodule Technology in Electric Arc Furnace Steelmaking ................................................................................... B-16

Nanocomposite Coatings for Life Extension in Zinc Pot Rolls .............................................................................................. B-16

Next Generation Heating System for Scale-Free Steel Reheating......................................................................................... B-16

Non-Chromium Passivation Techniques for Electrolytic Tin Plate.......................................................................................... B-16

Optical Sensor for Post-Combustion Control in Electric Arc Furnace Steelmaking .................................................................. B-16

Optimizing Blast Furnace Operation to Increase Efficiency and Lower Costs......................................................................... B-16

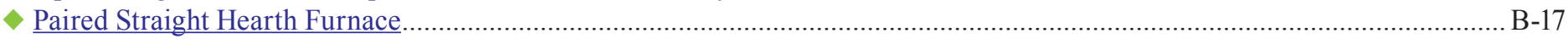

Processing Electric Arc Furnace (EAF) Dust into Salable Chemical Products....................................................................... B-17

Regeneration of Hydrochloric Acid Pickling Liquor ……...................................................................................................... B-17

Sensor-Based In-Line Control System (SICS) for the Surfaces of Continuously Cast Slabs .................................................... B-17

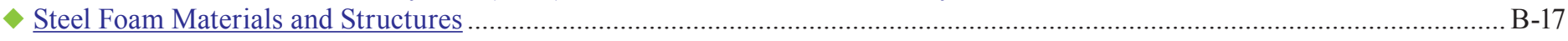

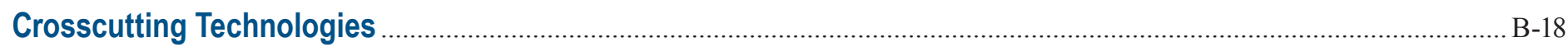

Advanced CHP System Utilizing Off-Gas from Coke Calcination ......................................................................................... B-18

Advanced Laser-Based Sensors for Industrial Process Control …….................................................................................... B-18

Advanced Membrane Separation Technologies for Energy Recovery ................................................................................... B-18

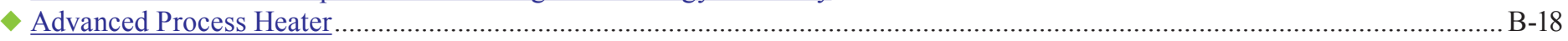

Advanced Transport Membrane Condenser for Energy and Water Recovery ....................................................................... B-19

Carbon Films for Next Generation Rotating Equipment Applications.................................................................................... B-19

Combined Heat and Power (CHP) Integrated with Burners for Packaged Boilers ................................................................. B-19

Dewatering Membrane for Hazy Hydro-Desulfurization of Unit Effluents ............................................................................... B-19

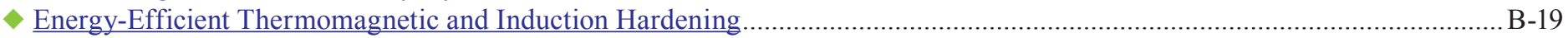

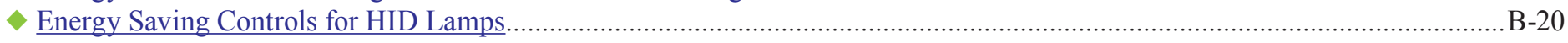

Energy-Savings' Model for the Heat Treatment of Aluminum Castings ................................................................................ B-20

Erosion-Resistant Nanocoatings for Improved Energy Efficiency in Gas Turbine Engines ..................................................... B-20

Flexible Combined Heat and Power (CHP) System with Low $\mathrm{NO}_{\underline{X}}, \mathrm{CO}$, and VOC Emissions ..................................................

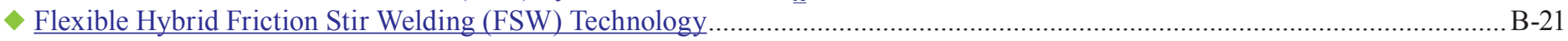

Fuel-Flexible Combustion Systems Using Opportunity Fuels in Gas Turbines....................................................................... B-21

Fuel-Flexible, Low-Emissions Catalytic Combustor for Opportunity Fuel Applications............................................................ B-21

Hierarchical Nanoceramics for Industrial Process Sensors................................................................................................. B-21 


\section{AMO Emerging Technologies}

IMPACTS

$\checkmark$ High Efficiency Liquid-Desiccant Regenerator

... -22

High-Efficiency, Low-Cost Small Turbine for Distributed Generation (DG) and Combined Heat and Power (CHP) .............

...22

High-Efficiency Microturbine with Integral Heat Recovery

... -22

High-Efficiency Thermoelectric Materials/Devices for Industrial Process Refrigeration and Waste Heat Recovery

B-22

$\checkmark$ High-Temperature Industrial Insulation Using Aerogels.....

B-22

High Temperature Resistant Superhydrophobic Nanocomposite Coatings.

B-23

$\checkmark$ Intelligent Controls for Refrigeration Systems

B-23

- Intensive Quenching Technology for Heat Treating and Forging Industries.

B-23

Large-Scale Manufacturing of Nanoparticulate-Based Lubrication Additives .

B-23

Low-Cost, High-Efficiency, Periodic-Flow Gas Turbine for Distributed Energy Generation ...

B-23

$\checkmark$ Low-Cost Microchannel Heat Exchangers ..

B-24

Low-Cost Process for Manufacturing Titanium Heat Exchanger Components for Desalination

B-24

Low-Cost Titanium Heat Exchanger Tube Development

B-24

Manufacturing of Superhydrophobic Surfaces with Nanoscale and Microscale Features

B-24

Maximus $^{\mathrm{TM}}$ Sonic Stop-Fill Device for LP Gas and Anhydrous Ammonia Tanks.....

B-25

- Microchannel Magnetic Coolers with Negative Magnetocaloric Effect

B- 25

Micro Gas Analyzer Solutions for Advancing Industrial Efficiency

B-25

Microreactor-Assisted Nanomaterial Deposition for Photovoltaic Thin-Film Production

B-25

Miniature, Inexpensive, Amperometric Oxygen Sensor.

B-26

Modifications and Optimization of the Organic Rankine Cycle...

B-26

Nanocatalysts for Diesel Engine Emissions Remediation.

B-26

Nanofluids for Industrial Cooling Applications

B-26

Nanomaterials for Batteries and Supercapacitors

B-26

Nanopowder Manufacturing via a Cost-Effective, Low-Carbon Footprint Process ……...............................................................26

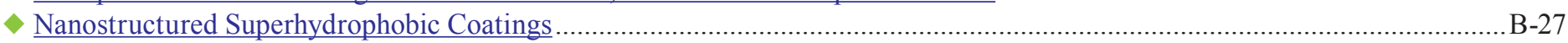

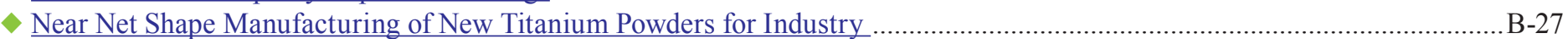

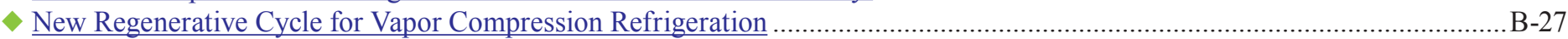

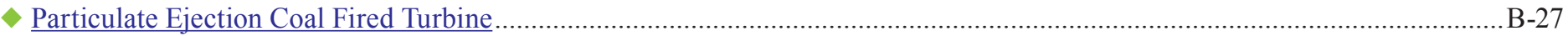

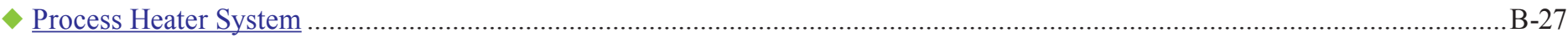

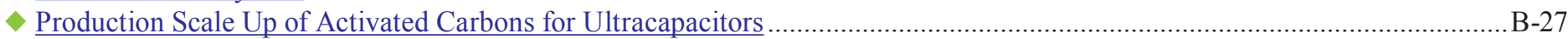

Production Scale Up of Nanoparticle-Based Lubricant Additives ……...............................................................................

Radiation Barrier Heating Mantle for High-Temperature Furnaces ……............................................................................. B-28

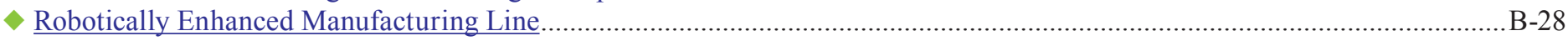

Self-Assembled, Nanostructured Carbon for Energy Storage and Water Treatment....................................................................B-28

Shear Rolling of Magnesium Sheet for Energy, Transportation, and Defense Applications ....................................................B-29

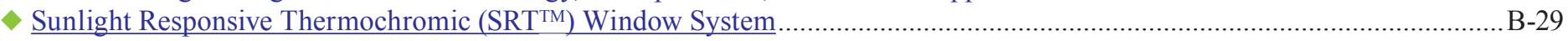

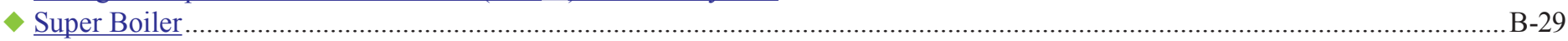

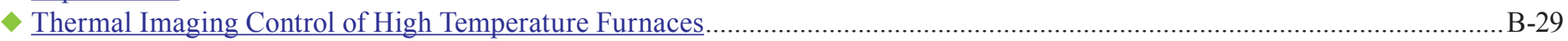

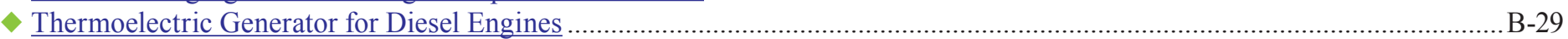

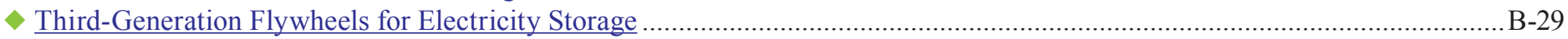

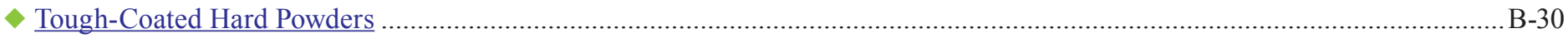

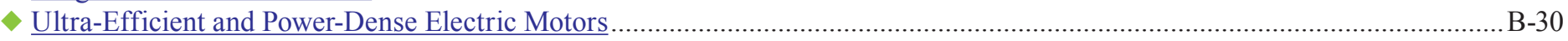

Ultra-Efficient Combined Heat, Hydrogen, and Power (CHHP) System .................................................................................3-30

Ultra-Fast Boriding in High-Temperature Materials Processing Industries .............................................................................. B-30

Ultramizer: Waste Heat Recovery System for Commercial and Industrial Boilers.................................................................B-30

Ultra-Thin Antifouling Surface Treatments for Industrial Heat Exchangers............................................................................ B-31

Ultratough, Thermally Stable Polycrystalline Diamond/Silicon Carbide Nanocomposites for Drill Bits ................................... B-31

Utility Interactive Inverter System for Distributed Generation ............................................................................................. B-31

Variable Speed, Low Cost Motor for Residential HVAC Systems ........................................................................................ B-31

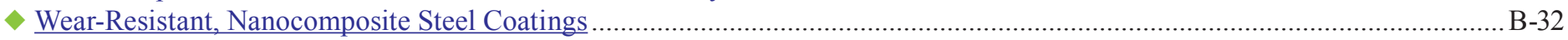

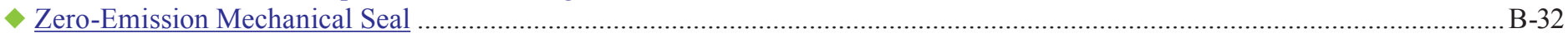




\section{AMO Emerging Technologies}

IMPACTS

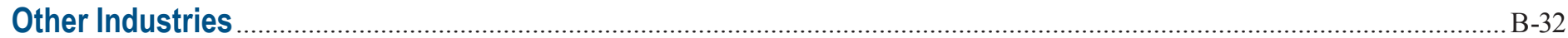

Adaptive Environmentally Contained Power and Cooling IT Infrastructure ...................................................................... B-32

Advanced Refrigerant-Based Cooling Technologies for Information and Communications Infrastructure................................ B-32

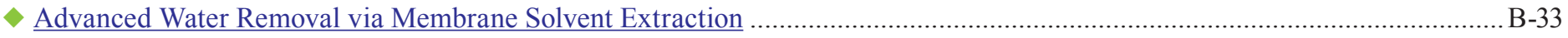

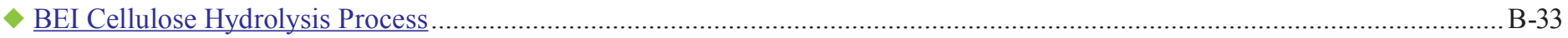

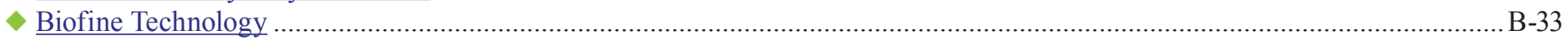

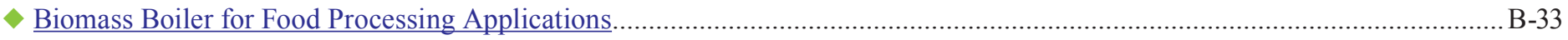

Distributed Optical Fiber Sensors for Continuous Liquid Level Tank Gauging .................................................................. B-33

Eco Oil: A Superior-Performance, Bio-Based Motor Oil ....................................................................................................... B-33

Economizer-Based Data Center Liquid Cooling with Advanced Metal Interfaces ...................................................................34

Flexible Distributed Energy and Water from Waste for the Food and Beverage Industry .........................................................3-34

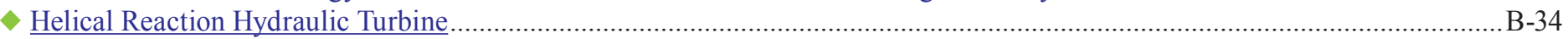

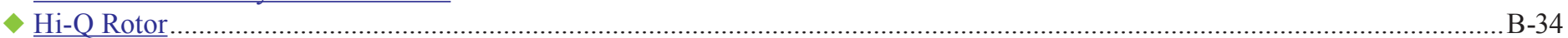

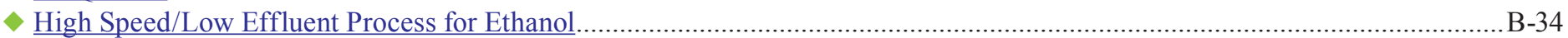

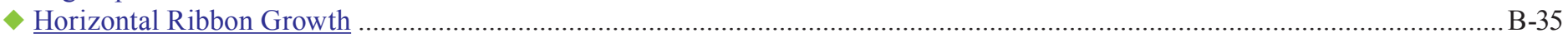

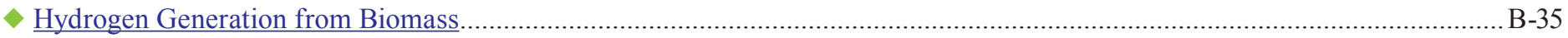

Low-Emissions' Burner Technology Using Biomass-Derived Liquid Fuel ........................................................................ B-35

Low Head, Vortex Induced Vibrations River Energy Converter ...................................................................................... B-35

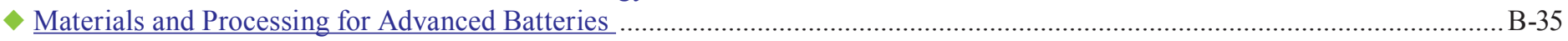

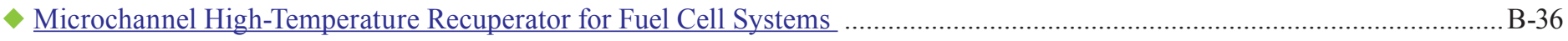

Nanoparticle Technology for Biorefinery of Non-Food Source Feedstocks ...................................................................... B-36

Novel Membrane-Based Process for Producing Lactate Esters ........................................................................................... B-36

Novel Sorbent to Clean Biogas for Fuel Cell Combined Heat and Power (CHP) ...................................................................36

Plastics, Fibers, and Solvents from Biosynthetically Derived Organic Acids.............................................................................3-36

Powering Cell Phones with Fuel Cells Running on Renewable Fuels................................................................................... B-36

Thermophotovoltaic Electric Power Generation Using Exhaust Heat.................................................................................. B-37

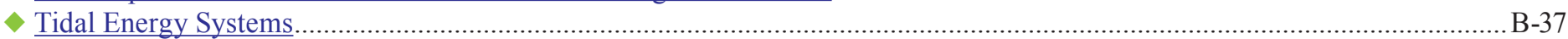

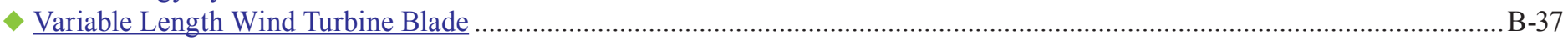

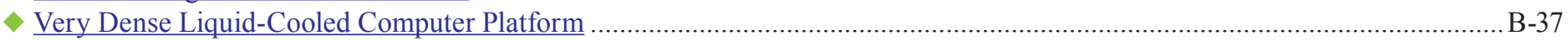

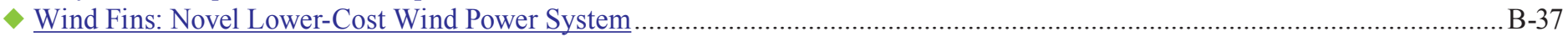

Yahoo! Compute Coop_-Next-Generation Passive Cooling Design for Data Centers ............................................................... B-38 


\section{AMO Emerging Technologies}

\section{Aluminum}

\section{$\triangle$ Direct Chill Casting Model \\ (www.secat.net)}

The direct chill (DC) casting process is used for $68 \%$ of the aluminum ingots produced in the United States. Ingot scraps from stress cracks and butt deformation account for a $5 \%$ loss in production. The interaction of the DC process is too complex to analyze by intuition or practical experience. A new DC casting model is being developed to increase the general knowledge of the interaction effects and should lower production losses to $2 \%$. The model will provide insights into the mechanisms of crack formation and butt deformation, and will help optimize DC process parameters and ingot geometry.

\section{Chemicals}

\author{
Acetic Acid Manufacture by the Selective \\ Photocatalytic Oxidation of Ethane \\ (www.kse-online.com)
}

Acetic acid is used as a chemical reagent for producing numerous plastics, synthetic fibers, and fabrics, as well as polymers and esters in manufacturing adhesives, paints, inks, and varnishes. Currently, carbon monoxide (CO) and methanol are used to produce acetic acid, but $\mathrm{CO}$ production wastes raw materials and generates greenhouse gas emissions. This project will develop a UV photocatalytic technology that improves the oxidation of ethane to acetic acid at high selectivity. The technique is more energy efficient, does not require high temperature and pressure, and does not over-oxidize the hydrocarbon raw materials to carbon dioxide. The technology can potentially be used in a wide range of chemical oxidation reactions, reducing energy use and greenhouse gas emissions in the chemical industry.

\section{Acetic Acid Recovery Using Membranes (www.mtrinc.com)}

Recovering and recycling acetic acid from aqueous streams are important activities in industrial separation but costly and energy intensive when performed by conventional technology. This need makes acetic acid recovery a promising target for a more efficient, lower-cost, simpler approach such as membrane technology. However, the required separation performance, combined with the need for robust chemical and thermal stability of the membrane materials, makes using membrane technology for acetic acid recovery very challenging. In this project, perfluorinated polymer membranes are used to dehydrate acetic acid using two new membrane processes. The membranes are stable in hot acetic acid/water mixtures and have good selectivities for separating water from acetic acid. The proposed membrane processes will lower energy costs by more than $50 \%$ compared with conventional separations. 


\section{Chemicals}

(continued)

\section{Affinity Ceramic Membranes with $\mathrm{CO}_{2}$ Transport Channels \\ (www.mediaandprocess.com)}

Compared with more conventional separation processes, membrane separation processes offer several advantages, including increased energy efficiency, compact design, and operational flexibility. Numerous unexploited applications exist for advanced separations in aggressive environments that rely on a membrane's affinity to a specific chemical as opposed to traditional molecular sieving. Highly selective thermally/hydrothermally stable inorganic membranes offer a solution to these difficult industrial separation applications.

\section{Ammonia Production Using Pressure Swing Adsorption \\ (www.smartkoncept-tech.com)}

A new process is being developed that will enable the energy-efficient production of ammonia. Pressure swing adsorption (PSA) technology will increase ammonia yield, reduce natural gas feedstock use, significantly lower energy consumption, and offer capital cost savings compared with traditional cryogenic methods. The PSA process is scalable and can be applied to retrofit existing ammonia plants or to build new field plants. It enables on-demand ammonia production eliminating the need to transport and store at power plants large amounts of ammonia, which is classified as a hazardous chemical by OSHA. The technology has applications in $\mathrm{NO}_{\mathrm{x}}$ and $\mathrm{CO}_{2}$-reducing technologies in the chemical industry and at power plants.

\section{Concurrent Distillation}

(www.utexas.edu)

The Trutna Tray (Co-Flo Tray) improves the performance of distillation and absorption trays by using a co-current flow design. Compared with the conventional sieve tray, the co-current tray increased production capacity by more than $100 \%$ without sacrificing separation efficiency. Three tray variations have been pilot-tested using an industrialscale distillation column. The de-entraining section of the Co-Flo Tray is routinely used by the UT Austin's Separation Research Program in all of its air/water and caustic scrubbing studies. The special collector design and the enhanced liquid/vapor separation capability offer great potential for future de-entraining applications.

\section{Chemicals}

(continued)

\section{$\checkmark$ Dimpled-Tube Heat Exchangers \\ (www.gastechnology.org)}

A project to improve the thermal efficiency of convective sections of industrial fired-process heaters demonstrates that a dimpled-tube technology will significantly improve the energy efficiency of fired-process heaters and will reduce fouling rates. The heat-transfer enhancement approach uses a tube surface with a system of threedimensional cavities (dimples). Cost-effective enhancement occurs because intensive vortex flow patterns are generated by cavities and provide intensive heat and mass transfer between the surface and the flowing media. A pilot-scale dimpled-tube test unit at a participating refinery increased heat flow by $50 \%$ to $60 \%$ compared with traditional tubes and reduced pressure drop by $30 \%$ to $40 \%$.

\section{Direct Conversion of $\mathrm{CO}_{2}$ to Methanol \\ (www.innosense.us)}

Although carbon capture and storage (CCS) technology has received the most attention for its potential to reduce emissions, processes that convert $\mathrm{CO}_{2}$ into useful products can provide a positive return on investment and not just be an unrecoverable cost. Compared with CCS technology, the potential revenue generated by using $\mathrm{CO}_{2}$-based products is likely to grow popular with time while reducing or stabilizing greenhouse gas emissions. Because of its reactivity, $\mathrm{CO}_{2}$ can be used as a raw feedstock material for producing chemicals such as methanol.

\section{Distillation Column Flooding Predictor \\ (www.2ndpoint.com)}

A new control technology more accurately identifies incipient floods in petrochemical distillation and separation columns. The Flooding Predictor, a patented pattern recognition technology, allows a column to be operated at or near the incipient flood point. The technology identifies patterns of transient instabilities that occur just before flooding events. Identifying the incipient flood point allows the control objective to be shifted from delta-pressure to the actual flood point. Shifting the control objective virtually eliminates column flooding events, while increasing throughput 


\section{AMO Emerging Technologies}

\section{Chemicals}

(continued)

\section{Electrodeionization for Product Purification (www.anl.gov) \\ This technology combines the advantages of ion exchange (an adsorption technology) and electrodialysis (a membrane separation) for a wide range of potential applications in the chemical industry, including direct production and separation of products, product purification and desalination, salt waste recovery, and water recycling. Targeted applications include organic acid production, dextrose desalination, ultrapure water production, product polishing, and waste salt recovery.}

\section{Fuel-Flexible Combustion System for Refinery and Chemical Plant Process Heaters \\ (www.etapartners.com) \\ By enabling process heaters to use opportunity gaseous fuels, this fuel-flexible combustion system reduces energy costs for industry and lowers both $\mathrm{CO}_{2}$ and $\mathrm{NO}_{x}$ emissions. Under development is a fuel blending and combustion system capable of automatic, safe, and reliable operation across a broad range of fuel compositions, including syngas, biogas, natural gas, and refinery fuel gas. Computational fluid dynamics analyses were applied to optimize the prototype system's aerodynamic, combustion, heat transfer, and emissions' performance.}

\section{Heat Integrated Distillation Using Microchannel Technology \\ (www.velocys.com)}

A new technology using compact equipment is being developed to reduce distillation capital cost and increase energy efficiency. Microchannel process technology enables highly efficient mass transfer, resulting in process intensification. The technology also integrates heat transfer with fractionation, eliminating the need for external heat exchange equipment. Microchannels can be used to target heat loads at precise locations in the equipment, which can be tailored to individual distillation stage requirements. Heat load tailoring reduces wasted energy to improve overall distillation efficiency. This technology will likely have initial applications in the separation of high-value materials.

\section{Chemicals \\ (continued)}

\begin{abstract}
High Octane Fuel-Stocks via Engineered Solid Acid Catalysts

(www.exelusinc.com)

High octane alkylate, an ideal clean fuel component for reformulated gasoline, is currently made using toxic liquid acid catalysts such as hydrofluoric acid. A commercially viable and environmentally superior alternative to conventional liquid-acid alkylation processes is being developed called the ExSact process. This pilot-tested process uses benign, engineered, solid-acid catalysts coupled with an innovative reactor design to produce highoctane gasoline. Low energy consumption and production of fewer by-products compared to existing technologies result in significant savings in operating costs.
\end{abstract}

\section{Low Cost Chemical Feedstocks Using a Natural Gas Liquid (NGL) Removal Process \\ (www.gastechnology.org) \\ Conventional NGL recovery technologies, such as cryogenic turbo-expanders, are highly energy intensive and expensive to operate, requiring low temperatures and substantial energy to recompress the processed gas back to the pipeline pressure. A new technology is being developed that is a low-cost and much more energy-efficient NGL recovery process that can be commercialized by the natural gas industry. Once commercialized, this technology has the potential to save up to 200 trillion Btu per year by 2020 , reduce the cost of NGL separation from natural gas, and provide cheaper feedstocks to the chemical and petrochemical industries.}

\section{- Low Emission Diesel Engines \\ (www.compactmembrane.com)}

Diesel engine exhaust is a major source of $\mathrm{NO}_{\mathrm{x}}$ pollution. The formation of $\mathrm{NO}_{\mathrm{X}}$ in diesel engines is dependent on the combustion temperature, which can be affected by the engine cylinder charge. An innovative membrane is being developed to adjust the cylinder charge and reduce the $\mathrm{NO}_{\mathrm{X}}$ emissions by delivering nitrogen-enriched air (NEA) to the diesel engine. The NEA system can reduce $\mathrm{NO}_{\mathrm{X}}$ formation in diesel engines by $50 \%$. 


\section{Chemicals}

(continued)

\section{Microchannel Reactor System for Hydrogen Peroxide Production \\ (www.fmc.com) \\ Newly developed reactors allow for on-site, on-demand generation of hydrogen peroxide $\left(\mathrm{H}_{2} \mathrm{O}_{2}\right)$ and reduce the costs of transportation, storage, and dilution associated with conventional $\mathrm{H}_{2} \mathrm{O}_{2}$ production methods. Microchannel reactors possess extremely high surface-to-volume ratios and exhibit enhanced heat and mass transfer rates. The unique design allows for the peroxide-generating reaction to occur at $\mathrm{H}_{2}$ concentrations above $5 \%$ without the risk of combustion. In addition, the reactor's low-pressure operating conditions maximize energy efficiency and safety.}

\section{$\checkmark$ New Design Methods and Algorithms for Multi- Component Distillation Processes \\ (www.purdue.edu)}

The ability to apply low-energy multicomponent distillation configurations can allow chemical manufacturers to reduce energy consumption in both existing and grassroots plants. However, determining an appropriate configuration is limited by an incomplete knowledge of the "search space" for a proper distillation network. Currently, no systematic method is available that reveals all possible distillation configurations to serve a particular purpose. The mathematical task and size of the problem in terms of computational effort pose enormous difficulties in finding an optimum distillation configuration.

\section{New Route to Styrene Monomer}

(www.exelusinc.com)

The ExSyM process is being developed using a new catalytic technology that maximizes styrene monomer production from toluene and methanol feedstocks.

Compared with conventional methods, ExSyM requires less capital costs, operates at lower temperatures, and lowers utility consumption. The process recovers and re-uses hydrogen by-product to help power the process - greatly reducing energy usage and carbon emissions. The process has been tested in bench-scale reactors, with the catalyst showing no signs of deactivation as long-term stability tests continue. As a retrofit for existing plants, ExSyM has great potential as a viable alternative to conventional styrene monomer production methods.

\section{Chemicals}

(continued)

\author{
Novel Membrane Reactor \\ (www.compactmembrane.com) \\ Various industrial processes, from pharmaceutical \\ production to polymer formation, involve organic \\ reversible reactions among acids, aldehydes, ketones, \\ alcohols, and amines. Researchers are developing a cost- \\ effective, robust membrane with universal applicability \\ in almost any organic-water environment for potential \\ separation of the reaction water. In contrast to existing \\ membrane technologies that have significant temperature \\ and chemical limitations, the extremely high ruggedness \\ of the new membrane would improve stability under \\ harsh operating conditions, be able to withstand high \\ temperatures when used with reactive chemicals $\left(266^{\circ} \mathrm{F}\right.$ or \\ higher), and have high water permeability.
}

\section{$\checkmark$ Process Intensification through Multifunctional Reactor Engineering \\ (www.cdtech.com) \\ An innovative process is being developed to increase energy efficiency and profitability in the chemical industry. Large-scale pulse flow reactor technology enables high- efficiency contacting and therefore increased mass transfer between fluid phases. The initial target application for this technology is the alkylation of olefins with isobutane to produce a high-octane gasoline blendstock. The pulse flow reactor will significantly reduce operating costs compared with conventional high-shear mixing that uses large-scale impellers. The novel reactor design also could benefit many other processes across the chemical industry, particularly those using liquid catalysts.}

\section{$\checkmark$ Purification Process for Purified Terephthalic Acid (PTA) Production (www.gtctech.com)} A novel purified terephthalic acid (PTA) production process using a two-step crystallization technique promises to make a significant economic impact on the PTA industry. The process operates at lower pressure and temperature, significantly reducing energy consumption, and enables the use of lower purity, lower-cost para-xylene feedstock. The process uses a highly selective, proprietary organic solvent blend that allows for bromine-free oxidation, which eliminates the environmental problems caused by methyl bromide and the high cost of corrosionresistant specialty alloys used in construction materials. 


\section{AMO Emerging Technologies}

IMPACTS

\section{Chemicals}

(continued)

\section{Reduction of Distillation Usage in Manufacturing Ethanol by Reactive Water Separation \\ (www.kse-online.com) \\ U.S. domestic ethanol production has grown \\ dramatically, from about 5 billion gallons in 2006 to a \\ peak production rate of over 12 billion gallons per year \\ in mid-2008. Reducing the energy use for removing \\ water in manufacturing fuel-grade ethanol from corn or other biomass materials is paramount to this industry. Converting a fermentation broth containing $5 \%$ to $10 \%$ ethanol into a fuel-grade ethanol containing $<1 \%$ water is energy intensive, and the energy requirements for U.S. ethanol plants are extremely high, currently estimated at 220 trillion Btu per year. The proposed reactive dehydration technology being developed is intended to substantially replace direct distillation of ethanol from water, consuming markedly less energy and creating nearly one billion dollars of energy savings annually.}

\section{Scalable Production of Fermentation-Derived Acetic Acid} (www.anl.gov)

Half of the 2.3 billion pounds of U.S. acetic acid production is used in manufacturing vinyl acetate monomer (VAM) and is economical only in very large production plants. Nearly $80 \%$ of the VAM is produced by methanol carbonylation, which requires high temperatures and exotic construction materials and is energy intensive. Fermentation-derived acetic acid production allows for small-scale production at low temperatures, significantly reducing the energy requirement of the process.

\section{Chemicals \\ (continued)}

\section{Solid Catalyzed Isobutane/Olefin Alkylation (www.precision-combustion.com)}

Alkylate is used in the petrochemical industry as an additive to improve gasoline combustion efficiency. Recent emphasis on reducing emissions and oil consumption has increased the number of applications using this additive, and demand for alkylate has risen. Alkylate production uses an acid-based alkylation process that requires significant energy intensive pre- and post-plant level processing of input reactants and spent output materials. The spent materials are flammable and acidic and, while a large portion is recycled back into the process, incur environmental/health risks and handling costs. This project will develop an environmentally friendly catalytic system that uses a durable zeolite-based solid catalyst that eliminates the use of liquid acids and their associated cost-intensive handling and processing. The new catalyst system also improves the service life of the solid catalyst by reducing polymerization on the catalyst's surface (a lifelimiting factor in previous solid catalyst reactors), which improves yield and energy consumption and decreases capital and operating costs.

\section{Solution Crystallization Modeling Tools (www.olisystems.com)}

Reliable simulation of crystallization requires accurate modeling of many factors. A new modeling tool synthesizes several essential elements, at least one of which has been only crudely approximated in previously available tools. This new modeling tool helps chemical engineers to better predict and control the crystal size distribution. It also improves the understanding of the effects of mixing and spatial variation of temperature and composition on the product quality, and ultimately will optimize crystallization efficiency. The resulting enhanced computational fluid dynamics capabilities are also applicable to a range of industrial applications beyond crystallization. 


\section{Forest Products}

Biomass Fractionation

(www.purevisiontechnology.com)

Biomass fractionation effectively separates lignocellulosic biomass into useful intermediate components, including cellulose fiber, xylose-rich syrup, lignin, and biogrowth media. The high-purity, high-yield cellulose fiber is available for efficient hydrolysis to glucose or for pulp applications. The glucose and xylose syrups can be converted to ethanol, butanol, and many other chemicals. The sulfur-free, highly depolymerized lignin can be converted to biofuels or can be used directly as boiler fuel. The low-toxicity, extractives-rich liquor is a suitable biogrowth media to produce a yeast co-product for animal feed protein markets and for biocatalyst propagation. The flexibility of the process provides a hedge against the volatile fuel market and allows for future technological upgrades to higher-value fuels, chemicals and other coproducts.

\section{Combustion System to Replace Fossil Fuels in Lime Sludge Kilns}

(www.houghtoncascade.com)

The U.S. pulp and paper manufacturing industry uses a considerable amount of fossil fuels, which produce greenhouse gases (GHGs). To regenerate lime to produce white liquor, kilns almost all exclusively operate on fossil fuels and are the single largest use of fossil fuels in pulp mills. This project will develop a lime sludge kiln combustion system that burns renewable fuels (lignin or torrefied wood) and eliminates or reduces fossil fuel use in pulp mills. The technology has the potential to reduce fossil fuel use by the equivalent of 18.5 million barrels of oil per year and to reduce GHG emissions by 10.5 million tons per year. The combustion technology developed here could also have other industrial applications that use fossil fuel burners; e.g., cement, phosphate, and bio-fuels industries.

\section{Forest Products}

(continued)

\section{Decontamination of Process Streams through Electrohydraulic Discharge (www.ipst.gatech.edu) \\ In recycling paper, "stickies" cause considerable downtime and require costly minerals and polymers to be added for handling and detackifying them during the recycling process. A new mechanical method - pulsed power technology - is being demonstrated at several recycling mills to replace these costly chemicals. This technology uses a shock wave, developed from a spark discharging under water, to diffuse the stickies and create hydroxyl radicals from water, which oxidizes the stickies. This oxidation causes the stickies to lose their tack and become benign, thus allowing recycling to continue unimpeded.}

\section{Direct Causticizing for Black Liquor Gasification in a Circulating Fluidized Bed}

(www.ipst.gatech.edu)

A new direct causticizing process is being developed that saves energy and increases the profitability of pressurized black liquor gasification (PBLG). The process performs the causticizing step in situ during BLG by applying titanates to the liquor in a pressurized circulating fluidized bed reactor. Complete direct causticizing eliminates the traditional lime cycle, saving both fossil energy and money compared with using energy-intensive lime kilns. The synthesis gas product from PBLG can be applied to either combined cycle power generation or liquid fuels such as mixed alcohols or Fischer Tropsch diesel, increasing the efficiency of the chemical recovery process while producing fuel feedstock or electricity.

\section{Directed Green Liquor Utilization (D-Glu) Pulping (www.ncsu.edu)}

Increases in the rate and selectivity of kraft pulping without incurring major capital costs will increase the economic return of the pulp and paper industry. A high sulfidity pretreatment of wood chips is one of the most promising and low capital means to achieve these increases. Green liquor is easily accessible in a kraft mill and has a naturally high sulfidity (rich in hydrosulfide ions), which is critical for accelerating pulping and providing a high value product. Researchers have discovered ways to reduce pulping time and energy requirements through the intelligent application of green liquor in the digester. 


\section{AMO Emerging Technologies}

\section{Forest Products}

(continued)

\section{Fibrous Fillers to Manufacture Ultra-High Ash/Performance Paper}

Mineral fillers that increase paper brightness and opacity and improve paper print quality have reduced costs by replacing wood fiber. However, filler loading has been limited to $15 \%$ to $20 \%$ because higher loading levels cause a loss of sheet strength and bulk as well as "dusting" during printing. A new fibrous filler technology has been developed that may overcome these problems and replace high-cost wood fiber. The new fillers will ultimately produce a composite paper containing up to $50 \%$ ash, with equal or better performance characteristics than conventionally attainable paper. The new technology will also lead to better retention of fillers, additives, and pulp fines, significantly reducing biological and chemical oxygen demands in the mill process water.

\section{Gas-Fired Drum Dryer}

(www.gastechnology.org)

A new paper dryer is being developed and pilot-scale tested to significantly increase the efficiency of papermaking. The Gas-Fired Paper Dryer (GFPD) is a natural-gasfired system that uses a combination of a flame sheet and dimpled pattern on the drum's inner surface to improve combustion stability, reduce pollutant emissions, and cost-effectively enhance heat transfer from combustion products to the paper web. This patented approach could be implemented into new or existing equipment. The GFPD will ultimately help the paper industry (especially drying limited mills) reduce energy use and increase the production rate of paper machines by $10 \%$ to $20 \%$.

\section{Innovative Back Surface Reflector for High- Efficiency Infrared Paper Drying}

(www.creare.com)

An innovative back surface reflector (BSR) that will

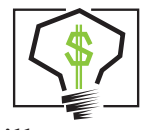
dramatically improve the efficiency, quality, and throughput of the papermaking process is being developed. Electric infrared (IR) dryers with current BSR technology suffer from extremely low energy efficiency, using only $10 \%$ of the input power supplied to an IR dryer to dry the paper; the rest is lost as waste heat. The new BSR design dramatically increases the percentage of input power that is absorbed by the paper sheet, decreasing energy costs and increasing product quality and throughput.

\section{Forest Products}

(continued)

\section{Lignin Recovery and Purification (www.techfish.com)}

Power companies are limited in their ability to reduce coal usage by burning biomass. By recovering lignin from pulp and paper mills, the sequential liquid-lignin recovery and purification process produces a biofuel comparable in energy density to coal. This process enables a paper mill to recover lignin from their black liquor, while retaining sensible heat and important pulping chemicals. The recovered lignin makes a biofuel substitute and allows a power company to replace coal with lignin to significantly reduce greenhouse gases.

\section{Low Temperature Plasma Technology for Treating VOC Emissions (www.drexel.edu)}

Pulp mills and wood product plants are under increasing pressure to control the emissions of volatile organic compounds (VOCs) generated during their operations. The present-day control technology - regenerative thermal oxidizers - is energy-intensive and depends on combustion technologies that heat the entire waste stream. An emerging technology using nonthermal plasmas can selectively and cost effectively destroy VOCs by producing excited species (free radicals and ions) that oxidize, reduce, or decompose pollutant molecules.

\section{Microwave Pretreatment Technology for Chemical Pulping \\ (www.ornl.gov)}

A new technology is being developed that improves both economic and environmental performance in chemical pulping processes. Microwave pretreatment is an energyefficient technology that enhances the ability of pulping chemicals to pass easily into wood chips. In addition to directly reducing the energy required to pulp wood, microwave pretreatment decreases the amount of natural gas required to operate the lime kiln and decreases process chemical usage. The technology allows larger and/or more diverse chip sizes to be pulped and increases pulp mill throughput. 


\section{Forest Products}

(continued)

\section{$\checkmark$ Novel Isocyanate-Reactive Adhesives for Structural Wood-Based Composites \\ (www.vt.edu)}

Laminated veneer lumber (LVL) is a wood composite that is produced by bonding thin wood veneers together and is used for various wood construction applications. The current LVL manufacturing process is energy intensive, using adhesives that require extensive wood drying (to moisture contents of $6 \%$ to $8 \%$ ) and high-temperature hot-pressing $\left(\sim 392^{\circ} \mathrm{F}\right)$. An alternative isocyanate-reactive that cures at room temperature (cold-setting) and is optimized for higher veneer moisture content promises significant energy savings. This new technology will also sharply reduce volatile organic compound emissions and improve product appearance and durability.

\section{$\checkmark$ Oxalic Acid Technology}

(www.biopulping.com)

As shown in pilot-scale tests, a short pretreatment of different types of wood chips with varying amounts of a dilute solution of oxalic acid saves electrical energy $(20 \%$ to $30 \%$ ), improves paper strength properties, and reduces resin content by $30 \%$ prior to mechanical pulping. The pretreatment also removes hemicellulose from wood chips, which could then be converted into value-added chemicals, including cellulosic ethanol. Based on pilot-scale results and the rising costs of electricity and the purchased price of softwood bleached kraft used in making paper, companies have expressed interest in evaluating this technology further.

\section{Pulse Drying of Paper Pulp}

(www.wavedry.com)

Paper manufacturing begins with wet pulp fibers

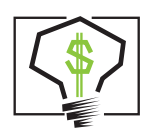
that are progressively shaped, dewatered, and dried through evaporation into finished products. Virtually all paper manufacturing production is limited by the evaporative drying stage. The most common air drying process is impingement evaporation, where hot gas jets blow on the wet paper web. However, pulse impingement drying improves efficiency of this process by $59 \%$ and speeds overall paper production by $21 \%$. Pulse drying of paper webs applies directly to "Yankee" and "MG" style paper drying equipment, and indirectly to newsprint, box board, and finer grades of paper.

\section{Forest Products}

(continued)

\section{$\checkmark$ Screenable Water-Based Pressure Sensitive Adhesives \\ (www.franklinadhesivesandpolymers.com)}

A new family of water-based pressure sensitive adhesives (PSA) that greatly increase the amount of paper products recoverable for recycling was developed and is being marketed. Screens can easily remove the new PSAs early in the paper recycling process. These products have an environmentally friendly impact by reducing the amount of high-grade paper going to landfills. In addition, eliminating waxes and adhesive contaminants from recycled pulp will greatly reduce costly process problems and increase final product quality in the paper industry.

\section{- Steam Cycle Washer for Unbleached Pulp (www.ptpc.com)}

A new commercial-scale steam cycle washer is being developed to increase profitability by substantially reducing energy consumption, improving fiber and product quality, and ensuring that environmental compliance exceeds current regulations. This steampressurized, high-consistency pulp washer will enhance pulp industry profitability by allowing most pulp mills to reduce electrical power consumption for unbleached pulp production by up to $21 \%$, evaporator load by $50 \%$, and plant effluent and fresh-water usage by $45 \%$.

\section{Terahertz Imaging in Kraft Recovery Boilers (www.enertechnix.com)}

Recovery boilers are a key component of all kraft pulp mills and are often the production bottleneck in such mills. Deposits can form on the outside of heat transfer tubes and plug the gas passages within the boiler's convective sections, leading to unscheduled outages and lost production. High-pressure steam lances (sootblowers) used to clean the outside of these heat transfer surfaces consume as much as $\$ 1$ million in steam per year per boiler, but the lack of adequate real-time inspection capability in large sections of the boiler prevent effective and efficient use of these sootblowers, leading to excessive steam usage. The proposed project will demonstrate and develop a terahertz measurement/imaging system that can be used to produce clear images at all interior locations of an operating kraft recovery boiler and quantitative measurements of the thickness and size of salt cake deposits on heat transfer tubes, allowing for more efficient use of sootblowing steam to remove deposits. 


\section{AMO Emerging Technologies}

\section{Glass}

\section{Advanced Combustion Space Model for Glass Melting (www.anl.gov) \\ Improved understanding and modeling of the combustion process in glass melting will result in innovative furnace designs that will have higher combustion and furnace efficiencies, minimized pollutant formation (primarily $\mathrm{NO}_{\mathrm{X}}$ reduction), and improved glass quality.}

\section{Advanced Oxy-Fuel-Fired Front-End System (www.owenscorning.com)}

A consortium of companies involved in the glass industry has developed the Advanced Oxy-Fuel-Fired Front-End System. A combination of burner modeling and bench trials was used to develop a burner and block that generate the appropriate size and shape of flame for optimal heat transfer distribution. This will result in reduced energy use and decreased $\mathrm{CO}_{2}$ emissions. The new burner system can be integrated into a front-end system with capital costs that are competitive with a conventional air/gas system. Fullscale installation and testing are under way in a Tennessee glass plant.

\section{Enabling Tool for Innovative Glass Applications (www.imp.mtu.edu)}

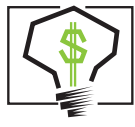

Flat architectural and automotive glasses have traditionally been fabricated using technologies that have inherent cutting limitations because they are generally incapable of fabricating glass products with small radii, concave edges, or pierced holes. A new technology uses waste glass as a low-cost media for abrasive water-jet cutting of glass and other materials. This technology can refine and automate the glass manufacturing process while reducing the number of stages and equipment required to produce intricate glass products. Other waste materials can also be used.

\section{Glass}

(continued)

\section{Energy Saving Glass Lamination via Selective Radio Frequency Heating (www.ceralink.com)}

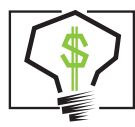

A new technique for glass lamination is being developed that will save significant amounts of energy and increase throughput. Traditional glass lamination involves bonding two or more sheets of glass with vinyl interlayers using an autoclave, which wastes large amounts of energy to get heat through the glass to the vinyl, where the heat is desired. The technology heats the interlayers using a single-step radio frequency process. The process will dramatically decrease the lamination time and will result in significant energy savings across the U.S. laminated glass industry.

\section{High-Intensity Plasma Glass Melter \\ A high-intensity plasma glass melter was developed with a square-foot-per-ton-per-day throughput index that is significantly smaller than commercial glass melters. This plasma technology package increases the systems' energy efficiency and reduces emissions. To achieve this high throughput and high quality, the system uses a dual-torch transferred arc-plasma technology, a rotating melt chamber to increase melt rate, skull melting to eliminate the need for a refractory lining and to reduce contamination of the glass from refractory and electrode components, and state-of-the- art control technology to provide stable conditions.}

\section{Manufacturing Ceramic Products from Waste Glass \\ (www.haunlabs.com)}

Ceramic products have traditionally been processed from raw materials that require high firing temperatures and energy-intensive processing steps. A new technology lowers energy costs by substituting raw materials with recycled waste glass. Products manufactured by this new method are less sensitive to contaminants in the glass and can be made from difficultto-recycle green or mixed-color container glass waste. Firing temperatures can be reduced by as much as $37 \%$, lowering energy costs and $\mathrm{CO}_{2}$ emissions. The technology has been used to design a low-cost highly-automated manufacturing process for producing ceramic tile from large volumes of waste glass. High-quality ceramic tile with competitive specifications has been processed from $92 \%$ to $100 \%$ recycled glass with a wide range of colors and surface textures. The technology has been applied to several types of glass, including post-consumer container, flat and lamp glass, and industrial fiber-glass waste streams. 


\section{Glass \\ (continued)}

\section{Submerged Combustion Melting \\ (www.gastechnology.org)}

A consortium of companies developed a high-intensity glass melter based on the submerged combustion melting technology. This melter serves as the melting and homogenization section of a segmented, lower-capital-cost, energy-efficient Next Generation Glass Melting System. This technology will potentially increase efficiency, lower capital costs, provide more flexible operation, and lower emissions.

\section{Metal Casting}

\section{$\checkmark$ Cupola Furnace Process Model}

A comprehensive mathematical model of the cupola furnace, a type of furnace used to melt iron that is subsequently cast into a variety of products, is being enhanced and updated. The model was incorporated into a user-friendly artificial-intelligence program that can help optimize the temperature, processing time, and other key variables of furnace operation. This improved operation results in energy savings, product quality enhancement, and waste reduction.

\section{In-Situ Real Time Monitoring and Control of Mold Making and Filling Processes}

(www.tntech.edu)

Two of the major R\&D priorities of the metalcasting industry are reduction in scrap and variation in casting quality, with a target $40 \%$ reduction in scrap by 2020 . In the past few decades, mold making technology has significantly improved, resulting in a reduction of scrap. Researchers are targeting improvements in lost foam casting and green sand casting. The results of this effort will provide an innovative approach to introduce technologies for real-time characterization of sand molds and lost foam patterns and the monitoring of the moldfilling process.

\section{Process to Recover and Reuse Sulfur Dioxide in Metal Casting Operations} (www.adsorption.com)

Sulfur dioxide $\left(\mathrm{SO}_{2}\right)$ is used as a catalyst in forming cold-box molds and cores in the metal casting industry. The $\mathrm{SO}_{2}$ is typically used once, scrubbed with a caustic solution, and then discarded (flushed to sewer or sent to a waste treatment facility). This new process recovers the $\mathrm{SO}_{2}$ for reuse by processing it through a pressure-swing adsorption system that is expected to recover at least $95 \%$ of the $\mathrm{SO}_{2}$. Using this process will reduce energy consumption, eliminate the need for caustic effluent, and pay back costs in less than 1 year 


\section{AMO Emerging Technologies}

\section{Mining}

\section{Drill-String Radar Navigation for Horizontal Directional Drilling \\ (www.stolarhorizon.com)}

Horizontal drilling in a coal seam can relieve methane gas trapped in a coal bed, increasing the danger to coal miners but supplying a desirable resource. Gamma sensors, currently used for horizontal drilling, cannot withstand the vibration of the drill and require additional costly drilling steps. Instead of gamma sensors, drill-string radar transmits radio waves and measures their reflection to identify boundary rocks, reducing vibration sensitivity and allowing real-time measurement while drilling. This technology will reduce the risk, cost, and time required for extraction.

\section{Grinding-Mill Optimization Software}

(www.mines.utah.edu)

Millsoft 3D is simulation software for visualizing the charge motion in semi-autogenous mills and ball mills used in the mining industry. The software also provides various quantitative information, such as power, forces on the mill lifters, and wear. The three-dimensional code uses the discrete element method to model the individual collisions of ball and rock particles. The software handles mills of all sizes and can be used for shell lifter design and energy optimization of SAG mills.

\section{Soft (Unfired) Ceramic Particles via Dynamic Cyclone Classification \\ (www.novafilter.com)}

Many industrial processes involve the separation

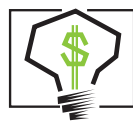

of particles from an airstream. The mining industry, in particular, has indicated a need for improved separation methods and reduced waste. In this technology, the particles are separated and transported by boundary layers and induced airflow vorticity near a stack of rotating (slightly separated) disks, which minimizes particle impact and attrition, as well as component wear. The dynamic cyclone classifier offers substantial potential for indirect energy savings by reducing the amount of off-spec product processed to achieve the same amount of product output. Smaller scale devices, operating under the same separation principles, can generate sharp particle classification cuts below 10 microns and are targeted for the pharmaceutical/ neutriceutical, food/additives, cosmetic and specialty chemical markets.

\section{Steel}

\begin{abstract}
Alumina-Forming Austenitic (AFA) Steels (www.ornl.gov)

AFA stainless steels provide an increased uppertemperature oxidation, or corrosion, limit that is $100^{\circ} \mathrm{F}$ to $400^{\circ} \mathrm{F}$ higher than that of conventional stainless steels. These new alloys deliver this superior oxidation resistance with high-temperature strengths approaching that of far more expensive nickel-based alloys without sacrificing the typical lower cost, formability, and weld ability of conventional stainless steels. The goal of this project is to develop and deploy AFA steels into turbine and other energy-related applications in order to improve engine efficiency and/or durability at a potentially lower cost than current alloys. An increased database of the properties and performance of wrought and cast AFA steels will enable additional U.S. industrial partners to employ these materials in applications including fuel cells, boilers, and chemical processing.
\end{abstract}

\section{Hot Oxygen Injection into the Blast Furnace (www.praxair.com)}

A new injection system has been developed to directly inject hot oxygen in blast furnace tuyeres. Material and energy balances on the blowpipe/raceway zone of the blast furnace have shown that injecting ambient temperature oxygen offers little overall benefit, whereas injecting hot oxygen offers several mechanisms for improving burnout. This process increases coal injection rates and reduces coke consumption. Consequently, direct injection of hot oxygen into blast furnace tuyeres improves operating cost, energy consumption, and emissions.

\section{Imaging-Based Optical Caliper for Objects in Hot Manufacturing Processes \\ (www.ogtechnologies.com)}

Dimension control is very important in manufacturing. Poor dimension control leads to surface defects, incorrect cross-section weight distribution, and final product straightness. Existing dimension control practices in the hot manufacturing processes are prone to inaccuracy and can potentially compromise worker safety. To improve the efficiency of dimension control and the safety of the steel and forging workers, a new product will be developed with innovations in the areas of imaging, software algorithms, and wireless communication. The expected benefits include enhanced safety, energy savings, improved yields, and reduced $\mathrm{CO}_{2}$ release in the steel industry, as well as job creation. 


\section{Steel \\ (continued)}

\section{Metallic Iron Nodule Technology in Electric Arc Furnace Steelmaking (www.umn.edu)}

Scrap steel substitutes are becoming increasingly valuable for material currently used in electric arc furnace smelting because of lower production costs. A novel approach is investigating ways to process available raw materials into a value-added, high quality iron feedstock product at a lower total cost. By overcoming furnace and feedstock limitations, high-quality steel scrap substitutes are being produced, increasing final steel quality produced in electric arc furnaces, and reducing overall production costs.

\section{Nanocomposite Coatings for Life Extension in Zinc Pot Rolls}

(www.mesocoat.com)

Galvanization of steel is used to develop a corrosionresistant surface for use in outdoor applications. However, the liquid metal — zinc - is corrosive and reacts with tooling to form dross, which can deform tooling and damage the product. The goal of this project is to develop a solid lubricant containing nanocomposite coatings that are resistant to liquid metal corrosion and environmental wear. Adding the solid lubricants to the metal-working tooling has been found to decrease contact and dynamic friction, resulting in reduced adhesion of the work material to the tooling. The ceramic nanoparticles have also been shown to enhance the coatings' wear and mechanical properties.

\section{Next Generation Heating System for Scale-Free Steel Reheating \\ (www.e3minc.com)}

A new system is being developed that reduces scale (iron oxide) formation in the steel reheating process. The technology employs fuel-rich combustion using preheated or oxygen-enriched air to control flue gas composition. This process substantially reduces energy use and costs associated with the handling, disposal, and reprocessing of scale. Reducing scale formation increases product yield and revenue by saving high-value steel that is currently lost as scale. Scale-free reheating improves productivity by reducing downtime and manpower to collect and remove scale from reheating furnaces. In addition, removing scale from final rolled products may improve product quality and reduce metallurgical defects that require reprocessing.

\section{Steel \\ (continued)}

\section{Non-Chromium Passivation} Techniques for Electrolytic Tin Plate (www.steel.org) Two previously identified non-chromium passivation treatments for electrolytic tin plate are being compared in a plant trial to determine their commercial viability. These new techniques will replace the existing cathodic dichromate treatment method that is facing environmental use restrictions. In addition, continued use of chromate treating solutions will result in ever-increasing operating costs.

\section{Optical Sensor for Post-Combustion Control in Electric Arc Furnace Steelmaking (www.steel.org)}

This project is developing an optical sensor for electric arc furnace steelmaking based on measuring off-gas temperature and carbon monoxide, carbon dioxide, and water vapor concentrations. The remote-sensing optical instrument is based on tunable infrared-laser technology and will provide input signals for control and optimization of oxygen use and post-combustion emissions. This new technology will also address needs for improving energy use and developing automated process controls.

\section{Optimizing Blast Furnace Operation to Increase Efficiency and Lower Costs \\ (www.purduecal.edu)}

A key component to the smelting process in iron making is the blast furnace $(\mathrm{BF})$ where recent concerns have been raised about suitable coal supply, energy efficiency and emissions. Improvement can be achieved by burning pulverized coal versus metallurgical or coke coal. Understanding the parameters that affect BF efficiency and productivity will become crucial as pulverized coal use increases and energy conservation is mandated. The complexity of a BF's materials burden and output gas distribution effects on productivity and stability are known but not fully understood. This project has developed software which can simulate BF behavior utilizing computational fluid dynamics. The software predicts $\mathrm{BF}$ gas distribution by including fluid flow and chemical kinetics as well as other fundamental BF operation parameters. Optimized BF operation for a given fuel injection rate and efficiency can be calculated and the resulting gas distribution compared to process monitoring data thus enabling improved BF efficiency and productivity and lower emissions. 


\section{AMO Emerging Technologies}

IMPACTS

\section{Steel \\ (continued)}

\section{$\checkmark$ Paired Straight Hearth Furnace \\ (www.steel.org)}

The paired straight hearth furnace is charged with selfreducing pellets that are composed of iron oxide and coal. When heated, the iron oxide is chemically reduced to produce a $95 \%$ metalized direct-reduced iron suitable for making steel or as a feed for electric arc furnaces. The sources of the iron oxide can be iron ore fines, recycled steel plant wastes, or a combination of the two. The reductant is high volatile coal. As the pellets are heated on the hearth, $\mathrm{CO}$ gas is evolved and then subsequently combusted above the pellet bed to provide the heat to drive the process.

\section{Processing Electric Arc Furnace (EAF) Dust into Salable Chemical Products (www.drinkardresearch.com) \\ This unique technology will hydro-metallurgically process EAF dust into saleable products. EAF dust is oxidized and digested in acid and then treated by a series of individual steps to isolate and retrieve individual components of the dust.}

\section{Regeneration of Hydrochloric Acid Pickling Liquor}

The PHAR ${ }^{\circledR}$ hydrochloric acid regeneration

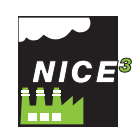

system is an innovative method of regenerating spent hydrochloric acid from steel pickling. Conventional pickling technology generates 1.5 billion gallons of spent pickle liquor nationwide each year, resulting in costly and energy-intensive handling, treatment, and disposal. This new technology eliminates the disposal problem, significantly reducing operating, environmental, and capital costs. The process uses sulfuric acid to restore hydrochloric acid for reuse. Salable ferrous sulfate heptahydrate is a by-product.

\author{
Steel \\ (continued)
}

\section{Sensor-Based In-Line Control System (SICS) for the Surfaces of Continuously Cast Slabs}

(www.ogtechnologies.com)

The current practice of continuous casting, the primary steel making process in the U.S., has opportunities for improving efficiency and energy savings. Each year, millions of tons of metal are scrapped and trillions of Btu are wasted because of process limits. The steel industry needs new sensors and advanced process controls to further promote process and energy efficiency. The proposed project brings advanced imaging and process control technologies to the casting applications. The goal is to develop and demonstrate a SICS with the synergy of existing technology and other innovations, which work in continuous casters, collecting data on surface features, verifying product quality, and providing process control to casting processes.

\section{Steel Foam Materials and Structures}

Metal foams with high levels of controlled porosity are an emerging class of ultra-lightweight materials receiving increased attention for a broad range of applications. Steel foams produced via a powder metallurgy process are about $50 \%$ lighter than conventional steel materials and can be produced as monolithic foams, as foam-filled tubular structures, and in sandwich panel geometries. The efficient energy-absorption characteristics of steel foams can increase safety in commercial and military vehicles. The light weight can improve operational efficiency and competitiveness in shipbuilding and rail systems. These foams can also be recycled and reproduced, as well as produced from recycled metal scrap. Additional process scale-up development is required to position steel foams for production readiness and commercialization. 


\section{Crosscutting Technologies}

\section{Advanced CHP System Utilizing Off-Gas from Coke Calcination \\ (www.gastechnology.org) \\ Calcined coke is a key component used in the iron, steel, and aluminum industries. Over the past few years, because of increased use of heavy oil grades, the sulfur content of green petroleum coke has increased by up to $7 \%$. To reach a required sulfur content level $(<2.5 \%)$ in the final calcined product, the green petroleum coke with high sulfur content requires higher temperatures and longer processing times for desulfurization versus that needed for calcination of the low-sulfur coke $(<4 \%)$. As a result more excess heat and emissions are released to the environment, operating costs are increased, and more expensive materials and components are needed. The new technology aims to cost effectively utilize waste heat (both sensible and chemical) from the green petroleum coke calcination process in a fluidized bed. The recovered waste heat is converted into electricity and process steam, thereby reducing energy consumption and pollutant emissions.}

\section{Advanced Laser-Based Sensors for Industrial Process Control \\ (www.lgrinc.com) \\ Effective monitoring and control of steel manufacturing plants, industrial furnaces, boilers, incinerators, and other combustion systems are limited by the accuracy, sensitivity, specificity, speed (time response), and reliability of available sensors. As a result, industrial high-temperature processes release excessive toxic emissions, pollutants, and greenhouse gases and consume excessive energy during operation. The proposed project will yield a novel, robust instrument capable of accurately measuring several critical (off-gas) exhaust emissions (pollutants and greenhouse gases) in real time with unprecedented speed and reliability.}

\section{Crosscutting Technologies \\ (continued)}

\section{Advanced Membrane Separation Technologies for Energy Recovery \\ (www.ornl.gov) \\ Recovering energy from lower-temperature waste} streams represents a significant savings' opportunity but is technically challenging and has only been done with very limited success. To operate efficiently at lower temperatures, heat exchangers need a large surface area and are often too complex and cost prohibitive to integrate into existing systems. New separation membrane materials are being developed for use in a transport-membranecondenser technology for recovering heat and water. The porous ceramic membrane condenses water and recovers heat from the waste stream. The new materials will be cost effective, efficient, durable, and resistant to corrosion and membrane fouling. This system has proven successful at laboratory scale and has the potential to recover waste heat in various industries or any application involving exhaust streams containing at least $15 \%$ moisture.

\section{Advanced Process Heater (www.spin-works.com)}

An innovative design combines the most advanced

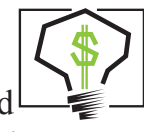
radiant tube heat transfer components into one highperformance package for industries that require highperformance heating. The advanced process heater (APH) incorporates a heat exchanger, burner, and flame holder with a traditional metallic radiant tube. Using time-proven, inexpensive composite material technology, the APH will provide superior heat transfer rates and thermal efficiencies compared with current equipment. In addition, the $\mathrm{APH}$ improves temperature uniformity by $50^{\circ} \mathrm{F}$ to $100^{\circ} \mathrm{F}$ while reducing $\mathrm{NO}_{\mathrm{x}}$ and $\mathrm{CO}_{2}$ emissions. 


\section{AMO Emerging Technologies}

\section{Crosscutting Technologies \\ (continued)}

\section{Advanced Transport Membrane Condenser for Energy and Water Recovery \\ (www.mediaandprocess.com) \\ Heat and water vapor losses in industrial gas exhaust streams are estimated to be $\sim 1,800$ trillion Btu/yr. Recovering this "low-quality" energy is intrinsically inefficient due to low temperature, large volume, and low pressure. In this project a transport membrane condenser (TMC) technology is used to overcome thermodynamic challenges. The TMC allows water to be extracted, thereby achieving $\sim 25 \%$ in energy savings and recovery of several hundred million gallons of water annually from the latent heat from industrial gas streams.}

\section{Carbon Films for Next Generation Rotating Equipment Applications (www.uic.edu)}

Two super-low-friction carbon surfaces, Near Frictionless Carbon (NFC) film, and a carbon surface converted from carbide, Carbide Derived Carbon (CDC), have been combined to achieve extended wear life and higher energy savings in rotating-equipment applications. Results indicate that $\mathrm{CDC}$ has impressive commercial potential for improving the wear life, increasing reliability and reducing dry-running breakdowns in mechanical seals, sliding bearings, and shafts. The technology is a net shape and size process that forms an adherent, low-friction, wear-resistant layer, as opposed to a coating, for all silicon carbide and other metal carbide components. Friction coefficients in the same range as the best diamond or diamond-like coatings were demonstrated, as well as dry-running capability.

\footnotetext{
Combined Heat and Power (CHP) Integrated with Burners for Packaged Boilers

(www.cmc-engineering.com)

CHP systems can achieve significant gains in fuel efficiency for generating power and reducing greenhouse gas emissions. The Boiler Burner Energy System Technology (BBEST), a CHP assembly of a gas-fired, simple-cycle 100-kW microturbine and a new ultra-low $\mathrm{NO}_{\mathrm{x}}$ gas-fired burner, will improve reliability while reducing costs and the need for maintenance. The BBEST system will achieve an overall CHP fuel efficiency of $82 \%$ to $84 \%$ and a power conversion efficiency of $3,800 \mathrm{Btu} / \mathrm{kWh}$. The CHP product will be used in new installations and as a retrofit for existing industrial and commercial boilers in place of conventional burners.
}

\section{Crosscutting Technologies \\ (continued)}

\section{Dewatering Membrane for Hazy Hydro- Desulfurization of Unit Effluents \\ (www.compactmembrane.com)}

Oil refinery products such as gasoline, kerosene, diesel, and fuel oils often go through a hydrodesulfurization (HDS) process to remove sulfur to reduce sulfur dioxide emissions during combustion. HDS is prone to water emulsion contamination or "haze," which can be difficult to remove. Hazy products cannot be used unless the haze is allowed to settle in a storage tank, creating shipping delays or storage constraints. A faster, cost-effective process to rapidly remove fuel haze is being developed using a new membrane in-line process. The process is expected to operate on a once-through basis and will target the removal of dissolved and dispersed water contamination. The membranes remove haze in a variety of water-fuel conditions and are very cost effective, having a product lifetime over 4 years. Other applications include removing water from chemical processing, pipeline ethanol, and other hydrocarbons such as lubricant and hydraulic fluids. The technology has already proven feasible at lab scale, and construction of a commercial size unit is in progress. Further testing will be conducted with industry partners in the laboratory and the field.

\section{Energy-Efficient Thermomagnetic and Induction Hardening \\ (www.eaton.com)}

In most industrial markets, maintaining dimensional tolerance of conventionally produced steel components during heat treatment or tempering can be challenging. To meet tolerance specifications, additional machining and retreatment are necessary but can be expensive and energy intensive. This project will develop an energy-efficient process using thermomagnetic processing and inductive high-frequency heat treatment. These new processes use thermal and magnetic interactions of bulk and surface material properties. The new processes consume less energy and achieves material durability without secondary non-value-added operations. 


\section{Crosscutting Technologies \\ (continued)}

\section{Energy Saving Controls for HID Lamps \\ (www.eesolutions.org)}

This new technology is a simple, cost effective

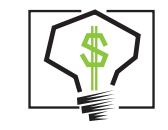
approach designed to work with conventional (magnetically ballasted) HID lamps of 70 to 1000 Watts, conserving up to $40 \%$ of typical energy consumption by managing illumination to customer needs or applicable standards. These intelligent controls save up to $50 \%$ of the maintenance costs associated with HID lighting. Many solutions offer improved HID lighting efficiency, but require replacement of existing lamps. This technology can be retrofit onto existing lamps thus saving capital costs. The fact remains that HID lighting is the most cost- and energy-efficient technology available today for high power (>100 Watts) lighting applications and this technology significantly improves energy efficiency and reduces maintenance costs in this lighting category.

\section{Energy-Savings' Model for the Heat Treatment of Aluminum Castings}

(www.wpi.edu)

A research program is extending the understanding of the evolution of microstructures during the heat treatment of complex, multi-component alloys. Quantitative relations among process, microstructure, and properties have been developed and applied to aluminum castings. The methodology developed can serve as a framework to develop quantitative process models for other alloy systems, including ferrous alloys. Compared with the current technology that specifies heat treatment cycle and furnace loadings based on prior specifications and historical "rules of thumb," the models are expected to reduce solutioninzing heat treatment times by $50 \%$ to $80 \%$, leading to $25 \%$ to $50 \%$ reductions in cycle time and energy consumption and $50 \%$ indirect reduction in non-energy environmental impacts and variable costs. The models are available for further commercialization and applications.

\section{Crosscutting Technologies \\ (continued)}

IMPACTS

\begin{abstract}
Erosion-Resistant Nanocoatings for Improved Energy Efficiency in Gas Turbine Engines

(www.netl.doe.gov)

Optimized erosion-resistant nanostructured composite coatings are being developed for gas turbine engine applications. This project will verify the nanomaterial technology as an enabler for inlet fogging in industrial gas turbines and as an effective erosion protection strategy in commercial aviation turbines. These nanocoatings will provide erosion protection to compressor airfoils, allowing engines to retain operational efficiency through a larger portion of their life cycle. Preventing airfoil degradation will decrease engine operating costs, reduce carbon emissions, and provide significant energy savings through reduced fuel consumption.
\end{abstract}

\footnotetext{
Flexible Combined Heat and Power (CHP) System with Low $\mathrm{NO}_{\mathrm{x}}, \mathrm{CO}$, and $\mathrm{VOC}$ Emissions

(www.gastechnology.org)

A CHP system can be a financially attractive energy option for many industrial facilities. However, supplemental emissions control systems must often be added to CHP installations in regions with air quality concerns. These emission controls increase CHP system costs and often decrease system efficiency, resulting in less-attractive economics. In this project, a new CHP system is addressing this challenge by incorporating a supplemental ultra-low$\mathrm{NO}_{\mathrm{X}}$ (ULN) burner into a $65-\mathrm{kW}$ microturbine and a heat recovery boiler. The ULN burner is expected to help the CHP system meet stringent emissions criteria and cost effectively improve overall system efficiency. Performance targets for the system include $\mathrm{NO}_{\mathrm{X}}$ emissions below $0.07 \mathrm{lb} / \mathrm{MWh}(50 \%$ reduction compared with a turbine and conventional boiler operating separately), $\mathrm{CO}$ emissions below $0.10 \mathrm{lb} / \mathrm{MWh}$, and $\mathrm{VOC}$ emissions below $0.02 \mathrm{lb} / \mathrm{MWh}$.
} 


\section{AMO Emerging Technologies}

IMPACTS

\section{Crosscutting Technologies \\ (continued)}

\section{Flexible Hybrid Friction Stir Welding (FSW) Technology \\ (www.ornl.gov)}

Welding is one of the most important and widely used fabrication technologies in modern industry. Traditional fusion welding processes (e.g., arc welding and laser welding) require significant heat inputs and frequently lead to property deterioration, such as cracking and porosity during solidification. FSW is a solid-state joining process invented to overcome fusion welding limitations. FSW is less energy intensive than competing technologies, while offering cost savings and increased productivity. The goal of this project is to advance the FSW process as a manufacturing technology that can be deployed for onsite construction of large, complex, and typically thick-sectioned structures made of high-performance and high-temperature materials (such as high-strength steels, titanium alloys, and super-alloys). This advancement would transform FSW from a specialty joining process into one with pervasive application potential across a number of industrial sectors where the payoff of energy reduction and environmental and economic benefits would be significant.

\section{Fuel-Flexible Combustion Systems Using Opportunity Fuels in Gas Turbines}

\section{(www.geglobalresearch.com)}

The majority of power generation gas turbines operate with natural gas; this low-cost, easy-to-use fuel source was readily available until heavy demand and supply volatility increased natural gas costs and interest in alternative fuel sources. Natural gas usage can be offset by a variety of opportunity fuel sources in industry, municipalities, and agriculture. A fuel-flexible gas turbine design must provide the appropriate power at high efficiency while meeting $\mathrm{CO}$ and $\mathrm{NO}_{\mathrm{X}}$ emissions targets, longer life, and lower cost requirements. This project addresses the technical constraints for developing fuel-flexible gas turbine nozzle technologies. The new fuel nozzles will enable efficient heat and power generation from industrial off-gases, other gasified waste streams, and mixtures of opportunity fuels with regular pipeline gases. Technology enhancements will include nozzles capable of burning lean or diluted fuel streams with ultralow BTU value.

\section{Crosscutting Technologies \\ (continued)}

\begin{abstract}
Fuel-Flexible, Low-Emissions Catalytic Combustor for
Opportunity Fuel Applications (www.precision-combustion.com)

This project aims to address the barrier of gas turbine fuel inflexibility by developing an injector with an integrated catalytic reactor to reform opportunity fuels before normal combustion. This reforming raises the fuel-air mixture temperature, changes its composition, and leads to a stable flame free of flashback and autoignition. The Rich Catalytic Lean-burn $\left(\mathrm{RCL}^{\circledR}\right)$ reactor demonstrates fuel flexibility with the capability of enabling ultra-low nitrogen oxide lean premixed combustion for wide range of gaseous opportunity fuels.
\end{abstract}

\section{Hierarchical Nanoceramics for Industrial Process Sensors \\ (www.geglobalresearch.com)}

Process heating is the largest fuel end-use in U.S. industry. Improving the efficiency of combustion systems for industrial heat and power would reduce national energy consumption. Progress in nanotechnology has led to the development of new classes of multifunctional ceramics, potentially applicable to high-temperature sensors.

Development of new nanoengineered ceramics for use in industrial process sensors could provide real-time feedback control over air-fuel mixtures in all industrial combustion heating applications. This project developed a robust, tunable, hierarchical nanoceramics materials platform for industrial process sensors in harsh environments. Nanoengineered materials are anticipated to dramatically increase the response of the materials to a wide variety of gases while retaining selectivity. The nanoengineered materials are also expected to remain stable at relatively high temperatures, enabling detection close to the source of combustion. These materials can form the basis for a new class of sensors, enabling widespread use of efficient combustion processes with closed loop feedback control in energy-intensive industries. 


\section{Crosscutting Technologies \\ (continued)}

\begin{abstract}
High Efficiency Liquid-Desiccant Regenerator (www.ailr.com)

The use of desiccants, which have a high affinity

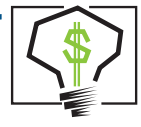
for moisture, can greatly reduce the energy required for typical drying and dehumidification. A new generation of liquid desiccant technology was developed that lowers overall cost and size, while improving the performance characteristics of existing dehumidification technologies. This new regenerator has the potential to almost double the efficiency of liquid-desiccant systems.
\end{abstract}

\section{High-Efficiency, Low-Cost Small Turbine for Distributed Generation (DG) and Combined Heat and Power (CHP)}

(www.candent-technologies.com)

The high-efficiency, low-cost small gas turbine for DG and CHP technology includes a small distributed power generation system with a projected thermal efficiency goal of $>50 \%$ and an installed cost goal of no more than $\$ 375 / \mathrm{kW}$. Additionally, when used in a CHP system, the turbine can substantially reduce the amount of energy consumed and greenhouse gases produced. The new advanced gas turbine's improved efficiency and multi-fuel capability (including biofuels) can reduce consumption of imported fossil fuels, greatly lower greenhouse emissionsespecially $\mathrm{NO}_{\mathrm{X}}$ - and further reduce $\mathrm{CO}_{2}$ emissions when configured with a CHP system. The gas turbine could replace many higher pollution diesels, with the benefits of lower exhaust emissions and higher thermal efficiency.

\footnotetext{
High-Efficiency Microturbine with Integral Heat Recovery

(www.capstoneturbine.com)

This project aims to develop a microturbine combined heat and power (CHP) system with $42 \%$ electrical efficiency and $85 \%$ CHP efficiency. A modified compressor and turbine assembly from the commercially deployed Capstone C200 microturbine will act as the low-pressure section of a two-shaft turbine system. The modified C200 assembly will result in an electrical output of $250 \mathrm{~kW}$. A new high-temperature, high-pressure compressor and turbine will be added to increase the electrical output to $370 \mathrm{~kW}$. The system will include a high-efficiency recuperator for exhaust heat recovery and will reduce $\mathrm{CO}_{2}$ and $\mathrm{NO}_{\mathrm{X}}$ emissions compared with existing microturbine designs. Various models of the system will be developed for operation with traditional fuels (e.g., natural gas, propane, and diesel) or renewable fuels such as landfill gas and digester gas.
}

\section{Crosscutting Technologies \\ (continued)}

\author{
High-Efficiency Thermoelectric Materials/Devices \\ for Industrial Process Refrigeration and Waste Heat \\ Recovery \\ (www.aegistech.net)
}

Applications for recovering process waste heat often require an intermediate step to convert thermal energy into other useable forms of energy, such as thermo-mechanical. Another energy conversion pathway is the thermoelectric effect, where thermal energy is directly converted into electricity. This project will develop nanocomposite materials that generate electricity when a temperature difference exists across the bulk of the material - called the Seebeck effect. These new nanomaterial composites are thermodynamically efficient and overcome the barriers of high cost and large-scale manufacturing.

\section{High-Temperature Industrial Insulation Using Aerogels \\ (www.trl.com)}

High-temperature carbon-based insulation is currently used in many advanced energy and materials industries, including silicon photovoltaics, light emitting diode lighting, and carbon fiber production. Because of the high temperatures involved $\left(1600^{\circ} \mathrm{C}-2800^{\circ} \mathrm{C}\right)$, the performance of the current insulation can result in significant energy losses in the manufacturing process. Using carbon nanotechnology, a carbon aerogel is infiltrated into the fiber insulation form to create a new composite insulation with significantly improved thermal performance. By replacing current insulation with the new and improved aerogelenhanced product, energy savings are anticipated to exceed $30 \%$. 


\section{AMO Emerging Technologies}

\section{Crosscutting Technologies \\ (continued)}

\begin{abstract}
$\checkmark$ High Temperature Resistant Superhydrophobic Nanocomposite Coatings

(www.neicorporation.com)

During recovery of waste heat streams, heat exchanger technology performance and efficiency rely heavily on heat transfer. Heat transfer is primarily affected by the thin film condensate that forms on the surface, which reduces the heat transfer rate considerably. Preventing film formation has proven to be challenging in commercial vapor-to-liquid heat exchanger applications. This project will develop a viable and cost-effective superhydrophobic surface treatment that promotes "drop-wise" condensate formation, which will improve heat transfer significantly. The surface treatment derives its properties from a novel microstructure and is durable and cost effective. This surface treatment also can increase the exchanger's heat transfer rate three to four times, improving efficiency and energy usage.
\end{abstract}

\section{$\checkmark$ Intelligent Controls for Refrigeration Systems (www.adatech.com)}

As much as $15 \%$ of electricity consumed by commercial and industrial refrigeration units can be saved by using intelligent defrost cycle controls. In typical installations, the defrost cycle is initiated at regular intervals during the day by a timer clock that is set to accommodate the peak humidity conditions of summer. In many cases, this causes the defrost cycle to begin too soon, and to run for an extended period of time. A new, low-cost frost sensor for defrost control systems has been developed and patented to start the defrost cycle only when necessary and to stop the cycle as soon as the ice has been removed from the heat exchanger.

\footnotetext{
Intensive Quenching Technology for Heat Treating and Forging Industries (www.intensivequench.com)

Intensive quenching technology (IQT) for steel products was developed as an alternative way of quenching steel parts. While conventional quenching is usually performed in environmentally unfriendly oil, the IQT process uses environmentally friendly water or low-concentration water/mineral salt solutions. Complete development and commercialization of IQT in heat-treating, powder metal, and forging industries will significantly reduce energy consumption and environmental impacts, thus enhancing the economic competitiveness of the domestic steel, metal casting, and mining industries.
}

\section{Crosscutting Technologies \\ (continued)}

\section{Large-Scale Manufacturing of Nanoparticulate-Based Lubrication Additives \\ (www.anl.gov)}

Lubrication applications currently consume 250 million barrels per year worldwide, and that consumption continues to increase. The major challenges for improving lubrication applications include reducing friction and increasing durability, which, if overcome, would reduce not only oil and fuel consumption but carbon dioxide emission and waste as well. This project is developing nanoparticulatebased additives using new boron-based materials instead of conventional sulphur- and phosphor-based additives. Producing these new high-performance additives uses advances in nano-manufacturing and nano-colloidal formulation. The raw materials required to manufacture these boron-based nano-lubricants are naturally occurring, abundant, nontoxic, and inexpensive.

\footnotetext{
Low-Cost, High-Efficiency, Periodic-Flow Gas Turbine for Distributed Energy Generation (www.ventions.com)

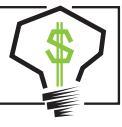
An innovative gas microturbine is being developed that can realize higher thermal-to-electrical efficiencies and lower manufacturing costs compared with existing microturbine designs. The expensive recuperator used in current microturbines is replaced with a lower-cost regenerator that increases cycle thermal efficiency by $10 \%$ or greater and simultaneously reduces capital cost by $40 \%$. The new system also is estimated to reduce $\mathrm{CO} 2$ and other pollutant emissions by $15 \%$ to $40 \%$.
} 


\section{Crosscutting Technologies \\ (continued)}

\section{Low-Cost Microchannel Heat Exchangers \\ (www.altextech.com)}

Conventional brazed-plate heat exchangers are used across a broad range of industrial applications, including the industrial and commercial chiller market. These heat exchangers significantly contribute to system efficiency, energy losses, volume, weight, and cost. However, attempting to improve efficiency or reduce losses increases the heat exchanger's volume, weight, and cost to unacceptable levels. This project will develop an alternative to a brazed-plate heat exchanger that is up to $84 \%$ and $75 \%$ lower in volume and weight, respectively, and has up to $88 \%$ lower energy losses. The technology, the innovative WASHEX high-performance design and continuous manufacturing process, will reduce cost by over $70 \%$. The size, weight, performance and low cost of WASHEX will allow it to be used in a wide variety of industrial and commercial chiller applications and will offer large market potential and energy savings.

\section{$\checkmark$ Low-Cost Process for Manufacturing Titanium Heat Exchanger Components for Desalination}

(www.mercorp.com)

Pure water is becoming increasingly scarce in many parts of the world, including regions of the United States. While distilling sea water is one solution, the cost of this process is very high due largely to the requirement for titanium heat exchangers to provide the required corrosion resistance. A new low cost process is being developed to provide a substantial reduction in the cost of titanium heat exchanger components. Titanium alloys have the unique combination of excellent strength and mechanical properties that make them desirable for a wide range of applications, including not only water desalination but automotive applications as well. The low-cost titanium alloys developed in this program will result in a major expansion of titanium for use in these applications.

\section{Crosscutting Technologies \\ (continued)}

\author{
Low-Cost Titanium Heat Exchanger Tube \\ Development \\ (www.pnnl.gov)
}

Titanium is the material of choice for many industrial heat exchanger applications. Low-cost, high-quality seamless titanium tubing could potentially improve the process and energy efficiency of manufacturing plants where extreme heat exchanger and process chemical conditions are prevalent. Titanium components are expensive and current fabrication processes further accentuate the cost. A new processing technique is being developed that uses solid-state consolidation of titanium hydride powder. This process reduces raw material and energy costs and improves overall yield compared with conventional processing techniques. This process is expected to enable greater availability of low-cost and high-quality titaniumfabricated components, benefiting numerous industries.

\section{Manufacturing of Superhydrophobic Surfaces with Nanoscale and Microscale Features}

(www.inl.gov)

This project aims to develop surfaces that have nanoand micro-structured features as small as $\approx 1 \mu \mathrm{m}$. Such structured surfaces are becoming increasingly useful in applications that enhance boiling and dropwise condensation heat transfer and enhance water repellency. The surfaces also show potential to reduce fluid flow drag/friction, biofouling, and other undesirable effects of water exposure. The industrial production of superhydrophobic surfaces, which are not yet available commercially, would enable a range of applications with far-reaching energy and environmental benefits. Air or gas gets trapped in the space between pillars (created on the structured surfaces), resulting in significantly reduced contact area between the liquid droplets and the solid surface. This project is using a unique spray-forming process to fabricate the molds and dies to manufacture structured surfaces, thus enabling high-volume manufacturing of structured surfaces. These molds and dies are then used to image these features onto surfaces via plastic injection molding, stamping, forging, die casting, or pressing. This approach is faster and more cost effective than conventional techniques. 


\section{AMO Emerging Technologies}

\section{Crosscutting Technologies \\ (continued)}

\section{Maximus $^{\mathrm{TM}}$ Sonic Stop-Fill Device for LP Gas and Anhydrous Ammonia Tanks \\ (www.adeptscience.net)}

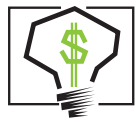

A new technology is being developed to prevent liquefied petroleum (LP) gas and anhydrous ammonia tanks from being overfilled. Outage gauges, the current technology used for this function, release LP gas or anhydrous ammonia for the entire duration of the tank refill. The resulting vapor release is wasteful, environmentally unfriendly, and potentially a health and fire risk. In contrast, the Maximus stop-fill technology relies on an advanced acoustic method to noninvasively detect the presence of liquid or gas at a specific point on a tank. As the liquid level rises, the acoustic signals received by the sensor change, indicating the presence of liquid on the other side of the tank wall. The Maximus thereby achieves the exact same result as an outage gauge without wasted energy, environmental pollution, or safety risks.

\section{Microchannel Magnetic Coolers with Negative Magnetocaloric Effect}

\section{(www.mercorp.com)}

Magnetic refrigeration near room temperature using the magnetocalorific effect was shown possible in the mid to late seventies. Cooling systems using magnetic cooling have potentially significant energy savings by eliminating the use of liquid refrigerants and associated mechanical components used in conventional refrigeration devices. Unfortunately the high cost of the magnets and mediocre performance has prevented commercialization. Research has focused on improved material performance but the brittle nature of these new materials cause fabrication problems. This project will develop a viable commercial magnetic refrigerator with the efficiency near that of a convention carnot cycle cooling system using inexpensive gadolinium magnetic materials. The performance gain is obtained by controlling the energy flow in the system using synchronized magnetic field motion. Potential energy savings from this technology are expected to be at least $20 \%$ over current convention refrigeration methods.

\section{Crosscutting Technologies \\ (continued)}

\section{Micro Gas Analyzer Solutions for Advancing Industrial Efficiency (www.honeywell.com)}

An innovative technology for on-line sampling and analysis of gas process streams in an industrial environment is being developed to enhance industrial efficiency. This new device couples a sampling and measurement system with a revolutionary gas composition micro-analyzer to provide continuous, on-line monitoring of gas process streams. By identifying and communicating variations in gas stream composition, the technology will improve product quality, reduce process upsets, avoid product loss and reduce waste.

\footnotetext{
Microreactor-Assisted Nanomaterial Deposition for Photovoltaic Thin-Film Production

(www.pnnl.gov)

Despite reducing fossil fuel consumption for energy generation, renewable energy sources have obstacles and technical challenges - e.g., cost, efficiency, and environmental impact. A cost-effective and environmentally friendly manufacturing process is being developed for photovoltaic (PV) related nanomaterials and thin films. Current PV manufacturing involves high costs, poor material utilization, high carbon emissions, and significant chemical waste. A microreactor-assisted nanomaterial-based process is being developed to enable just-in-time production of intermediates or particles for immediate deposition on the desired substrate. In addition, portions of the process are enabled by supercritical fluids, which drastically reduce the use harmful solvents in these processes. The nanomaterial deposition part of the process allows better material utilization and film formation via particle property (e.g., size and shape) control and molecular level deposition control for solid films. The process improves PV films and offers shorter manufacturing times and could be applicable to other nanoscale material production.
} 


\section{Crosscutting Technologies \\ (continued)}

\section{Miniature, Inexpensive, Amperometric Oxygen Sensor}

A new sensor to measure oxygen partial pressure

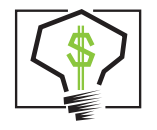
from parts-per-million levels to $100 \%$ oxygen has been developed. It has particularly good sensitivity in the combustion range of $0.1 \%$ to $5 \%$ oxygen partial pressure. The new amperometric sensor, which is a multi-layer ceramic capacitor, is ideal for inexpensive mass production. The large reduction in cost of the sensor will economically allow any combustion process, including industrial, commercial, or residential furnaces and boilers, to be more closely monitored and controlled, thus saving energy.

\section{Modifications and Optimization of the Organic Rankine Cycle \\ (www.inl.gov) \\ Waste heat from industrial applications and processes has been recognized as an extremely abundant source of recoverable energy. An optimized organic rankine cycle has been developed for the conversion of low-temperature waste heat from gas turbine or reciprocating engine exhaust to electricity. An evaporator placed directly in the hot exhaust gas stream reduces system cost and improves efficiency by eliminating the usual secondary heat exchanger loop. This safe, robust direct evaporator design can be integrated with the gas turbine or reciprocating engine as a single package that is easy for customers to install and operate.}

\section{Nanocatalysts for Diesel Engine Emissions Remediation}

(www.ornl.gov)

The widespread use of highly fuel-efficient diesel engines instead of gasoline engines can occur only if $\mathrm{NO}_{\mathrm{X}}$ emissions in diesel engine exhaust can be reduced to benign gases to enable them to meet EPA regulatory requirements. Conventional catalysts are unable to reduce $\mathrm{NO}_{\mathrm{X}}$ in the presence of excess air found in diesel emissions. As such, several new approaches are being investigated, with ureaor ammonia-assisted selective catalytic reduction (urea- or $\mathrm{NH}_{3}$-selective catalytic reduction [SCR]) of $\mathrm{NO}_{\mathrm{x}}$ as the leading technology. This technology needs to overcome poor durability and a narrow operating temperature range. A project is developing zeolite-based nanocatalysts whose modified molecular structures overcome the constraints in urea- or $\mathrm{NH}_{3}$-SCR technology for treating diesel engine emissions. The new technology will enable a wider market share for diesel engines, thereby increasing energy savings as well as reducing exhaust emissions per mile driven.

\section{Crosscutting Technologies \\ (continued)}

\begin{abstract}
Nanofluids for Industrial Cooling Applications (www.anl.gov)

Industrial-grade coolants are used in public utilities; transportation, oil, and gas industries; the food and beverage processing industry; the chemicals and plastics industry; solar energy conversion to electricity; and heating, ventilation, and air conditioning systems for buildings. This project targets improvements in the thermal properties of nanofluids for use as industrial-grade coolants. Nanofluids are being developed that have enhanced heat transfer coefficients between $10 \%$ and $50 \%$ more than the base fluid, which will significantly save energy and reduce associated emissions.
\end{abstract}

\section{$\checkmark$ Nanomaterials for Batteries and Supercapacitors} More efficient electrical energy storage will be required to support the increasing demand for renewable energy. One approach to improve storage efficiency is an advanced capacitor design using nanotechnology. Capacitors can be charged and discharged quickly but have relatively low energy storage capability compared with a battery. Applying nanostructured materials and their properties to electrochemical supercapacitors can enhance energy density without compromising high power density and cyclic ability. These materials can now be produced at lower cost for fabricating batteries and capacitors. The technology enables automobile manufacturers, power tool companies, and consumer electronics designers and manufacturers to develop battery-powered products with longer run times and lower weight and cost.

\footnotetext{
Nanopowder Manufacturing via a Cost-Effective, LowCarbon Footprint Process

(www.ngimat.com)

The goal of this project is to scale up a versatile nanopowder production process to enable high-volume materials' manufacturing for energy-storage and energy conversion applications. Nanomaterials enabled by this process will reduce dependence on foreign energy sources, decrease harmful greenhouse gas emissions, and forge a resurgence of the U.S. manufacturing sector. This project is trying to boost production volumes of high-performance nanopowders by scaling up the versatile, cost-effective, and environmentally friendly NanoSpray Combustion process. Low-cost precursors and bio-derivable solvents are used in a simple self-sustaining combustion-based process to achieve these objectives.
} 


\section{AMO Emerging Technologies}

\section{Crosscutting Technologies \\ (continued)}

\begin{abstract}
Nanostructured Superhydrophobic Coatings
(www.ornl.gov)

Water-based drag, corrosion, icing, biofouling, and wetting in most water-exposure applications and processes increase energy consumption as well as replacement and maintenance costs. Many applications could benefit from a coating that reduces these problems (e.g., marine transportation, industrial liquid handling, structural steel, communication and power cables, roofing, and roadway materials). Water-repelling, durable, nanostructured superhydrophobic materials will be developed that substantially reduce a variety of negative effects between water and a treated substrate. The key to this application is the nanomaterials' ability to trap a layer of air between the substrate coating and any liquid having a high surface tension, like water. These remarkable, water-repellant, powder-based coatings are cost effective and easy to apply and can be manufactured from readily available raw materials.
\end{abstract}

\section{Near Net Shape Manufacturing of New Titanium Powders for Industry}

(www.ornl.gov)

Industry recognizes titanium as a superior material for many applications because of its high-strength, low density, excellent corrosion resistance, good elevated temperature performance, and allowance for damage-tolerant design. However, these properties have not been realized in many industrial applications because of the high cost and low yield of conventional fabrication methodologies for titanium components. Producing low-cost titanium components from synthesized titanium powders has the potential to enable a paradigm shift in producing and applying titanium, leading to significant energy savings and enhanced performance. This project is developing manufacturing technologies to process new titanium powders into fully consolidated near net shape components for industrial applications with high yields. Various technologies will be used, including press and sinter, pneumatic isostatic forging, hot isostatic pressing, adiabatic compaction, and additive manufacturing.

\section{Crosscutting Technologies \\ (continued)}

\section{New Regenerative Cycle for Vapor Compression Refrigeration \\ (www.mdienergy.com)}

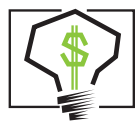

A new refrigeration technology is being developed that increases efficiency and saves energy relative to existing refrigeration techniques. The technology uses a novel thermodynamic cycle characterized by the regenerative use of the potential energy of the working fluid. A compressor compresses the working fluid to only $50 \%$ to $60 \%$ of the final pressure, while a jet device provides additional compression by using the internal potential energy of the working fluid flow. The compressor requires less mechanical energy, resulting in significant energy savings.

\section{Particulate Ejection Coal Fired Turbine (www.novafilter.com) \\ A sub-scale prototype of a medialess inertial

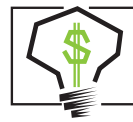 rotary disk filter was successfully evaluated to operate at the high temperatures/pressures typically found in coal- fired gas turbine generators. This technology demonstrates $98 \%$ to $99 \%$ coal ash removal efficiency without fouling, thus reducing the need for conventional disposable porous ceramic candle filters for hot gas filtration. Constant filtration efficiency and non-varying pressure drop across the all-metal filter eliminates brittle ceramic failures and allows operation at higher gas temperatures, which eliminates gas reheating and improves energy efficiency. The continuously self-cleaning technology may also eliminate landfilling of spent/replaced ceramic candles.}

\footnotetext{
Process Heater System (www.exxonmobil.com) A new generation of process heaters has been developed and demonstrated that is extremely low in emissions. This innovative system incorporates several advanced technologies: 1) ultra-low-emission (ULE) burners; 2) a specially designed fired heater with enhanced heat recovery, optimized for use with the ULE burner systems; and 3) on-line tube metal temperature sensors and burner control system to optimize heater operation, reduce maintenance costs, and increase run lengths. The technology will have applications for a broad range of refining and chemical processes. The advanced heater components are being developed for new or retrofit applications.
} 


\section{Crosscutting Technologies \\ (continued)}

\section{Production Scale Up of Activated Carbons for Ultracapacitors (www.tda.com)}

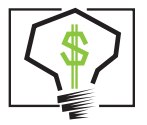

Electric and hybrid vehicles are promising technologies for decreasing the dependence on petroleum. Cost effective and efficient energy storage devices are needed for these vehicles to remain economically viable, and ultracapacitors are a leading energy storage technology for this purpose. The most important parameter in determining the power and energy density of a carbon-based ultracapacitor is the amount of surface area accessible to the electrolyte, which is primarily determined by pore size distribution. The major problems with current carbons are that their pore size distribution is not optimized for liquid electrolytes and the best carbons are very expensive. Methods that use low-cost feedstock (carbohydrates) were developed to prepare porous carbons with tunable pore size distribution at a greatly reduced production cost.

\section{Production Scale Up of Nanoparticle-Based Lubricant Additives}

(www.nanomech.biz)

Friction is one of the major causes for fatigue failures of gears and bearing surfaces used in traditional and nonrenewable energy systems. To increase the use of nonrenewable energy sources, reduce dependence on foreign energy sources, and increase productivity, a method is needed to improve mechanical system lubrication. Novel nanoparticle-based lubricants promise to increase reliability and energy efficiency for many applications of mechanical parts. Commercial-scale nanomanufacturing capability allows for the novel nanolubricants to be widely deployed to increase energy efficiency, facilitate the growth of nonrenewable energy, and increase productivity of U.S. industries.

\section{Crosscutting Technologies \\ (continued)}

\section{Radiation Barrier Heating Mantle for High-Temperature Furnaces (www.procedyne.com)}

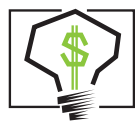

Retort furnaces, which consist of a heating-mantle jacket surrounding a retort vessel, are widely used to generate high temperatures for the metal-processing, chemicalprocessing, and heat-treating industries. A new porous wall radiation barrier (PWRB) heating mantle represents a breakthrough in heating mantles that significantly increases heat-transfer rates over both the existing gas-fired heating mantle and the electrically heated mantle. This unique development results in a heat-transfer rate in the $1,800^{\circ} \mathrm{F}$ to $2,400^{\circ} \mathrm{F}$ range that is 2 to 4 times greater than electric and conventional gas-fired mantles.

\section{$\checkmark$ Robotically Enhanced Manufacturing Line (www.timken.com)}

Conventional metal processing lines employ equipment that frequently use energy inefficiently, release greenhouse gases, and increase the exposure of laborers to process related safety risks. A new project is developing an advanced, low-volume manufacturing line that operates ondemand, thereby saving energy and manpower. The system is designed to replace over-sized, energy-intensive furnaces that require continuous and therefore unproductive heating. In development, the novel process has been demonstrated to be about $22 \%$ more energy efficient than conventional small lot processing methods. This manufacturing line is also more productive and produces fewer emissions.

\section{Self-Assembled, Nanostructured Carbon for Energy Storage and Water Treatment}

(www.ornl.gov)

Materials research has far-reaching implications in many industrial applications. Energy storage and water treatment are of particular interest as their demand and usage increase. Carbon-nanomaterials can provide solutions to a wide gamut of applications where technical progress has become challenging. Implementing the products of nanostructured materials research is not without constraints, especially scale-up, reliability, and high manufacturing costs. This project will overcome those difficulties by producing materials for use in cost-effective ultracapacitor devices for energy storage and safe, effective, and affordable capacitive deionization water treatment systems. 


\section{AMO Emerging Technologies}

IMPACTS

\section{Crosscutting Technologies \\ (continued)}

\begin{abstract}
Shear Rolling of Magnesium Sheet for Energy, Transportation, and Defense Applications

(www.ornl.gov)

The major hurdle in deploying magnesium products is the cost of magnesium-alloy sheet production and its poor formability. A technique is being developed for processing magnesium sheet with the potential to improve its formability while lowering cost requirements and energy consumption. To develop the process, a unique shear rolling mill will be designed and fabricated. The effect of process parameters (e.g., temperature and shear ratio) on the texture and formability of two magnesium alloys will be evaluated. The shear rolling process technology will be demonstrated in an industrial environment, and fabricated components using the materials will be produced.
\end{abstract}

\section{$\checkmark$ Sunlight Responsive Thermochromic $\left(S R T^{\mathrm{TM}}\right)$ Window System \\ (www.pleotint.com)

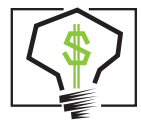 \\ A new high-performance window capable of variable tint is being developed that combines dynamic sunlight control, high insulation values, and low solar gain. The Sunlight Responsive Thermochromic windows can reversibly change light transmission based on thermochromic materials activated solely by the heating effect of the sun. The window design allows for good daylighting, a low solar heat gain coefficient, a low U-value, and a high insulation value. Energy savings up to $30 \%$ are estimated compared with traditional window systems.}

\footnotetext{
$\checkmark$ Super Boiler

(www.gastechnology.org)

The Super Boiler concept using ultra-high-efficiency, ultra-low-emission steam generation technologies is targeted for broad industrial applications over the next 15 to 25 years. The concept combines a suite of enabling technologies such as a staged intercooled combustion system with forced internal recirculation, high-intensity heat transfer surfaces, an advanced transport membrane condenser, and a smart control system in an integrated package. The performance goals include $94 \%$ fuel efficiency, $5 \mathrm{vppm} \mathrm{NO}_{\mathrm{X}}$ and $\mathrm{CO}$, and $50 \%$ size and weight reduction compared with a conventional firetube boiler.
}

\section{Crosscutting Technologies \\ (continued)}

\section{Thermal Imaging Control of High Temperature Furnaces \\ (www.gastechnology.org)}

The near-infrared thermal imaging system fine-tunes the main furnace controller for improved combustion performance. The system uses multiple infrared wavelengths combined with a periscope probe to map the full field of combustion space during furnace operation. Control algorithms minimize differences between measured field temperatures and temperature set points and send output signals to the main furnace combustion control. Optimizing the combustion process has been shown to decrease the total fuel use by at least $5 \%$, with a corresponding decrease in airborne emissions.

\section{$\checkmark$ Thermoelectric Generator for Diesel Engines (www.hi-z.com) \\ This new technology generates electric energy from waste heat and has many applications in the power industry, as well as in the chemical and petroleum industries. One possible application is as an array on the exhaust of the gas turbine to increase efficiency. Heavy earth moving equipment for mining presents another potential application. A prototype generator is being tested by a truck manufacturer and has been driven on their test track for 500,000 miles to demonstrate the ability to endure shock and vibration.}

\section{$\checkmark$ Third-Generation Flywheels for Electricity Storage \\ (www.launchpnt.com)}

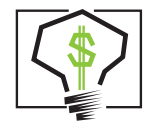

A new type of electricity storage flywheel is being developed that can be scaled up cost effectively to much larger power and capacity than existing flywheel designs. This new third-generation flywheel - the Power Ring uses totally new architecture and is designed to eventually reach electricity storage capacities exceeding 5 megawatthours per unit. The design uses a new class of magnetic bearing and a thin-walled composite hoop rotated at high speed to store kinetic energy. Power Ring flywheels will have many applications to support the U.S. power grid and to provide a reliable source of emergency power during electrical outages. 


\section{Crosscutting Technologies \\ (continued)}

\section{Tough-Coated Hard Powders \\ (www.allomet.net)}

Revolutionary tough-coated hard powder (TCHP)

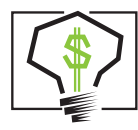

pseudoalloys combine the extremes of fracture toughness, hardness, wear resistance, light weight, low coefficient of friction, and thermal properties. Designed nanostructures are created by nano-encapsulating extremely hard micrometer-scale core particles (e.g., diamond) with very tough materials (e.g., tungsten carbide and cobalt), which in the consolidation process become the contiguous matrix. As many unique properties can coexist in a TCHP variety as there are different core particle materials present in the uniform tough substrate. Extreme strength, double-digit component and tool life, and reduced friction and thermal losses combine to enable the potential for billions of dollars in annual cost, energy, and environmental impact improvements.

\section{Ultra-Efficient and Power-Dense Electric Motors} (www.baldor.com)

A new technology increases motor efficiency while reducing the size and weight of the motor. The lowloss, high power density motor is more efficient, lighter, and smaller than current alternatives, including NEMA Premium ${ }^{\circledR}$ motors. The product will be a general-purpose motor that can replace existing induction motors for a wide range of line-start and variable-speed applications. The motor will be able to be started and run across the line or operated from a standard (volts/hertz) drive without requiring a rotor position feedback device.

\section{$\checkmark$ Ultra-Efficient Combined Heat, Hydrogen, and Power (CHHP) System}

(www.fuelcellenergy.com)

The CHHP system is based on a modified version of a commercial $300-\mathrm{kW}$, high-temperature fuel cell. The system uses reducing gas produced by the fuel cell to directly replace hydrogen and nitrogen used in a bright annealing process at a copper production facility. The reducing gas completely eliminates the hydrogen and nitrogen gas mix used in the copper reduction furnace. Because not all reducing gas will be needed in the annealing process, the CHHP system incorporates a lowtemperature, bottoming cycle fuel cell to increase overall system efficiency to as high as $>75 \%$.

\section{Crosscutting Technologies \\ (continued)}

\author{
Ultra-Fast Boriding in High-Temperature Materials \\ Processing Industries \\ (www.anl.gov)
}

To improve the performance and durability of metals, some form of surface treatment is used. Ultra-fast boriding is a faster process that is energy efficient and environmentally friendly. It is a thermo-electrolytic process that forms a very hard and durable compound at the surface of the treated material. Despite the shorter processing times, the ultra-fast process deposits thicker protective coatings compared with conventional techniques. The process consumes less energy and does not produce gaseous emissions or environmental waste. The process also provides the added benefits of increased productivity and product durability.

\section{Ultramizer: Waste Heat Recovery System for Commercial and Industrial Boilers}

(www.cannonboilerworks.com)

The majority of combustible fuels consumed in U.S. industry are for process heating. In natural gas combustion $18 \%$ of the waste stream is water vapor, which equates to $10 \%$ of the energy input. This project will develop and commercialize a turnkey system that will improve the energy efficiency of industrial boilers. The technology will recover the latent heat by recondensing the watervapor content in waste streams. The system will use a previously patented transport membrane condenser (TMC), which is not prone to corrosive by-product fouling, unlike conventional systems using economizers. The TMC uses a nanoporous membrane to selectively remove pure water from the waste stream, which can be reused to reduce make-up water demand. The recovered latent heat energy can be used to reduce energy input for steam generation. 


\section{AMO Emerging Technologies}

IMPACTS

\section{Crosscutting Technologies \\ (continued)}

\section{Ultra-Thin Antifouling Surface Treatments for Industrial Heat Exchangers \\ (www.atfinet.com)}

Heat exchangers are widely used in power generation, chemical production, petrochemical refining, air conditioning, and automotive, aerospace, and many emerging industries including hybrid vehicles, fuel cell systems, thermal solar, and biomass processing plants. Fouling of heat exchangers is a serious and longstanding problem causing significant energy losses, premature material failures, and increased downtime/maintenance. With increased emphasis on environmental regulatory standards, such as carbon cap, energy-intensive production facilities will be required to improve energy efficiency. This requirement will impose harsher conditions for the heat exchangers, exacerbating fouling and related problems. This project is directed towards reducing or eliminating fouling by using a novel and innovative coating material that is an ultra-thin (no impact on heat transfer), glassy coating material and can be deposited using an environmentally friendly, simple, and versatile process.

\section{Ultratough, Thermally Stable Polycrystalline Diamond/Silicon Carbide Nanocomposites for Drill Bits \\ (www.lanl.gov)}

The search for natural resources continues to deeper depths and presents new drilling challenges for the gas, petroleum, and geothermal energy industries. New super-hard, wear-resistant, and durable materials are needed to improve drilling performance. Conventional polycrystalline diamond (PCD) compact materials have two major weaknesses-poor thermal stability and low impact strength-which can lead to slower drilling or premature failure. To offset these weaknesses, this project is developing new nanocomposite materials that combine PCDs with silicon carbide nanocomposites and nanofibers. The improved drilling efficiency of these nanocomposite materials will reduce energy consumption and capital costs.

\section{Crosscutting Technologies \\ (continued)}

Utility Interactive Inverter System
for Distributed Generation
(www.advancedenergyconversion.com)

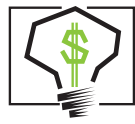

A $2.5-\mathrm{kW}$ utility interactive inverter system has been developed and is being tested and refined for use in distributed generation. The system embodies zerovoltage switching technology that will yield a system that is smaller, less expensive to manufacture, and more efficient than existing commercial technologies. By strategically focusing on a $2.5-\mathrm{kW}$ utility interactive inverter employed in solar photovoltaic applications the company has found a stable regulatory environment and a market that is quickly expanding in this power level which supports numerous technologies.

\section{Variable Speed, Low Cost Motor for Residential HVAC Systems \\ (www.dynamotors.com)}

Existing variable-speed motors cost at least four times as much as single-speed motors and thus are currently used in only $5 \%$ of residential HVAC systems. A revolutionary low-cost, brushless, variable-speed motor technology uses solid-state switches on the rotating armature to control motor torque and speed. A variablespeed motor running continuously at half speed compared with a single-speed motor running at full speed but half the time uses $25 \%$ of the power to move the same amount of air in an HVAC blower, thus saving energy. 


\section{Crosscutting Technologies \\ (continued)}

Wear-Resistant, Nanocomposite Steel Coatings (www.ornl.gov)

Steel is used in a broad range of engineering, mining, and construction applications because of its mechanical properties, availability, and relatively low cost, but it is not optimized for wear resistance. Component wear can lead to direct and indirect increased costs and energy losses, including losses due to plant inefficiencies and downtime for repairs. This project addresses the limitation of wear in steel components by developing a high-yield, low-cost, and scalable manufacturing process to optimize wear-resistant nanocomposite coatings and components for a wide range of applications. Laser fusing and powder metallurgy consolidation of amorphous iron-based powders are manufacturing technologies that are being used to develop coatings and bulk components, respectively, with complex metal boron-carbide nanoprecipitates in a very hard metal matrix. The coatings form a metallurgical bond with the substrate while effectively increasing the hardness by two to seven times and wear resistance by up to an order of magnitude of the steel component where applied.

\section{Zero-Emission Mechanical Seal (www.cerom.lsu.edu/projects seal.htm) Several zero emissions mechanical seal designs have been developed for use in petroleum and chemical processing pumps. The seals offer superior heat transfer capability compared with conventional seals by introducing special cooling channels into the surface of the stationary (mating) ring. The surface temperature can be controlled with simultaneous reduction of surface wear, allowing seals to run dry and qualify for zero emissions. This technology should reduce downtime, increase seal life, and decrease harmful environmental effects that occur from seal leakage. By reducing the friction and wear between the seal surfaces, the new designs should decrease power loss and save energy.}

\section{Other Industries}

IMPACTS

\section{Adaptive Environmentally Contained Power and Cooling IT Infrastructure \\ (www.hp.com)}

The majority of power consumed by data centers is for room conditioning and cooling. Despite the availability of low power design server components, power demand continues to increase as the internet continues to grow. This project researched and developed a fully enclosed information technology (IT) server rack system up to 100 kilowatts per system. The system provides power and cooling using high-voltage AC (400-480 v) and chilled water as the primary inputs but can also accept alternative energy power sources, such as wind and solar, to achieve a power usage effectiveness of 1.25 or less. The system will aggressively manage energy use to ensure the best use of available power and cooling resources based on grid demand signals, peak demand usage times, and availability/ strength of alternative sources of energy. The systems can be used in a standard data center or in any type of building to provide computing and storage capabilities that are room neutral from an environmental-impact perspective.

\section{Advanced Refrigerant-Based Cooling Technologies for Information and Communications Infrastructure (www.alcatel-lucent.com)}

The ability to reduce cooling costs and increase real estate utilization will be an attractive feature for information and communication technology (ICT) facilities. ICT facilities are typically cooled by computer room air-conditioning units, which provide cold air that is drawn into racks of heat-dissipating equipment by rack- and component-level fans. The current technology has many disadvantages: (1) transport and cooling of large quantities of air are energy inefficient; (2) mixing of hot and cold air streams results in localized hot spots, which can adversely affect component reliability and regions of poor cooling and system overcompensation; and (3) high-heat-density equipment often necessitates running server fans at high speeds, which increases energy use, acoustic noise, and fan failure rates. The technology created in this project provides energy-efficient shelf-level cooling of equipment racks in a telecom central office or data center. The system also can cool up to $\sim 10$ times greater heat densities than existing technology, allowing data-center designers to use higher equipment densities, reduce floor space requirements, and lay out the equipment as best dictated by function, without having to consider local overheating from the high-heat-density equipment. 


\section{AMO Emerging Technologies}

\section{Other Industries}

(continued)

\begin{abstract}
Advanced Water Removal via Membrane Solvent Extraction

(www.3m.com)

As U.S. ethanol production increases, two major concerns need to be addressed - water consumption and input energy. For every gallon of ethanol produced, about four gallons of water are used and at least $30 \%$ of the input energy is consumed during the distillation process. A new technology is being developed, membrane solvent extraction (MSE), that will reduce water and energy usage. The MSE's pervaporation process increases the process yield almost 10 times and can reuse waste energy streams (heat) within the plant. MSE technology can be retrofitted, reduces energy and water consumption by about $40 \%$, and can be applied to various bioethanol production paths.
\end{abstract}

\section{$\checkmark$ BEI Cellulose Hydrolysis Process}

The BEI Dilute-Acid Cellulose Hydrolysis

(DACH) Process and Reactor System uses a

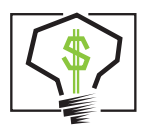

double tubular reactor system in two stages, which is automatically controlled to continuously convert cellulose feedstock into fermentable sugars solution products. The second stage of the BEI-DACH process reactor system recovers excess and surplus process heat and acid-chemicals for reuse in the first stage, providing exceptional energy and acid efficiencies and related economic savings. The BEI-DACH reactor system process hydrolyzes cellulose into a pentose, hexose, and glucose sugars solution at the point of use. These DACH sugars may then be continuously yeast-fermented into ethanol and/ or single-cell-protein and into other organic chemicals as commercial products.

\section{$\checkmark$ Biofine Technology}

\section{(www.biofinetechnology.com)}

The Biofine technology can convert low-grade cellulosecontaining wastes from paper mills, municipal solid waste plants, logging and agricultural operations, and other sources into levulinic acid, a versatile platform chemical that is an intermediate to several high-value chemical and oxygenated fuel products. Cellulose is converted to levulinic acid using a novel, high-temperature, dilute acid hydrolysis reaction system.

\section{Other Industries \\ (continued)}

\section{Biomass Boiler for Food Processing Applications (www.burnsmcd.com)}

Boilers are a critical element of U.S. industrial operations, consuming roughly $20 \%$ of the natural gas used in the manufacturing sector. The food processing industry alone uses over 10,000 boilers to serve its heating and power needs. More than $70 \%$ of these boilers consume natural gas, amounting to an annual consumption of 237 trillion Btu. This project aims to reduce the food processing industry's large natural gas consumption through the research, development, and demonstration of biomass boiler applications that can be widely commercialized effectively and cost-competitively throughout the industry. The project will include the design and pilot demonstration of an innovative biomass boiler system using a combination of wood waste and tire-derived fuel waste.

\section{Distributed Optical Fiber Sensors for Continuous Liquid Level Tank Gauging}

The Noverflo Multipoint Tank Gauging (NMTG)

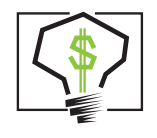
system is a family of fiber optic sensor arrays designed for the oil and gas, transportation, and food/beverage processing industries. Compared with similar products, the NMTG offers a simple design that allows both low and high accuracy measurements to be made at a very low cost. The system can make accurate measurements in liquids of shifting densities and performs continuous density measurements at any tank level. A new data acquisitions system allows the NMTG to monitor hundreds of sensors and numerous external-switching devices without any upgrades to existing systems.

\section{Eco Oil: A Superior-Performance, Bio-Based Motor Oil}

One way to reduce dependence on foreign oil is to

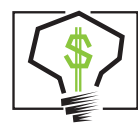
reduce the consumption of refined petroleum products. Eco Oil is an enhanced, bio-based synthetic motor oil that will help reduce refined petroleum consumption, adding stability to our national supply. Increased availability of bio-based motor oil also provides product diversity, creating additional options for government and consumer purchases, and results in fuel savings because of reduced engine friction. Reduced fuel usage also could lead to lowered emissions from internal combustion engines, reducing pollution. 


\section{Other Industries \\ (continued)}

\section{Economizer-Based Data Center Liquid Cooling with Advanced Metal Interfaces}

(www.watson.ibm.com)

From 2005 to 2010, data center electricity consumption increased by $36 \%$ and currently accounts for roughly $3 \%$ of all U.S. electricity consumption. About $25 \%$ of the energy consumed in data centers is used for IT cooling, which consists of facility refrigeration equipment for providing computer room air conditioning. This research project is developing two complementary technologies to reduce data center cooling energy. The first is advanced metal thermal interfaces for improved thermal conduction of heat from high-power server components to liquid-cooled heat sinks. The second technology is a dual enclosure liquid cooling system, which uses a liquid loop to transport heat from the volume servers in an enclosed rack to an outdoor dry heat exchanger for rejecting the heat to the outdoor air environment. The project has demonstrated chiller-less cooling of an operational $13-\mathrm{kW}$ rack of volume servers with a cooling energy consumption of $3.5 \%$ of the IT energy for a typical warm summer New York day with a $75^{\circ} \mathrm{F}$ average outdoor temperature.

\section{Flexible Distributed Energy and Water from Waste for the Food and Beverage Industry \\ (www.geglobalresearch.com)}

A comprehensive wastewater processing solution is being developed that recovers energy and purified water from industrial wastewater effluent streams. The integrated waste-to-value system consists of multiple components, including pretreatment, anaerobic digestion, aerobic reaction, filtration and gas processing, and combustion in a boiler and/or gas engine. This project addresses the challenge of variations in operating conditions and wastewater composition by developing an automated monitoring and supervisory controls solution. The control solution aims to improve the performance and reliability of the integrated waste-to-value system and reduce the occurrence of severe upsets by up to $90 \%$ using automated corrective action.

\section{Other Industries \\ (continued)}

\section{Helical Reaction Hydraulic Turbine \\ (www.lucidenergy.com)}

The Gorlov Helical Turbine (GHT) is a newly

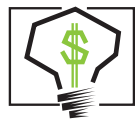

developed technology that is relatively inexpensive and ecologically benign and provides a reliable source of electricity by extracting the kinetic energy from flowing water. It is designed for hydroelectric applications in free flowing watercourses, which eliminates the need for a dam or other obstruction to the natural current flow. The GHT uses airfoil-shaped blades, which provide a reaction thrust that can rotate the GHT at twice the speed of the water flow. The GHT is self-starting and can produce power from a water flow as low as five feet per second, with power increasing in proportion to the water velocity cubed. Testing has demonstrated the GHT's superior power efficiency (35\%) in free flowing water currents compared with conventional turbines.

\section{Hi-Q Rotor}

(www.hiqproducts.com)

The Hi-Q Rotor is an advanced low-wind speed,

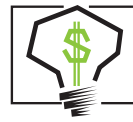
hight efficiency, tri-symmetric wind blade theat presents a new geometry for wind blade technology. This innovative technologyy has high value for collecting wind in low and very low wind speeds where conventional turbines are ineffective. The Hi-Q Rotor was developed to harvest wind in Class 2, 3, and 4 wind sites.

\section{High Speed/Low Effluent Process for Ethanol (www.bio-process.com) \\ The High Speed/Low Effluent (HS/LE) process} increases ethanol fermentation 5 to 8 times faster compared with current industry rates by using a newly developed, self-aggregating yeast strain. Either a "consecutive batch" or "continuous cascade" technology can be used for this fermentation process, for either wet mill or dry mill corn ethanol production. Cane juice, molasses, sweet sorghum, and other sugar/starch feedstocks may also be used with this process. In addition, a lowenergy distillation process can improve ethanol production economics. 


\section{AMO Emerging Technologies}

\section{Other Industries}

(continued)

\section{Horizontal Ribbon Growth \\ (www.oakland.edu)}

This innovative technology consists of a process

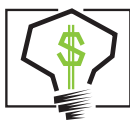

to develop crystalline silicon sheet from a polycrystalline silicon source. Its primary goal is the efficient, low-cost production of high-quality crystal silicon sheet for the solar and electronics industry. Development of this process will provide several important benefits, such as high production rates, low cost in terms of material and energy input, good dimensional control, improved crystal quality, and remarkable purity the same as the source material.

\section{Hydrogen Generation from Biomass (www.virent.com)}

A newly patented process is enabling the

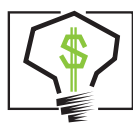
economic production of hydrogen from a range of biomassderived feedstocks, including glycerol and sugars. The key breakthrough in the reforming process is a proprietary catalyst that operates in the aqueous phase and has high hydrogen selectivity at low temperature. The process reforms water soluble oxygenated hydrocarbons in a single step and produces a hydrogen rich gas that is easily purified and that can be used as fuel stock for energy systems requiring a clean source of hydrogen, including fuel cells and transportation.

\section{Low-Emissions' Burner Technology Using Biomass- Derived Liquid Fuels}

(www.eng.ua.edu)

The fuel-flexible, low-emissions burner technology developed in this project can use biomass-derived liquid fuels, such as glycerin or fatty acids, as a substitute for natural gas, thereby reducing energy consumption, lowering greenhouse gas emissions, and increasing fuel flexibility. The project will employ two newly developed combustion techniques to atomize the crude glycerin effectively: porous inert media combustion and a flowblurring injector. Commercial product uses include biodiesel producers, boiler operators, and the metal casting industry.

\section{Other Industries \\ (continued)}

\section{Low Head, Vortex Induced Vibrations River Energy Converter \\ (www.vortexhydroenergy.com)}

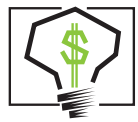

A revolutionary technology is being developed to extract useful energy from low-head or low-power falling water resources. The technology is based on the vortex-induced vibrations (VIV) of cylinders. For decades, engineers have been trying to prevent VIV from damaging offshore equipment and structures. By exploiting and maximizing VIV rather than preventing it, the vibrations can be transformed into a valuable electrical resource. In harnessing this potentially destructive force, the calculated energy density is five times greater than the best available competing technology, which is a free-flowing water turbine.

\section{Materials and Processing for Advanced Batteries (www.ornl.gov)}

Lithium secondary batteries are projected to be one of the energy storage leapfrog technologies for full electrification of the automotive drive train and may provide stationary storage solutions that enable the effective use of fluctuating renewable energy sources. Tremendous potential also exists for continued production scaleup of low-power lithium secondary batteries for consumer electronics. To maintain needed nanoscale features for improved performance, industry needs assistance in scaling up advanced manufacturing approaches for electronics, industrial, and automotive applications. In particular, the production of battery electrode dispersions and coatings remains an area where performance and product yield can be significantly improved. Preserving nanoengineered features is also critical to achieving required cycle life for the major components and will likely necessitate new processing technologies. Introducing large-scale lithium secondary battery technology for energy storage and harvesting will require significant new investment in production facilities to change not only from old to new chemistries, but from small-scale consumer electronics to large-scale industrial applications. 


\section{Other Industries \\ (continued)}

\begin{abstract}
Microchannel High-Temperature Recuperator for Fuel Cell Systems

(www.fuelcellenergy)

A new technology offers an efficient, microchannel-based waste heat recuperator that can be incorporated into a high-temperature fuel cell system. Adding an efficient recuperator to a high-temperature fuel cell is expected to increase the average electrical efficiency of the system from $47 \%$ to $58 \%$, exhibiting considerably higher electrical efficiency than an average combustion engine (32\%) or a microturbine $(28 \%)$. As a result of this increased efficiency, a hybrid fuel cell is projected to reduce $\mathrm{CO}_{2}$ emissions by $\sim 50 \%$ compared with a simple cycle gas turbine, and to maintain low emissions of criteria pollutants such as $\mathrm{NO}_{\mathrm{X}}, \mathrm{SO}_{\mathrm{X}}$, and $\mathrm{CO}$. These results are ideal for industries that place a premium on the reliability of electric power and for areas where low emission levels are needed, such as urban and nonattainment areas.
\end{abstract}

\section{Nanoparticle Technology for Biorefinery of Non-Food Source Feedstocks}

(www.ameslab.gov)

Rising petroleum prices and renewable energy initiatives have increased research into alternative fuels, in particular, biodiesel, which is biodegradable and nontoxic and is produced from various feedstocks. The use of cropbased feedstock for biodiesel fuel is limited by available cultivation acreage, low yield, and potential negative impact of higher prices in the food source market. Alternatively, a non-foodstock approach using waste animal fat or biomass or microalgae would be costly and complex. To overcome these drawbacks, a new process is using nanoparticle-based catalysts to cultivate microalgae to produce biodiesel fuel that meets industry standards. The new nanoparticle technology will be scaled up from pilot to industrial scale.

\footnotetext{
Novel Membrane-Based Process for Producing Lactate Esters

(www.vertecbiosolvents.com)

This research aims to develop nontoxic replacements for halogenated and toxic solvents. The new method, called "Direct Process", uses proprietary advanced fermentation, membrane separation, and chemical conversion technologies to convert renewable carbohydrate feedstocks into lactate esters in an energy-efficient, waste-reducing, and cost-effective way.
}

\section{Other Industries}

(continued)

\begin{abstract}
Novel Sorbent to Clean Biogas for Fuel Cell Combined Heat and Power (CHP)

(www.tda.com)

This project developed a new, high-capacity, expendable sorbent to remove sulfur species from anaerobic digester gas, thereby providing a nearly sulfur-free biogas that meets the cleanliness requirements of fuel cell power plants. This sorbent bed operates downstream of a bulk desulfurization system as a polishing bed and for removal of any residual hydrogen sulfide $\left(\mathrm{H}_{2} \mathrm{~S}\right)$ and other organic sulfur species from the biogas. The sorbent is an enabling technology that will allow small-scale fuel cell CHP systems to operate on biogas as an alternative to natural gas. This technology is ideal for any industry employing anaerobic digesters such as wastewater treatment, food processing, and agriculture applications.
\end{abstract}

\section{Plastics, Fibers, and Solvents from Biosynthetically Derived Organic Acids (www.bio-amber.com) \\ Biologically-derived succinic acid is produced by fermenting sugar derived from grains and other biomass. After separation and purification, the succinic acid is used as a chemical intermediate that is converted into a wide assortment of products such as plastics for automobiles and household items, fibers for clothing, food additives, solvents, deicers, agricultural products, ink, and water treatment chemicals.}

\section{Powering Cell Phones with Fuel Cells Running on Renewable Fuels}

(www.tekion.com)

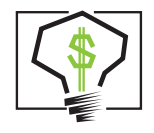

Small passive fuel cells that operate on air and formic acid are being developed to reduce electricity consumption from charging batteries. This renewable-fuel micro fuel cell will be used to charge cell phones, which use about 1.5 billion kWh per year, two-way radios, laptops, PDAs, and other portable devices, including military and emergency applications. 


\section{AMO Emerging Technologies}

\section{Other Industries}

(continued)

\section{Thermophotovoltaic Electric Power Generation Using Exhaust Heat (www.jxcrystals.com)}

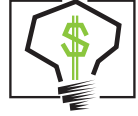

This new technology produces electricity directly from furnace exhaust waste heat by using infrared-sensitive photovoltaic cells. The cells are mounted inside ceramic tubes that are heated in the high-temperature exhaust stream from furnaces. This technology allows on-site generation of electricity from waste heat in industrial or residential applications.

\section{$\checkmark$ Tidal Energy Systems}

(www.verdantpower.com)

The kinetic energy of flowing water is a source of

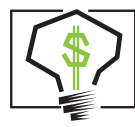
renewable energy. Systems similar to underwater wind turbines have been developed and are being demonstrated in tidal currents. The systems convert the kinetic energy of the tidal current to mechanical power, which is applied through a gearbox to an internal generator or to a directdrive generator for electrical power. These water-to-wire, dam-less hydro systems have demonstrated little to no environmental impacts. On-going studies are showing that fish are safely swimming either around or through the slow revolving rotors of these kinetic hydropower systems.

\section{Variable Length Wind Turbine Blade (www.frontierwind.com)}

The use of variable length blades on wind turbines, as opposed to the current use of fixed

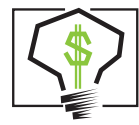
length blades, improves the wind turbine's performance, efficiency, and cost-effectiveness. Low wind speed provides better electrical output with longer blades, while high wind speeds demand shorter blades to minimize mechanical loading. The outboard (tip portion) of the blade fits inside the inboard (inner portion) and can be telescoped in and out according to wind conditions. Energy capture is expected to increase by about $10 \%$ to $15 \%$, by increasing wind capture at existing sites and by expanding the number of locations where wind energy is feasible. Can be used in new or retrofit applications. Reduces system loading thus increasing system life while increasing energy generation.

\section{Other Industries \\ (continued)}

Very Dense Liquid-Cooled Computer Platform
Electricity consumption by data centers and
telecommunication centers is $3 \%$ of the entire U.S. consumption and continues to rise with increased demand from internet, email, and social media usage. The energy consumed by facility air-conditioning and equipment cooling in those data centers accounts for $\sim 25 \%$ of the total energy usage. Recent efforts have focused on developing technologies and methods to improve energy utilization for data center cooling. The cooling technology under development in this project uses liquid cooling and has been shown to reduce the energy required for cooling by up to $75 \%$ compared with air-cooling methods. A new data center architecture will be designed specifically for use with liquid cooling. This new liquid cooling technology, when coupled with a standard data center highefficiency cooling system, is expected to increase data center infrastructure efficiency (DCiE) by more than $40 \%$ compared with the current average $\mathrm{DCiE}$ of approximately 0.61 .

\section{Wind Fins: Novel Lower-Cost Wind Power System}

An innovative vertical axis wind turbine is being developed as an alternative to conventional small horizontal-axis wind turbines (HAWTs). The Wind Fin technology exploits the kinetic energy of a vertically aligned, aerodynamic oscillating blade to generate electricity. The unique design blends more readily into the natural landscape than HAWTs and virtually eliminates lethality to birds and bats. Wind tunnel tests have shown that this technology will be comparable to or superior in performance to similar-sited wind turbines $(20 \mathrm{~kW})$ but at approximately half of the system cost. In addition, the Wind Fin can generate power at wind speeds as low as $5 \mathrm{mph}$, whereas many alternative systems require wind speeds of $10 \mathrm{mph}$ or greater to begin operation. Testing has indicated that the technology will be technically and economically feasible over a wide range of sizes, potentially resulting in Wind Fins with a power output of $50 \mathrm{~kW}$ to $100 \mathrm{~kW}$. 


\section{AMO Emerging Technologies}

\section{Yahoo! Compute Coop-Next-Generation Passive Cooling Design for Data Centers \\ (info.yahoo.com) \\ As of 2011, the internet is accessible by almost $31 \%$ of the world's population compared with $<0.5 \%$ in 1995 . \\ This increased demand for internet services (e.g., web hosting, information retrieval, email, and video sharing) requires the infrastructure and computing and data storage capability to be expanded. The energy consumed by the information and communication technology sector has increased by $\sim 36 \%$ since 2005 . Conventional data centers are typically environmentally controlled and $\sim 25 \%$ of the power consumed is used for HVAC (cooling). The Yahoo! compute coop (Y!CC) is an integrated, building-based air- handler for energy-efficient cooling of data centers. The Y!CC uses outside air for cooling rather than conventional chiller equipment and is similar in shape to a chicken coop. The Y!CC can significantly improve energy usage, lower operating costs, and almost eliminate the need for additional cooling equipment.}




\section{Appendix C: Historical AMO Technology Successes}

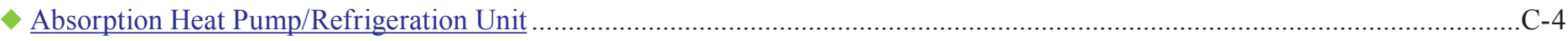

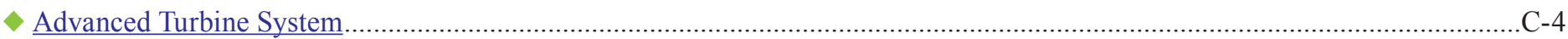

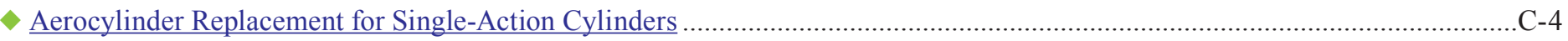

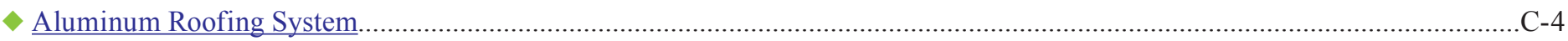

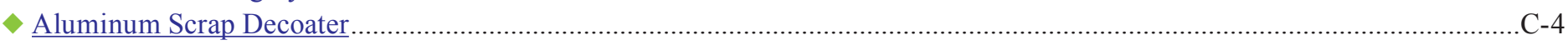

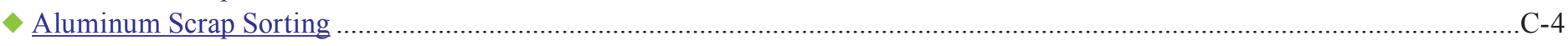

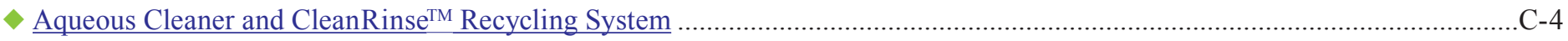

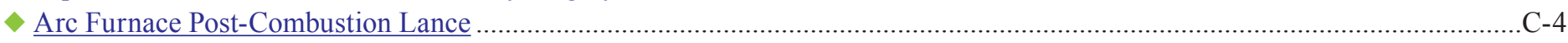

Auxiliary Air-Conditioning, Heating and Engine Warming System for Trucks .......................................................................

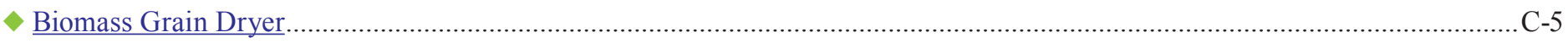

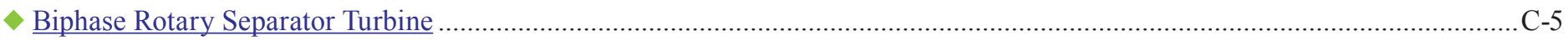

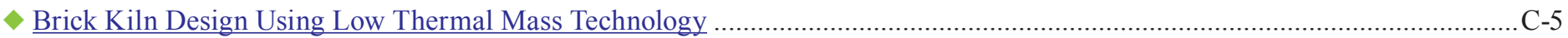

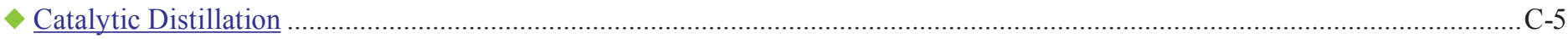

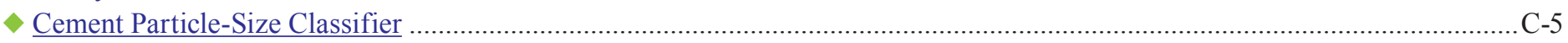

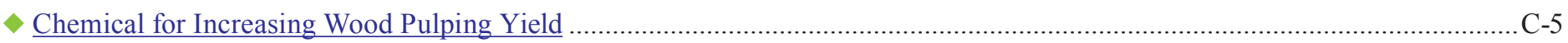

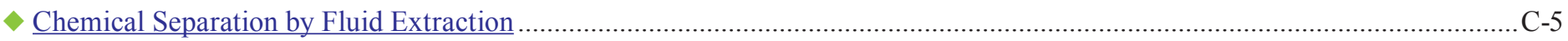

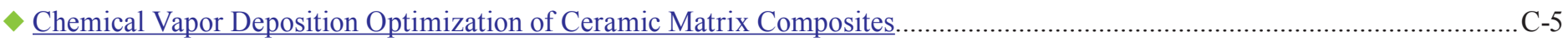

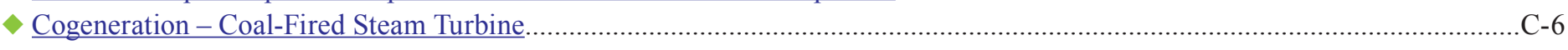

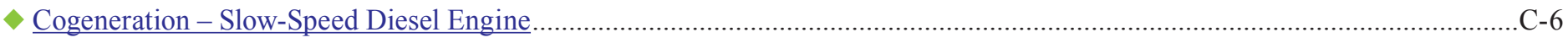

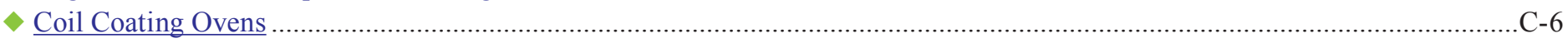

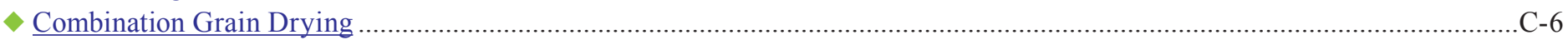

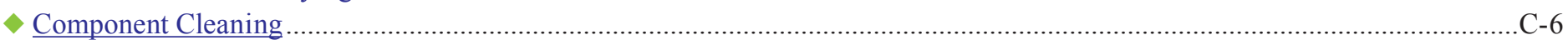

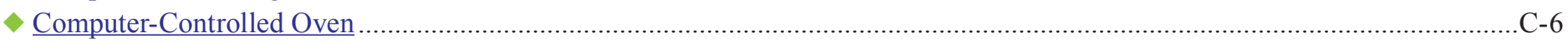

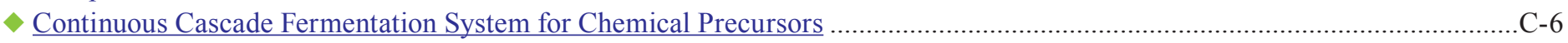

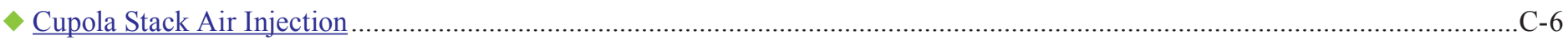

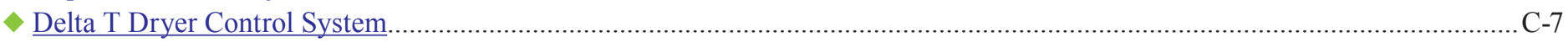

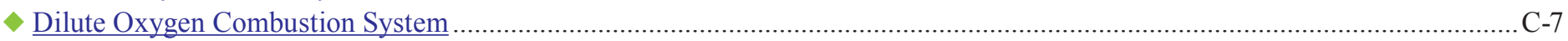

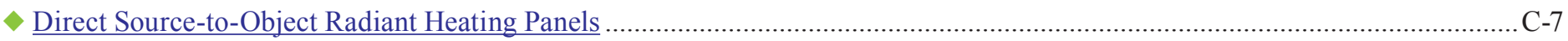

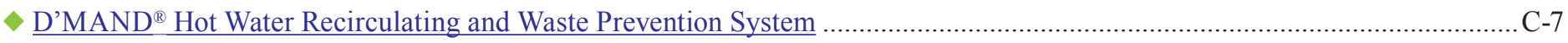

DryWash $^{\circledR}$

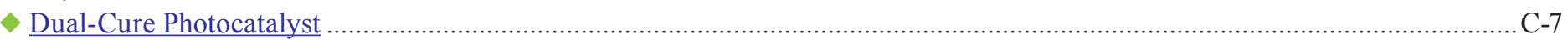

Dual-Pressure Euler Turbine for Industrial and Building Applications .....................................................................................

Dye Bath Reuse

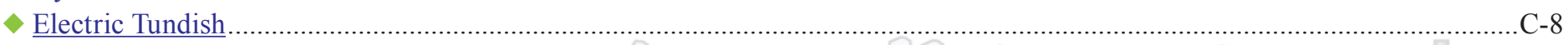

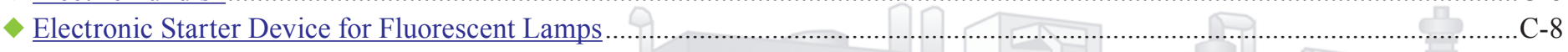

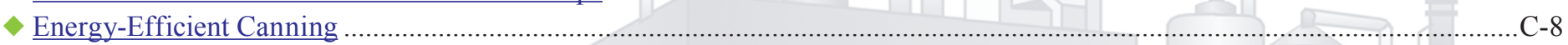

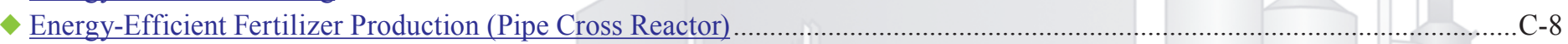

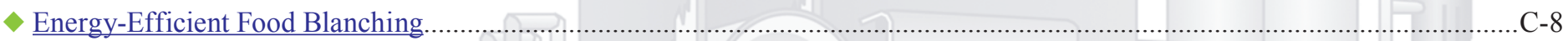

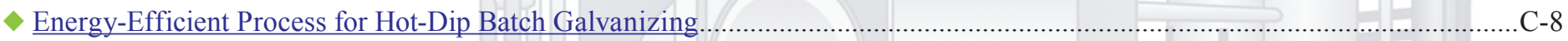

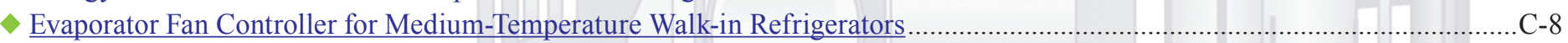

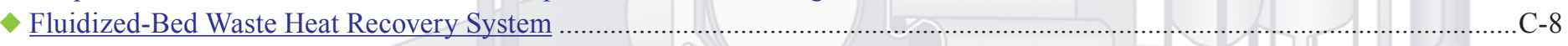

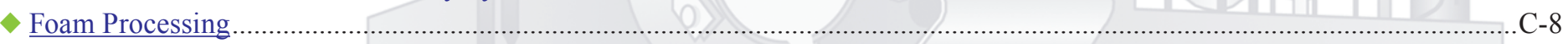

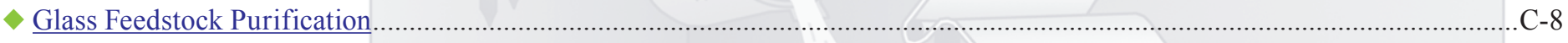

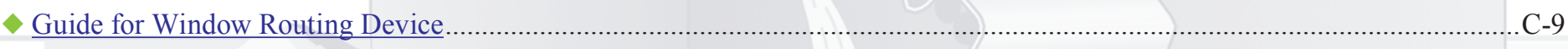

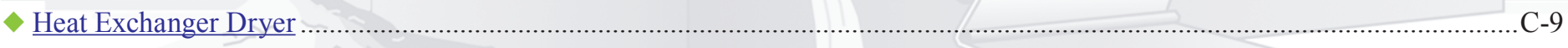

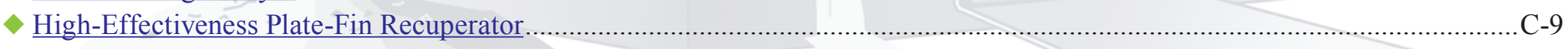

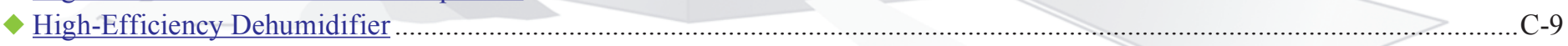

High-Efficiency Direct-Contact Water Heater ……............................................................................................................

$\begin{array}{ll}\text { DOE Advanced Manufacturing Office } & \text { C-1 }\end{array}$ 


\section{Historical AMO Technology Successes}

$\checkmark$ High-Efficiency Weld Unit.

High-Temperature Burner Duct Recuperators

$\checkmark$ High-Temperature Radiant Burner.

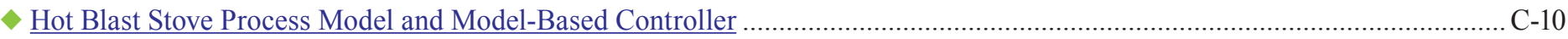

Humidity Sensor (Optical)

Hydrochloric Acid Recovery System.

Hyperfiltration - Textiles

Hyperfiltration Process for Food.

Improved Composite Tubes for Kraft Recovery Boilers

Improved Diesel Engines

Improved Poured Concrete Wall Forming System

$\checkmark$ Infrared Polymer Boot Heater

$\Delta$ Ink Jet Printer Solvent Recovery.

Irrigation Systems

Irrigation Valve Solenoid Energy Saver

Lightweight Steel Containers

Membrane Filtration Technology to Process Black Olives.

Membrane Separation of Sweeteners.

Meta-Lax Stress Relief Process.

METHANE de-NOX ${ }^{\circledR}$ Reburn Process.

Methanol Recovery from Hydrogen Peroxide Production.

C-11

Method of Constructing Insulated Foam Homes

Micell Dry-Cleaning Technology

C-12

- Nickel Aluminide Trays and Fixtures for Carburizing Heat Treating Furnaces

C-12

Night Sky - A New Roofing Technology

Nitrogen-Methanol Carburization.

No-Clean Soldering Process

No-VOC Coating Products

Onsite Process for Recovering Waste Aluminum

Organic Rankine-Cycle Bottoming Unit

$\checkmark$ Oxy-Fuel Firing

Oxygen-Enhanced Combustion for Recycled Aluminum

Paint Wastewater Recovery.

- Pallet Production Using Postconsumer Wastepaper.

- Pervaporation to Recover and Reuse Organic Compounds..

$\checkmark$ PET Bottle Separator.

$\checkmark$ Pinch Analysis and Industrial Heat Pumps...

Plating Waste Concentrator...

$\checkmark$ Powder Paint Coating System

PowerGuard ${ }^{\circledR}$ Photovoltaic Roofing System....

PowerRim $^{\mathrm{TM}}$ High Wattage Energy Saving Compact Fluorescent Lamp Adaptor for Recessed Down Lights.

Pressurized Ozone Ultrafiltration Membrane System.

Radiation-Stabilized Burner

Real-Time Neural Networks for Utility Boilers

Recovery of Acids and Metal Salts from Pickling Liquors

$\checkmark$ Recuperators

Recycling of Aluminum Dross/Saltcake Waste. 


\section{Historical AMO Technology Successes}

IMPACTS

Reverse Brayton Cycle Solvent-Recovery Heat Pump

C-15

Robotic Inspection System for Storage Tanks ...

C-15

RR-1 Insulating Screw Cap

C-16

$\checkmark$ Scrap Tire Recycling.

C-16

- Selective Zone Isolation for HVAC Systems...

C-16

- Shorter Spherodizing Annealing Time for Tube/Pipe Manufacturing

C-16

- SIDTEC $^{\mathrm{TM}}$ Condenser Maintenance Program

C-16

- $\underline{\text { Slot Forge Furnace/Recuperator. }}$

C-16

- Smart Screening Systems for Mining

C-16

- Solar Process Heat

C-16

SolaRoll ${ }^{\mathbb{R}}$ Solar Collector System

C-16

$\checkmark$ SOLARWALL ${ }^{\circledR}$ Air Preheating System.

C-17

- Solvent Recovery from Effluent Streams

C-17

$\checkmark$ Stalk and Root Embedding Plow.

C-17

- Steel Reheating for Further Processing.

C-17

Supercritical Purification of Compounds for Combinatorial Chemical Analysis

C-17

$\checkmark$ SuperDrive - A Hydrostatic Continuously Variable Transmission (CVT)

System $100^{\circledR}$ Compressor Controls

Textile Finishing Process

C-18

The Solar SKYLITE Water Heater

C-18

- Thin Wall Casting of Stainless Steel

C-18

Transfer Rolls for Steel Production

C-18

Ultrasonic Tank Cleaning.

C-18

Uniformly Drying Materials Using Microwave Energy

C-18

Use of Recovered Plastics in Durable Goods Manufacturing .

C-18

Variable-Frequency Microwave Furnace

C-19

$\checkmark$ V-PLUS $^{\text {TM }}$ Refrigerant Oil Cooling System.

C-19

Wallace Energy Systems Solar Assisted Heat Pump Water Heater...

C-19

Waste Atactic Polypropylene to Fuel

Waste Energy Recovery

Waste Fluid Heat Recovery System

Waste-Minimizing Plating Barrel.

- Wear Resistant Composite Structure of Vitreous Carbon Containing Convoluted Fibers

$\checkmark$ XTREME Cleaner ${ }^{\mathrm{TM}}$ - Removal of Light and Sticky Contaminants. 


\section{Historical AMO Technology Successes}

\section{Absorption Heat Pump/Refrigeration Unit (www.energy-concepts.com) \\ An advanced water ammonia absorption unit was developed that is powered by waste heat and provides refrigeration to refineries. The unit also recovers salable products, liquid petroleum gas or gasoline, which were formerly flared as reformer waste propane gas. Two units were installed in refineries and have cumulatively saved 2.87 trillion Btu since 1997.}

\section{Advanced Turbine System \\ As part of the Industrial Power Generation Program, an advanced metallic material, first-stage turbine vane was developed. This vane allows turbines to operate at higher compression ratios and/or temperatures than conventional gas turbines resulting in an efficiency improvement of $15 \%$, less down-time, and less maintenance. The use of these vanes has resulted in an energy savings of 245 billion Btu.}

\section{Aerocylinder Replacement for Single-Action Cylinders (www.smedbergmachine.com) \\ The aerocylinder, a machinery shock absorber, replaces conventional, single-action compressed-air cylinders in industrial forging, stamping, and welding applications. The aerocylinder has been installed on over 400 stamping and welding presses, primarily in the automotive industry. Using this system reduces downtime, prolongs equipment life, improves final product quality, and has resulted in an energy savings of more than 340 billion Btu since 1988.}

\section{Aluminum Roofing System (www.transmet.com) \\ This technology uses aluminum chips to reflect about $70 \%$ of the solar radiation received on asphalt roofs, which reduces building cooling needs. This invention has saved over 635 billion Btu since its introduction in 1984 and is now used on more than 35 million square feet of roofing.}

\footnotetext{
Aluminum Scrap Decoater (www.er-co.com)

An innovative aluminum-scrap melting process was developed that efficiently recycles oil-laden aluminum scrap, reducing solid waste and emissions. The process uses an indirect-fired controlled-atmosphere kiln to remove machining lubricants, oils, and other materials from the scrap aluminum. Once removed, these materials are combusted in an afterburner, destroying all VOCs and releasing heat that can be used to drive the process. Since 1997, the three facilities using this process have cumulatively saved 1.93 trillion Btu.
}

\section{Aluminum Scrap Sorting}

This particle-sorting technology used laser induced breakdown spectroscopy to sort nonferrous metal scrap from the reusable materials from aluminum-intensive vehicles. The process included physical property sorting and chemical composition sorting and was capable of realtime, piece-by-piece batching of specific alloy compositions from the analyzed scrap. This process improves the melt composition of recycled materials and is more efficient and less energy intensive than existing chlorination, fractional solidification, and electro-refining processes. This technology has resulted in cumulative energy savings of more than 2 trillion Btu since 2002.

\section{Aqueous Cleaner and CleanRinse ${ }^{\mathrm{TM}}$ Recycling System (www.ecoshieldenv.com) \\ A simple mini-reactor system for cleaning aqueous waste streams chemically converts organic oily contaminants into surfactants and emulsifiers. This conversion increases the cleaning solution's ability to remove oil, grease, and dirt. The system regenerates the cleaning solution on- site, generating less waste water and often decreasing the cleaning time required. The system has low energy needs and can be coupled with an energy-efficient bioreactor that will convert excess soap into biomass. Since 1997, the two systems in use have cumulatively saved 149 billion Btu.}

\section{Arc Furnace Post-Combustion Lance (www.praxair.com)}

A technology was developed that was applied in electric arc furnaces to increase productivity, reduce energy requirements, and improve control. The system consists of a water-cooled lance and controls to inject oxygen to combust the carbon monoxide in and above the furnace's foamy slag. The six installed systems have saved a total of 2.46 trillion Btu of energy.

\section{Auxiliary Air-Conditioning, Heating and Engine Warming System for Trucks (www.ponypack.com)}

An auxiliary power unit was developed to maintain cab power in heavy-duty, long-haul trucks when the main engine is not operating. This unit takes fuel from the truck's fuel tanks to heat and air-condition the cab and sleeper, to generate electricity to keep the battery charged, and to furnish hot water to keep the truck's engine warm. Since 1988, more than 3000 units have been installed on trucks and have saved an estimated 19.9 trillion Btu in the form of diesel fuel. 


\section{Historical AMO Technology Successes}

IMPACTS

\section{Biomass Grain Dryer}

Originally developed for grain-drying processes, this heat exchanger system later expanded into the furniture industry. By burning husklage, wood waste, or other biomass fuels, the process quickly disposed of combustible waste, provided an alternative energy source, and saved landfilling fees. Used within both the corn and furniture manufacturing industries, this system resulted in a cumulative 1.35 trillion Btu in energy savings and reduced landfill scrap by thousands of tons since being commercialized.

\section{Biphase Rotary Separator Turbine}

A biphase turbine recovers waste energy from pressurized process streams that separate into liquid and gas when the streams are depressurized. Conventional turbines cannot be used efficiently with two-phase flows because they cannot withstand the forces released during the liquid's rapid evaporation to a vapor. This turbine is being used by 125 large (500-ton) chillers and is saving $15 \mathrm{~kW}$ per chiller, for a cumulative savings of 107 billion Btu.

\section{Brick Kiln Design Using Low Thermal Mass Technology (www.swindelldressler.com) \\ An innovative brick kiln was developed that uses low thermal mass and low- $\mathrm{NO}_{\mathrm{X}}$ burner technologies. This brick kiln uses three technical innovations: ceramic-fiber insulation in lieu of traditional refractory brick, a lower profile stack design for brick kiln cars, and more but smaller low- $\mathrm{NO}_{\mathrm{X}}$ gas burners. These innovations result in a reduction in natural gas usage of $35 \%$ compared to a conventional kiln. The two brick kilns have cumulatively saved 280 billion Btu.}

\section{Catalytic Distillation}

(www.neochem.net)

Distillation is one of the most energy-intensive industrial processes, accounting for over $40 \%$ of the energy consumed by the chemicals industry each year. This single-stage catalytic reaction/distillation process has become a major commercial success and has improved the energy efficiency and productivity of certain chemical processes, including the production of methyltertiary- butyl-ether (MTBE) and tertiary-amyl-methyl-ether (TAME). Since its introduction in 1982, the 36 units installed in the United States have saved 43 trillion Btu.

\section{Cement Particle-Size Classifier}

A system was developed to control the size distribution of cement particles and to help reduce the current energyintensive regrinding process. Cement products produced from the improved particle distribution consumed less energy and were of better quality. This system yielded a total of approximately 9.5 trillion Btu in energy savings since its commercialization in 1984.

\section{Chemical for Increasing Wood Pulping Yield (www.chemstone.com)}

Unevenly processed wood chips in the pulp industry result in poor-quality pulp, often requiring reprocessing. A cooking aid was developed that reduced the amount of virgin wood feedstock needed to process wood chips and increased pulp yield and quality. The cooking aid helps pulp-cooking liquors penetrate the chips, resulting in more uniform cooking, and enabling the production of more uniform fibers in less time and with less energy. Since 1995, 23 mills in the United States have used this chemical system to save over 8 trillion Btu.

\section{Chemical Separation by Fluid Extraction}

This technology removes hazardous organic compounds from contaminated solid or liquid waste streams. The technology is more energy efficient than conventional technical hazardous waste treatment methods. The use of this technology has resulted in energy savings of 440 trillion Btu since 1990.

\section{Chemical Vapor Deposition Optimization of Ceramic Matrix Composites}

Ceramic matrix composites comprise a technology that is practical for a wide range of industrial and aerospace applications. Ceramic matrix composites are extremely heat-tolerant and corrosion-resistant, making them ideal for applications requiring lightweight materials capable of withstanding high temperatures. Chemical vapor deposition (CVD) is used to enhance the physical characteristics of the ceramic matrix composites. A computer model was developed and used to increase the throughput of two CVD coating reactors that optimized the coating process used to make ceramic matrix composites. 


\section{Historical AMO Technology Successes}

\section{Cogeneration - Coal-Fired Steam Turbine}

Using a coal-fired boiler and turbine exhaust steam system, a cogeneration process was developed for use primarily within the textile industry. The 16 systems installed saved more than 31 trillion Btu of energy/year and significantly reduced emissions due to lower demand for utilitygenerated electricity.

\section{- Cogeneration - Slow-Speed Diesel Engine}

This stationary internal combustion, slow-speed, twostroke diesel engine was developed to accommodate limited space and/or varying load demands. The compact, slow-speed diesel engine has excellent efficiency, greater load flexibility, and lower fuel and maintenance costs than conventional cogeneration options. The three installed units have saved a total of approximately 17.7 trillion Btu of energy.

\section{Coil Coating Ovens}

This system was developed to recover thermal energy previously lost in the solvent-based paint curing/ incineration process. Heat, recovered from solvent vapor combustion in zone incinerators, was routed back into the curing oven to vaporize more solvent. The thermal incinerators normally used were replaced by afterburners and a waste heat boiler to produce process steam. A three-fourths reduction in natural gas requirements and a reduction in pollution control energy resulted in over 35 trillion Btu of cumulative energy savings since the system was commercialized. The savings were increased even further as a result of a technology upgrade that eliminated the zone-burning portion of the process.

\section{$\checkmark$ Combination Grain Drying}

Designed to prevent spoilage during storage and reduce energy consumption, this system used a high-speed dryer and storage bin equipped with a drying fan. The grain was first dried by a high-speed, hot-air dryer, then transferred to a drying/storage bin that delivered ambient air to cool and further dry the grain to a moisture content of around $14 \%$. This combination drying method improved grain quality, increased drying capacity, and reduced propane and natural gas consumption.

\section{Component Cleaning}

A chemical product for industrial cleaning was developed based on supercritical fluid technology. Equipment was developed that converted carbon dioxide $\left(\mathrm{CO}_{2}\right)$ into a fluid that was used to clean metal, plastics, printed wire boards, etc. This technology takes the place of chlorofluorocarbon (CFC) solvents in the cleaning process and has reduced the energy needed to evaporate the solvents during the drying process.

\section{Computer-Controlled Oven}

To lower volatile organic compound (VOC) emissions, the computer-controlled oven technology was developed that permits operation at a higher percentage of lower explosive limits, reducing in dilution air requirements and the energy required to heat the high-temperature ovens. Optimizing airflows reduces VOC emissions that, in turn, reduces VOC incineration requirements. Fifteen installations saved a cumulative total of 27.75 trillion Btu of energy since being commercialized in 1982.

\section{Continuous Cascade Fermentation System for Chemical Precursors}

(www.bio-process.com)

A cascade reactor for ethanol production from carbohydrate feedstocks was developed that eliminated the need to fill, empty, and wash a fermenter as part of a batch operation. Feed is introduced continuously into the first of three to five stirred reactors placed in series, with the outflow of one reactor flowing into the next reactor. This continuous operation allows quick and complete saccharification and fermentation of feedstocks and removal of ethanol into a gas phase as it is produced. Since its introduction in 1996, this reactor has saved over 800 billion Btu.

\section{- Cupola Stack Air Injection}

This process reduced the carbon monoxide (CO) content of the effluents from a cupola furnace and improved the efficiency of combustion in the furnace during production of gray iron. This process eliminated the need for afterburners and the large amounts of energy they used to reduce the $\mathrm{CO}$ content in the emissions. By injecting air into the exhaust gases below the furnace charging door, the $\mathrm{CO}$ was ignited at temperatures already existing in the stack, with the resulting final exhaust gas having a $\mathrm{CO}$ concentration of less than $1 \%$. Cupola stack air injection saved a total of 80 billion Btu of energy before being superseded by more advanced technology. 


\section{Historical AMO Technology Successes}

IMPACTS

$\checkmark$ Delta T Dryer Control System

(www.moisturecontrols.com)

This dryer control system significantly improves control capability because it measures moisture content continuously in the dryer rather than only at the exit from the dryer. This more precise temperature control saves $10 \%$ to $20 \%$ more energy than conventional dryer control systems. Over 300 Delta T control systems have been installed and have saved more than 17 trillion Btu since 1985.

\section{Dilute Oxygen Combustion System}

(www.praxair.com)

The dilute oxygen combustion (DOC) system improved steel reheat furnace performance and provided very low $\mathrm{NO}_{\mathrm{X}}$ emissions. By replacing combustion air with oxygen, the DOC system needs less fuel to heat steel and also gives lower flue gas temperatures. These features allow a reheat furnace to operate economically at higher production rates. The 24 systems installed in the United States have saved more than 28 trillion But since 1999.

\section{Direct Source-to-Object Radiant Heating Panels (www.radiantnow.com) \\ Radiant heating systems transfer heat directly to a person or object in a manner similar to sunlight, eliminating energy consumed by mechanical heat-delivery requirements. These systems can save up to $50 \%$ in heating costs compared with baseboard electric-resistance heating and up to $30 \%$ compared with heat pumps. Since 1981, more than 375,000 radiant heating panels have been sold, saving more than 1.45 trillion Btu.}

\section{$\triangle D^{\prime} M A N{ }^{\circledR}$ Hot Water Recirculating and Waste Prevention System}

\section{(www.gothotwater.com)}

A system was developed for water heaters to conserve water and energy while providing hot water on demand. The system moves the tepid water back to the water heater rather then discarding it prior to hot water delivery. The primary energy savings are from the reduced amount of energy needed to heat the water returned to the water heater tank. More than 33,000 units have been installed in residential and commercial applications and have cumulatively saved 604 billion Btu.

\section{$\triangle$ DryWash $^{\oplus}$}

A $\mathrm{CO}_{2}$-based system for dry cleaning fabrics was developed that eliminated the need to use perchlorethylene as the cleaning solvent. Perchlorethylene has adverse environmental impacts. DryWash uses liquid $\mathrm{CO}_{2}$-based fluid as the base solvent but adds a new surfactant (dirt removing detergent additive) and then applies this new combination of cleaning liquids with a unique spraying device and agitation mechanism in a self-contained system. The 86 DryWash machines in use in the United States have saved 88 billion BTU since 2000 .

\section{Dual-Cure Photocatalyst}

Traditional volatile organic compound (VOC)-based coatings release undesirable organic chemical vapors into the atmosphere during the drying or curing phase of the coating application. A novel photocatalyst system was developed as part of a dual-cure process that allows lightactivated, simultaneous polymerization of two monomers to produce a material consisting of two independent but interpenetrating polymer networks. The VOC emission levels from this process are substantially below those obtained using conventional coating technologies, and cure times are shorter. Since its introduction in 1995, this system has saved over 3.7 trillion Btu.

\section{Dual-Pressure Euler Turbine for Industrial and Building Applications}

A dual-pressure Euler turbine was developed that dramatically improved generation efficiency. It can be used in place of a steam system's pressure reduction valve and uses the energy dissipated by the valve to produce electricity. Combined with traditional technology, turbine efficiency can be increased from $40 \%$ up to $80 \%$. The nine units operating in the United States have saved 187 billion Btu since 2004.

\footnotetext{
Dye Bath Reuse

To reduce the use of chemicals, water, and energy, two process modifications were developed for batch-dying textiles. These modified processes involved reconstituting and recycling the spent dye bath, eliminating the final rinse-water step. These modifications resulted in a cumulative energy savings of 2 trillion Btu prior to being replaced with advanced technologies.
} 


\section{Historical AMO Technology Successes}

\section{Electric Tundish}

An enclosed and more efficient holding furnace or tundish was developed and demonstrated for the continuous casting of copper alloys. Switching to electricity to heat the tundish rather than gas or oil results in an energy efficiency increase from $20 \%$ to $98 \%$. Four tundishes were installed in 1994 and operated until the manufacturing facility closed in 1996.

\section{Electronic Starter Device for Fluorescent Lamps}

A quick and reliable electronic lamp starter was developed for small fluorescent applications. This technology was an important improvement for lower wattage fluorescent lamps which still use older preheat circuit designs. Use of the inexpensive and easily installed starter can double the life of a fluorescent lamp. More than 1.6 million units have cumulatively saved 3.1 trillion Btu.

\section{Energy-Efficient Canning}

A thermal syphon recycle system using a recycling steam jet vacuum compressor and a recirculation pump and heat exchanger outside of the cooker were two methods developed to improve energy efficiency in the canning industry. From the installation of 100 new or retrofitted units, a cumulative energy savings of nearly 3 trillion Btu were realized.

\section{Energy-Efficient Fertilizer Production (Pipe Cross Reactor)}

An ammonia granulation technology was developed to reduce moisture content and energy consumption in the production of pellet fertilizers. The process employed a pipe-cross configured reactor, mounted within a granulator, where liquid raw materials were mixed and then dried via heat from the chemical reaction. Seven reactors were constructed that produced a superior product with a $1 \%$ moisture content, reduced pollution, and contributed a cumulative energy savings of 2.6 trillion Btu.

\section{Energy-Efficient Food Blanching (www.key.net) \\ This blanching technology, for processing fruits, vegetables, and potatoes for shelf-life protection, recirculates and reuses steam, dramatically reducing water and energy use, and wastewater production. The system improves nutrient retention, taste, and appearance through shorter cook cycles and takes up only about $60 \%$ as much floor space as conventional blanching equipment. The 62 installed systems saved over 11 billion Btu since 1998 .}

\section{Energy-Efficient Process for Hot-Dip Batch Galvanizing (www.ferrotech.com)}

This process combines a thermally stable flux solution and a preheat furnace to reduce energy use and increase batch galvanizing productivity while reducing waste generation. Hot-dip galvanizing is widely used to protect steel from corrosion. The process was used at a Pennsylvania steel company and saved 4 billion Btu of energy.

\section{Evaporator Fan Controller for Medium-Temperature Walk-in Refrigerators}

A new control system was developed for low- and medium-temperature walk-in refrigerators and freezers that senses refrigerant flow and adjusts the evaporator fan speed, saving fan motor energy when cooling is not needed. Energy consumption is reduced by about $40 \%$, and lower running times increase equipment life span and cut maintenance and replacement costs. Since 1997, more than 1400 controllers have cumulatively saved 85 billion Btu.

\section{Fluidized-Bed Waste Heat Recovery System}

A self-cleaning waste heat recovery system was developed to replace industrial furnace conventional recuperators. The system employed finned heat exchange tubes submerged in a bed of spherical alumina particles that absorbed heat from the hot gas and transferred it to the finned tubes. The water flowing through the tubes was converted to steam for use elsewhere in the plants while the alumina particle agitation kept the tubing clean and distributed the heat evenly.

\section{Foam Processing}

To replace the very energy-intensive wet processing of textiles, a process was developed to substitute mediumdensity foam for some of the water processing. A 50\% to $70 \%$ moisture retention reduction was realized along with a significant decrease in energy previously required for drying, water usage, and pollution control. This technology, and several similar techniques, achieved a cumulative energy savings of more than 11 trillion Btu.

\section{Glass Feedstock Purification}

An optical sortation technology, which removes ceramic and other contaminants from glass cullet using optical sensors and computer-controlled jets of compressed air, was developed. This technology was used to recycle 50 tons/ day of glass at one plant for two years thus resulting in a cumulative energy savings of 48 billion Btu. 


\section{Historical AMO Technology Successes}

IMPACTS

\section{Guide for Window Routing Device}

(www.bi-glass.com)

A tool guide to control the operation of a router was developed for converting single-glazed wooden-framed windows into double-glazed windows. Single-pane glass can thus be replaced with panes that are more energyefficient without replacing the sash members or the entire window. This technology was used by licensees in the United States and England and has saved more than 520 billion Btu of energy.

\section{Heat Exchanger Dryer}

This modified multideck dryer that incorporated a heat recovery system, was developed for the wood board products industry. Air-to-air, air-to-water, and air-to-liquid heat exchangers enabled the previously lost heat from exhaust gases to be reused throughout the plant. Three installations yielded nearly 800 billion Btu in cumulative energy savings.

\section{High-Effectiveness Plate-Fin Recuperator \\ Materials and fabrication techniques were developed that made the previously cost prohibitive plate-fin recuperators more economically feasible for a larger number of industrial applications. The recuperators can recover $90 \%$ of the energy from exhaust as hot as $1550^{\circ} \mathrm{F}$, are more compact than conventional techniques, and use a flexible flow pattern. Further, the technology provides more heat transfer surface per cubic foot of volume and is often used in nonfouling heat recovery applications. More than 100 units were installed with a cumulative energy savings of around 5 trillion Btu.}

\section{High-Efficiency Dehumidifier \\ (www.heatpipe.com)}

A system was developed to recover reheat energy and to control the humidity in all types of buildings. This system uses heat pipe technology to increase the humidifying capacity of air-conditioning equipment and operates without any mechanical or electrical inputs. More than 12,000 units have been sold and have cumulatively saved 1.38 trillion Btu.

\section{$\checkmark$ High-Efficiency Direct-Contact Water Heater (www.kemcosystems.com) \\ This industrial/commercial water heating system uses a water-cooled burner sleeve and combustion zone to extract all possible energy from natural gas combustion by bringing water into direct contact with a submerged- flame jet-type burner. More than 3,000 units are in use throughout the United States, and have saved a cumulative total of more than 300 trillion Btu in natural gas.}

\section{High-Efficiency Weld Unit \\ An inverter welding power source that included a multiprocess capability was developed for arc welding processes. Up to $75 \%$ smaller in size and weight than conventional units, this system's portability and improved weld quality also provided energy savings of up to $45 \%$ over conventional power sources. More than 75,000 units were sold, resulting in a cumulative energy savings of 21 trillion Btu before they were replaced by more advanced welding technology.}

\section{High-Temperature Burner Duct Recuperators}

Two ceramic tube recuperators, able to withstand $2000^{\circ} \mathrm{F}+$ temperatures, were designed to recover heat from hightemperature industrial furnace exhausts. Used in iron forging and steel production, fuel consumption was reduced by approximately $50 \%$.

\section{High-Temperature Radiant Burner \\ (www.alzeta.com)}

The high-temperature radiant burner forms the core of a thermal processing unit that destroys up to $99.9 \%$ of one of the most potent classes of global warming gases known - the perfluorocarbons (PFCs) that are generated during semiconductor manufacturing. The burner operates reliably at high process temperatures and provides uniform, well controlled heat while increasing the efficiency of traditional burner systems. Since its introduction in 1995, over 5000 burners have saved more than 9.4 trillion Btu in the United States. 


\section{Historical AMO Technology Successes}

\section{Hot Blast Stove Process Model and Model-Based Controller}

A central control system was developed and installed on a blast furnace to optimize the thermal efficiency of the hot-blast stove system. The controller is linked to process optimization algorithms that determine heating fuel rates, thus minimizing fuel requirements and reducing the number of disruptions in iron production. This invention has saved more than 220 billion Btu since its installation in 1998.

\section{Humidity Sensor (Optical) \\ An optical humidity sensor (hygrometer) that determines humidity by measuring the absorption of ultraviolet light was developed for the pulp and paper industry. Replacing less reliable humidity sensors, the hygrometer maximizes drying efficiency by optimizing the balance of exhausted and makeup air. Multiple installations realized a cumulative energy savings of 20 billion Btu.}

\section{Hydrochloric Acid Recovery System (www.betacontrol.com) \\ An on-site, closed-loop $\mathrm{HCl}$ recovery system was developed for galvanizers and small- and medium-size steel manufacturers. Benefits of the recovery system included reduced demand for virgin $\mathrm{HCl}$, the elimination of the use of chemicals for neutralizing waste acid, and energy and cost savings associated with processing, transporting and disposing of the waste acid The use of this system resulted in cumulative energy savings of 410 billion Btu.}

\section{Hyperfiltration - Textiles}

Hyperfiltration, a membrane-based separation technique, was adapted to treat textile industry wastewater. This process also found widespread use in the food-processing, biotechnology, pharmaceutical, pulp/paper, chemical, electronic, and nuclear industries. Allowing recovery of raw materials and minimizing waste, this process achieved a cumulative energy savings of nearly 1 trillion Btu.

\section{Hyperfiltration Process for Food (www.niroinc.com) \\ A membrane hyperfiltration process is being used to separate juice into pulp and liquid fractions. This process replaces the energy-intensive thermal evaporation step in the concentration process. This process has been installed in 17 locations and has saved more than 13 trillion Btu since 1989.}

$\checkmark$ Improved Composite Tubes for Kraft Recovery Boilers (www.sandvik.com)

Originally, carbon steel tubes were used for tube panels in black liquor recovery boilers, but severe corrosion thinning and occasional tube failures led the forest products industry and boiler manufacturers to search for materials that could better survive in the recovery boiler environment. As a result of this search, weld overlay and co-extruded tubing alloys were developed and are being used in over 18 U.S. kraft recovery boilers and numerous foreign installations. Boiler manufacturers used these improved tubes in new and rebuilt kraft recovery boilers to cumulatively save over 4.5 trillion Btu in the United States.

\section{- Improved Diesel Engines}

A computer model was developed to help engine designers overcome some of the technical barriers to advanced, more fuel-efficient engines. The new KIVA model allows designers to see the effects of alterations to engine geometry without actually building the engine. KIVA was used to make piston design modifications and other design modifications to diesel engines for heavy trucks. The resulting engine increased truck mileage by nearly onehalf mile/gallon. The improved engines have cumulatively saved 1160 trillion Btu.

\section{Improved Poured Concrete Wall Forming System (www.liteform.com) \\ A method for pouring concrete walls for building basements and crawlspaces was developed that uses lightweight, highly insulative extruded polystyrene forms. If left in place, these forms create walls that are both load- bearing and thermally insulating, up to R-22. Over 47 million square feet of walls have been installed that have cumulatively saved 978 billion Btu.}

\section{Infrared Polymer Boot Heater (www.inductoheat.com)}

This electric high energy flux infrared heater and control system efficiently heats thermoplastic and polymer boots for applications requiring placement of the boots on steel parts (e.g., vehicle steering assemblies and CV joints). The technology converts electrical energy to radiant energy at $90 \%$ efficiency and delivers the heat only to areas needed to be heated. The 5 boot heater systems, in use since 2000 , have cumulatively saved 0.22 billion Btu. 


\section{Historical AMO Technology Successes}

IMPACTS

\section{Ink Jet Printer Solvent Recovery}

(www.quadtechworld.com)

A solvent recovery system for commercial printers was developed that reduces emissions of VOCs, including methyl ethyl ketone, methanol, isopropyl alcohol, and acetone. This closed-loop recycling system reduces the amount of fluid required by ink-jet printing, thereby reducing printing costs and improving productivity by reducing printer downtime for fluid replacement. Since 1997, the 658 systems that were installed have cumulatively saved 450 billion Btu.

\section{- Irrigation Systems}

The design of efficient low-pressure impact sprinklers, low-pressure spray heads, and improved drop tubes upgraded center-pivot irrigation systems dramatically. Operating at lower pressures, these systems required $10 \%$ less water intake, reduced runoff, and yielded a cumulative energy savings of approximately 49 trillion Btu due to reduced pumping requirements.

\section{Irrigation Valve Solenoid Energy Saver (www.alextronix.com)}

A battery operated, multi-station, irrigation valve control unit was developed that can operate out to a distance of almost 20 miles without using any primary copper wiring. This controller provides 10 times the battery life and 100 times the operating distance of any other controller. More than 3800 of these control units have been sold and have cumulatively saved 17 billion Btu since 1999.

\section{Lightweight Steel Containers}

A process for manufacturing lightweight steel containers uses the container's internal pressure for rigidity rather than a thick wall. The resulting container wall is substantially thinner, which reduces the container's metal content by $40 \%$ but provides equivalent or better strength. The process saves energy by using less material in the container, less material processing, and less transportation weight. Two container production lines have cumulatively saved 3 billion Btu.

\section{Membrane Filtration Technology to Process Black Olives \\ A zero discharge wastewater purification and reclamation system was installed at an olive production plant. This system used a cyclone separation system followed by ultrafiltration and reverse osmosis to recycle wastewater back into the plant. Since its installation in 1997, it has saved 100 billion Btu.}

\section{Membrane Separation of Sweeteners}

A system to preconcentrate corn steep water was accomplished via a hollow-fiber membrane process. Resistant to fouling, this system extracted more than $50 \%$ of the water from the corn steep stream prior to evaporation, thus significantly reducing energy requirements. Additionally, a spinoff technology was commercialized for wastewater treatment.

\section{Meta-Lax Stress Relief Process \\ (www.bonal.com)}

A process applies subresonant vibrational energy to relieve stress in metal objects. The process replaces heat treating applications and reduces the energy and time needed to heat treat metal. The equipment is portable and treats a wide variety of work pieces in a pollution-free operation. More than 990 units have cumulatively saved 136 trillion Btu.

\section{$\checkmark$ METHANE de-NOX Reburn Process}

This process is a reburn technology that uses $5 \%$ to $25 \%$ natural gas heat input to improve combustion of solid waste fuels and to control emissions of $\mathrm{NO}_{\mathrm{x}}$ and $\mathrm{CO}$. The METHANE de-NOX process injects natural gas above the grate and uses flue gas recirculation to enhance mixing and create an oxygen-deficient atmosphere that retards $\mathrm{NO}_{\mathrm{x}}$ formation. Overfire air is injected higher in the furnace to burn out the combustibles. The process helps combustion systems operate more efficiently; require less maintenance; and reduce emissions of $\mathrm{NO}_{\mathrm{x}}, \mathrm{CO}$, and VOCs. The reburn technology is operating on three paper mill boilers and on 26 utility coal-fired cogeneration boilers. These 29 units have saved 1.34 trillion Btu since 1998.

\section{Methanol Recovery from Hydrogen Peroxide Production \\ (www.fmc.com)}

A process was developed to recover and clean contaminated methanol for reuse in producing hydrogen peroxide. This process recovers more than $90 \%$ of the methanol needed to produce hydrogen peroxide, thereby saving the energy needed to produce virgin methanol. The process also saves energy by reducing the transportation of virgin methanol. The two units using this process have cumulatively saved 244 billion Btu. 


\section{Historical AMO Technology Successes}

\section{Method of Constructing Insulated Foam Homes}

(www.homecorpintl.com)

A method was developed for constructing buildings that are both energy efficient and structurally sound. The home consists of an exterior patented wall system made of expanded polystyrene (EPS) foam insulation panels with an internal steel-reinforced concrete post and beam design. This wall has an R-40 insulation panel with an internal steel-reinforced concrete post and beam design. The roof is insulated by EPS slabs sandwiched between the rafters and has an R-50 insulation value. The 326 homes constructed using this method saved a cumulative total of 38 billion Btu since 1996.

\section{Micell Dry-Cleaning Technology}

A new dry-cleaning technology was developed that replaces perchlorethylene or petroleum-based solvents used by conventional dry-cleaning systems. The Micell technology uses liquid $\mathrm{CO}_{2}$ and a patented detergent system that enhances the cleaning ability of the liquid $\mathrm{CO}_{2}$. Most of the $\mathrm{CO}_{2}$ is recycled after cleaning and the operating time of the machine is much less than a conventional system saving energy. Since 1999 more than 39 Micell units have been sold and used in the United States and have saved 34 billion Btu.

\section{Nickel Aluminide Trays and Fixtures for Carburizing Heat Treating Furnaces}

Nickel aluminide alloy is a high-strength heat-resistant alloy that is very resistant to carburization. Nickel aluminide heat-treating furnace assemblies were used to replace steel rack assemblies that failed at high heat in an auto parts production plant. Compared with conventional alloys, the new assemblies last three to five times longer and are at least three times stronger at the high operating temperatures, which improves energy and production efficiencies. Since 2001, the new assemblies have cumulatively saved 34 billion Btu.

\footnotetext{
Night Sky - A New Roofing Technology

A natural evaporating roofing/cooling system was developed for flat or slope-roofed commercial buildings to increase the roof's life expectancy and reduce building cooling loads by $50 \%$. This system spray-cools water on the roof at night and then applies the cooled water to reduce subsequent cooling loads. Systems involving more than 95,000 square feet have been installed and have cumulatively saved 2 billion Btu.
}

\section{Nitrogen-Methanol Carburization}

A system was developed for steel manufacturers that replaced the conventional endothermic atmosphere process with a nitrogen-methanol carburization process. In addition to improving the strength, hardness, and wear resistance of the steel parts, the system proved more reliable and easier to operate. Significant reductions in carbon dioxide and other pollutants were noted along with a cumulative energy savings of 12 trillion Btu.

\section{$\checkmark$ No-Clean Soldering Process}

After soldering, electronic equipment used to be cleaned using CFC solvents. Changing the soldering technique eliminated the need to use CFC solvents for cleaning, resulting in energy savings and reduced $\mathrm{CFC}$ waste. This process has cumulatively saved 3.9 trillion Btu.

\section{No- VOC Coating Products (www.rustoleum.com)}

A new line of waterborne coatings was developed that reduce or eliminate VOC emissions during formulation and application. The production of these new coatings requires lower processing temperatures, which reduces their energy impact. The coatings' quick-drying characteristics save further energy by avoiding heating and ventilation in the drying process. These new coatings can be applied to many surfaces including metal products. Many of these new products dry far more quickly than other products so multiple coats can be applied in one day rather than two or three. This dramatically cuts labor costs and returns the facility to use much sooner. Similarly, the corrosion resistance of the coatings is superior to any solvent-based coatings on the market. The use of these coatings has saved 7 billion Btu since 1998.

\section{Onsite Process for Recovering Waste Aluminum}

In the production of aluminum automobile wheels approximately $30 \%$ of the aluminum content is machined away as chips during the cutting and grinding steps. A process for recycling the chips onsite rather than offsite improves the energy efficiency and productivity of chip recycling while simultaneously reducing airborne pollutants and other manufacturing wastes. This process has resulted in cumulative energy savings of 139 billion Btu. 


\section{Historical AMO Technology Successes}

IMPACTS

\section{Organic Rankine-Cycle Bottoming Unit}

This organic Rankine-cycle system was developed to replace less-efficient, conventional steam Rankine-cycle systems in generating electricity from lower temperature waste-heat sources. It was found to be adaptable to a variety of solar and geo-thermal energy applications as well as suitable for many types of industrial waste-heat streams. The system consists of a standard Rankine-cycle engine, toluene as the working fluid, a waste-heat boiler, a wastegas flow-control valve, system controls, and an electric generator. The installation of several units cumulatively saved 500 billion Btu of energy.

\section{Oxy-Fuel Firing}

(www.praxair.com)

This oxygen-enriched combustion system for glass-melting furnaces significantly reduces energy requirements. About one-fourth of all glass-melting capacity in the United States has been converted to oxy-fuel firing. In addition to energy savings, this technology reduces $\mathrm{NO}_{\mathrm{x}}$ emissions by up to $90 \%$ and particulates by up to $30 \%$. Since its commercialization in 1990, oxy-fuel firing technology has saved more than 25 trillion Btu.

\section{Oxygen-Enhanced Combustion for Recycled Aluminum \\ (www.airproducts.com) \\ A new metal melting system was developed and demonstrated that uses a low- $\mathrm{NO}_{\mathrm{x}}$ combustion burner integrated with an onsite vacuum-swing-absorption (VSA) oxygen-generation system. This new burner system operated on a recycled aluminum furnace and used controlled mixing of fuel, air, and high-purity oxygen streams to lower emissions and improve flame quality. The integration of the new burner with the VSA system greatly reduces $\mathrm{NO}_{\mathrm{x}}$ emissions while reducing energy usage and increasing melting productivity. This technology has cumulatively saved 25 billion Btu since 1999.}

\section{Paint Wastewater Recovery}

A system was developed to reclaim and reuse wastewater generated during equipment cleaning used in water-based paint-production operations. The system vastly reduces the volume of wastewater contaminated with metals and solvents that must be disposed of as hazardous waste. Energy savings resulted from the reduced fuel use for transporting and incinerating the waste. The process has cumulatively saved over 30 billion Btu of energy.

\section{Pallet Production Using Postconsumer Wastepaper} A process produces paper pallets made of $40 \%$ postconsumer waste paper. Substituting virgin wood with this recycled product reduces by $60 \%$ the energy required to produce pallets, saves landfill space, and decreases air and water pollution. The process has cumulatively saved over 2 billion Btu.

\section{Pervaporation to Recover and Reuse Organic Compounds \\ (www.mtrinc.com)}

A membrane technology was developed which treats small-volume, less than 20 gallons per minute, waste streams contaminated with organic compounds. Smallvolume wastewater streams are difficult and expensive to treat with most conventional organic-compounds control technologies. The three installed units cumulatively saved 57 billion Btu.

\section{PET Bottle Separator}

Recycling certain plastics for conversion into fuel oil necessitated the development of a separation process that could sort containers of PET (polyethylene terephthalate), high-density polyethylene, and aluminum. One bottling plant using this process recycled 18 million pounds of PET and saved a total of 1.2 trillion Btu of energy.

\section{- Pinch Analysis and Industrial Heat Pumps \\ Pinch analysis was used to locate the most productive process modifications and heat pump opportunities within a complex process to improve overall process efficiency. A pinch analysis of a wet-corn-milling plant showed that adding two new thermal vapor recompression heat pumps to existing evaporators could reduce overall process fuel use by $33 \%$. These two heat pumps have cumulatively saved 917 billion Btu.}

\section{$\checkmark$ Plating Waste Concentrator}

A low-cost, vapor-recompression evaporation system was developed for the plating and surface-finishing industry to reduce water pollution and recover costly plating chemicals. The waste concentrator was designed with two evaporators, one to concentrate the wastewater and the other to use waste heat as an energy source. Recovery of plating metals, reduced hazardous material treatment costs, and energy recycling all contributed to improved operating costs and energy efficiencies. This technology was used in 62 applications and resulted in a cumulative energy savings of 3 trillion Btu. 


\section{Historical AMO Technology Successes}

\section{Powder Paint Coating System}

The current standard for applying anti-chip primer to vehicles is a solvent-borne paint spray system that has a transfer efficiency (ratio of paint solids deposited on the vehicle to total volume used) of about $50 \%$. A powder anti-chip process that contains no solvents and, considering recycling, has an effective transfer efficiency exceeding $99 \%$ was developed. The system virtually eliminates VOC emissions and paint sludge generation, eliminating the costs to transport and dispose of sludge. Energy requirements for the powder process are much lower than for solvent-based processes due to greatly reduced air-heating requirements and the elimination of energy requirements for incinerating VOCs. This system has been installed in 14 locations in the United States and has saved more than 5.6 trillion Btu since 1996.

\section{PowerGuard ${ }^{\circledR}$ Photovoltaic Roofing System \\ (www.sunpowercorp.com) \\ A roofing system was developed that offers building insulation, shading, roof protection, and solar power generation encompassed in a single roofing panel. These have been installed on commercial or residential buildings that have flat or low-slope roofs. Since its introduction in 1994, more than $21 \mathrm{MW}$ have been installed across the United States for an energy savings of 385 billion Btu.}

\section{PowerRim ${ }^{\text {TM }}$ High Wattage Energy Saving Compact Fluorescent Lamp Adaptor for Recessed Down Lights (www.powerlux.com) \\ Compact fluorescent lamps (CFLs) use one-fourth the electricity and last nearly 10 to 13 times longer than incandescent bulbs. Many commercial settings - malls, hotels, motels - are excellent sites for CFLs. The PowerRim high-wattage CFL retrofit adaptor kit for recessed down lights was developed that allows $100-\mathrm{W}$ to 200 -W incandescent lights to be converted to higher- wattage CFLs. The ballast is located at ceiling level keeping it cooler, thus extending ballast life and improving operating efficiency. The use of an optional glare shield placed below the lamp further reduces the operating temperature of the ballast, thus increasing its life and its efficiency. In addition, the glare shield radiates light out from the fixture, using it more efficiently. Since 1998 more then 47,000 PowerRim units have been installed and have saved 330 billion Btu.}

Pressurized Ozone/Ultrafiltration Membrane System This technology for closed-loop systems uses pressurized ozone with dissolved air flotation and an ultrafiltration membrane in series. This system allows total dissolved solids (TDS) in process water to be readily converted to total suspended solids for efficient removal. Contaminated mill process water thereby can be continually and cost effectively cleaned to the high-quality process water standards required for reuse in the mill. After passing through the new system, process water is far cleaner and of higher quality than water from other processes and requires far less energy for reheating than fresh water. The system reduces the production problems associated with buildup of TDS in paper mill operations and provides operational benefits such as reduced energy needs and fewer chemicals and additives. This system substantially reduces both effluent discharge and the need for fresh water. The paper plant where this system was installed in 2004 saved 1.26 trillion Btu.

\section{Radiation-Stabilized Burner (www.alzeta.com)}

A new technology, the radiation-stabilized burner (RSB), was developed that is an ultra-low $\mathrm{NO}_{\mathrm{x}}$ and $\mathrm{CO}$ burner for applications in industrial boilers and process heaters. Characteristics of the RSB that improve performance relative to conventional burners include full premixing of fuel and air to the greatest extent possible prior to combustion, surface stabilization through the use of radiant zones and high flux zones on the burner surface, and controlled flame shape above the burner surface. This results in low emissions without sacrificing thermal efficiency or boiler reliability. Since 1999, over 350 burners in the United States have cumulatively saved more than 337 billion Btu.

\section{Real-Time Neural Networks for Utility Boilers (www.neuco.net)}

A computer model was developed that uses an advanced form of artificial intelligence known as neural networks to optimize combustion in coal-fired boilers. This system improved boiler efficiency by as much as $5 \%$ and reduced $\mathrm{NO}_{\mathrm{X}}, \mathrm{CO}_{2}$ and $\mathrm{SO}_{\mathrm{X}}$ emissions. The cost of reducing $\mathrm{NO}_{\mathrm{X}}$ emissions using the model is much lower than the cost of installing low- $\mathrm{NO}_{\mathrm{x}}$ burners or catalytic converters. The system has been installed on 64 boilers and has saved more than 57 trillion Btu since 1995. 


\section{Recovery of Acids and Metal Salts from Pickling Liquors \\ Steel fabrication processes often use pickling (immersing steel in acid) to remove oxide layers from recently heated steel. The Pickliq ${ }^{\circledR}$ process was developed to make sulfuric acid recovery cost-effective for smaller installations. The process combines diffusion dialysis, energy transfer, and low-temperature crystallization technologies to efficiently recover acids and metal salts. It has demonstrated significant gains in production capacity, quality control, and productivity. Since its introduction in 1995, the process has saved more then 11 billion Btu in the United States.}

\section{Recuperators}

A cross-flow ceramic recuperator made of cordierite (a magnesium-aluminum silicate) was developed to recover heat from exhaust gases in high-temperature (up to $2600^{\circ} \mathrm{F}$ ) furnaces. Corrosion and oxidation resistant, the compactly sized recuperator eliminated the need for a flue gas dilution system. These units cumulatively saved over 24 trillion Btu in energy and reduced both thermal and emissions pollution.

\section{Recycling of Aluminum Dross/Saltcake Waste (www.aleris.com)}

The melting process used by the secondary aluminum industry when recycling aluminum creates a waste stream known as black dross/saltcake. A new process was developed that separates the dross into its basic components - aluminum metal, fluxing salts, and nonmetallic products. The aluminum metal and salt fluxes can be sold back to the secondary aluminum industry or other industries. The remaining nonmetallic products can be made into commercially salable products completely avoiding land filling. Since 1997, the three plants using this new process have cumulatively saved 13.5 trillion Btu.

\section{Removal of Bark from Whole Logs}

A machine, the Cradle Debarker ${ }^{\mathrm{TM}}$, was developed that removes bark from delimbed tree stems in a process that strips off less wood, allows for greater operator control, and improves the productivity of the debarking process. Unlike drum debarkers, which use a covered cylinder, the open top of this debarker lets the operator remove stems that have completed the debarking process and recycle others that require further processing. The four debarker units have cumulatively saved 132 billion Btu.

\section{Restaurant Exhaust Ventilation Monitor/Controller (www.melinkcorp.com) \\ Typical exhaust hoods in restaurants operate at full speed all day long and sometimes all night long even when cooking is not taking place. A microprocesor-based controller for commercial kitchen ventilation systems was developed that optimizes system performance for four key parameters: kitchen comfort, fire safety, occupant health, and energy efficiency. It monitors and reduces the fan speed during idle periods of kitchen activity to save energy and employs sensors that monitor heat and smoke levels for safety. More than 2,700 units have been sold and have saved more than 600 billion Btu since 1994.}

\section{Retractable ${ }^{\circledR}$ Labyrinth Packing Seals for Turbine Shafts \\ (www.turbocare.com) \\ This invention is a redesigned shaft-sealing ring for utility and industrial steam turbines that self-adjusts from the gap required for start-up to that required for normal operation. The result is less wear damage and improved turbine efficiency. The packing seals are still available for sale from TurboCare, Inc. More than 600 of these seals have been installed and have saved more than 74 trillion Btu. Additionally, spinoff technologies were developed to further improve steam power efficiency.}

Reverse Brayton Cycle Solvent-Recovery Heat Pump A reverse Brayton cycle heat pump was developed to economically and efficiently recover solvents from numerous industries. This heat pump reduces the demand for new solvents, saving petroleum feedstock and the energy used to produce virgin solvents, and captures for reuse solvents that would have been released to the atmosphere. Ten heat pumps have been installed and have cumulatively saved 4.98 trillion Btu.

\section{Robotic Inspection System for Storage Tanks (www.solexrobotics.com)}

This technology consists of a remotely operated robotic inspection vehicle that is submerged in bulk liquid storage tanks to gather input on structural and corrosion problems. This system replaces the time-consuming conventional inspection process of draining the tank, washing it out, inspecting it, and then refilling it. This technology has cumulatively saved 280 billion Btu. 


\section{Historical AMO Technology Successes}

\section{RR-1 Insulating Screw Cap}

A new insulated screw cap assembly was developed for use on commercial and industrial buildings with membrane and metal roofs. The new assembly replaces conventional metal or plastic fasteners and improves the energy performance of the roofs. The assembly reduces heat transfer through the fastener and is more resistant to condensation and corrosion. More than 300,000 fastener assemblies have been sold since 1997, cumulatively saving 13 billion Btu.

\section{Scrap Tire Recycling}

This process converts scrap tires into high-value products, conserving energy and new materials while reducing the amount of scrap tires sent to landfills. This treatment process combines surface-treated rubber particles with other polymers such as polyurethane, epoxy, and polysulfide to form unique composites with improved strength, tear resistance, and resilience. This process has saved a cumulative 0.16 trillion Btu in natural gas.

\section{Selective Zone Isolation for HVAC Systems (www.retrozone.com)}

A method for selectively controlling air flow from a central HVAC system can now fit into ducts that cannot accept conventional dampers because of poor access. The flexible dampers can save $20 \%$ to $30 \%$ of a typical heating and cooling bill in a large house or commercial building by sealing off unoccupied rooms. More than 4000 systems have been sold and have cumulatively saved 305 billion Btu.

\section{Shorter Spherodizing Annealing Time for Tube/Pipe Manufacturing (www.timken.com) \\ A process was developed for through-hardened steel that reduces the annealing time by $20 \%$. The enhanced spherodizing cycle improved the manufacturing of tubes and pipes while maintaining key steel parameters and reducing the amount of energy used in the process. The optimized cycle also improved production while generating a quality product with the desirable metallurgical properties for forming and machining. The process has cumulatively saved 138 billion Btu.}

\section{SIDTEC ${ }^{\mathrm{TM}}$ Condenser Maintenance Program (www.gewater.com) \\ An on-line condenser tube cleaning system uses ultra-high molecular weight polyethylene tube cleaners to remove both soft and hard deposits. The system maintains system efficiency and keeps the thermal power plant operating. Twelve power plants have used the system and have cumulatively saved 136 trillion Btu.}

\section{Slot Forge Furnace/Recuperator \\ A high-performance slot forge furnace design that incorporated a ceramic shell-and-tube recuperator was developed to recover approximately half of the heat energy previously lost in the furnace exhaust gases. Additionally, modified recirculation burners, improved temperature and air/fuel ratio controls, and lightweight furnace wall insulation reduced energy requirements per pound of steel by approximately $4100 \mathrm{Btu}$. The use of this technology resulted in a cumulative energy savings of 13 trillion Btu.}

\section{Smart Screening Systems for Mining}

A smart screening system was developed that vibrates only the screen rather than the entire machine and supporting structure in the material separation process. The system saves energy by replacing the massive electrical motor and eccentric shaft with miniaturized "smart" motors combination with multi-staged resonators. The motors are programmed to vibrate the screening panel at an optimal set rate, even as the material load varies over time, thus optimizing the throughput and energy savings of the screening system. Since its introduction in 2003, the 44 units installed in the United States have saved 3 billion Btu.

\section{Solar Process Heat}

This project was developed to expand the use of solar process heating systems primarily within the government and institutional sectors. Reducing the need for fossil fuels, solar heat supplies water preheating, process hot water, and steam as well as process hot air, cooling, and refrigeration.

\section{SolaRoll ${ }^{\circledR}$ Solar Collector System}

A flexible rubber tubing solar collector system was developed to be used to heat hot water, swimming pools, and building heating systems. The collectors are an extrusion of ethylene-propylene-diamine rubber and are primarily used for heating swimming pools. The systems replace conventional natural gas or electric heat pump systems. More than 35 million square feet of SolaRoll ${ }^{\mathbb{B}}$ have been sold and have saved more than a cumulative 25 trillion Btu of energy. 
SOLARWALL ${ }^{\circledast}$ Air Preheating System

(www.solarwall.com)

A solar air heating system heats incoming ventilation and makeup air using a metal cladding system installed on the south-facing wall of a building. This system also reduces a buildings heat loss in the winter and lowers the cooling loads in the summer by preventing solar radiation from striking the south wall of the building. More than 40 systems with over 200,000 square feet of wall are operating in the United States and have cumulatively saved 76 billion Btu. A spinoff technology has been developed that resulted in a combined solar heat and power system.

\section{Solvent Recovery from Effluent Streams \\ (www.mtrinc.com)}

A membrane system was developed for recovering volatile organic compounds and chlorofluorocarbons from petrochemical waste streams. This system allows solvents to be recovered from waste streams that are too diluted or too concentrated with solvents to use other methods. In addition to eliminating the environmental release of these solvents, the 27 units in operation in the United States have saved more than 15 trillion Btu since 1990.

\section{-Stalk and Root Embedding Plow}

(www.romeplow.com)

A stalk and root embedding plow was invented that reduces costs and saves time in preparing cotton fields for planting. Disposing of cotton stalks and roots in the field after harvest is an energy-intensive operation. Nationwide, many cotton farmers use conventional tillage practices that involve shredding the stalks and making several tillage passes over the field to prepare a new seedbed. The plow deeply entrenches whole stalks and roots into the soil in one pass, eliminating the need to shred the stalks. The 79 plows sold in the United States have saved a cumulative total of 123 billion Btu of energy.

\footnotetext{
- Steel Reheating for Further Processing (www.praxair.com)

A low $\mathrm{NO}_{\mathrm{X}}$, oxygen-burner retrofit using $100 \%$ oxygen was developed for steel reheating that requires less fuel to heat steel. These burners result in energy savings of $60 \%$ per ton of steel while increasing the quality of the metal. Emissions are reduced enough to eliminate the need for NOX removal equipment and the steel is more uniformly heated resulting in better mill performance and an increase in productivity. Since its introduction in 1998, this system has saved 1 trillion Btu.
}

\section{Supercritical Purification of Compounds for Combinatorial Chemical Analysis}

An innovative approach to combinatorial chemistry for the drug discovery industry was developed called supercritical fluid chromatography (SFC). Using the SFC process, samples can be purified and dried 20 to 100 times faster than by conventional liquid chromatography systems. The SFC technology provides a solute purity of $95 \%$ or greater, very rapid fraction collection with full automation, no need for manual intervention and reduces liquid-solvent waste. Over 150 SFC systems have been installed and have saved 3.77 trillion Btu since 2000 .

\section{$\checkmark$ SuperDrive - A Hydrostatic Continuously Variable Transmission (CVT)}

This hydraulic transmission system increases efficiency by uncoupling engine revolutions per minute (rpm) from wheel speed. This design allows an electronic control module to seek the lowest rpm at which sufficient torque is available to maintain the desired speed. This method allows the vehicle to maintain a constant speed over varying terrain with little or no increase in engine rpm. Because this is a closed-loop hydraulic system incorporating variable pumps and motors, it has the capacity for hydraulic braking by activating a flow control valve. The improved fuel efficiency, an average of $25 \%$ to $40 \%$, more than offsets the reduction in transmission efficiency for heavy-duty trucks and buses. The SuperDrive system was installed on three buses and has saved 6 billion Btu since 2004.

\footnotetext{
System $100{ }^{\circledR}$ Compressor Controls

(www.cccglobal.com)

A compressor control system was developed that allows the operation of both pipeline and process compressors to operate efficiently without surge or recycle. The compressors are usually powered indirectly by natural gas (steam for process compressors and gas-powered turbines for pipeline compressors). Energy savings are typically in the $5 \%$ to $10 \%$ range. Total sales of the control systems were more than 3600 units and they have cumulatively saved more than 400 trillion Btu.
} 


\section{Historical AMO Technology Successes}

\section{Textile Finishing Process}

A new process for finishing textiles was developed that increases productivity and energy efficiency. In the new process finishing chemicals are diluted with air instead of water and applied to the fabric as foam. No additional mechanical or vacuum moisture removal is necessary, thus saving energy and water. The moisture content of the fabric is cut in half, allowing a new energy-efficient, high-speed tenter frame to be used. This technology has cumulative saved more than 227 billion Btu since 1999.

\section{The Solar SKYLITE Water Heater}

(www.solarroofs.com)

A solar skylight water heater system was developed that uses lightweight, low-cost polymeric materials. A typical installation uses two solar collectors and the entire system can be installed in a few hours. The system can serve as a skylight and provide energy to the home's water heater. More than 1400 systems have been installed and these have cumulatively saved more than 75 billion Btu of energy. A spinoff technology was developed that improves solar energy capture.

\section{Thin Wall Casting of Stainless Steel}

An alloy of cast stainless steel composition was developed that allows the use of the Hitchiner counter-gravity casting process for stainless steel parts rather than conventional sand casting. Using the Hitchiner process allows components to be cast with wall thickness of less than $3 \mathrm{~mm}$ - nearly two to three times less than conventional casting. This process increases automation, increases throughput by a factor of two to three compared with the conventional process, and produces a significantly higher yield with very low defect rates. The use of this alloy has saved over 460 billion Btu since 2000.

\section{Transfer Rolls for Steel Production (www.duraloy.com)}

A nickel aluminum alloy was developed and demonstrated that was used to move steel plates through the heat treatment process in heat-treat roller hearth furnaces. Nickel aluminide is a strong, hard, inter-metallic material that resists wear, deformation, and fatigue from repeated stress or high temperatures. Because the alloy becomes stronger and harder at high temperatures, nickel aluminide transfer rolls are well suited to replace steel transfer rolls. Benefits include reductions in maintenance, greater throughput and productivity, and fuel cost reduction per ton of steel. The 273 transfer rolls installed in the United States have cumulatively saved 154 billion Btu.

\section{$\checkmark$ Ultrasonic Tank Cleaning}

(www.telsonic.com)

Chemical and pharmaceutical companies typically use volatile organic compound (VOC)-emitting solvents to clean their storage tanks in a process that is both labor and energy-intensive. An ultrasonic tubular resonator was developed that eliminates the use of VOC-emitting cleaning solvents and reduces cleaning time from about 1 day to 1 hour. The unit is small and can be placed into the tank through an opening in the top, eliminating the need for maintenance workers to enter the tank as required with conventional cleaning. Energy savings from the use of this technology are based on decreased cleaning energy use as well as the reduced use of solvents. Since 1995, this technology has saved more than 40 billion Btu.

\section{- Uniformly Drying Materials Using Microwave Energy} (www.industrialmicrowave.com)

A system was developed that uses microwave energy to dry materials uniformly. Traditionally, microwave-drying systems have scorched the portions of materials that were close to the radiation source, while materials further from the source remained moist. This new system overcame the problem by using rectangular wave-guides to maximize the exposure area of the material passing through the system. This system reduces the cost of drying and has cumulatively saved 211 billion Btu.

\section{Use of Recovered Plastics in Durable Goods Manufacturing \\ (www.mbapolymers.com) \\ An advanced mechanical recovery technology that can effectively recover plastic waste material from complex manufacturing scrap and end-of-life durable goods including automobiles, appliances, electrical, and electronic equipment was developed. This technology separates as many as three different plastics at one time in a mixed waste stream and segregates metal, metal coatings, rubber, glass, foam, and fabric from the plastic waste. Since its introduction in 1996, this technology has cumulatively saved over 400 billion Btu.}




\section{Historical AMO Technology Successes}

\section{Variable-Frequency Microwave Furnace} (www.microcure.com)

Microwave heating can speed the curing of thermo-setting resins and polymer-matrix composites. Conventional microwave furnaces use standing waves that create a non-uniform energy distribution in the working cavity. A variable-frequency microwave furnace was developed that eliminates non-uniform energy distribution and provides reproducible heating with every batch. Various types of polymer products can be uniformly cured, often in $5 \%$ of the time of conventional processing. The 48 units in the United States have saved 47 billion Btu since 1995.

\section{V-PLUS ${ }^{T M}$ Refrigerant Oil Cooling System}

\section{(www.vilter.com)}

The V-Plus system injects refrigerant liquid into the outlet stream of a screw-compressor for industrial refrigeration and cooling systems. The result is increased system capacity, extended system lifetime, and energy savings. Over 250 units have been installed and have saved more than 1 trillion Btu since 1982.

\section{Wallace Energy Systems Solar Assisted Heat Pump Water Heater}

A system was developed for extracting heat from a source (air or water) and applying this heat to water. The heat pump water heater provides both water heating and space cooling. The systems can be used in applications that need large amounts of hot water and cooling, such as laundries and schools. More than 103 units are in use and have cumulatively saved 118 billion Btu.

\section{Waste Atactic Polypropylene to Fuel}

This pyrolysis process converted a polypropylene plastic by-product, called atactic polypropylene, to fuel oil and gas. A total of 17 million pounds/year of atactic polypropylene was pyrolyzed into 2 million gallons/year of commercialgrade fuel oil that yielded a cumulative energy savings of 500 billion Btu.

\section{Waste Energy Recovery}

Two waste-to-energy plants were constructed, one in Honolulu, Hawaii and one in Tacoma, Washington, that burn the combustible portion of municipal solid waste (MSW). The combustible MSW materials are burned to produce steam, which in turn, is used to power a conventional steam turbine/generator to produce electricity. These plants reduce the amount of electricity that must be produced by fossil fuels, as well as the amount of MSW that must be disposed of in landfills. These two installations have yielded more than 35 trillion Btu of energy since being commercialized.

\section{Waste Fluid Heat Recovery System}

A heat recovery system that extracts energy from waste fluids was developed that increases heat transfer coefficients two to four times higher than conventional designs. Using a new coil and tube design for the heat exchanger reduces energy consumption by recovering up to $70 \%$ of heat usually lost in the waste fluid. More than 2660 units were sold since 1997, cumulatively saving 144 billion Btu.

\section{Waste-Minimizing Plating Barrel (www.selectives.net)}

An innovative plating barrel uses a honeycomb formation that results in a thinner walled barrel. The new barrel has greater solution transfer, higher current density plating, reduced bath concentration, and better plating of difficult chemistries such as alloy plating. Energy savings result from reduced process time and better plating efficiency. More than 1100 of these new barrels have been sold since 1997, cumulatively saving 4.1 trillion Btu.

\section{Wear Resistant Composite Structure of Vitreous Carbon Containing Convoluted Fibers}

A new method was developed to manufacture a carbon composite material consisting of a vitreous silicon/ carbide matrix containing carbon fibers. The graphite fiber-reinforced ceramic matrix complex operates at high temperatures and is resistant to acids, bases, and organic solvents in seal configurations. The material is used in motorcycle and automobile brake rotors to reduce the amount of energy required to accelerate the vehicle, reducing fuel consumption, and increasing the acceleration rate. The material has cumulatively saved 7 billion Btu. 


\section{Historical AMO Technology Successes}

\section{XTREME Cleaner ${ }^{\mathrm{TM}}$ - Removal of Light and Sticky Contaminants \\ (www.kadant.com) \\ A new centrifugal cleaner was developed that replaces conventional dispersion systems in paper mills for recycling waste paper containing "stickies," wax, polyethylene, and binding glue. The new cleaner uses 50\% less energy than the conventional systems, significantly reducing costs for paper mills and allowing them to use lower-grade, lower-cost furnish without compromising the quality of the final paper product. The cleaner eliminates downtime for removing sticky contaminant buildup from processing machinery and reduces machine or paper breaks. Since 1997, twelve cleaner systems have cumulatively saved 1.56 trillion Btu.}




\section{Appendix D: \\ Method of Calculating Results for the IAC Program}


The Industrial Assessment Centers (IAC) within the Advanced Manufacturing Office (AMO) have been successfully generating energy savings for over 30 years. Twenty-six IACs located within engineering departments at top universities across the U.S. conduct energy assessments for small- and medium-sized manufacturers and train the future workforce of energy engineers.

The following table presents energy savings calculated and summed from four sources associated with the IAC program from 1977-2010: (1) IAC energy assessments, (2) assessments performed by IAC student alumni, (3) replication assessments within firms served by the IAC, and (4) IAC website-related energy savings. Output and savings estimates rely on information from the IAC assessment database (administered by Rutgers University), the IAC student registry, and evaluations conducted by Oak Ridge National Laboratory (ORNL). The IAC database documents savings recommendations and implementation history for plant assessments conducted over a 28 -year period, covering more than 15,200 assessments and nearly 114,000 savings recommendations. The IAC student registry, established in 2001, tracks the progress of students from their starting date until their departure from the IAC. Finally, ORNL evaluations have studied the longer-term effects of plant assessments, career paths of IAC alumni, and the savings potential of web-based materials offered by the IAC.

Tabulations shown in the table are based on data collected by the IACs and studies done to estimate the nonassessment benefits. The first two rows of the table show the number of assessments conducted each year and the savings associated with each new assessment. The savings from each assessment are assumed to persist for seven years. Therefore, the energy saved in each year (shown in row three) is the sum of energy savings from new assessment savings for that year plus the savings from measures implemented in the previous six years that continue to persist.

The contribution of assessments (or other, equivalent professional services) performed by IAC student alumni is estimated based on averaged student registry data and feedback from IAC alumni who are practicing energy engineers. In 2010, 106 fully trained students graduated from the IAC, and cumulatively over 3,061 IAC students graduated. According to ORNL research and alumni feedback, about $50 \%$ of the alumni have remained in the energy-efficiency business and each alumnus performs the equivalent of 4 assessments per year for 11 years after leaving the IAC program. The benefits of each energy assessment (or equivalent intervention) were assumed to persist for seven years, after which the aged energy assessment was "retired" for the purposes of this estimation. The annual energy savings from alumni assessments are shown in row four in the table.
The savings from replications from assessment activities are calculated as $25 \%$ of the energy saved in the prior year from all assessment activities. This calculation accounts for the ancillary effect of additional implementations that are initiated later but are the result of the IAC's influence. These implementations may be accomplished at the same plant as the original implementations, or at other plants within the same company, or within other plants at other companies as plant managers/engineers/workers change jobs but take the energy efficiency know-how with them. The annual energy savings from replication activities are shown in row five in the table.

The IAC website maintained at Rutgers University was estimated to begin having an impact on energy savings in 1998. The methodology for determining the savings from web users relies on server data, IAC assessment savings, and data from the literature to approximate energy savings associated with the on-line, user-friendly version of the IAC database. While most centers host IAC-related websites, several of which contain useful software tools and publications developed by students and faculty, IAC savings estimates focus solely on the on-line version of the IAC database. The output estimate for the IAC website is based on the number of unique plants that used the online database. Server reports from Rutgers have identified about 19,200 annual visitors to the website, 5,750 of which were likely to represent unique U.S. plants. According to software use experience for similar programs, only $11 \%$ of those accessing the IAC database likely use it and only $14 \%$ of this number implement energy saving projects with the information provided. The estimates of energy savings are based on the savings generated by the unique plants that use the on-line database each year to implement energy-saving projects. Each unique plant that implements a project is assumed to save the equivalent of a single IAC assessment, or 6,166 MMBtu in 2010. As with the other assessments, energy savings are assumed to persist for seven years.

The annual and cumulative energy savings from all IAC activities are shown in the table for each year. In 2010, the annual energy savings are $241 \mathrm{TBtu}$ and the cumulative energy savings through 2010 are 2,443 TBtu. Energy cost savings, carbon reduction, and other benefits are related to energy savings by projected fuel prices and emission coefficients. The cumulative energy cost savings and the cumulative carbon reduction are shown for the IAC program through 2010 in the last two rows of the table. 


\section{Method of Calculating Results for the IAC Program}

IMPACTS

\begin{tabular}{|c|c|c|c|c|c|c|c|c|}
\hline Item & 1977 & 1978 & 1979 & 1980 & 1981 & 1982 & 1983 & 1984 \\
\hline Number of Assessments & 82 & 70 & 636 & 224 & 359 & 253 & 211 & 248 \\
\hline $\begin{array}{l}\text { Annual Energy Saved Per New Assessment } \\
\text { (MBtu/Assessment-Year) }\end{array}$ & 3,212 & 3,212 & 3,212 & 3,212 & 3,212 & 1,782 & 2,047 & 3,504 \\
\hline Energy Saved From Assessments (TBtu) & 0.263 & 0.488 & 2.53 & 3.39 & 5.01 & 5.65 & 6.41 & 7.11 \\
\hline Energy Saved From Alumni Assessments (TBtu) & - & - & 0.09 & 0.27 & 0.57 & 0.84 & 1.26 & 2.27 \\
\hline Replication Energy Savings $(T B t u)$ & 0.0 & 0.065 & 0.125 & 0.52 & 0.24 & 0.37 & 0.16 & 0.19 \\
\hline Annual Energy Savings (TBtu) & 0.263 & 0.553 & 2.74 & 4.18 & 5.82 & 6.86 & 7.82 & 9.57 \\
\hline Cumulative Energy Savings (TBtu) & 0.263 & 0.816 & 3.56 & 7.74 & 13.6 & 20.4 & 28.2 & 37.8 \\
\hline Cumulative Energy Cost Savings $(B \$)$ & 0.001 & 0.002 & 0.009 & 0.025 & 0.054 & 0.090 & 0.131 & 0.181 \\
\hline Cumulative Carbon Reduction (MMTCE) & 0.005 & 0.015 & 0.066 & 0.143 & 0.249 & 0.375 & 0.518 & 0.694 \\
\hline Item & 1985 & 1986 & 1987 & 1988 & 1989 & 1990 & 1991 & 1992 \\
\hline Number of Assessments & 368 & 298 & 324 & 388 & 340 & 360 & 455 & 531 \\
\hline $\begin{array}{l}\text { Annual Energy Saved Per New Assessment } \\
\text { (MBtulAssessment-Year) }\end{array}$ & 4,208 & 4,520 & 3,898 & 3,842 & 4,724 & 3,821 & 3,207 & 3,942 \\
\hline Energy Saved From Assessments (TBtu) & 8.49 & 7.92 & 8.40 & 8.87 & 10.0 & 11.2 & 12.2 & 12.8 \\
\hline Energy Saved From Alumni Assessments (TBtu) & 3.96 & 6.27 & 8.79 & 11.8 & 16.0 & 19.9 & 23.3 & 27.1 \\
\hline Replication Energy Savings (TBtu) & 0.44 & 0.80 & 0.84 & 0.88 & 1.09 & 1.39 & 1.19 & 1.26 \\
\hline Annual Energy Savings (TBtu) & 12.9 & 15.0 & 18.0 & 21.5 & 27.2 & 32.5 & 36.7 & 41.2 \\
\hline Cumulative Energy Savings (TBtu) & 50.7 & 65.7 & 83.7 & 105 & 132 & 165 & 202 & 243 \\
\hline Cumulative Energy Cost Savings $(B \$)$ & 0.247 & 0.308 & 0.382 & 0.466 & 0.578 & 0.721 & 0.874 & 1.05 \\
\hline Cumulative Carbon Reduction (MMTCE) & 0.931 & 1.21 & 1.54 & 1.93 & 2.43 & 3.02 & 3.68 & 4.43 \\
\hline Item & 1993 & 1994 & 1995 & 1996 & 1997 & 1998 & 1999 & 2000 \\
\hline Number of Assessments & 585 & 776 & 879 & 867 & 720 & 723 & 755 & 705 \\
\hline $\begin{array}{l}\text { Annual Energy Saved Per New Assessment } \\
\text { (MBtu/Assessment-Year) }\end{array}$ & 3,314 & 3,074 & 2,978 & 3,002 & 2,500 & 2,185 & 2,856 & 2,408 \\
\hline Energy Saved From Assessments (TBtu) & 13.4 & 14.6 & 16.0 & 17.1 & 17.8 & 18.2 & 18.4 & 18.1 \\
\hline Energy Saved From Alumni Assessments (TBtu) & 30.0 & 33.3 & 36.4 & 38.9 & 41.0 & 43.2 & 45.9 & 47.7 \\
\hline Replication Energy Savings (TBtu) & 1.70 & 1.54 & 1.84 & 2.04 & 2.17 & 1.84 & 1.66 & 2.25 \\
\hline Web Users Energy Savings (TBtu) & - & - & - & - & - & 0.04 & 0.12 & 0.20 \\
\hline Annual Energy Savings (TBtu) & 45.1 & 49.6 & 54.2 & 58.1 & 61.0 & 63.3 & 66.1 & 68.3 \\
\hline Cumulative Energy Savings (TBtu) & 288 & 337 & 392 & 450 & 511 & 574 & 640 & 708 \\
\hline Cumulative Energy Cost Savings $(B \$)$ & 1.23 & 1.44 & 1.65 & 1.91 & 2.18 & 2.43 & 2.70 & 3.07 \\
\hline Cumulative Carbon Reduction (MMTCE) & 5.24 & 6.13 & 7.10 & 8.14 & 9.24 & 10.4 & 11.6 & 12.8 \\
\hline
\end{tabular}


Method of Calculating Results for the IAC Program

IMPACTS

\begin{tabular}{|c|c|c|c|c|c|c|c|c|}
\hline Item & 2001 & 2002 & 2003 & 2004 & 2005 & 2006 & 2007 & 2008 \\
\hline Number of Assessments & 639 & 649 & 620 & 635 & 555 & 450 & 385 & 403 \\
\hline $\begin{array}{l}\text { Annual Energy Saved Per New Assessment } \\
\text { (MBtu/Assessment-Year) }\end{array}$ & 3,935 & 6,800 & 6,620 & 7,140 & 7,070 & 9,540 & 8,182 & 7,809 \\
\hline Energy Saved From Assessments (TBtu) & 18.2 & 19.9 & 21.3 & 24.5 & 27.4 & 30.3 & 32.3 & 33.5 \\
\hline Energy Saved From Alumni Assessments (TBtu) & 54.3 & 69.4 & 85.1 & 106 & 127 & 155 & 178 & 198 \\
\hline Replication Energy Savings (TBtu) & 1.97 & 3.33 & 6.14 & 6.05 & 6.78 & 6.65 & 8.68 & 7.23 \\
\hline Web Users Energy Savings (TBtu) & 0.38 & 0.79 & 1.29 & 1.91 & 2.76 & 3.98 & 4.65 & 5.00 \\
\hline Annual Energy Savings (TBtu) & 74.9 & 93.4 & 114 & 139 & 164 & 196 & 224 & 243 \\
\hline Cumulative Energy Savings (TBtu) & 783 & 877 & 991 & 1,129 & 1,294 & 1,490 & 1,714 & 1,957 \\
\hline Cumulative Energy Cost Savings $(B \$)$ & 3.49 & 3.97 & 4.68 & 5.68 & 7.17 & 9.09 & 11.4 & 14.6 \\
\hline Cumulative Carbon Reduction (MMTCE) & 14.1 & 15.8 & 17.9 & 20.4 & 23.3 & 26.9 & 30.9 & 35.3 \\
\hline Item & 2009 & 2010 & 2011 & 2012 & 2013 & 2014 & 2015 & 2016 \\
\hline Number of Assessments & 325 & 286 & & & & & & \\
\hline $\begin{array}{l}\text { Annual Energy Saved Per New Assessment } \\
\text { (MBtu/Assessment-Year) }\end{array}$ & 7,040 & 6,166 & & & & & & \\
\hline Energy Saved From Assessments (TBtu) & 31.6 & 28.9 & & & & & & \\
\hline Energy Saved From Alumni Assessments (TBtu) & 202 & 201 & & & & & & \\
\hline Replication Energy Savings (TBtu) & 6.76 & 5.90 & & & & & & \\
\hline Web Users Energy Savings (TBtu) & 5.15 & 5.02 & & & & & & \\
\hline Annual Energy Savings (TBtu) & 246 & 241 & & & & & & \\
\hline Cumulative Energy Savings (TBtu) & 2,202 & 2,443 & & & & & & \\
\hline Cumulative Energy Cost Savings $(B \$)$ & 16.8 & 19.2 & & & & & & \\
\hline Cumulative Carbon Reduction (MMTCE) & 39.7 & 44.0 & & & & & & \\
\hline
\end{tabular}




\section{Appendix E: Method of Calculating Results for Technology Deployment Programs}

Large Plant Assessments..

E-2

Training. E-3

$\checkmark$ Software Tools Distribution. E-3

$\checkmark$ Qualified Specialists E-3

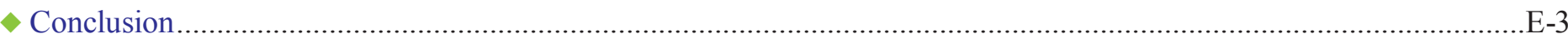

Technology Deployment Programs Table. E-4 


\section{Method of Calculating Results for Technology Deployment Programs}

In support of the Advanced Manufacturing Office's (AMO's) mission to improve the energy intensity of the U.S. industrial sector, activities under the technology deployment program (formerly the Save Energy Now Initiative) help industrial plants operate more efficiently and profitably by identifying opportunities for saving energy. In 2010, Save Energy Now worked across the industrial sector to provide savings in a systems-based approach. This approach is designed to provide industrial plant managers with information to evaluate opportunities and implement projects that improve the efficiency of energy systems within their production facilities. These process-supporting energy systems include those with motors and drives, fans, pumps, air compressors, steam, and process heat. The system-based approach relies on five main delivery activities to deliver technical information to a target audience of larger, more energy-intensive manufacturing establishments: (1) large energy-intensive plant assessments, (2) Save Energy Now LEADER plants (now Better Plants), (3) training, (4) software tools, and (5) qualification of specialists by AMO to address improving energy efficiency from the system-based perspective.

Estimates of energy savings presented in this report are based on a methodology originally developed by Oak Ridge National Laboratory in 2002 and refined as the result of a peer review conducted in 2004. The impacts presented for 2010 Save Energy Now activities reflect the on-going efforts to implement recommendations from the peer review and improve the accuracy of savings estimates. Improvements include (1) integration of results from a participant survey, (2) better understanding of energy characteristics of participating plants, (3) consistent registration information for software users, and (4) follow-up implementation information from assessments. Savings estimates for years prior to 2004 have not been adjusted to reflect these most recent improvements.

The AMO data system provides information on participants in all activity areas and uses the data to estimate output and savings outcome performance of Save Energy Now. Participants include representatives from domestic or international manufacturing plants, corporations, research or educational institutions, state and local governments, and engineering or consulting organizations. Using information on participant affiliation, the data system provides the number of unique, domestic plants participating in each activity. The number of unique plants is then scaled back to estimate the number of unique U.S. plants that are believed to take action to implement energy savings projects as a result of the dissemination of this information.
Estimates of energy savings from Save Energy Now's activities focus on the four core activities of assessments, training, software, and qualified specialists. As a result of the peer review, estimates were constrained to these activities because of their significant savings potential and the higher quality of available data. The basic methodology for estimating the energy outcome is a combination of implemented energy savings reported for assessments and calculated savings for training, software use, and qualified specialists. Energy benefits generated by assessments are based on implementation results from follow-up with participating manufacturing plants. Savings associated with unique U.S-based plants that implement projects following interaction with qualified specialists or by participating in training or use of software are estimated using recent participant survey feedback and historical assessment data from Save Energy Now and the Industrial Assessment Centers (IACs). Savings and descriptions for each of the five main delivery activities are summarized below.

\section{Large Plant Assessments}

In 2006, under the Save Energy Now campaign, ITP shifted resources to conduct system-focused assessments at 200 energy-intensive manufacturing plants across the country. Prior to this, ITP offered annual plant-wide assessments (PWAs) to a limited number of large plants. The two assessment approaches are vastly different. The Save Energy Now assessments are provided to a larger number of plants; however, they are limited to analysis of a single energy system and demonstration of and training for using the relevant ITP software tool. Conversely, PWAs were delivered to a smaller group of plants to identify overall energy use in manufacturing processes and develop a more comprehensive set of opportunities for savings. Both approaches highlight opportunities for best energy management practices for industry, including the adoption of new, efficient technologies.

In 2010, 101 Save Energy Now assessments (SENAs) were completed; replication activities were limited and are not included in the impacts estimate. Implemented savings reported from SENAs totaled 5.00 TBtu. Savings from the PWAs in previous years are assumed to persist for seven years, and this effect adds $98.63 \mathrm{TBtu}$ in savings for 2010 . The total energy savings generated in 2010 from the old assessments in large, energy-intensive plants was 103.63 TBtu, and the cumulative savings generated from 2000 through 2010 was 594 TBtu. 


\section{Method of Calculating Results for Technology Deployment Programs}

\section{Save Energy Now LEADER Plants (now Better Plants)}

Save Energy Now LEADER/Better Plants is the national initiative of the AMO that aims to drive a $25 \%$ reduction in industrial energy intensity in 10 years (25 in 10). To achieve the 25 in 10 goal, the focus of AMO's technology deployment efforts are concentrated on providing support to Save Energy Now LEADER/Better Plants companiesindustrial companies that sign a voluntary pledge to reduce their facilities' energy intensity by $25 \%$ or more in 10 years. DOE provides tailored technical assistance to help a company develop an energy baseline and energy management plan and also with training that teaches them long-term skills to selfsustain energy efficiency efforts. Participating companies are given priority access to energy assessments.

Energy savings for LEADER plants are reported annually by the participating companies using the LEADER pledge reporting forms. To avoid double counting of energy savings implemented as a result of large and medium plant assessments (SENA and IAC assessments) at LEADER plants, energy savings from SENA and IAC assessments are subtracted from the total new energy savings reported by the LEADER plants. In 2010, 68 out of total 108 companies that signed the LEADER pledge submitted their annual pledge reporting forms. These 68 LEADER companies represent 1,343 unique plants. Energy savings reported by LEADER companies minus energy savings from SENA and IAC assessments conducted at LEADER plants for 2010 is 13.61 TBtu.

\section{Training}

Training activities continue to play a key role in AMO's technology deployment strategy. Participants who attend end-user training learn how to apply the software in their own plants to identify and implement savings in energyintensive systems. The number of unique plants participating in a training activity is recorded in the AMO data system. From 1998 through 2010, representatives from over 7,400 unique plants attended training sessions. In 2010, of 513 plants attending training sessions, about 156 were estimated to actually take action to implement projects in their own energy-intensive systems, resulting in an estimated savings of $0.90 \mathrm{TBtu}$. Additionally, savings that persist from measures implemented as a result of training conducted in previous years contributed 17.20 TBtu in 2010. AMO training saved 18.1 TBtu in 2010 and cumulatively saved 404.8 TBtu from 1998 through 2010.

\section{Software Tools Distribution}

AMO has a variety of resources to help address a company's energy management needs and facilitate energy-efficiency decision-making. A range of software tools is available to help a plant manager perform a self-assessment of a plant's fan, motor, pumping, compressed air, steam, and process heating systems. Software tools available in 2010 included Fan System Assessment Tool (FSAT), AirMaster+, MotorMaster, Pumping System Assessment Tool (PSAT), Steam System Scoping Tool (SSST), Steam System Assessment Tool (SSAT), Process Heating Assessment Tool (PHAST), and 3E Plus. Users may download the software from AMO's website or use the AMO Technology Deployment CD-ROM, which contains the entire suite of software tools.

Software is proving to be a powerful means of disseminating technical information for AMO. According to the AMO data system, 2,353 unique plants obtained software in 2010. It is estimated that 318 plants took action to implement projects, saving an estimated 2.81 TBtu. Savings from measures implemented in previous years that persist in 2010 contributed 30.17 TBtu. AMO software tools saved 32.98 TBtu in 2010 and cumulatively saved 367 TBtu from 1998 through 2010.

\section{Qualified Specialists}

Qualified specialists are industry professionals who have completed additional training and demonstrated proficiency in using AMO software tools. Specialists apply these tools to help industrial customers identify ways to improve system efficiency. In 2010, DOE offered specialist qualifications in the following software tools: Steam Systems, PSAT, AirMaster+, FSAT, and PHAST.

By the end of 2010, 531 software specialists were qualified by DOE. In 2010, an estimated 1,452 plants interacted with qualified specialists, resulting in implemented projects at 741 plants. Estimated savings from qualified specialists' activities in 2010 are 7.74 TBtu. Savings that persist in 2010 from measures implemented in 2001 through 2009 contributed 37.3 TBtu. Qualified specialists saved 45.04 TBtu in 2010 and cumulatively saved 198 TBtu from 2001 through 2010.

\section{Conclusion}

The table below shows the total annual energy savings from AMO's Save Energy Now activities from 1998 through 2010. The subtotals from the five delivery activities are added together to calculate the total annual energy savings for 2010 of $214 \mathrm{TBtu}$ and a cumulative energy savings of 1,579 TBtu. Fuel prices and emission coefficients for various fuels from Energy Information Administration publications were used to determine cumulative energy cost savings and carbon reduction. 


\begin{tabular}{|c|c|c|c|c|c|c|c|}
\hline & 1998 & 1999 & 2000 & 2001 & 2002 & 2003 & 2004 \\
\hline \multicolumn{8}{|l|}{ Large Plant Assessments } \\
\hline Unique Plants Implementing Improvements Each Year & - & - & 2 & 14 & 17 & 8 & 9 \\
\hline New Plant Replications & - & - & - & 1 & 10 & 22 & 5 \\
\hline Annual Energy Savings from Large Plant Assessments (TBtu) & - & - & 0.61 & 1.28 & 9.45 & 20.5 & 27.4 \\
\hline Cumulative Energy Savings from Large Plant Assessments (TBtu) & - & - & 0.61 & 1.28 & 11.3 & 31.9 & 59.3 \\
\hline \multicolumn{8}{|l|}{ Save Energy Now LEADER Plants (now Better Plants) } \\
\hline Number of Unique Plants Participating & - & - & - & - & - & - & - \\
\hline Annual Energy Savings from LEADER Companies (TBtu) & - & - & - & - & - & - & - \\
\hline Cumulative Energy Savings from LEADER Companies (TBtu) & - & - & - & - & - & - & - \\
\hline \multicolumn{8}{|l|}{ Training } \\
\hline Unique Plants Reached Each Year & 75 & 150 & 300 & 330 & 791 & 652 & 693 \\
\hline Unique Plants Implementing Improvements Each Year & 38 & 75 & 150 & 165 & 396 & 326 & 347 \\
\hline Annual Energy Savings from Training $(T B t u)$ & 0.84 & 2.51 & 5.86 & 10.2 & 28.5 & 44.0 & 49.8 \\
\hline Cumulative Energy Savings from Training (TBtu) & 0.84 & 3.35 & 9.21 & 19.4 & 47.9 & 91.9 & 142 \\
\hline \multicolumn{8}{|l|}{ Software Tools Distribution } \\
\hline Unique Plants Reached Each Year & 479 & 959 & 4,793 & 10,718 & 9,608 & 5,847 & 1,842 \\
\hline Unique Plants Implementing Improvements Each Year & 96 & 192 & 959 & 2,143 & 1,922 & 1,169 & 368 \\
\hline Annual Energy Savings from Software $(T B t u)$ & 0.24 & 1.04 & 4.63 & 13.3 & 21.1 & 32.4 & 36.0 \\
\hline Cumulative Energy Savings from Software (TBtu) & 0.24 & 1.28 & 5.91 & 19.2 & 40.3 & 72.7 & 109 \\
\hline \multicolumn{8}{|l|}{ Qualified Specialists } \\
\hline Number of Qualified Specialists & - & - & - & 27 & 89 & 177 & 300 \\
\hline Unique Plants Interacting Each Year with Qualified Specialists & - & - & - & 13 & 43 & 85 & 667 \\
\hline Unique Plants Implementing Improvements Each Year & - & - & - & 7 & 22 & 43 & 352 \\
\hline Annual Energy Savings from Qualified Specialists (TBtu) & - & - & - & 0.17 & 0.77 & 3.30 & 8.42 \\
\hline Cumulative Energy Savings from Qualified Specialists (TBtu) & - & - & - & 0.17 & 0.94 & 4.24 & 12.7 \\
\hline \multicolumn{8}{|l|}{ Sum of All Save Energy Now Areas } \\
\hline Unique Plants Reached Each Year & 554 & 1,109 & 5,095 & 11,076 & 10,469 & 6,614 & 3,216 \\
\hline Unique Plants Implementing Improvements Each Year & 134 & 267 & 1,111 & 2,330 & 2,367 & 1,568 & 1,081 \\
\hline Annual Energy Savings $(T B t u)$ & 1.08 & 3.55 & 11.1 & 25.0 & 59.8 & 100 & 122 \\
\hline Cumulative Energy Savings (TBtu) & 1.08 & 4.63 & 15.7 & 40.7 & 101 & 201 & 322 \\
\hline Cumulative Energy Cost Savings $(B \$)$ & 0.004 & 0.019 & 0.080 & 0.219 & 0.525 & 1.15 & 2.02 \\
\hline Cumulative Carbon Reduction (MMTCE) & 0.019 & 0.083 & 0.282 & 0.732 & 1.81 & 3.61 & 5.81 \\
\hline
\end{tabular}




\section{Method of Calculating Results for Technology Deployment Programs}

IMPACTS

\begin{tabular}{|l|l|l|l|l|l|l|}
2005 & 2006 & 2007 & 2008 & 2009 & 2010 & 2011 \\
\hline
\end{tabular}

\begin{tabular}{|c|c|c|c|c|c|c|c|}
\hline \multicolumn{8}{|l|}{ Large Plant Assessments } \\
\hline Unique Plants Implementing Improvements Each Year & 8 & 200 & 258 & 260 & 159 & 101 & - \\
\hline New Plant Replications & 1 & 0 & 0 & 0 & 0 & 0 & - \\
\hline Annual Energy Savings from Large Plant Assessments (TBtu) & 40.8 & 75.9 & 93.8 & 111 & 110 & 104 & - \\
\hline Cumulative Energy Savings from Large Plant Assessments (TBtu) & 100 & 176 & 270 & 381 & 491 & 594 & - \\
\hline \multicolumn{8}{|l|}{ Save Energy Now LEADER Plants (now Better Plants) } \\
\hline Number of Unique Plants Participating & - & - & - & - & - & 1,343 & - \\
\hline Annual Energy Savings from LEADER Companies (TBtu) & - & - & - & - & - & 13.61 & - \\
\hline Cumulative Energy Savings from LEADER Companies $(T B t u)$ & - & - & - & - & - & 13.61 & - \\
\hline \multicolumn{8}{|l|}{ Training } \\
\hline Unique Plants Reached Each Year & 1,197 & 929 & 562 & 566 & 652 & 513 & - \\
\hline Unique Plants Implementing Improvements Each Year & 599 & 282 & 171 & 172 & 198 & 156 & - \\
\hline Annual Energy Savings from Training $(T B t u)$ & 54.1 & 55.3 & 53.1 & 49.9 & 32.7 & 18.1 & - \\
\hline Cumulative Energy Savings from Training (TBtu) & 196 & 251 & 304 & 354 & 387 & 405 & - \\
\hline \multicolumn{8}{|l|}{ Software Tools Distribution } \\
\hline Unique Plants Reached Each Year & 3,088 & 3,536 & 2,547 & 2,740 & 3,663 & 2,353 & - \\
\hline Unique Plants Implementing Improvements Each Year & 618 & 477 & 344 & 370 & 495 & 318 & - \\
\hline Annual Energy Savings from Software $(T B t u)$ & 41.7 & 49.2 & 49.1 & 44.3 & 41.4 & 33.0 & - \\
\hline Cumulative Energy Savings from Software (TBtu) & 150 & 200 & 249 & 293 & 334 & 367 & - \\
\hline \multicolumn{8}{|l|}{ Qualified Specialists } \\
\hline Number of Qualified Specialists & 351 & 443 & 613 & 431 & 415 & 531 & - \\
\hline Unique Plants Interacting Each Year with Qualified Specialists & 844 & 1,084 & 1,150 & 913 & 1,064 & 1,452 & - \\
\hline Unique Plants Implementing Improvements Each Year & 434 & 553 & 587 & 466 & 543 & 741 & - \\
\hline Annual Energy Savings from Qualified Specialists (TBtu) & 14.9 & 22.3 & 28.8 & 34.5 & 39.8 & 45.0 & - \\
\hline Cumulative Energy Savings from Qualified Specialists (TBtu) & 27.6 & 49.9 & 78.7 & 113 & 153 & 198 & - \\
\hline \multicolumn{8}{|l|}{ Sum of All Save Energy Now Areas } \\
\hline Unique Plants Reached Each Year & 5,138 & 5,749 & 4,517 & 4,479 & 5,538 & 5,762 & - \\
\hline Unique Plants Implementing Improvements Each Year & 1,660 & 1,512 & 1,352 & 1,268 & 1,395 & 2,659 & - \\
\hline Annual Energy Savings $(T B t u)$ & 152 & 203 & 225 & 240 & 224 & 214 & - \\
\hline Cumulative Energy Savings (TBtu) & 474 & 676 & 901 & 1,141 & 1,365 & 1,579 & - \\
\hline Cumulative Energy Cost Savings $(B \$)$ & 3.41 & 5.39 & 7.71 & 10.8 & 12.9 & 15.0 & - \\
\hline Cumulative Carbon Reduction (MMTCE) & 8.55 & 12.2 & 16.3 & 20.6 & 24.6 & 28.4 & - \\
\hline
\end{tabular}




\section{Appendix F: Method of Calculating Results from DOE's Combined Heat and Power Activities}

$\checkmark$ CHP Table...

F-3 


\section{Method of Calculating Results from DOE's Combined Heat and Power Activities}

Industrial Distributed Energy, a cross-cutting activity within the Advanced Manufacturing Office (AMO), builds on activities conducted by DOE's Office of Industrial Technologies during the 1980s and 1990s and the DOE Distributed Energy Resources program since 2000. Since 1990, the use of distributed energy within the United States, primarily combined heat and power (CHP), has increased significantly. CHP capacity additions between 1990 and 2009 totaled $56.4 \mathrm{GW}$, according to the CHP Installation Database maintained by ICF International for DOE through a contract with Oak Ridge National Laboratory.

According to a report prepared by ORNL, if CHP capacity were to reach $20 \%$ of U.S. electricity production by 2030 , more than 5.3 quad of energy would be saved, and $\mathrm{CO}_{2}$ emissions would be reduced by 848 million metric tons. This represents $60 \%$ of the projected greenhouse gas emissions production from 2006 to 2030 .

DOE distributed energy activities since 1990 include R\&D, market transformation, and deployment activities. $R \& D$ activities have focused on developing advanced reciprocating engine systems, advanced industrial gas turbines, microturbines, thermally activated technologies, fuel cells, and integrated energy systems. As a result, many commercial products have been successfully developed. Market transformation activities have focused on project support, education, and outreach and have recently been led by eight Regional Clean Energy Application Centers that offer individualized solutions to end users and promote the adoption of CHP to state policymakers and regulators. DOE also has continually supported public-private partnerships with various CHP stakeholders through collaborations with other federal agencies, state governments and agencies, trade associations and private industry, and non-government organizations in order to increase market deployment of CHP technology.

Before 2007, attribution of energy from DOE distributed energy activities was not well documented. ICF International recently developed a preliminary methodology for calculating and attributing energy savings from DOE distributed energy activities. This methodology will be refined and reviewed by external peers.

The energy savings' benefit of a CHP system is from the aggregate reduction in overall fuel consumption. A CHP system replaces both a separate on-site thermal system (furnace or boiler) and purchased power (typically electricity from a central station power plant) with a single, integrated system that produces thermal energy and power concurrently. To calculate the fuel use avoided by a CHP system, both outputs of the CHP system must be accounted for. The CHP system's thermal output displaces the fuel normally consumed in on-site thermal generation in a boiler or other equipment, and the power output displaces the fuel consumed from gridconnected power plants. Quantifying a CHP system's fuel savings involves subtracting the fuel use released from the CHP system from the fuel use that normally would occur without the system (i.e., using conventional separate heat and power).

The CHP energy savings' estimates are based on CHP operating characteristics contained in the CHP Installation Database, which is recognized as the leading source for current and comprehensive data on U.S. CHP installations and market trends. As of June 1, 2009, the database contained 3,518 operating CHP installations representing 84,923 MW of electric capacity. The database includes detailed data for each site including location, application, CHP technology, fuel type, electric generating capacity, ownership, servicing utility, and system start-up date. The database contains partial information on thermal application and capacity, sales to the grid, thermal sales, annual fuel use, annual generation, and annual thermal utilization. Annual CHP capacity additions were generated from the database starting in 1990 by system size ( $<20 \mathrm{MW}, 20$ to $50 \mathrm{MW},>50 \mathrm{MW})$ and fuel type.

CHP energy savings' estimates are derived from operating information (i.e., fuel consumption, electricity, and thermal energy generated) for the CHP fleet contained in or derived from the CHP database. A key operating parameter is the CHP system's power-to-heat ratio. This parameter was calculated directly for sites with data on both electric generation and thermal output. For sites missing information on the thermal output, a typical power-to-heat ratio was assumed based on the prime-mover technology and the electric capacity of the CHP system. Performance characteristics, including the power, thermal, and overall efficiencies of the operating CHP capacity, are estimated for 13 different fuel types; and summary data are derived for each fuel type, including annual electric generation, thermal output, and fuel consumption.

In the absence of data to track the DOE program impact for every CHP installation, a portion of energy savings from all CHP systems installed since 1990 were linked to DOE's efforts. Attribution of benefits for DOE activities are based on DOE program activities to advance CHP technology in each market segment and are estimated to be $50 \%$ of the capacity additions $<20 \mathrm{MW}, 25 \%$ of the capacity additions from 20 to $50 \mathrm{MW}$, and $10 \%$ of the capacity additions $>50$ MW. DOE's most extensive efforts have supported CHP $<20 \mathrm{MW}$, which uses engine, microturbine, and fuel cell technologies. DOE also supported turbine technology focused on CHP units from 20 to $50 \mathrm{MW}$; manufacturers have also transferred these technologies to CHP units $>50 \mathrm{MW}$. 


\section{Method of Calculating Results from DOE's Combined Heat and Power Activities}

IMPACTS

Total CHP capacity additions from 1990 to 2010 and the resulting energy savings attributed to DOE activities based on the methodology described above are depicted in the table. The annual and cumulative energy savings from CHP systems are shown in the table for each year. In 2010, the annual energy savings are $215 \mathrm{TBtu}$ and the cumulative energy savings through 2010 are 2,963 TBtu. Energy cost savings, carbon reduction, and other benefits are related to energy savings by projected fuel prices and emission coefficients. The cumulative CHP energy cost savings and the cumulative carbon reduction are shown through 2010 in the last two rows of the table.
Through funding from the American Reinvestment and Recovery Act, AMO advanced CHP as one of the more promising efficient energy solutions that can help to revitalize the American economy, enhance the nation's energy security, and reduce carbon pollution. CHP can achieve efficiencies of as much as $80 \%$ compared with roughly $45 \%$ for conventional heat and power production.

Total CHP Capacity Additions with Energy, Cost, and Carbon Savings Attributed to DOE Activities

\begin{tabular}{|c|c|c|c|c|c|c|c|c|c|}
\hline Item & 1990 & 1991 & 1992 & 1993 & 1994 & 1995 & 1996 & 1997 & 1998 \\
\hline \multicolumn{10}{|l|}{ Capacity Additions (MW) } \\
\hline$<20 \mathrm{MW}$ & 385.7 & 243.0 & 234.1 & 179.4 & 200.1 & 201.1 & 206.9 & 164.8 & 154.8 \\
\hline $20-50 \mathrm{MW}$ & 903.1 & 687.8 & 342.3 & 435.7 & 398.0 & 372.2 & 229.1 & 93.6 & 221.9 \\
\hline$>50 \mathrm{MW}$ & $3,462.3$ & $2,453.8$ & $2,693.0$ & $2,651.9$ & $5,131.4$ & $2,162.5$ & $2,123.4$ & $2,311.3$ & $1,123.5$ \\
\hline Total Capacity Additions & 4,751 & 3,385 & 3,269 & 3,267 & 5,730 & 2,736 & 2,559 & 2,570 & 1,500 \\
\hline Annual Energy Savings (TBtu) & 23.2 & 39.8 & 52.7 & 66.6 & 85.6 & 96.2 & 107.1 & 116.7 & 124.6 \\
\hline Cumulative Energy Savings (TBtu) & 23.2 & 63.0 & 115.7 & 182.3 & 267.9 & 364.1 & 471.2 & 588.0 & 712.5 \\
\hline Cumulative Energy Cost Savings (B\$) & 0.027 & 0.070 & 0.124 & 0.190 & 0.270 & 0.357 & 0.452 & 0.555 & 0.657 \\
\hline Cumulative Carbon Reduction (MMTCE) & 0.6 & 1.6 & 2.9 & 4.6 & 6.7 & 9.1 & 11.8 & 14.8 & 17.9 \\
\hline Item & 1999 & 2000 & 2001 & 2002 & 2003 & 2004 & 2005 & 2006 & 2007 \\
\hline \multicolumn{10}{|l|}{ Capacity Additions (MW) } \\
\hline$<20 \mathrm{MW}$ & 252.6 & 317.2 & 299.3 & 238.2 & 222.9 & 182.8 & 214.2 & 187.4 & 171.7 \\
\hline $20-50 \mathrm{MW}$ & 177.7 & 386.8 & 379.8 & 361.0 & 132.0 & 124.5 & 28.0 & 149.2 & 99.0 \\
\hline$>50 \mathrm{MW}$ & $1,825.9$ & $2,425.4$ & $5,528.9$ & $4,436.0$ & $3,395.0$ & $3,192.0$ & $1,391.0$ & 0.0 & 224.0 \\
\hline Total Capacity Additions & 2,256 & 3,129 & 6,208 & 5,035 & 3,750 & 3,499 & 1,633 & 337 & 495 \\
\hline Annual Energy Savings (TBtu) & 134.5 & 149.6 & 170.3 & 180.3 & 190.6 & 194.0 & 199.6 & 199.8 & 201.3 \\
\hline Cumulative Energy Savings (TBtu) & 847.0 & 996.6 & 1,167 & 1,347 & 1,538 & 1,732 & 1,931 & 2,131 & 2,333 \\
\hline Cumulative Energy Cost Savings (B\$) & 0.768 & 0.898 & 1.051 & 1.209 & 1.389 & 1.603 & 1.875 & 2.120 & 2.375 \\
\hline Cumulative Carbon Reduction (MMTCE) & 21.3 & 25.1 & 29.3 & 33.9 & 38.7 & 43.6 & 48.6 & 53.7 & 58.7 \\
\hline Item & 2008 & 2009 & 2010 & 2011 & 2012 & 2013 & 2014 & 2015 & 2016 \\
\hline \multicolumn{10}{|l|}{ Capacity Additions (MW } \\
\hline$<20 \mathrm{MW}$ & 189.8 & 201.9 & 203.7 & - & - & - & - & - & - \\
\hline $20-50 \mathrm{MW}$ & 81.2 & 169.0 & 155 & - & - & - & - & - & - \\
\hline$>50 \mathrm{MW}$ & 141.0 & 235.0 & 250 & - & - & - & - & - & - \\
\hline Total Capacity Additions & 412 & 606 & 609 & - & - & - & - & - & - \\
\hline Annual Energy Savings (TBtu) & 205.5 & 210.2 & 214.7 & - & - & - & - & - & - \\
\hline Cumulative Energy Savings (TBtu) & 2,538 & 2,748 & 2,963 & - & - & - & - & - & - \\
\hline Cumulative Energy Cost Savings (B\$) & 2.693 & 3.027 & 3.398 & - & - & - & - & - & - \\
\hline Cumulative Carbon Reduction (MMTCE) & 64.0 & 69.3 & 74.7 & - & - & - & - & - & - \\
\hline
\end{tabular}




\section{Methodology for Technology Tracking and Assessment of Benefits}

Technology Tracking.

G-2

Methods of Estimating Benefits.

G-2

Deriving the AMO Cost/Benefit Curve.

G-3 


\section{Methodology for Technology Tracking and Assessment of Benefits}

\section{Technology Tracking}

For over 30 years, the Advanced Manufacturing Office (AMO), previously the Industrial Technologies Program (ITP), has been tracking and recording information on technologies developed through cost-shared R\&D projects with industry. The tracking process considers technologies that can be classified as commercially successful, mature, or emerging.

When full-scale commercial units of a technology are operational in private industry, that technology is considered commercially successful and is on the active tracking list. When a commercially successful technology unit has been in operation for approximately 10 years, that particular unit is then considered a mature or historical technology and is usually no longer actively tracked.

Emerging technologies are those in the late development or early commercialization stage of the technology life cycle (roughly within one to two years of commercialization). While preliminary information is collected on emerging technologies, they are not placed on the active tracking list until they are commercially available to industry.

The active tracking process involves collecting technical and market data on each commercially successful technology, including details on the following:

$\checkmark$ Number of units sold, installed, and operating in the United States and abroad (including size and location)

Units decommissioned since the previous year

$\checkmark$ Energy saved by the technology

$\diamond$ Environmental benefits from the technology

$\checkmark$ Improvements in quality and productivity achieved through use of the technology

$\checkmark$ Other impacts of the technology, such as employment and effects on health and safety

Marketing issues and barriers

\section{Methods of Estimating Benefits}

Information on technologies is gathered through direct contact with either vendors or end users of the technology. These contacts provide the data needed to calculate the unit energy savings associated with an individual technology, as well as the number of operating units.

Unit energy savings are unique to each technology. Technology manufacturers or end users usually provide unit energy savings, or at least enough data for a typical unit energy savings to be calculated. The total number of operating units is equal to the number of units installed minus the number of units decommissioned or classified as mature in a given year - information usually determined from sales data or end user input. Operating units and unit energy savings can then be used to calculate total annual energy savings for the technology.

The cumulative energy savings represents the accumulated energy saved for all units for the total time the technology has been in operation. This includes previous savings from nowmature units and decommissioned units, even though these units are not included in the current year's savings.

Once cumulative energy savings have been determined, longterm impacts on the environment are calculated by estimating the associated reduction of air pollutants. This calculation is straightforward, based on the type of fuel saved and the pollutants typically associated with combustion of that fuel. For example, for every million Btu of coal combusted, approximately 1.25 pounds of sulfur oxides (known acid rain precursors) are emitted to the atmosphere. Thus, every million-Btu reduction in coal use results in the elimination of 1.25 pounds of polluting sulfur oxides.

The results for annual and cumulative energy savings, as well as cumulative pollutant emissions reductions for actively tracked technologies, are shown in Table 1 on pages 10 and 11 of this report. 


\section{Methodology for Technology Tracking and Assessment of Benefits}

IMPACTS

\section{Deriving the AMO Cost/Benefit Curve}

The approach to estimating the net benefits of AMO energy savings used here relied on the following methodology. First, estimate the cumulative production cost savings which provides an estimate of the gross benefit of the AMO program since its inception. Next, estimate the cumulative appropriations that were allocated by the government to support the development of these technologies that saved energy. Finally, make adjustments to the gross energy savings to account for the cost to industry of adopting the new technologies. The method is based on the following sequence of steps:

$\checkmark$ Cumulative energy savings - The accumulated energy savings (Btu) produced by AMO-supported technologies that have been commercialized and tracked since the program began. As of 2010, this figure was 3,729 trillion Btu.

AMO appropriations - This is the cumulative funding provided for AMO programs. As of FY 2010, this number was $\$ 3.24$ billion.

$\checkmark$ Cost of industrial energy saved - This is the fuel price (dollars/Btu) that would have been paid to purchase energy multiplied by annual savings. The nominal prices (in dollars per million Btu) for various fuels are reported in the Energy Information Administration's Annual Energy Review (AER). Nominal fuel prices extending back in time from 2010 to 1978 were obtained from the 2010 AER. These prices are adjusted for inflation based on an index of all fuels and power as reported by the Bureau of Labor Statistics, but normalized to 2010 so that all prices are in current dollars. These real annual fuel prices are multiplied by the amount of energy saved per fuel type per year for each of the AMO commercialized and tracked technologies.

$\checkmark$ Correct for Implementation Costs - Since reliable information was not available about the incremental capital and operating and maintenance costs of these new technologies, an assumption must be made to adjust for these costs. The assumption used is that industry demands at least a two-year payback period on all such investments, so the first two years of the cumulated energy savings was ignored for each of the technologies, given that these first two years savings are needed to recoup the life-cycle capital costs of adopting the new technology. Again, these costs are adjusted for inflation just as are the fuel prices for savings.
In addition to technology energy savings, savings from the IAC Program, the TDP, and CHP activities were also determined on an annual basis as described in Appendices 4,5 , and 6 , respectively. The economic benefits are the accumulation of these savings over time adjusted for inflation, as described above. The economic costs are twofold: AMO appropriations and the implementation costs reflected in the two-year payback period. The appropriations are adjusted for inflation by using the implicit deflator for non-defense federal government expenditures, as published by the Bureau of Economic Analysis of the U.S. Department of Commerce. The implementation costs are adjusted for inflation in the same manner as fuel savings. The net economic benefits are then the benefits minus the costs.

Just as this method may not account for some benefits spinoffs, derivative technologies, etc. - this method also may not account for some incremental costs. For example, there may be incremental capital costs associated with the use of a particular technology that are not currently captured in the tracking process, and thus are not included in the cost side of the equation.

The results of the application of this method are shown in the following graph. 


\section{Methodology for Technology Tracking and Assessment of Benefits}

IMPACTS

\section{Cumulative Production Cost Savings Minus Cumulative Program and Implementation Costs}

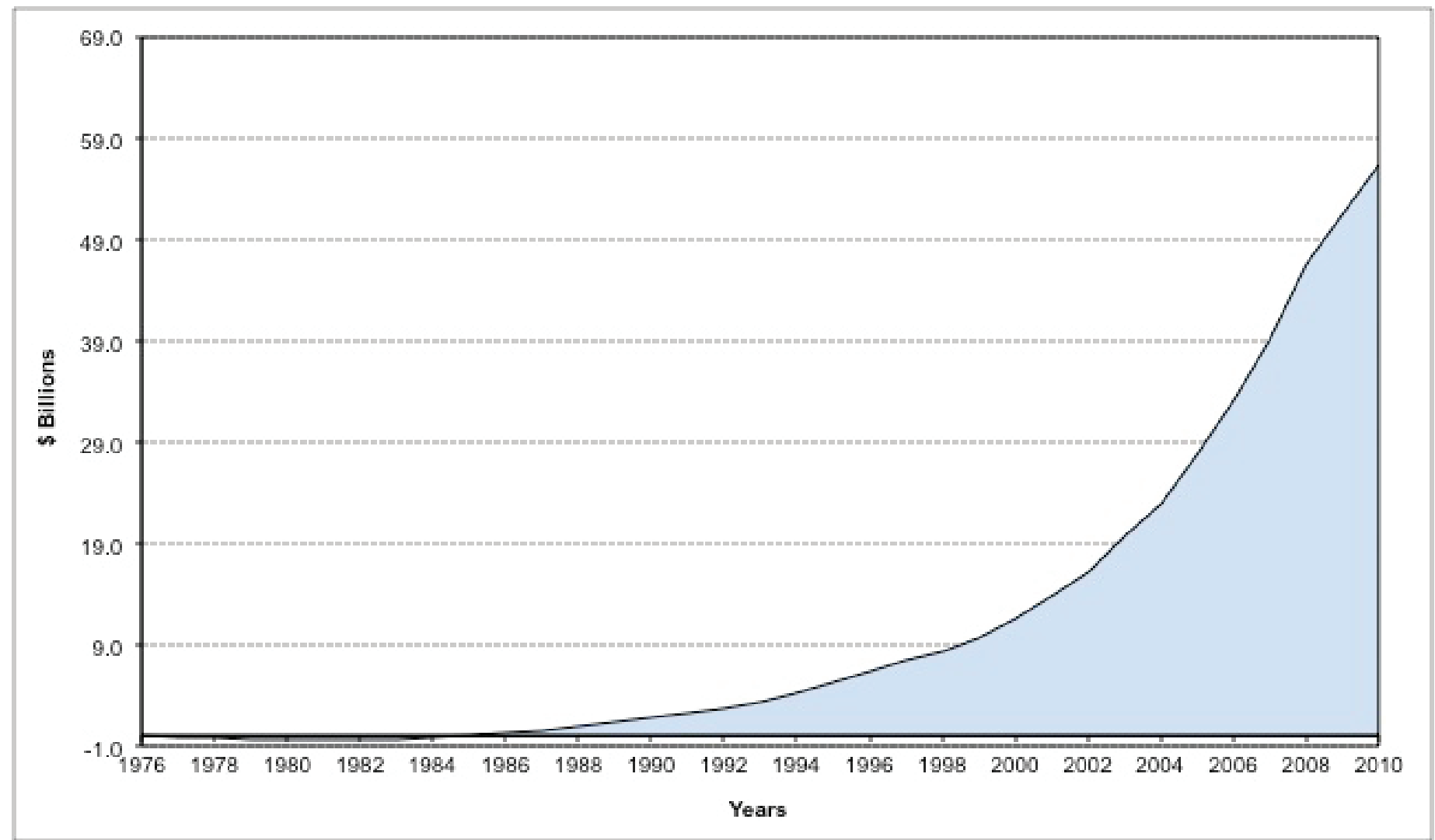

The cumulative federal costs for AMO through fiscal year 2010 total \$3.24 billion. Cumulative energy savings from completed and tracked AMO projects and

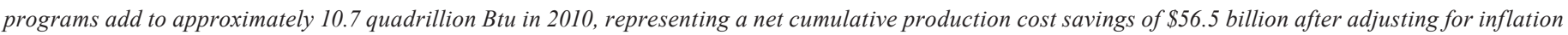

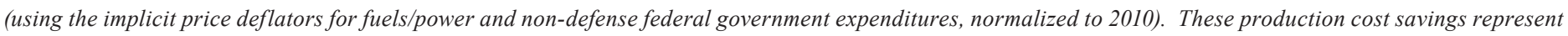
the net total value of all energy saved by technologies developed in AMO programs plus the energy cost savings from the IAC Program, the TDP, and CHP

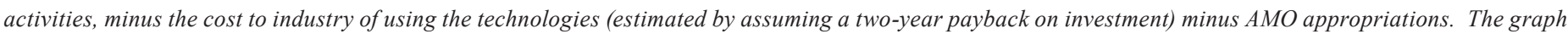
shows that benefits substantially exceed costs. 

Prepared by Pacific Northwest National Laboratory for the U.S. Department of Energy Building Technologies Program

PNNL-22354 | March 2013

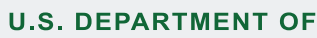
Energy Efficiency \& Renewable Energy

\section{EERE Information Center}

1-877-EERE-INFO (1-877-337-3463)

www.eere.energy.gov/informationcenter 